UNIVERSIDADE DE SÃO PAULO

ESCOLA DE ENGENHARIA DE SÃO CARLOS

DEPARTAMENTO DE ENGENHARIA DE ESTRUTURAS

\title{
LIGAÇÕES PARAFUSADAS EM CHAPAS FINAS E PERFIS DE AÇO FORMADOS A FRIO
}

\section{Carlos Henrique Maiola}

Tese apresentada à Escola de Engenharia de São Carlos da Universidade de São Paulo como parte dos requisitos para obtenção do título de Doutor em Engenharia de Estruturas

Orientador: prof. Dr. Maximiliano Malite

São Carlos - SP 
AGRADECIMENTOS:

A Deus pelo dom da vida.

À Max pela orientação e principalmente pela amizade.

Aos Amigos cultivados nestes anos, pela amizade, disposição e sabedoria.

Aos Funcionários do Laboratório de Estruturas. Aos Secretários da Seção de Pós-Graduação e aos Funcionários da Biblioteca pela constante disposição em ajudar-me.

Ao Pessoal da 1a Igreja Batista em São Carlos pela amizade incondicional..

À FAPESP pelo apoio financeiro. 
Dedico esta:

Primeiro aos que me acolheram, amaram e educaram, depois à que me aceitou e amou e por fim aos que vieram para serem amados e educados. 


\section{RESUMO}

MAIOLA, C.H. (2004). Ligações parafusadas em chapas finas e perfis de aço formados a frio. Tese (Doutorado) - Escola de Engenharia de São Carlos, Universidade de São Paulo, São Carlos, 2004. 125 p +apêndices.

Devido à crescente demanda por perfis formados a frio destinados à fabricação de estruturas de aço no Brasil, aliada a desatualização da norma brasileira NB-143:1967, fez-se necessário a publicação de uma nova norma brasileira de 'Dimensionamento de Estruturas de Aço Constituídas por Perfis Formados a Frio' a NBR14762:2001. Essa apresenta, para o dimensionamento das ligações, expressões adaptadas da norma norte-americana AISI:1996. As adaptações foram inseridas com o intuito de simplificar o cálculo e foram determinadas apenas por ajustes teóricos, faltando, portanto uma investigação mais criteriosa. Deste modo tornou-se prioritário o estudo das ligações em chapas e perfis com pequena espessura, para avaliação destas expressões propostas. Neste âmbito analisou-se neste trabalho o comportamento estrutural de ligações parafusadas em chapas e perfis formados a frio de pequena espessura, mediante análise teórica e experimental de corpos-de-prova, os quais foram definidos de maneira a se obter os diversos modos de falha, em especial a ruptura da seção líquida. Com os resultados experimentais pôde-se sugerir modificações nas expressões do coeficiente redutor da área líquida 'C IND. T', aplicado na avaliação da resistência ao estado limite de ruptura da seção líquida efetiva. Com os resultados desta pesquisa, espera-se colaborar com futuras edições da norma brasileira, fornecendo subsídios em suas futuras revisões

Palavras chaves: ligações parafusadas, chapas finas de aço, perfis formados a frio, ruptura da seção líquida. 


\begin{abstract}
MAIOLA, C.H. Bolted connection in thin sheet and cold-formed steel members.

Ph.D. Thesis - Escola de Engenharia de São Carlos, Universidade de São Paulo, São Carlos, 2004.
\end{abstract}

The growing demand for cold-formed steel members of steel structures in Brazil, allied to the obsolescence of the Brazilian NB-143:1967 standard, led to the need for a new Brazilian code for the "Design of Cold-formed Steel Structural Members", the NBR 14762:2001 standard.

This new standard contains expressions adapted from the America AISI:1996 code for the design of connections. The adaptations were included with the purpose of simplifying the calculation and were determined merely for theoretical adjustments; hence, they lack a more careful investigation. It has thus become a matter of priority to study the connections in thin sheets and coldformed members to evaluate the proposed expressions.

The work reported on here therefore analyzed the structural behavior of bolted connections in thin sheets and cold-formed members based on theoretical and experimental analyses of test specimens, which were defined in order to obtain the various failure modes, particularly on sheet tearing in the net section. Based on the experimental results, suggestions are made for modifications in the expressions of the reduction coefficient of the net area $\mathrm{Ct}$, applied in evaluations of the tensile strength of the effective net section.

It is expected that the results of this research will contribute to future editions of the new Brazilian code, supplying inputs for use in future revisions.

Keywords: bolted connections, thin sheet of steel, cold-formed members, sheet tearing in the net section 


\section{Lista de Siglas}

ABCEM - Associação Brasileira da Construção Metálica

AISC - American Institute of Steel Construction

AISI - American Iron and Steel Institute

ASTM - American Society for Testing and Materials

CSA - Canadian Standards Association

EESC-USP - Escola de Engenharia de São Carlos da Universidade de São Paulo RCSC - Research Council on Structural Connections

\section{Lista de Símbolos}

maiúsculos:
A -área
-alongamento na ruptura (base de medida $50 \mathrm{~mm}$ )
Ae -área líquida efetiva da seção transversal
$A_{n} \quad$-área líquida da seção transversal
C - chapa
C. -coeficiente de redução da área líquida, de acordo com a NBR 1 4762:2001
DL -dupla cantoneira
Fu -força última experimental
Fu1 -força última experimental para um parafuso
L $\quad$-comprimento da ligação
LI - cantoneira de abas iguais
LD - cantoneira de abas desiguais
U - perfil U
U $\quad$-coeficiente de redução da área líquida, de acordo com o AISI (corresponde ao $\mathrm{C}_{t}$ ) 
minúsculos:

d -diâmetro nominal do parafuso

$d_{h}, d_{0}$-diâmetro nominal do furo

e - -distância; na direção da solicitação, do centro do furo padrão à borda mais próxima do furo adjacente ou à extremidade da parte conectada

$e_{1}, e_{2}$-distância, na direção perpendicular a solicitação, do centro do furo padrão à extremidade da parte conectada

ft - "tensão nominal de tração"

fu - resistência à ruptura do aço

fup -resistência à ruptura do parafuso

$f_{y}$-resistência ao escoamento do aço

g -Espaçamento dos parafusos na direção perpendicular à solicitação ou para um único parafuso é a largura da chapa

inúmero de parafusos

$r$-razão da força transmitida pelo parafuso ou parafusos contidos na seção em análise pela força de tração na referida seção

s - largura da chapa conectada dividida pelo número de furos na seção transversal analisada

$s^{\prime} \quad$-largura do elemento conectado $+\bar{x} ;$ ( Holcomb et al. (1995)

$t \quad$-Espessura da chapa ou do elemento conectado

$\overline{\boldsymbol{x}} \quad$-excentricidade da ligação

gregas:

$\sigma_{n} \quad$ tensão nominal associada à área líquida

$\gamma \quad$-coeficiente de ponderação 


\section{SUMÁRIO}

Resumo

Abstract

Lista de Siglas

Lista de Símbolos

Sumário

CAPÍTULO 01.

INTRODUÇĀO

1.1 HISTÓRICO

02

1.2 CARACTERÍSTICAS DOS PERFIS FORMADOS A FRIO 05

$\begin{array}{ll}1.3 \text { JUSTIFICATIVA DO TRABALHO } & 07\end{array}$

1.4 OBJETIVOS DO TRABALHO 08

\section{CAPÍTULO 02}

LIGAÇŌES PARAFUSADAS EM CHAPAS FINAS E PERFIS FORMADOS A FRIO

2.1 INTRODUÇĀO

2.2 PESQUISAS REALIZADAS (considerações gerais) 13

2.3 LIGAÇĀO PARAFUSADA EM CHAPA FINA 16

2.3.1 Resistência à ruptura da seção líquida 16

2.3.2 Rasgamento x esmagamento 25

2.3.3 Forças resistentes de cálculo 26

2.4 LIGAÇÃO PARAFUSADA EM PERFIS FORMADOS A FRIO 28

2.4. 1 Resistência à ruptura da seção líquida 29

2.4.2 Estudo comparativo $\quad 35$ 
CAPÍTULO 03

PROCEDIMENTO EXPERIMENTAL

3.1 DISPOSIÇŌES GERAIS 42

3.2 PREPARAÇÃO DOS CORPOS-DE-PROVA 43

3.2.1 Fabricação 43

3.2.2 Montagem dos ensaios $\quad 44$

3.2.3 Instrumentação $\quad 45$

3.3 EXECUÇĀO DOS ENSAIOS 47

3.4 CONFIGURAÇÃO DOS CORPOS-DE-PROVA 48

3.4. 1 Ligações parafusadas em chapas finas de aço 48

3.4.2 Ligações parafusadas em perfis formados a frio 51

CAPÍTULO 04

ANÁLISE NUMÉRICA

4.1 INTRODUÇÃO

4.2 MODELAGEM NUMÉRICA 58

4.2.1. Parâmetros para a avaliação dos modelos numéricos 58

4.2.2. Geração e avaliação do modelo numérico 60

4.2.2.1. Elemento tipo e malha utilizados 60

4.2.2.2. Condições de contorno 64

4.2.2.3. Método de carregamento 66

4.2.2.4. Não-linearidade geométrica 66

4.2.2.5. Não-linearidade física 66

4.3 RESULTADOS DA ANÁLISE NUMÉRICA 70

CAPÍTULO 05

RESULTADOS E DISCUSSĀO

5.1 INTRODUÇÃO

5.2 LIGAÇŌES PARAFUSADAS EM CHAPAS FINAS DE AÇO

5.2.1 Esmagamento 75

5.2.2 Ruptura da seção líquida 85

5.2.2.1 Avaliação do coeficiente $C_{t} \quad 86$ 
5.2.2.2 Determinação do parâmetro g 98

5.2.2.3 Ligações submetidas ao corte duplo 100

5.3 LIGAÇŌES PARAFUSADAS EM PERFIS DE AÇO FORMADOS A FRIO 102

5.3.1 Esmagamento 102

5.3.2 Ruptura da seção líquida 108

5.3.2.1 Ligações onde nem todos os elementos estavam conectados 108

5.3.2.2 Ligações com todos os elementos conectados $\quad 113$

5.3.2.3 Ligações em duplas cantoneiras $\quad 114$

\section{CAPÍTULO 06}

- CONCLUSĀO

6 CONCLUSŌES

REFERÊNCIAS

\section{Apêndices:}

$\begin{array}{ll}\text { A Caracterização do material } & 126\end{array}$

B Configurações geométricas das peças ensaiadas 128 
CAPÍTULO 01

INTRODUÇÃO 


\subsection{HISTÓRICO}

A utilização dos perfis formados a frio na construção metálica começou a se desenvolver realmente por volta da segunda metade do século XIX nos Estados Unidos e Inglaterra. Nessa época o excesso de chapas finas de aço produzidas nos Estados Unidos exigiu novas aplicações para este produto (WINTER, 1959). No entanto, a utilização destas chapas de aço na produção de perfis estruturais formados a frio era restrita e deficiente de informações técnicas, portanto esbarrava na ausência de normas de dimensionamento específicas e de pesquisas sobre o comportamento estrutural dos seus elementos.

Frente a esta necessidade, O 'Committee on Building Research and Technology', então chamado 'Committee on Building Codes', do AISI ('American Iron and Steel Institute'), patrocinou, a partir de 1939, vários projetos de pesquisa na Universidade Cornell, tendo como responsável o Prof. George Winter, o propósito era estudar o comportamento estrutural dos perfis formados a frio, obtendo as informações necessárias para a elaboração de uma norma específica.

As pesquisas desenvolvidas por Winter e seus colaboradores resultaram no desenvolvimento de métodos de cálculo concernentes ao projeto de perfis de aço formados a frio (YU 2000), o qual culminou em 1946 com a primeira edição da 'Specification for the design of light gage steel structural member' organizada e publicada pelo AISI. A partir desta publicação os perfis formados a frio se tornaram não somente competitivos como também passaram a complementar o tradicional perfil laminado. Edições posteriores desta especificação foram publicadas em 1956, 1960, 1962, 1968, 1980, 1986, 1991, 1996 e 2001. 
Nas especificações do AISI, posteriores à edição de 1980, foram incluídos novos conceitos de dimensionamento, baseados em resultados de pesquisas, tendo como objetivo principal providenciar uma melhor correspondência com as especificações do 'Research Council on Structural Connections' (RCSC) e do 'American Institute of Steel Construction' (AISC) (LABOUBE \& YU 1997). A edição de 1991 foi a primeira a utilizar o método de introdução da segurança nos cálculos baseados na teoria dos estados limites. Em 1996, foi publicada a edição comemorativa dos 50 anos desta norma, incorporando os dois métodos de introdução da segurança (tensões admissíveis e estados limites), ficando a critério do projetista a escolha de qual método utilizar.

A norma do AISI para o cálculo de estruturas em perfis formados a frio obteve reconhecimento em todo o mundo desde a sua primeira edição, sendo utilizada como referência para o desenvolvimento de pesquisas, projetos e outras normas.

Outro marco das pesquisas com os perfis formados a frio foi a criação, em 1990, na Universidade de Missouri-Rolla, do "Center for Cold-Formed Steel Structures", o qual a partir de outubro de 2000 passou a ser denominado "W. W. YU Center for Cold-formed Steel Structures" em homenagem ao seu emérito fundador. Tendo por objetivo, promover, organizar e divulgar as pesquisas em perfis formados a frio.

Outros países que vêm se destacando na pesquisa de componentes estruturais em perfis de aço formados a frio são:

O Canadá, o qual, incluindo resultados de pesquisas próprias, publicou em 1984, pelo 'Canadian Standards Asociation (CSA)', a norma CAN3-S136-1984 "Cold Formed Steel Structural Members", sendo uma das primeiras normas para o dimensionamento de perfis formados a frio baseada no método de introdução da segurança em estados limites.

A Austrália, que, por meio de pesquisas conduzidas pelo Prof. Hancock e outros, publicou em 1996 a norma australiana para o dimensionamento de estruturas de aço em perfis formados a frio, AS/NZS 4600:1996 "Cold-formed Steel Structures". 
No Brasil, o emprego dos perfis formados a frio iniciou-se praticamente no final da década de 60, quando algumas empresas adquiriram equipamentos específicos para a realização das operações de dobramento a frio (MALITE et al.1998b).

Com o início da sua utilização houve a necessidade de uma norma nacional para o dimensionamento destes perfis. Com isso, em 1967, sob o patrocínio da empresa TECNOFER, foi publicada a NB-143:1967 'Cálculo de estruturas de aço constituídas por perfis leves' cujo texto foi baseado na edição de 1962 da especificação do AISI (MOLITERNO, 1989).

Essa norma não foi adequadamente divulgada e pouco foi utilizada, não sofrendo revisões ao longo do tempo, consistindo então num documento obsoleto e muito vago em alguns itens, como por exemplo o referente as ligações. Isto fez com que a maioria dos projetistas de estruturas metálicas adotassem para o cálculo de estruturas em perfis formados a frio a especificação do AISI, constantemente revisada e compatível, em suas edições mais recentes, com a especificação do AISC, sendo esta bem difundida no meio técnico da construção metálica.

Atualmente, foi publicada a nova norma brasileira que trata do dimensionamento de perfis de aço formados a frio, a NBR-14762:2001 "Dimensionamento de Estruturas de Aço Constituídas por Perfis Formados a Frio", baseada no método de introdução da segurança em estados limites, esta norma inclui aspectos da construção metálica brasileira e promove uma melhor compatibilidade com outras normas nacionais, não satisfeito quando se utiliza uma especificação estrangeira.

É fato que a utilização destes perfis na construção metálica brasileira vem crescendo de forma significativa, sendo decorrente da pouca variedade de perfis laminados e do custo relativamente alto dos perfis soldados. É evidente que os perfis formados a frio não substituem por completo os perfis laminados e soldados. Entretanto, devido ao menor custo, hoje representam economia, quando se trata de construção metálica (MALITE 1993b).

Os perfis de aço formadas a frio têm alcançado lugar de destaque, principalmente em obras de menor porte, onde são utilizados como estrutura principal, como edifícios de pequena altura, residências(CASA MODULAR CSN 
1998) e galpões, as quais possuem, em geral, pequenos vãos e carregamentos de pequena intensidade.

Para edifícios mais elevados, estes perfis são utilizados de maneira complementar, como: - perfis secundários, estrutura para cobertura (tesouras, joists), telhas, fôrmas de aço (steel-deck), painéis de vedação, esquadrias, sistemas de dutos, etc. (COLD-FORMED STEEL IN TALL BUILDINGS 1993). Fôrmas para concretagem, andaimes e escoramentos, são outros exemplos que ilustram a versatilidade desses perfis na construção civil.

Outro aspecto interessante, em termos de Brasil, consiste no fato de que uma significativa parte dos perfis formados a frio utilizados estruturalmente são fabricados com aços denominados de "qualidade comum", ou seja, sem qualificação estrutural, sendo chapas destinadas à estampagem (classificação SAE 1010 a 1020) e voltadas ao mercado da indústria mecânica em geral. Isto faz com que, no mercado, se encontrem perfis oriundos de chapas de vários tipos de aço, ocorrendo uma grande variabilidade com relação à composição química e, conseqüentemente, com relação às propriedades mecânicas (MALITE 1993b).

\subsection{CARACTERÍSTICAS DOS PERFIS FORMADOS A FRIO}

Perfis formados a frio são aqueles obtidos pelo dobramento a frio de chapas de aço. As operações de conformação destas chapas se distinguem hoje em dia em três processos denominados dobramento ou prensagem, calandragem e perfilagem, os quais são realizadas por máquinas denominadas prensas dobradeiras, calandras e perfiladeiras (também conhecidas por mesas de roletes), respectivamente.

Geralmente, utilizam-se materiais com espessura variando de $0,4 \mathrm{~mm}$ a 8,0 $\mathrm{mm}$, entretanto, pode-se conseguir espessuras maiores, desde que o equipamento disponível para executar as dobras, o tipo de aço e o raio de dobramento sejam apropriados para tal, pois perfis fabricados com aços de dureza elevada poderão apresentar trincas nas regiões das dobras (YU 2000).

Os processos de conformação permitem uma grande flexibilidade na fabricação destes perfis, conferindo uma grande liberdade de escolha ao 
projetista, seja no formato da seção transversal, bem como nas suas dimensões, resultando em perfis de elevada relação inércia/peso. A figura 1.1 apresenta algumas possibilidades para as seções transversais de perfis formados a frio.

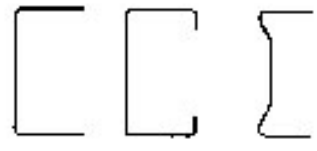

(a) (b)

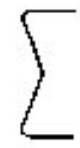

(d)

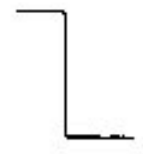

$\{\theta\}$

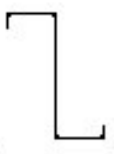

(it)

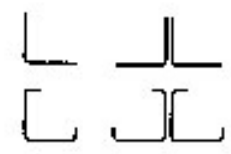

(g) (h)

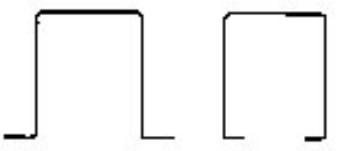

(ii)

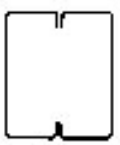

ik)

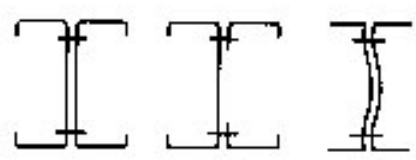

(li) (m)

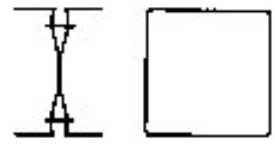

(p) (q)

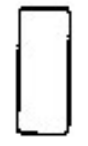

(r)

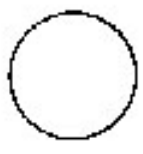

\{s\}

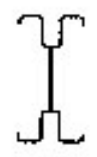

(t)

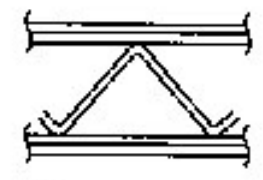

(t)

FIGURA 1.1 - Seções transversais mais comuns dos perfis formados a frio.

(fonte YU 2000)

No Brasil as seções transversais mais empregadas são as do tipo cantoneira simples e dupla (fig. 1.1g e h), perfis $U$ e $U$ enrijecido(fig. 1.la e b), perfis I (formada por dois perfis $U$ - fig. 1.11, $\mathbf{m}, \mathbf{n} \in \mathbf{p}$ ), cartola (fig. 1.1i) e as de seção fechada circular ou retangular (fig. 1.1 q, $r$ e s). A seção tipo $Z$ (fig. 1.le e f), que é bastante utilizada nos Estados Unidos, ainda encontra pouca utilização nas construções em aço executadas no país.

No caso específico de terças e longarinas, as seções do tipo $U$ e $U$ enrijecido têm sua supremacia estabelecida. A padronização destas seções segue as prescrições da norma brasileira NBR 6355:2003 "Perfis estruturais de aço formados a frio - Padronização".

O trabalho a frio altera as propriedades mecânicas do aço virgem, ocorrendo acréscimo na resistência ao escoamento e na resistência à ruptura, redução na ductilidade do material e o surgimento de novas tensões residuais.

A pequena espessura das chapas utilizadas na sua fabricação resultam em elevada relação largura/espessura dos elementos planos que compõem a seção transversal, tornando-os mais suscetíveis aos efeitos localizados, como: 
flambagem local dos seus elementos, flambagem distorcional da seção transversal e aos modos de falha relativos às ligações, tanto parafusadas como soldadas.

\subsection{JUSTIFICATIVA DO TRABALHO}

Apesar da grande aceitação dos perfis formados a frio no mercado, a inexistência de uma norma nacional atualizada dificultava a correta aplicação desses perfis.

Diante desta realidade, em agosto de 1997 foi constituído pela ABCEM (Associação Brasileira da Construção Metálica) um Grupo de Trabalho para a elaboração da nova norma brasileira NBR14762:2001 "Dimensionamento de Estruturas de Aço Constituídas por Perfis Formados a Frio".

Na elaboração dessa norma tomou-se como base a especificação do AISI:1996 em estados limites e seu suplemento nol publicado em 1999, norma esta amplamente utilizada no Brasil e em vários países.

Atrelado ao desenvolvimento da nova norma brasileira houve uma intensificação das pesquisas com este tipo de estrutura, visando calibrar ou mesmo propor novas prescrições para futuras edições (MALITE et al. 1998).

Dentre os diversos itens dessa norma, o dimensionamento de barras segue de maneira mais fiel as prescrições das normas estrangeiras, requerendo menores cuidados que o dimensionamento das ligações, que, por conveniência, passaram por maiores alterações.

Em particular, um item que gerou dificuldade foi a verificação do estado limite último de ruptura na seção líquida para ligações parafusadas em chapas finas de aço e, principalmente em perfis formados a frio, por ser esse um estado limite último vinculado à ocorrência de efeitos localizados, que em geral governam o projeto de ligações em elementos finos, e ainda incipiente nas normas. Portanto merecendo uma investigação mais detalhada das suas prescrições. 


\subsection{OBJETIVOS DO TRABALHO}

Este trabalho tem como objetivo principal promover uma investigação criteriosa das prescrições da norma brasileira de "Dimensionamento de Estruturas de Aço Constituídas por Perfis Formados a Frio" NBR14762:2001, quanto ao tema das ligações parafusadas, focalizando a avaliação experimental do coeficiente redutor da área líquida $\left(\boldsymbol{C}_{\boldsymbol{t}}\right)$ apresentado por esta, tanto para chapas como para perfis formados a frio, quando da avaliação da força normal resistente à ruptura da seção líquida efetiva.

Buscando deste modo subsídios para propor modificações das expressões apresentadas em norma, as quais poderão ser incorporadas em futuras revisões.

Este objetivo será dividido em duas frentes, como segue:

\section{- Ligações parafusadas em chapas finas de aço.}

Analisar o comportamento estrutural de ligações parafusadas em chapas finas de aço submetidas a corte simples e duplo, com base em análises teóricas e experimentais de diversas configurações de ligações, avaliando e identificando os correspondentes modos de falha, com ênfase na ruptura da seção líquida, aferindo as expressões de cálculo do coeficiente de redução da área líquida $\boldsymbol{C}_{\boldsymbol{t}}$ para chapas.

\section{- Ligações parafusadas em perfis de aço formados a frio.}

Analisar o comportamento estrutural de ligações parafusadas em perfis de aço formados a frio, com base em análises teóricas e experimentais de ligações em cantoneiras e perfis $U$, avaliando e identificando os correspondentes modos de falha, com ênfase na ruptura da seção líquida, aferindo as expressões de cálculo do coeficiente de redução da área líquida $C_{t}$ para os perfis formados a frio. 
CAPÍTULO 02

LIGAÇÕES PARAFUSADAS EM CHAPAS FINAS E PERFIS FORMADOS A FRIO 


\subsection{INTRODUÇÃO}

As ligações podem ser consideradas como a parte mais importante de uma estrutura metálica, tanto do ponto de vista estrutural, pois constituem descontinuidades cujo comportamento deve ser analisado de forma mais precisa possível, quanto em relação ao custo de produção

Segundo McGUIRE (1988) entre 30 a $40 \%$ do custo total de um edifício metálico de múltiplos andares, em perfis laminados, são provenientes direta ou indiretamente do sistema de ligações.

Grande parte deste custo é atribuído principalmente à mão-de-obra empregada na sua fabricação e montagem (SALES 1995), sendo que, na busca por economia, por vezes, a simplicidade dos detalhes das ligações exerce impacto razoável nos custos finais.

No entanto, na escolha do tipo de ligação, além dos fatores econômico e estético, deve-se levar em conta também os fatores estruturais, tanto do dispositivo de ligação quanto dos elementos a serem ligados, comparando-os com as exigências que se deseja da ligação. Estes fatores estruturais se dividem em:

- Resistência $\Rightarrow$ depende do tipo de dispositivo de ligação e das propriedades dos elementos ligados (espessura, resistência ao escoamento ou à tração, etc.). Normas de dimensionamento específicas trazem as expressões de cálculo adotadas na avaliação da resistência para diversos tipos de ligações. Valores mais realistas da resistência podem ser determinados por ensaios. 
- Rigidez $\Rightarrow$ a rigidez da ligação influencia na resposta da estrutura, esforços internos e deslocamentos, como um todo ou em partes.

- Capacidade de deformação $\Rightarrow$ garante uma boa distribuição de esforços no elemento de ligação e da estrutura. Uma ligação sem capacidade de deformação pode causar uma ruptura frágil da estrutura ou elemento ligado.

Uma variedade de dispositivos de ligação para as estruturas leves (chapas finas e perfis formados a frio) já foram estudados, visando garantir simplicidade de detalhes com bom comportamento estrutural [COLD-FORMED steel in tall buildings (1993)]. São esses: parafusos auto-atarraxantes e auto-brocantes (screws), rebites a frio, ligação por pressão (press-joining) (PEDRESCHI \& SINHA 1996) e ligações por adesivos. Entretanto, estes sistemas não proporcionam a resistência, e em certos casos, nem a rigidez conseguida pelos sistemas tradicionais (a solda e o parafuso).

Em particular para as ligações parafusadas, sua importância vem crescendo na construção moderna, sendo utilizadas numa grande variedade de aplicações, principalmente em ligações executadas no campo.

Desde que as estruturas leves começaram a ser utilizadas extensivamente nos Estados Unidos, muitos estudos vêm sendo realizados para determinar a resistência das ligações parafusadas em chapas finas e perfis formados a frio. As especificações de cálculo contidas nas normas do AISI, desde sua primeira edição em 1946, baseada nos trabalhos realizados na Universidade de Cornell, já contemplavam o cálculo de ligações parafusadas em chapas finas de aço (YU 2000).

No Brasil, o tema ligações parafusadas é bastante difundido quando se trata de estruturas constituídas por perfis laminados e soldados, mas é pouco divulgado no caso de estruturas constituídas por perfis formados a frio, em grande parte devido à omissão da NB 143:1967 -"Cálculo de estruturas de aço constituídas por perfis leves", em relação às ligações.

Com a recente norma brasileira NBR14762:2001 "Dimensionamento de estruturas de aço constituídas por perfis formados a frio", espera-se preencher esta lacuna nas especificações dos perfis formados a frio, principalmente quanto às ligações. 
Na elaboração dessa norma, um item em particular que gerou dificuldade foi a verificação do estado limite último de ruptura da seção líquida para ligações parafusadas em chapas finas de aço e perfis formados a frio. Por ser esse um estado limite muito susceptível à ocorrência de efeitos localizados, que, em geral, governam o projeto de ligações em elementos finos, principalmente quando da concentração de tensões junto aos furos.

A norma brasileira para o dimensionamento de estruturas de aço constituídas por perfis formados a frio NBR 14762:2001, para levar em conta no dimensionamento estes efeito localizados, adota um coeficiente de redução da área líquida, denominado de $\boldsymbol{C}_{\boldsymbol{t}}$, na avaliação da força normal de tração resistente para esse estado limite.

Com a adoção desse coeficiente procurou-se dar um tratamento similar ao da norma brasileira de perfis "pesados" NBR 8800:1986. Entretanto, é importante frisar que o coeficiente $\boldsymbol{C}_{\boldsymbol{t}}$ proposto pela norma de perfis formados a frio é mais abrangente que o estabelecido pela NBR 8800:1986, pois não considera a influência da concentração de tensões somente para situações e perfis pré-determinados, mas sim em chapas finas e perfis com as mais diversas configurações de ligações, inclusive quando todos os elementos estão conectados.

Por outro lado o AISI:1996, até a publicação do seu Suplemento n 1, em 1999, e outras normas estrangeiras consideram a influência da concentração de tensão junto aos furos, para o caso do estado limite de ruptura da seção líquida, apenas em chapas finas.

Com a publicação do Suplemento n 1 do AISI:1996 em 1999, esta passou a adotar para o cálculo da ruptura da seção líquida de perfis formados a frio, procedimento similar ao do AISC:1993, ou seja, adotou coeficientes redutores da área líquida em função da relação $\overline{\boldsymbol{x}} / \boldsymbol{L}$ (excentricidade pelo comprimento da ligação).

Numa versão inicial do texto da norma brasileira NBR14762:2001, adotou-se para avaliação do coeficiente $C_{t}$ procedimento similar ao do AISI:1996 aplicado a chapas finas e extrapolou-se a sua utilização para o caso de ligações parafusadas em perfis formados a frio, isto é, os perfis seriam tratados como uma chapa equivalente. Tal procedimento, embora aparentemente razoável, não dispunha de investigação mais aprofundada e, com a publicação do 
Suplemento $n^{\circ} 1$ do AISI:1996 (1999), foi substituído pelo então adotado por esta norma.

Esse novo procedimento não apresentava nenhuma relação quando comparado ao tratamento inicial de chapa equivalente, apresentando variáveis distintas.

Portanto é objetivo principal deste trabalho, a aferição das expressões de cálculo adotadas pela NBR14762:2001. Para avaliação da resistência à ruptura da seção líquida, aplicadas as ligações parafusadas em chapas finas de aço e perfis formados a frio.

\subsection{PESQUISAS REALIZADAS (considerações gerais)}

Desde 1939, várias pesquisas sobre ligações parafusadas em chapas finas, Utilizando parafusos comuns ASTM-A307 (com e sem arruela) e de alta resistência ASTM-A325, vêm sendo realizadas na Universidade de Cornell e em outras instituições americanas.

Nessa época, WINTER (1956) já afirmava que os critérios para a avaliação da resistência das ligações parafusadas em estruturas convencionais de aço (perfis laminados ou soldados) não poderiam ser diretamente aplicados aos perfis formados a frio, onde os efeitos localizados são mais pronunciados e, em geral, conduzem a situações mais desfavoráveis.

Assim, a finalidade dessas pesquisas era estudar o comportamento estrutural de tais ligações e fornecer informações úteis para o desenvolvimento de procedimentos de cálculo confiáveis.

De maneira geral, para as ligações parafusadas com solicitação perpendicular ao eixo do parafuso (força cortante), resultados de ensaios publicados por WINTER (1956), indicaram a ocorrência de quatro modos de falha:

1- rasgamento entre furo e borda, figura 2.1 a;

2- esmagamento da chapa junto ao parafuso, figura $2.1 \mathrm{~b}$ e d;

3- ruptura da chapa na seção líquida, figura 2.1 c;

4- cisalhamento do parafuso. 
Um quinto modo de falha, caracterizado pelo esmagamento da chapa junto ao parafuso associado à rotação do parafuso, foi proposto em 1976 por YU e MOSBY (HOLCOMB et al 1995) da Universidade de Missouri-Rolla, estes constataram que esse modo de falha é mais pronunciado nas ligações com apenas uma seção de parafusos na direção perpendicular à solicitação.

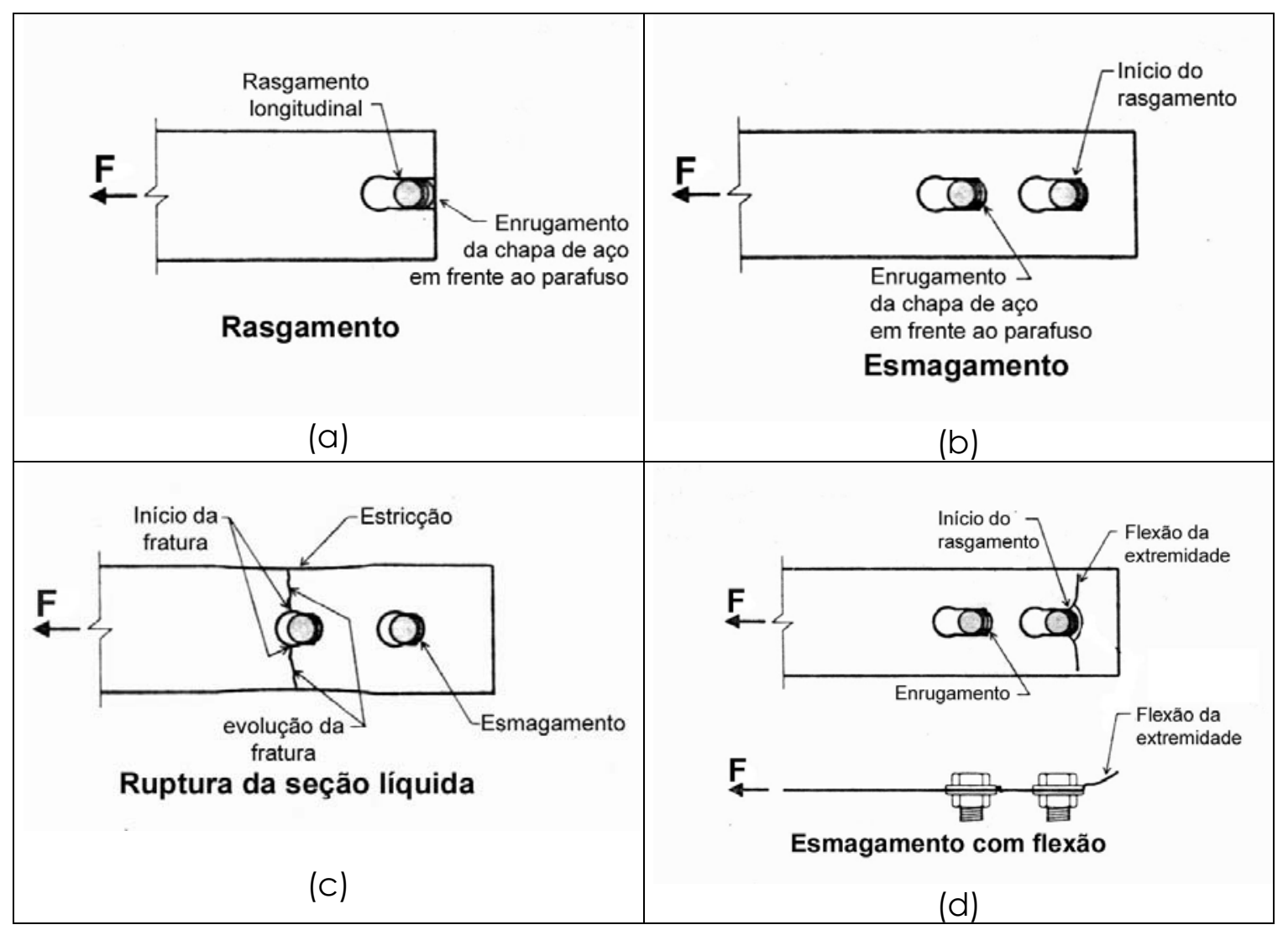

FIGURA 2.1 - Modos de falha associados à chapa para as ligações parafusadas em chapa fina

Com base na bibliografia consultada, lista-se a seguir os parâmetros que afetam a resistência das ligações parafusadas em chapas finas e perfis formados a frio:

- Diâmetro do parafuso, d

- Dimensão do furo, $\boldsymbol{d}_{\boldsymbol{h}}$

- Espaçamento dos parafusos paralelo à solicitação, e

- Espaçamento dos parafusos normal à solicitação, $\mathbf{g}$

- Distância entre fura e borda normal à solicitação, $\mathbf{e}_{1}$ e $\mathbf{e}_{2}$

- Espessura do elemento conectado, $\boldsymbol{t}$

- Resistência ao escoamento e à tração do aço (metal base), $\boldsymbol{f}_{\boldsymbol{y}}$ e $\boldsymbol{f}_{\boldsymbol{u}}$ 
- Resistência à tração do parafuso, $\boldsymbol{f}_{\text {up }}$

- Número de parafusos, $\boldsymbol{n}$

- Ligação solicitada ao cisalhamento simples ou duplo

- Relações como: $\mathbf{e} / \boldsymbol{d}, \boldsymbol{d} / \boldsymbol{t}, \boldsymbol{d} / \mathbf{s}$ e $\boldsymbol{f}_{u} / \boldsymbol{f}_{\mathbf{y}}$

Também a utilização de arruelas junto ao parafuso interfere no comportamento da ligação em chapa fina. CHONG \& MATLOCK (1975) e GILCHRIST \& CHONG (1979) constataram que a não utilização de arruelas nestas ligações, até então muitas vezes omitidas na prática sem qualquer embasamento científico, levava a uma redução de $5 \%$ a $37 \%$ na capacidade resistente da ligação, sendo o caso mais crítico quando da utilização de apenas um único parafuso.

Concluíram ser necessário a utilização de fatores de ponderação adequados quando não se utilizam arruelas, recomendação esta adotada posteriormente pelo AISI, o qual apresentou duas expressões para o cálculo da força normal de tração quando da verificação do estado limite último de ruptura da seção líquida, uma para ligações com a utilização de arruelas junto à cabeça do parafuso e a porca, e outra quando da utilização de somente uma ou nenhuma arruela.

Outro fator que interfere na resistência das ligações parafusadas é a ductilidade do aço empregado nos elementos conectados. As especificações do AISI foram baseadas principalmente em resultados de ensaios realizados com aços dúcteis. Um aço é considerado dúctil, por essa norma, quando a relação entre a resistência à ruptura e a resistência ao escoamento $\left(\boldsymbol{f}_{\mathrm{u}} / \boldsymbol{f}_{\mathbf{y}}\right)$ for maior ou igual a 1,08, e o alongamento na ruptura não for menor que 10\% (para base de media de 50mm). Segundo esta norma, o uso de aços que não atendam aos requisitos anteriores fica restrito a elementos secundários e, mesmo assim, deve-se considerar $75 \%$ de suas resistências nos cálculos.

Pesquisas realizadas por SELEIM \& LABOUBE (1996), nos Estados Unidos, e por ROGERS \& HANCOCK (1998), na Austrália, procuraram desenvolver novas prescrições de cálculo para várias configurações de ligações parafusadas utilizando chapas de aço de alta resistência e baixa ductilidade.

Pesquisas mais recentes estão voltadas para as ligações parafusadas em perfis formados a frio, tema até pouco tempo atrás não abordado diretamente 
nas normas de cálculo. YU e LaBoube (1996), apresentaram expressões para a avaliação da resistência à ruptura da seção líquida de ligações parafusadas em perfis formados a frio, as quais foram mais tarde incorporadas ao texto do AISI:2001.

\subsection{LIGAÇÃO PARAFUSADA EM CHAPA FINA}

Para os modos de falha referentes ao elemento de ligação, ou seja; ruptura da seção líquida (fig. 2.1c), rasgamento entre furos ou entre furo e borda (fig. 2.1 a) e esmagamento da parede dos furos (fig. 2.1b), são apresentados, a seguir, os métodos de avaliação da força normal de tração resistente para as ligações parafusadas em chapas finas de aço, segundo as especificações de cálculo do AISI, EUROCODE e da NBR.

\subsubsection{Resistência à ruptura da seção líquida}

A ruptura da seção líquida nas ligações parafusadas é identificada pela estricção da seção, seguida da fratura do material iniciada junto às bordas do furo central (ou dos furos centrais), propagando-se para as extremidades da chapa (fig $2.1 \mathrm{c}$ ).

Segundo as normas citadas anteriormente, a determinação da força normal resistente de tração de uma ligação parafusada, considerando a ruptura da seção líquida, é influenciada pela resistência do material $\left(\boldsymbol{f}_{\mathbf{u}}\right)$, pela área líquida da seção transversal $\left(\boldsymbol{A}_{\boldsymbol{n}}\right)$ e também pela concentração de tensões junto aos furos, provocada por forças localizadas, transmitidas às chapas pelos parafusos quando estes são solicitados ao corte (WINTER, 1956).

Esta influência da concentração de tensões na resistência da ligação é considerada nas expressões de cálculo, ou por meio de uma tensão associada à área líquida (conforme o AISI e o EUROCODE), ou por meio de um coeficiente redutor da área líquida (conforme a NBR), como apresentado a seguir. 


\section{Procedimento do AISI}

Logo no início dos estudos das ligações em chapas finas, WINTER (1956) propôs, com base em resultados de ensaios, uma expressão para a tensão nominal associada à área líquida $\left(\sigma_{n}\right)$, consistindo a resistência à ruptura do material modificada por um coeficiente de redução em função da relação $\mathbf{d} / \mathbf{g}$ (sendo $\boldsymbol{d}$ o diâmetro do parafuso e $\mathbf{g}$ o espaçamento entre furos na direção perpendicular a solicitação), como representado a seguir:

$$
\sigma_{n}=\left(0,10+3,0 \frac{d}{g}\right) f_{u}
$$

A expressão original de Winter foi adotada pelo AISI em suas primeiras edições, sendo aplicável exclusivamente às ligações que utilizassem duas arruelas (junto à cabeça do parafuso e à porca). Estudos posteriores a 1975 , realizados por CHONG \& MATLOCK (1975) e GILCHRIST \& CHONG (1979), apresentaram uma nova expressão da tensão associada à área líquida aplicável as ligações parafusadas quando da utilização de somente uma arruela junto ao parafuso ou nenhuma (eq. 2.2).

$$
\sigma_{n}=\left(0,6-0,66 r+2,92 \frac{d}{g}\right) f_{u}
$$

Em 1982, novos estudos enfocando os efeitos da relação entre o diâmetro do parafuso e o espaçamento entre furos $(\mathbf{d} / \mathbf{g})$ na resistência à tração de ligações parafusadas em chapas, utilizando ou não arruelas, para configurações de ligações contendo uma, duas ou três seções de parafusos na direção perpendicular à solicitação, foram apresentados por YU na ' 6 th International Specialty Conference on Cold-formed Steel Structures' promovida pela Universidade de Missouri - Rolla.

Yu demonstrou com estes estudos que a concentração de tensões é menos acentuada quando mais de uma seção de parafusos é utilizada. Assim baseado em resultados de ensaios, reproduzidos a seguir nos gráficos das figuras 
2.2 e 2.3, ele explica a adoção pelo AISI:1980 de novas expressões para o cálculo da tensão associada à área líquida, as quais adotam além da já conhecida relação $\mathbf{d} / \mathbf{g}$ também o parâmetro $\boldsymbol{r}$, definido como a relação entre a força transmitida pelos parafusos da seção analisada pela força atuante nessa seção.

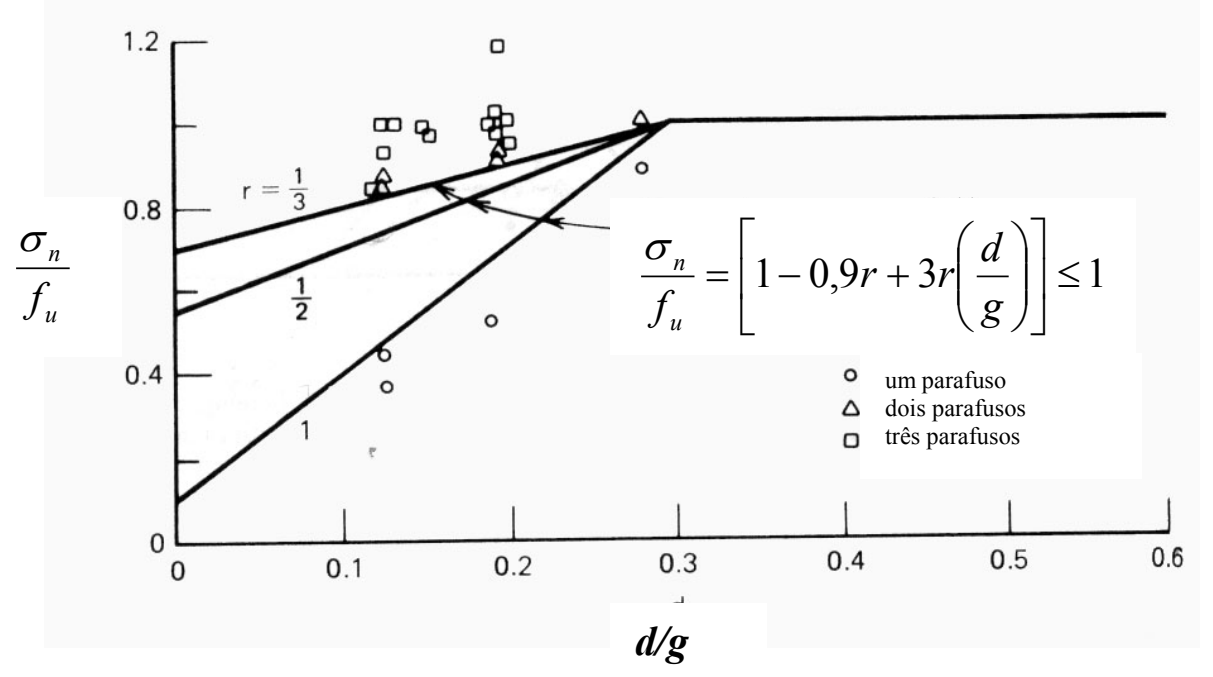

FIGURA 2.2 - Efeito da relação d/g no cálculo de $\sigma_{n}$ para ligações parafusadas utilizando arruelas (YU 1982)

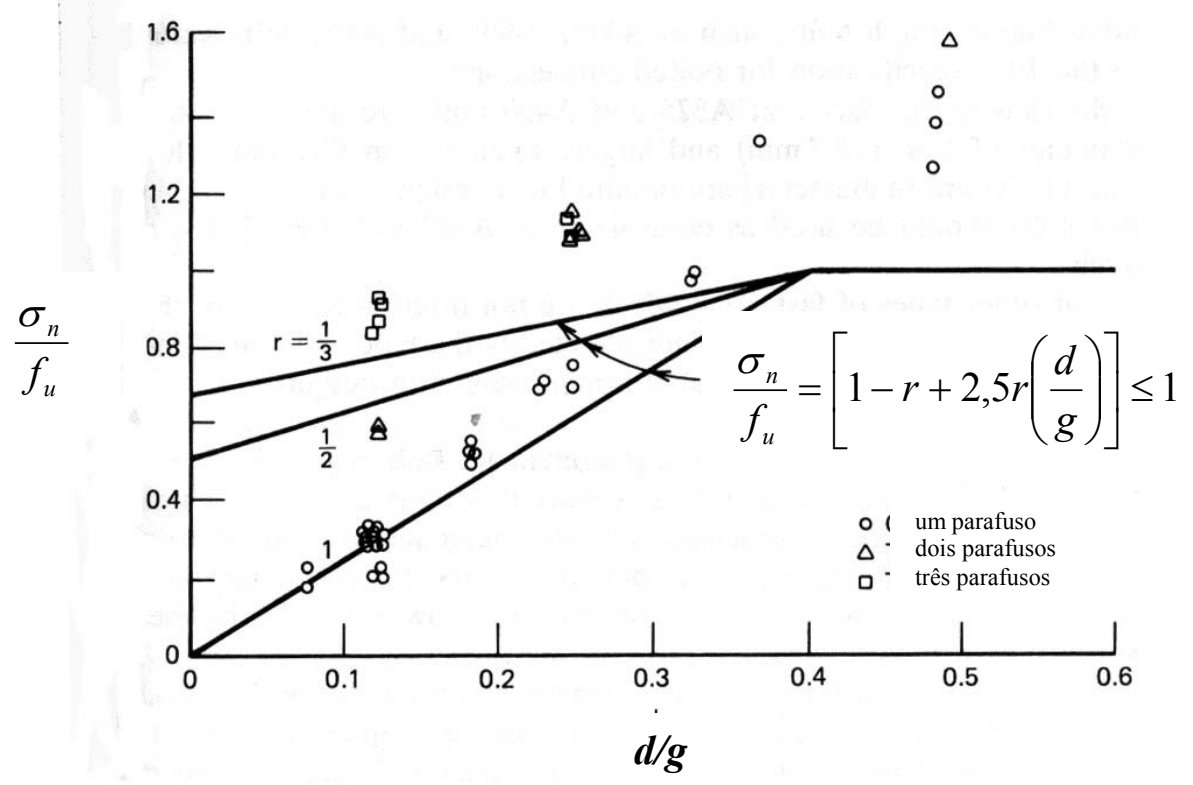

FIGURA 2.3 - Efeito da relação d/g no cálculo de $\sigma_{n}$ para ligações parafusadas não utilizando arruelas (YU 1982) 
O parâmetro $\boldsymbol{r}$ tem por objetivo levar em conta no cálculo a configuração geométrica da ligação, pois, conforme apresentado nos gráficos anteriores (fig. 2.2 e 2.3), a falha na seção líquida com duas seções de parafusos ( $r=1 / 2)$ e três seções $(r=1 / 3)$ ocorre para tensões maiores do que para o caso de apenas uma seção de parafusos $(r=1)$. Observa-se também que a situação mais crítica ocorre para pequenas relações $\mathbf{d} / \mathbf{g}$, isto devido a maior concentração de tensões nesses casos.

Assim, a especificação do AISI de 1980 adota para o cálculo da força normal resistente de tração para o estado limite último de ruptura da seção líquida as seguintes expressões:

- quando são previstas a utilização de arruelas junto à cabeça do parafuso e à porca;

$$
N_{t, R}=\left[1-0,9 r+3 r \frac{d}{g}\right] f_{u} A_{n} \leq f_{u} A_{n}
$$

- quando não são previstas a utilização de arruelas ou só uma arruela é prevista;

$$
N_{t, R}=\left[1-r+2,5 r \frac{d}{g}\right] f_{u} A_{n} \leq f_{u} A_{n}
$$

Onde:

-r é a razão da força transmitida pelo parafuso ou parafusos contidos na seção em análise pela força de tração no elemento;

-d é o diâmetro do parafuso;

-g é o espaçamento dos parafusos perpendicular à linha da força, ou para um único parafuso é a largura da chapa.

Na edição de 2001 do AISI, o coeficiente de redução associado à área líquida, agora denominado $\boldsymbol{f}_{\boldsymbol{t}}$, aplica-se somente para as ligações parafusadas com apenas uma seção de parafusos perpendicular à solicitação, suprimindo com isso o parâmetro $r$. 
Segundo esta nova abordagem, a avaliação da força normal resistente de tração para o estado limite de ruptura da seção líquida efetiva será feita pela seguinte expressão:

$$
N_{t, R}=A_{n} f_{t}
$$

Sendo o valor de $\boldsymbol{f}_{\boldsymbol{t}}$ avaliado da seguinte maneira:

$\Rightarrow$ Ligações que utilizam arruelas junto a cabeça do parafuso e a porca.

- para ligações com um parafuso, ou uma seção de parafusos perpendicular a direção da solicitação:

$$
f_{t}=(0,1+3 d / s) f_{u} f_{u}
$$

- para mais de uma seção de parafusos perpendicular a direção da solicitação:

$$
f_{t}=f_{u}
$$

$\Rightarrow$ Ligações que não utilizam arruelas, ou utilização somente uma arruela junto a cabeça do parafuso ou a porca.

- para ligações com um parafuso, ou uma seção de parafusos perpendicular a direção da solicitação:

$$
f_{t}=(2,5 d / s) f_{u} s_{u}
$$

- para mais de uma seção de parafusos perpendicular a direção da solicitação:

$$
f_{t}=f_{u}
$$

Portanto segundo o AISI:2001, a resistência à tração para o estado limite último de ruptura da seção líquida efetiva, para as ligações parafusadas em chapas finas, será determinada pela área líquida da seção transversal e também pela resistência à tração do aço da parte conectada $\left(f_{u}\right)$, sendo que, para as ligações com apenas um parafuso ou uma única seção de parafusos perpendicular à solicitação, essa resistência será reduzida por um coeficiente que é função da relação $d / s$, onde $s$ é tomado como a largura da chapa conectada dividida pelo número de furos na seção transversal analisada, ou seja, não importando os seus espaçamentos, no caso de mais de um furo. 
Essa nova formulação adotada pelo AISI esta fundamentada na análise de resultados experimentais (CARRIL, LaBOUBE e YU, 1994 apud draft do AISI), os quais demonstraram que para ligações em chapas finas utilizando apenas um parafuso ou uma única seção de parafusos perpendicular a solicitação, a rotação da ligação, a deformação fora do plano desta e a concentração de tensões junto aos furos, são excessivas.

Já para as ligações que utilizam mais de uma seção de parafusos esta rotação e a deformação fora do plano da ligação são menos acentuadas e a concentração de tensões é amenizada pela redistribuição plástica das tensões, não se fazendo necessária a redução da resistência (Rogers e Hancock, 1998)

\section{Procedimento do EUROCODE}

O EUROCODE 3 part 1.3:1996, é similar a do AISI:1996 quando da utilização de arruelas, como pode ser visto a seguir.

$$
N_{t, R}=\left[1+3 r\left(d_{0} / u-0,3\right)\right] f_{u} A_{n} \leq f_{u} A_{n}
$$

As diferenças nas expressões destas duas normas encontra-se na avaliação do coeficiente redutor da resistência à ruptura do material, onde a variável $\boldsymbol{d}_{0}$ é definida como o diâmetro nominal do furo e não do parafuso como apresentado pelo AISI. E sendo o parâmetro u, tomado como:

$$
\mathbf{u}=\left(\mathbf{e}_{1}+\mathbf{e}_{2}\right) \quad \text { mas } \quad \mathbf{u} \leq \mathbf{g}
$$

conforme figura 2.4 .

Ou seja, u será tomado como a soma das distâncias entre os centros dos furos de extremidade às respectivas bordas, na direção perpendicular à solicitação, com este valor não sendo maior do que o espaçamento entre furos. 


\section{Procedimento da NBR}

A NBR 14762:2001 apresenta procedimento similar ao do AISI, adotando um coeficiente de redução da área líquida denominado $\boldsymbol{C}_{\boldsymbol{t}}$. Procedeu-se desta maneira visando uma melhor concordância com a norma de perfis pesados NBR 8800:1986.

No entanto, este coeficiente $\boldsymbol{C}_{\boldsymbol{t}}$ tem sua origem na expressão do coeficiente redutor apresentada pelo AISI:1996 para o caso de ligações sem arruelas ou com apenas uma arruela junto ao parafuso, situação mais desfavorável.

Para se obter as expressões apresentadas pela NBR14762:2001 das expressões originais, deve-se substituir $\circ$ parâmetro $r$ pelos valores correspondentes a uma, duas, três e quatro linhas de parafusos (valores 1, 1/2, 1/3 e 1/4, respectivamente), estabelecendo deste modo quatro expressões de cálculo (fig. 2.5), aplicadas como segue:

-quando todos os parafusos da ligação estão contidos em uma única seção transversal:

$$
C_{t}=2,5(d / g) \leq 1,0
$$

-quando existem duas seções de parafusos perpendiculares à direção da solicitação, alinhados ov em zig-zag:

$$
C_{t}=0,5+1,25(d / g) \leq 1,0
$$

-quando existem três seções de parafusos perpendiculares à direção da solicitação, alinhados ou em zig-zag:

$$
C_{t}=0,67+0,83(d / g) \leq 1,0
$$

-quando existem quatro ou mais seções de parafusos perpendiculares à direção da solicitação, alinhados ou em zig-zag:

$$
C_{t}=0,75+0,625(d / g) \leq 1,0
$$


Nas expressões anteriores, o coeficiente $C_{t}$ é função apenas da relação $\mathbf{d} / \mathbf{g}$, que avalia a "intensidade da concentração de tensão". Quando são comparadas ligações com a mesma quantidade de parafusos na direção da solicitação, conclui-se que, para valores menores da relação $\mathbf{d} / \mathbf{g}$, isto é, parafusos mais espaçados, há maior concentração de tensão e, conseqüentemente, resulta um valor menor de $\boldsymbol{C}_{\boldsymbol{t}}$.

O valor adequado de $\boldsymbol{C}_{\boldsymbol{t}}$ depende de uma avaliação racional da grandeza g, o que implica cuidados ao se estabelecer esse valor. Nas ligações projetadas de maneira que os parafusos sejam dispostos uniformemente na região da ligação, o que é desejável tendo em vista amenizar a concentração de tensão, o espaçamento entre os parafusos assume valor constante e é da ordem do dobro do espaçamento entre furo e borda, portanto $\mathbf{g}$ será o próprio espaçamento entre parafusos, conforme a definição da nova norma.

Nos casos em que o espaçamento entre furos $\mathbf{g}$ for inferior à soma das distâncias entre os centros dos furos de extremidade às respectivas bordas, na direção perpendicular à solicitação $\left(\mathbf{e}_{1}+\mathbf{e}_{2}\right), \mathbf{C}_{t}$ deve ser calculado substituindo $\mathbf{g}$ por $\left(\mathbf{e}_{1}+\mathbf{e}_{2}\right)$. Procedimento contrário ao sugerido pelo EUROCODE 3 part 1.3:1996.

Havendo um único parafuso na seção analisada, $\boldsymbol{C}_{\boldsymbol{t}}$ deve ser calculado tomando-se $\mathbf{g}$ como a própria largura bruta da chapa.

Os parâmetros: espaçamento entre furos (g) e espaçamentos entre furo e borda na direção perpendicular a solicitação ( $\mathbf{e}_{1}$ e $\left.\mathbf{e}_{2}\right)$, são apresentados na figura 2.4 a seguir.

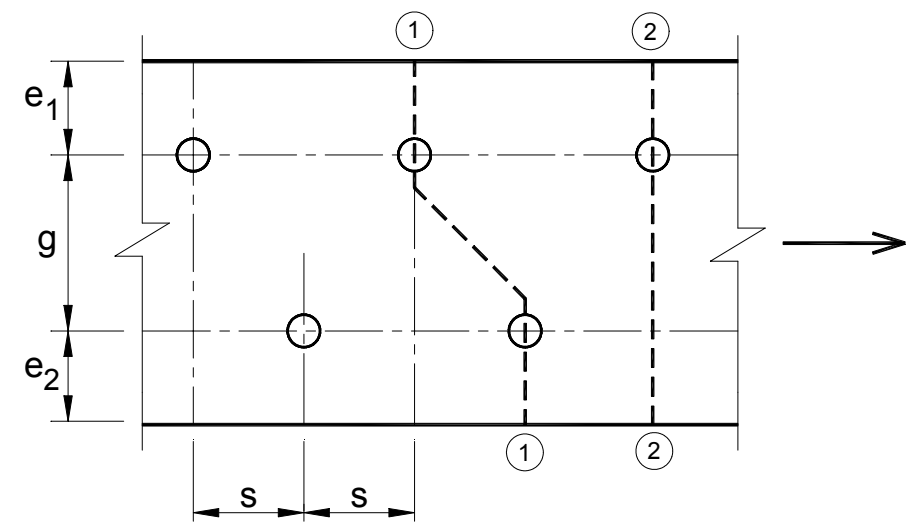

FIGURA 2.4 - Distâncias entre furo e borda e entre furos segundo a NBR 14762:2001 
As expressões para o cálculo do coeficiente $C_{t}$ são apresentadas no gráfico da figura 2.5 . Para os valores de $\mathbf{d} / \mathbf{g}$ acima de 0,4 adota-se para 0 coeficiente $\boldsymbol{C}_{\boldsymbol{t}}$ um valor unitário, ficando portanto, a área líquida efetiva igual à área líquida da seção transversal.

Como as distâncias mínimas entre centros de furos ou entre centro de furo e borda, estabelecidos por norma, são iguais respectivamente à $\mathbf{3 d}$ e $\mathbf{1 , 5 \boldsymbol { d }}$, respeitados estes valores, teremos como relação $\mathbf{d / g}$ máxima o valor de $\mathbf{0 , 3 3 3}$ $(1 / 3)$, valor abaixo do patamar unitário para o coeficiente $C_{t}$.

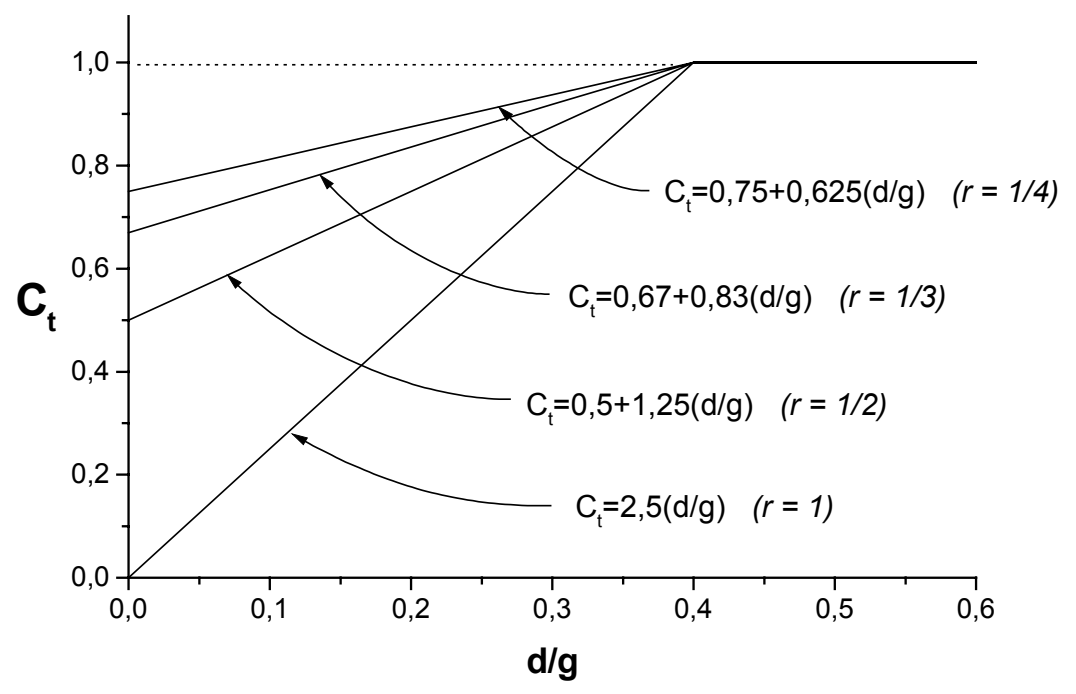

FIGURA 2.5 - Coeficientes $\boldsymbol{C}_{t}$, em função da relação $\mathbf{d} / \mathbf{g}$, segundo a NBR 14762:2001 


\subsubsection{Rasgamento x esmagamento}

Na ruptura por esmagamento, ocorre o enrugamento da chapa de aço em frente ao parafuso, ocasionando a deformação excessiva da chapa na região do furo (fig. 2.1b). Já nas ligações cuja ruptura se caracteriza por rasgamento, ocorre inicialmente o enrugamento da chapa de aço em frente ao parafuso, seguido por duas linhas de rasgamento da chapa, aproximadamente paralelas e longitudinais, estendendo-se da região do enrugamento do material até a extremidade da chapa ou até borda do furo adjacente (fig 2.1 a).

Apesar de não ser este o objetivo principal do trabalho, cabe aqui um breve comentário sobre os procedimentos de cálculo para a avaliação da força nominal resistente para os estados limites últimos de rasgamento e esmagamento de uma ligação parafusada, adotados pelas três especificações citadas anteriormente.

Segundo estas especificações, o estado limite de rasgamento é afetado pela resistência do material $\left(\boldsymbol{f}_{u}\right)$, pela espessura da chapa $(\boldsymbol{t})$ e pela distância do centro do furo à borda do furo adjacente ou à extremidade da chapa (e) tomada na direção da solicitação, ficando portanto a expressão de cálculo com a seguinte configuração:

$$
F_{R}=t . e . f u
$$

O estado limite último de 'rasgamento entre furos ou entre furo e borda', segundo o EUROCODE 3 part 1.3:1996 e a nova norma brasileira NBR 14762:2001,

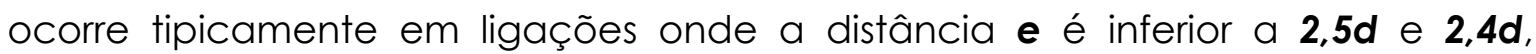
respectivamente, respeitando-se o limite inferior recomendado de $\mathbf{1 , 5} \boldsymbol{d}$, onde $\boldsymbol{d}$ é o diâmetro do parafuso. Acima desses o modo de ruptura previsto é o esmagamento da parede do furo.

Já O AISI:1996 faz distinção quanto a utilização ou não de arruelas e do tipo de solicitação da ligação. Para as configurações ensaiadas, ou seja, ligações parafusadas em chapas submetidas ao cisalhamento simples, esse limite fica em 3d para o caso da utilização de arruelas junto à cabeça do parafuso e a porca, e 2,22d para o caso da utilização de apenas uma arruela ou da não utilização destas. 
Estas limitações são melhor visualizadas no gráfico da figura 2.6, onde estão representadas as curvas da força resistente ao rasgamento e esmagamento em função da relação da distância do centro do furo padrão à borda mais próxima do furo adjacente ou à extremidade do elemento conectado (e), pelo diâmetro do parafuso (d).

Portanto os valores adotados pela nova norma brasileira para a avaliação da força resistente ao esmagamento entre furos ou entre furo e borda, são intermediários aos dois casos apresentados pelo AISI:1996 e inferiores ao do EUROCODE 3 part 1.3:1996.

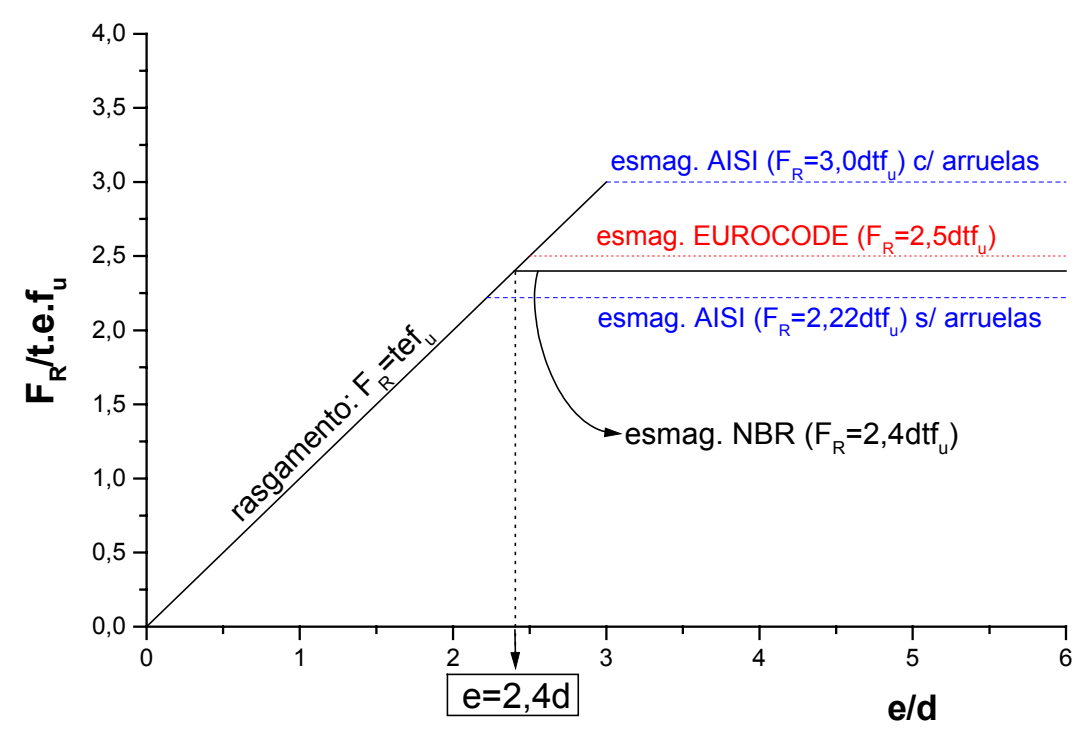

FIGURA 2.6 - Resistências ao rasgamento e esmagamento em função da relação $e / d$

\subsubsection{Forças resistentes de cálculo}

Observa-se uma igualdade nos valores da força nominal de tração referentes ao estado limite último de ruptura da seção líquida efetiva, apresentados pela NBR 14762:2001 e pelo AISI:1996 no caso da não utilização de arruelas. Essa é devida a similaridade no modo de avaliação deste estado limite, das expressões dos coeficientes redutores da área líquida $\left(\boldsymbol{C}_{\boldsymbol{t}}\right)$ e da resistência à ruptura do material, respectivamente 
Essa igualdade não prevalece quando da avaliação dos valores de cálculo para as forças resistentes de tração, isto se deve a adoção de coeficientes redutores da resistência diferentes, ou seja, 1,35 adotado pela NBR 14762:2001 e 1,54 pelo AISI:1996, sendo este último 12,6\% maior.

Já O EUROCODE 3 part 1.3:1996, apesar de suas expressões levarem a forças resistentes maiores que a NBR14762:2001, esse adota um coeficiente redutor da resistência menos conservador, com valor de 1,25 (7,4\%menor).

Comparando-se agora as forças resistentes de cálculo para o estado limite último de esmagamento da parede do furo, apresentadas pelas três especificações de cálculo citadas, demonstradas na tabela 2.1, nota-se para esta situação o caráter conservador da NBR 14762:2001, apresentando valores de cálculo superiores somente ao caso de cisalhamento simples sem a utilização de arruelas apresentado AISI:1996.

TABELA 2.1 - Forças resistentes de cálculo para a falha por esmagamento

\begin{tabular}{|c|c|c|c|c|c|}
\hline Caso* & $\begin{array}{l}\text { AISI/96 } \\
\text { (1) }\end{array}$ & $\begin{array}{c}\text { EUROCODE } \\
\text { (2) }\end{array}$ & $\begin{array}{l}\text { NBR } \\
\text { (3) }\end{array}$ & (3)/(1) & $(3) /(2)$ \\
\hline$a$ & $\begin{array}{c}F_{R d}=3,33 f_{u d t} / \gamma \\
\gamma=1 / \phi=1 / 0,55=1,82\end{array}$ & \multirow{5}{*}{$\begin{array}{c}\mathrm{F}_{\mathrm{Rd}}=2,50 \mathrm{fudt}_{\mathrm{d}} / \gamma \\
\gamma=1,25\end{array}$} & \multirow{5}{*}{$\begin{array}{c}\mathrm{F}_{\mathrm{Rd}}=2,40 \mathrm{f}_{\mathrm{Ud}} \mathrm{dt} / \gamma \\
\gamma=1,35\end{array}$} & 0,97 & \multirow{5}{*}{0,89} \\
\hline b & $\begin{array}{c}F_{R d}=3,00 f_{u d t} / \gamma \\
\gamma=1 / \phi=1 / 0,65=1,54\end{array}$ & & & 0,91 & \\
\hline C & $\begin{array}{c}F_{R d}=3,00 f_{u d t} / \gamma \\
\gamma=1 / \phi=1 / 0,60=1,67\end{array}$ & & & 0,99 & \\
\hline$d$ & $\begin{array}{c}F_{R d}=3,00 f_{u d t} / \gamma \\
\gamma=1 / \phi=1 / 0,65=1,54\end{array}$ & & & 0,91 & \\
\hline e & $\begin{array}{c}F_{\mathrm{Rd}}=2,22 \mathrm{f}_{\mathrm{Udt}} / \gamma \\
\gamma=1 / \phi=1 / 0,70=1,43\end{array}$ & & & 1,15 & \\
\hline
\end{tabular}

*Casos, adotados somente pelo AISI:1996:

Para ligações que utilizam arruelas junto a cabeça do parafuso e a porca:

a-) face interna das chapas submetidas ao cisalhamento duplo, cujo material da parte conectada tenha a relação $f_{u} / f_{y} \geq 1,08$;

b-) face interna das chapas submetidas ao cisalhamento duplo, cujo material da parte conectada tenha a relação $f_{u} / f_{y}<1,08$;

c-) cisalhamento simples ou face externa das chapas submetidas ao cisalhamento duplo.

Para ligações que utilizam somente uma arruela ou nenhuma:

d-) face interna das chapas submetidas ao cisalhamento duplo;

e-) cisalhamento simples ou face externa das chapas submetidas ao cisalhamento duplo. 


\subsection{LIGAÇÃO PARAFUSADA EM PERFIS FORMADOS A FRIO}

Observa-se, em projetos, que muitas das aplicações para as ligações parafusadas envolvem ligações "excêntricas" em perfis, ou seja, nem todos os elementos da seção transversal são conectados.

Como a transferência de forças entre os elementos conectados ocorre somente pelos parafusos, a tensão que pode ser admitida uniformemente distribuída na seção transversal longe da ligação, precisa ser "estrangulada" para o entorno do parafuso ou parafusos. Quando a ligação é excêntrica, a seção transversal na região da ligação não é solicitada na sua totalidade (figura 2.7). Esse fenômeno é denominado em referências de língua inglesa de "shear lag" [SALMON \& JOHNSON (1990)], devido ao fato desse mecanismo de transferência de força concentrada mobilizar tensões de cisalhamento na peça.

Esta distribuição de tensões não uniforme na vizinhança da ligação favorece a ruptura da seção líquida, reduzindo a capacidade das barras submetidas à tração.

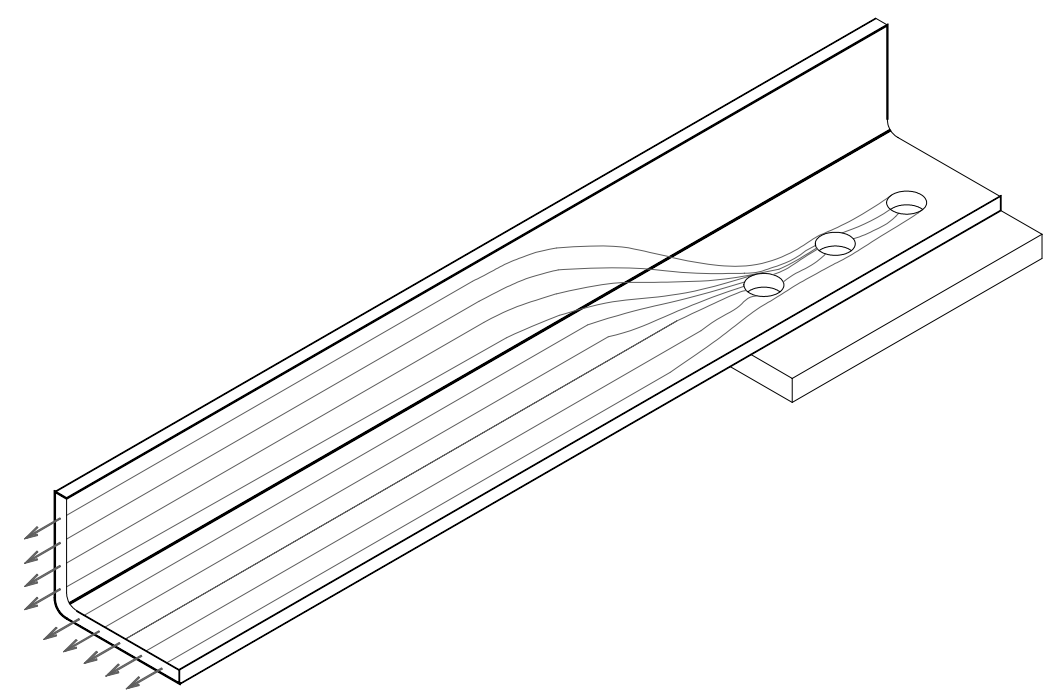

FIGURA 2.7 - Ilustração esquemática do fluxo de tensões em uma cantoneira ligada por uma aba (efeito shear lag) 
No entanto, até 1999 nenhuma especificação de cálculo para perfis de aço formados a frio apresentava um procedimento específico para avaliação da resistência de barras tracionadas com base na ruptura da seção líquida levando em consideração esta distribuição de tensões não uniforme. Com a publicação do Suplemento no 1 do AISI:1996,em 1999, esse contexto veio a mudar, pois foram apresentadas as primeiras expressões para a determinação da resistência nominal à tração na seção líquida efetiva de cantoneiras e perfis $U$ formados a frio.

Tais expressões, constantes na edição de 2001 do AISI e também adotadas pela NBR 14762:2001, foram baseadas em investigações conduzidas por Holcomb et al (1995) e LaBoube \& Yu (1998), e procuraram manter a mesma abordagem aplicada pelo AISC:1993. Como pode ser visto a seguir:

\subsubsection{Resistência à ruptura da seção líquida.}

\section{Procedimento do AISC}

As expressões para o cálculo da força normal resistente de tração para o estado limite de ruptura da seção líquida efetiva em ligações parafusadas, adotada na especificação do AISC, foram baseadas nos estudos feitos por Munse \& Chesson (1963). Estes estudos mostraram que vários parâmetros influenciam nesta resistência, como: geometria e área líquida da seção transversal, efeito "shear lag" e resistência do material.

Estes estudos consideraram a influência do "shear lag" na resistência da ligação pela adoção de um coeficiente de redução da área líquida determinado por ensaios dentro de limites de variação de $\pm 10 \%$ (KULAK et al 1987), sendo este função do comprimento da ligação (L) e da excentricidade da seção transversal da peça ligada em relação ao plano de corte dos parafusos $(\bar{x})$. 
O coeficiente redutor utilizado no cálculo de uma área líquida efetiva $\left(\boldsymbol{A}_{\mathbf{e}}\right)$, consta nas especificações AISC:1993, sob a denominação de coeficiente $\boldsymbol{U}$, apresentado a seguir.

$$
U=1-\bar{x} / L \leq 0,9
$$

onde:

$\mathrm{U}=$ coeficiente de redução da área líquida (efeito "shear lag");

$\overline{\boldsymbol{x}}=$ excentricidade da ligação;

$\mathrm{L}=$ comprimento da ligação.

A excentricidade da ligação é definida como a distância do centro de gravidade da seção transversal ao plano de cisalhamento dos parafusos (fig 2.8). Para as ligações em perfis U conectados pelas mesas, o AISC:1993 sugere que o mesmo seja tratado como duas cantoneiras e a excentricidade seja determinada em relação a uma delas (fig $2.8 \mathrm{c}$ ).

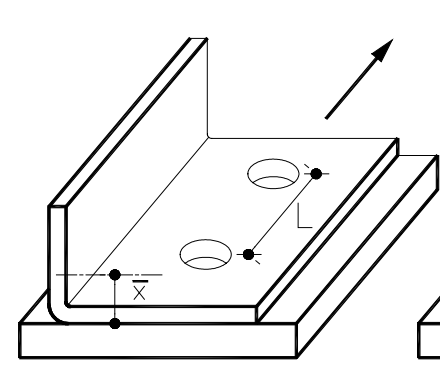

(a)

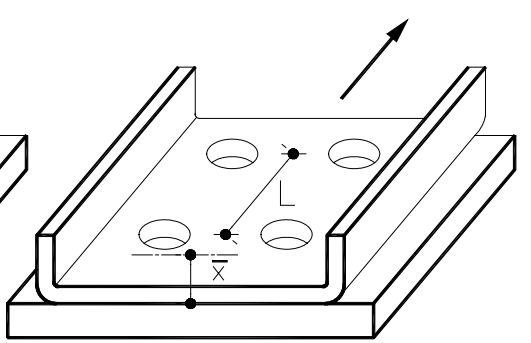

(b)

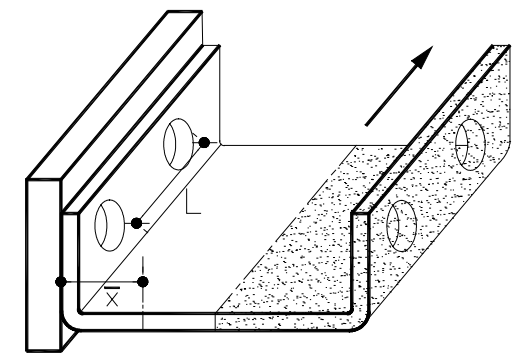

(c)

FIGURA 2.8 - Determinação de $\bar{x}$ e L para ligações parafusadas conforme sugerido pelo AISC:1993

\section{Estudos conduzidos por Holcomb et al. (1995):}

A pesquisa conduzida por Holcomb et al. (1995) procurou desenvolver uma expressão para melhor avaliar a resistência à tração de perfis formados a frio (cantoneiras e perfis U), relacionada com a ruptura da seção líquida.

Essa expressão foi baseada na formulação apresentada pela especificação do AISC:1993 para esse modo de falha. No entanto ficou 
demonstrado que o comportamento estrutural das ligações parafusadas em perfis de aço formados a frio apresentam diferenças significativas em relação aos perfis laminados e soldados, uma vez que a pequena espessura dos elementos conectados implica maiores efeitos localizados e conseqüentemente favorece a ocorrência desse estado limite último no metal base. Não podendo, portanto, aplicar diretamente a expressão do AISC:1993 aos perfis formados a frio. O trabalho de Holcomb consistiu na calibração do coeficiente redutor da área líquida $(\boldsymbol{U})$ apresentado por esta especificação, para a utilização nesses perfis.

O procedimento utilizado nessa calibração foi o de determinar a influência dos parâmetros geométricos na resistência última do perfil e a partir de uma análise estatística, baseada em regressões lineares de resultados de ensaio, desenvolver um novo fator redutor da área líquida, representado entre colchetes na expressão a seguir, a qual expressa a força resistente à ruptura da seção líquida sugerida por Holcomb.

$$
N_{t, R}=A_{n} f_{u}\left[3,987 \cdot\left(t / s^{\prime}\right)+0,514\right]\left[0,5997 \cdot(\bar{x} / L)^{-0,3008}\right]
$$

onde:

$\dagger$ = espessura da chapa de aço;

$\mathrm{s}^{\prime}=$ largura do elemento conectado $+\bar{x}$;

$\bar{x}$ e L já definidos anteriormente

\section{Procedimento do AISI}

Ajustes na expressão do coeficiente $\boldsymbol{U}$ apresentado por Holcomb et al (1995) foram sugeridos por LaBoube \& Yu (1996) e mais tarde incorporadas as especificações do AISI:1996 em seu Suplemento n¹, publicado em 1999, e mantidos em sua edição de 2001. Estas expressões são aplicadas na avaliação da resistência nominal à tração da seção líquida de perfis formados a frio, aplicáveis às cantoneiras e perfis $U$ conectados por duas ou mais seções de parafusos na direção perpendicular à solicitação. 
Segundo esta especificação, a força normal resistente de tração referente ao estado limite último de ruptura da seção líquida deve ser calculada por:

\section{$N_{t, R}=A_{e} f_{U}$}

Onde:

$\mathbf{f}_{\mathbf{u}}=\mathbf{a}$ resistência à ruptura da parte conectada;

$\mathbf{A e}=\mathrm{a}$ área líquida efetiva, dada por $A_{n} . U$.

Os valores do coeficiente de redução da área líquida (U) foram definidos como:

$\boldsymbol{U}=1,0$ para seções onde todos os elementos são conectados;

Caso contrário, o coeficiente $\boldsymbol{U}$ deve ser determinado do seguinte modo:

- para cantoneiras com duas ou mais seções de parafusos na direção da solicitação:

$\boldsymbol{U}=\mathbf{1 , 0}-\mathbf{1 , 2 0} \cdot \overline{\mathbf{x}} / \mathbf{L}<\mathbf{0 , 9} \quad$ (porém não menor que 0,4)

- para perfis U com duas ou mais seções de parafusos na direção da solicitação:

$\boldsymbol{U}=\mathbf{1 , 0}-\mathbf{0 , 3 6} \cdot \overline{\mathbf{x}} / \mathbf{L}<\mathbf{0 , 9} \quad$ (porém não menor que 0,5 )

Onde:

$\bar{x}=$ distância do plano de cisalhamento ao centróide da seção transversal (fig. 2.8 e 2.9);

$L=$ comprimento da ligação (fig. 2.9).

Para as ligações parafusadas em cantoneiras, quando apenas uma aba é conectada, ou em perfis $U$ conectados pela alma, a determinação do valor da variável $\bar{x}$ é feita como demonstrado na figura 2.8 .

Quando a ligação é feita pelas mesas de um perfil U, o AISI:2001 não traz claramente o modo de se avaliar esta variável. Comparações de resultados de ensaios publicados por LaBoube \& Yu (1996), conduzem para que seja tomado como valor de $\bar{x}$ a metade da altura do perfil $U$, como apresentado a seguir na figura 2.9. 


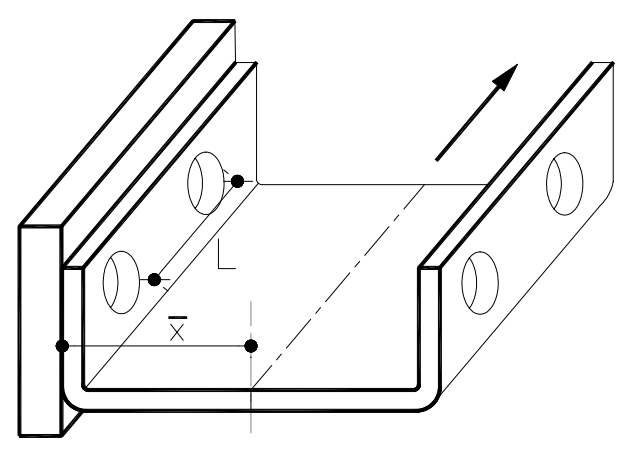

FIGURA 2.9 - Determinação de $\bar{x}$ para perfis $U$ formados a frio conectados pelas mesas

\section{Procedimento da NBR}

A norma brasileira de "Dimensionamento de Estruturas de Aço Constituídas por Perfis Formados a Frio" NBR14762:2001 considera para o cálculo da força normal resistente de tração referente ao estado limite último de ruptura da seção líquida de perfis, a aplicação de um coeficiente de redução da área líquida, o qual como para o caso de chapa fina também é denominado $\boldsymbol{C}_{t}$. Embora tenha recebido a mesma denominação, o coeficiente $C_{t}$ para perfis é o próprio coeficiente $\boldsymbol{U}$ do AISI:2001, portanto leva em consideração o efeito da concentração de tensão nos elementos conectados do perfil.

Durante a elaboração do texto da norma brasileira, as expressões adotadas para a avaliação de $\boldsymbol{C}_{\boldsymbol{t}}$ no caso de ligações parafusadas em perfis formados a frio, foram abordadas de duas maneiras:

Na versão inicial, os valores de $C_{t}$ para os perfis foram os mesmos adotados para o caso de ligações parafusadas em chapa fina (ver subitem 2.3.1 em (Procedimento da NBR'), tratando os perfis como uma chapa equivalente e os valores de $\mathbf{g}, \mathbf{e}_{\mathbf{1}}$ e $\mathbf{e}_{2}$ eram tomados como ilustrado na figura 2.10. 

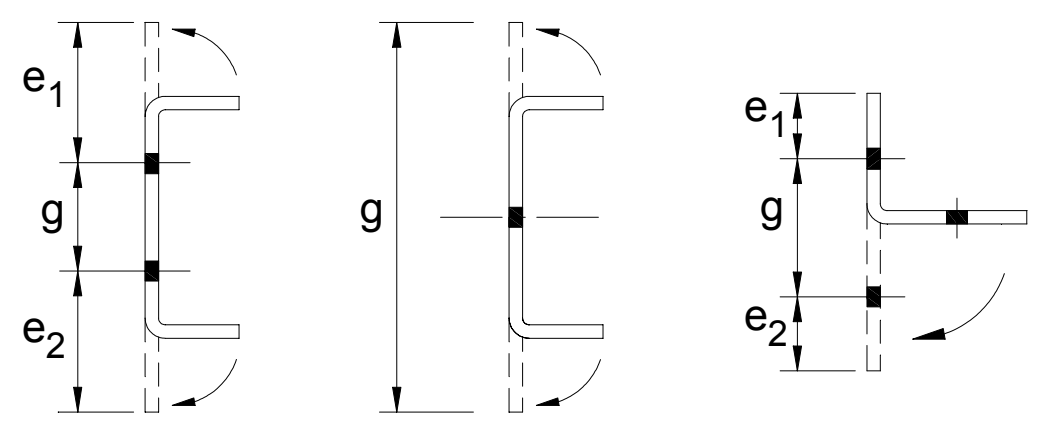

FIGURA 2.10 - Perfis tratados como chapa equivalente

Na versão final, as expressões de $\boldsymbol{C}_{\boldsymbol{t}}$ para os perfis são as mesmas as adotadas pelo AISI:2001 (coeficiente $\boldsymbol{U}$ ), para o caso de duas ou mais seções transversais com parafusos (ver subitem anterior).

Nos casos onde todos os parafusos estão contidos em uma única seção transversal, situação não prevista pela norma americana, o perfil deverá ser tratado como chapa equivalente (figura 2.10), sendo:

$C_{t}=2,5(d / g) \leq 1,0 \quad$ (mesma expressão adotada para as chapas - eq. 2.10)

É importante registrar que o procedimento da versão inicial da norma brasileira nada mais é que uma extrapolação das expressões de $\boldsymbol{C}_{t}$ desenvolvidas para chapas, aplicadas também ao caso dos perfis. Não há portanto um embasamento teórico-experimental que confira confiabilidade a esse procedimento.

Os dois procedimentos citados anteriormente levam a valores diferentes de $\boldsymbol{C}_{\boldsymbol{t}}$ para uma mesma configuração de ligação, como pode ser visto nas figuras 2.11 e 2.12, as quais apresentam gráficos que relacionam os resultados de força última obtidos nos ensaios americanos, com valores teóricos da força resistente. 


\subsubsection{Estudo comparativo}

A seguir são apresentados alguns resultados de ensaios de ligações parafusadas em perfis formados a frio, submetidos ao cisalhamento simples, realizados na Universidade de Missouri-Rolla (HOLCOMB et al. 1995), cujos apresentaram como modo de falha a ruptura da seção líquida. Este resultados são comparados as forças resistentes nominais avaliadas segundo as expressões apresentadas anteriormente.

Tratam-se de ligações parafusadas em cantoneiras e perfis $U$ com dimensões e configurações de furação apresentadas nas Tabelas 2.2 e 2.3. Nestas são representados também o posicionamento das variáveis $\mathbf{g}, \mathbf{e}_{\mathbf{1}}$ e $\mathbf{e}_{\mathbf{2}}$ utilizadas na aplicação do método de chapa equivalente. Foram utilizados parafusos ASTM A325 com 12,5mm de diâmetro, dispostos em 1, 2 e 3 seções perpendiculares à direção da solicitação, sem a utilização de arruelas, com distâncias entre centros de furos e entre centro de furo e borda na direção da solicitação iguais a $\mathbf{3 d}$. O material empregado foi aço carbono nas espessuras de $1 \mathrm{~mm}$ e $3 \mathrm{~mm}$.

TABELA 2.2 - Configurações de ligações parafusadas em cantoneiras (ensaios de HOLCOMB et al. - 1995).

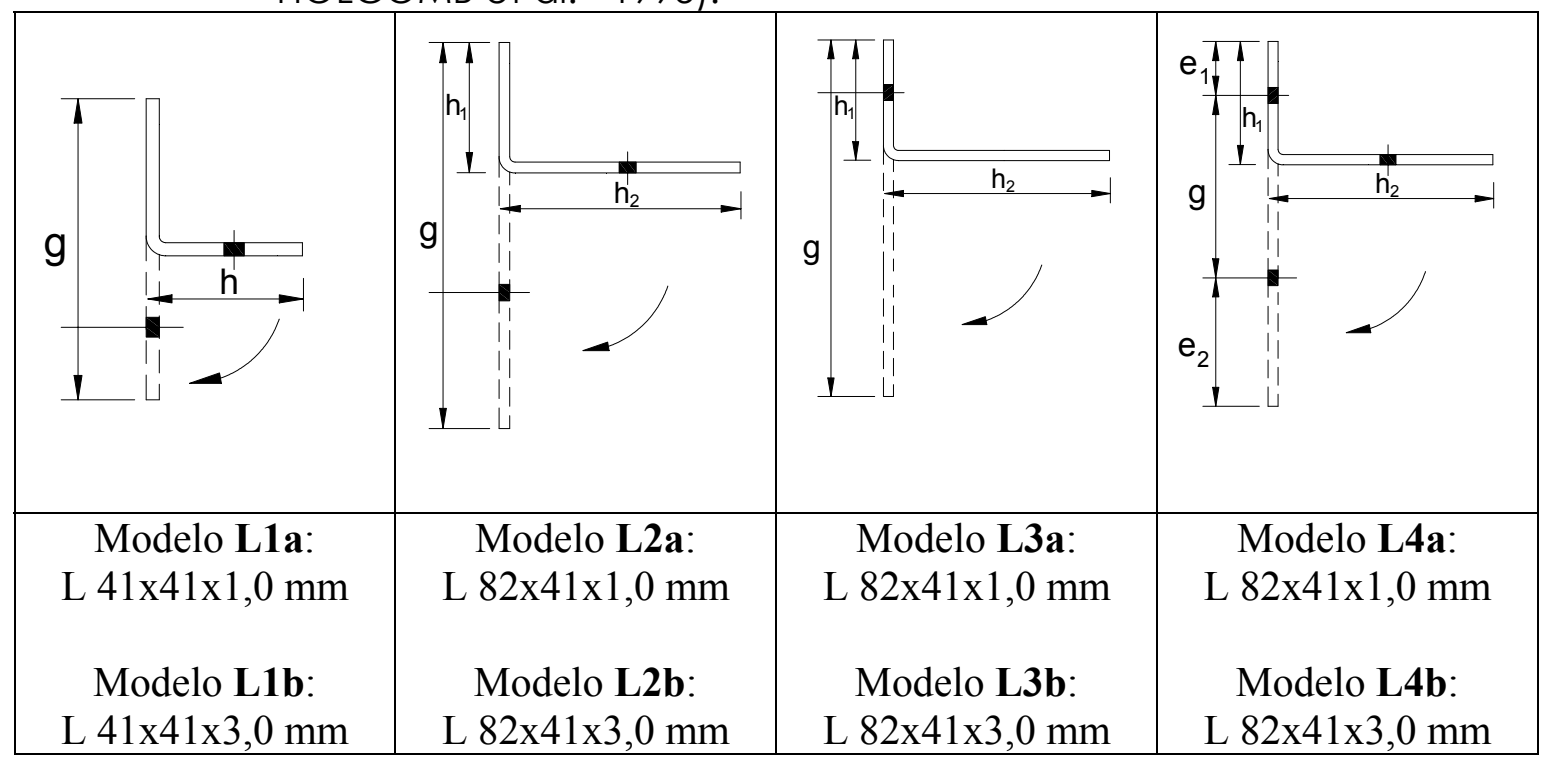


TABELA 2.3 - Configurações de ligações parafusadas em perfis $U$ (ensaios de HOLCOMB et al. - 1995).

\begin{tabular}{|c|c|c|c|}
\hline &
\end{tabular}

Nos gráficos das figuras 2.11 e 2.12 (para perfis com 1mm e $3 \mathrm{~mm}$ de espessura respectivamente), foram comparados os valores da força última experimental com os valores da força resistente à ruptura da seção líquida, calculados segundo as expressões da especificação americana para perfis laminados AISC:1993 (AISC), pelas expressões apresentadas no Suplemento nol do AISI:1996, de 1999 (AISI/NBR) e adotadas também pela nova norma brasileira de dimensionamento de perfis formados a frio NBR14762:2001, pelas expressões inicialmente adotadas por esta norma (Chapa equivalente) e finalmente pela expressão sugerida no trabalho de HOLCOMB et al. (1995) (Holcomb). 
a-) todos os parafusos contidos em uma única seção

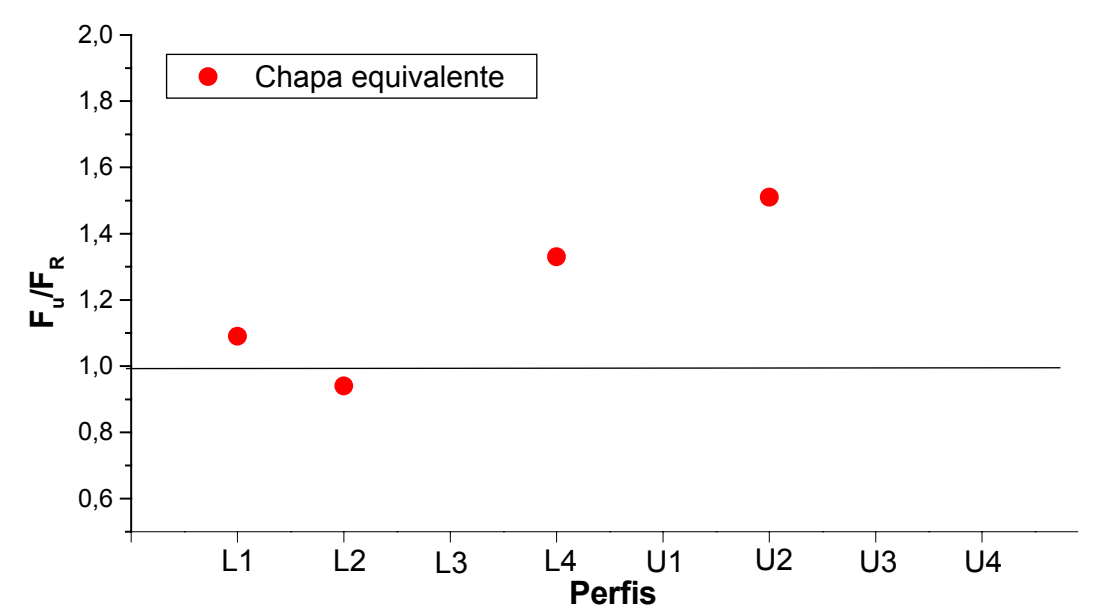

b-) 2 parafusos na direção da solicitação

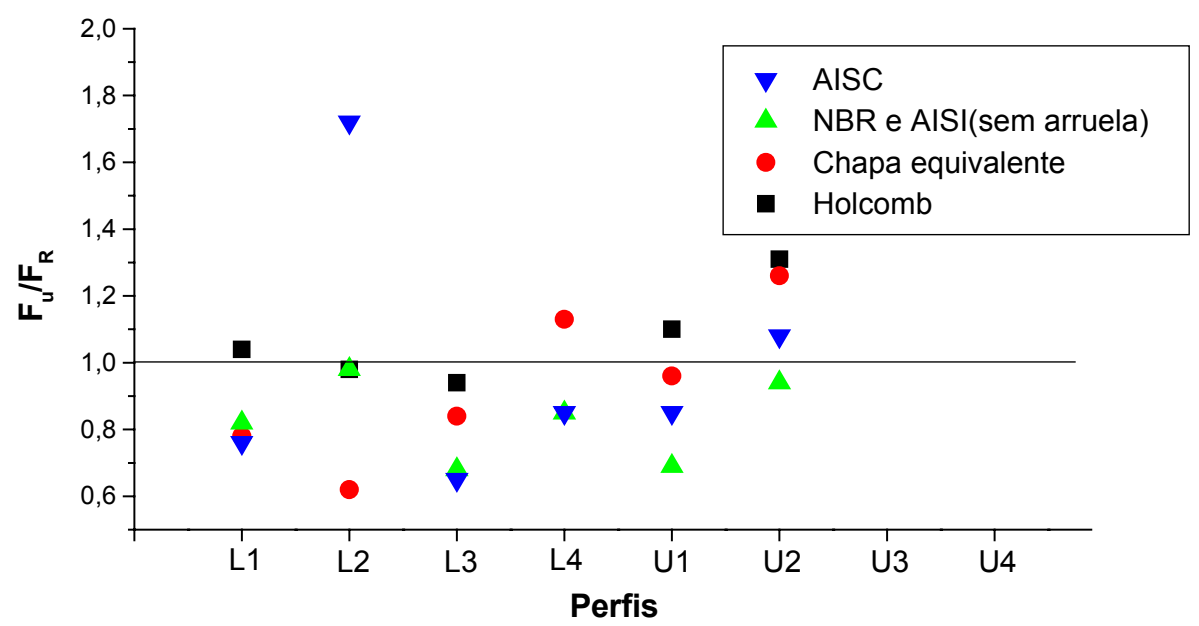

c-) 3 parafusos na direção da solicitação

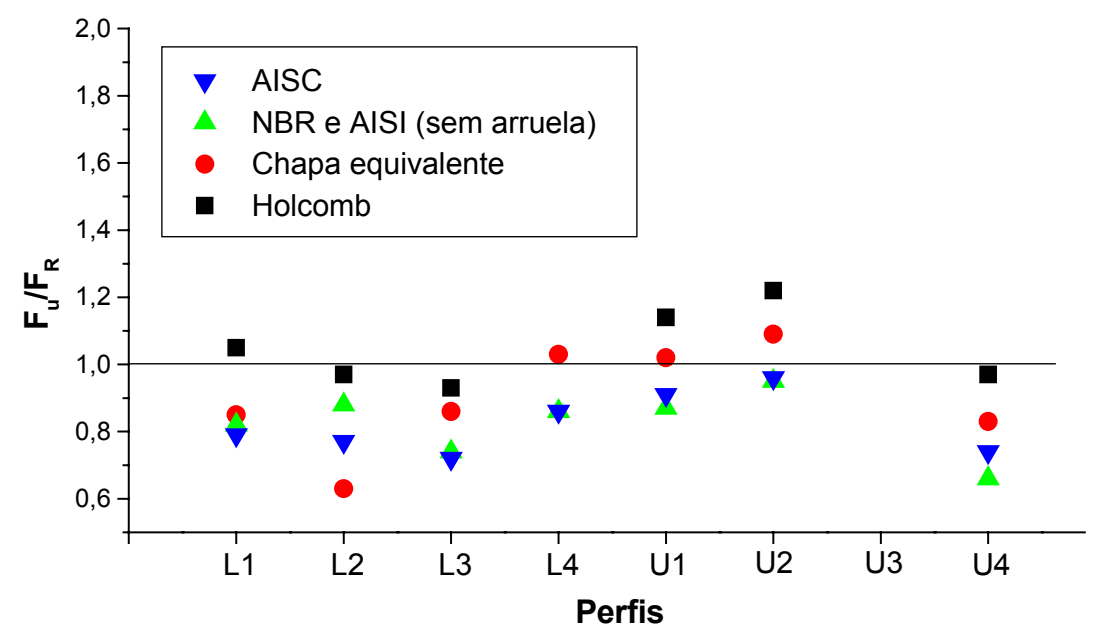

FIGURA 2.11 - Relação da força última de ensaio $\left(\boldsymbol{F}_{\boldsymbol{u}}\right)$ pelas forças resistentes $\left(\boldsymbol{F}_{\boldsymbol{R}}\right)$ analisadas teoricamente (perfis com $1 \mathrm{~mm}$ de espessura) 
a-) todos os parafusos contidos em uma única seção

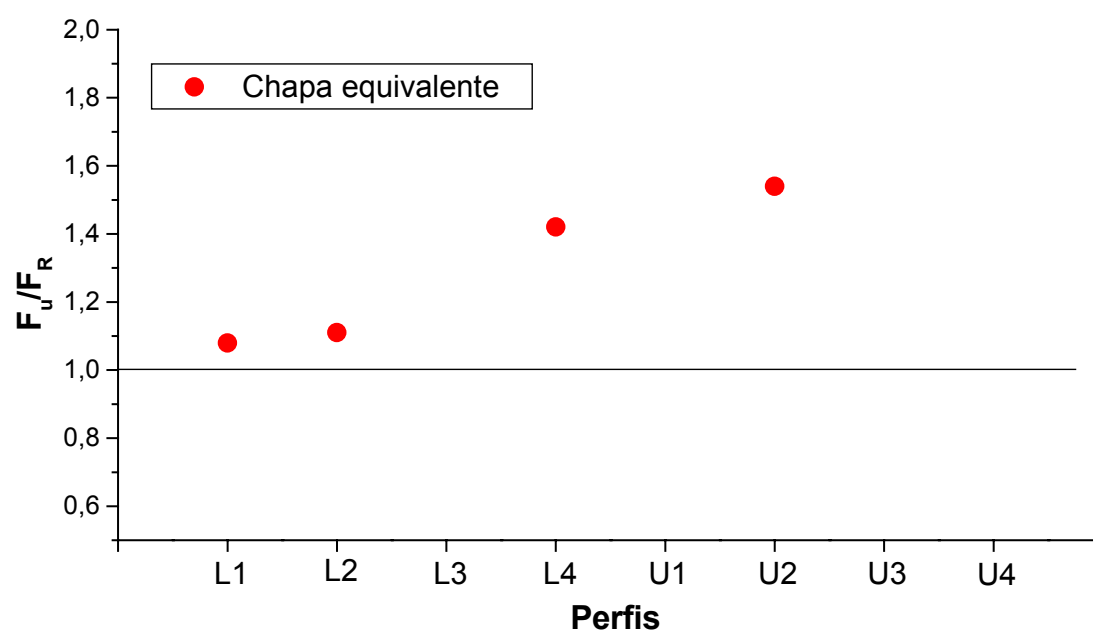

b-) 2 parafusos na direção da solicitação

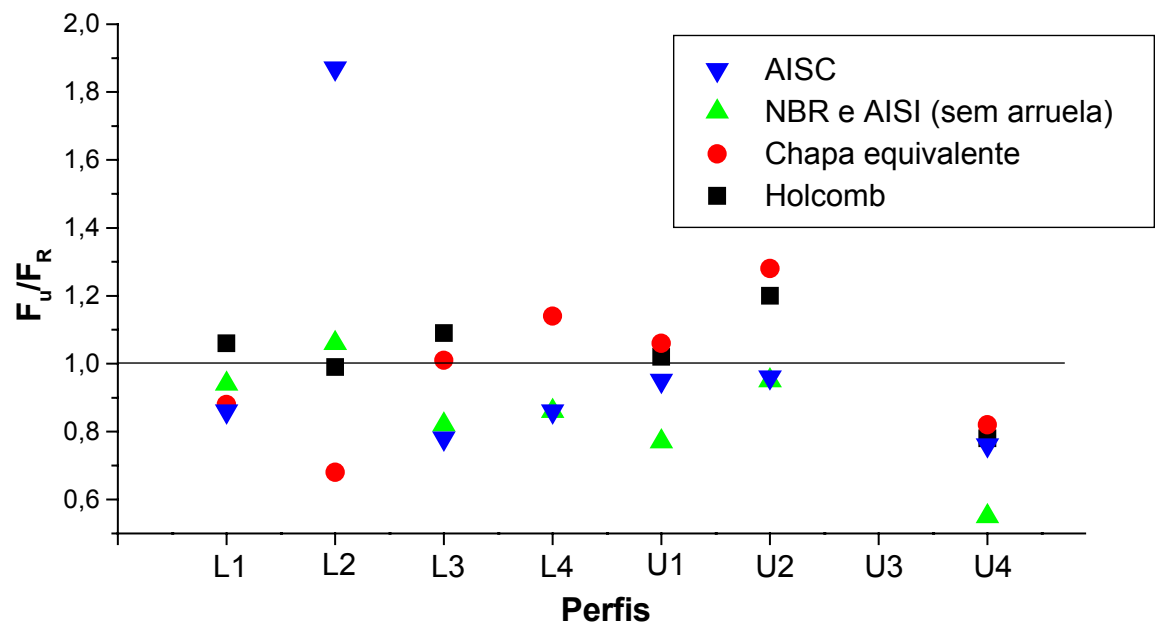

c-) 3 parafusos na direção da solicitação

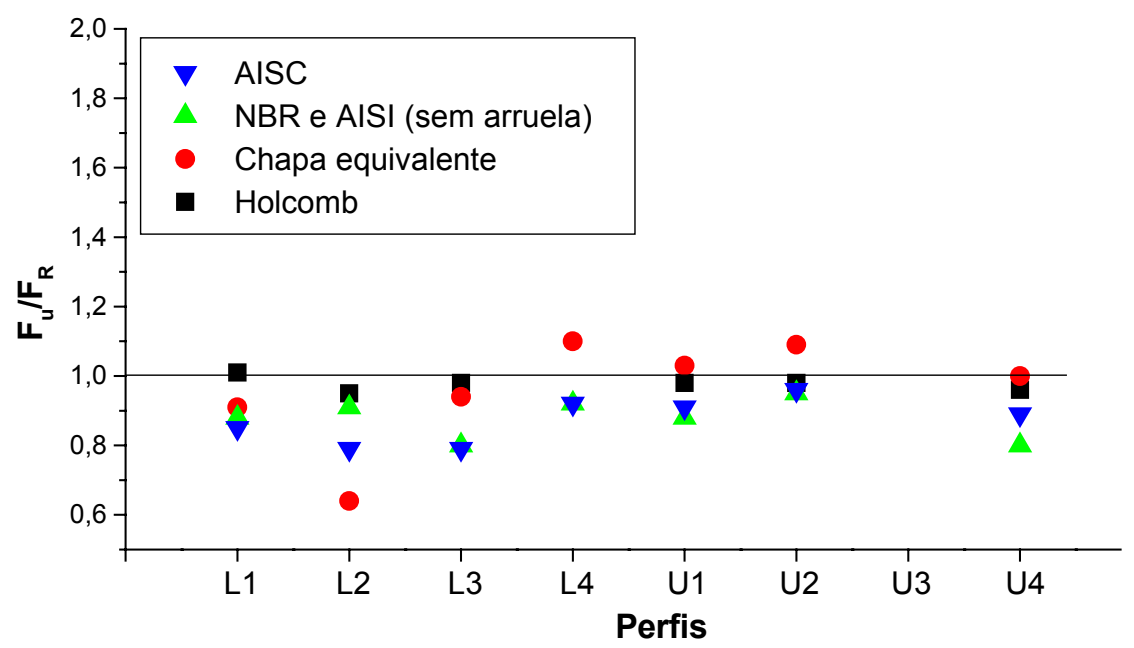

FIGURA 2.12 - Relação da força última de ensaio $\left(\boldsymbol{F}_{\mathbf{U}}\right)$ pelas forças resistentes $\left(\boldsymbol{F}_{\boldsymbol{R}}\right)$ analisadas teoricamente (perfis com $3 \mathrm{~mm}$ de espessura) 
Ao contrário da nova norma brasileira, as outras especificações não prevêem a utilização de ligações com todos os parafusos contidos em uma única seção, isso se deve principalmente a aspectos construtivos.

Experimentalmente, observa-se que para estas configurações ocorre uma elevada concentração de tensão (pressão de contato) junto aos furos, o que gerou um alto índice de falha por esmagamento da parede do furo (colunas em branco nos gráficos anteriores), ou por uma combinação de esmagamento e ruptura da seção líquida, conforme configurações L1, L2, L4 e U2 para perfis de $1 \mathrm{~mm}$, representada na figura 2.11 a e $L 4$ para os perfis de $3 \mathrm{~mm}$, figura 12.b, justificando a dispersão dos resultados, sendo que na maioria das vezes o valor da força última experimental foi superior à estimada teoricamente.

Nas ligações com duas ou três seções de parafusos, os resultados apresentados nos gráficos anteriores mostram diferenças significativas para a maioria dos perfis analisados.

Para as cantoneiras, as forças resistentes que mais se aproximaram dos resultados experimentais foram as avaliadas pela expressão apresentada por Holcomb et al. (1995). No entanto o maior problema na aplicação desta expressão está na correta definição de suas variáveis, principalmente para o parâmetro $\underline{s}$.

A expressão definida na primeira versão da norma brasileira (chapa equivalente) não apresentou bons resultados, principalmente para a cantoneira de abas desiguais com a ligação feita pela maior aba (modelo L2). Ao contrário desta, a expressão do Suplemento no1 do AlSI:1996, apresentou seus melhores resultados para este modelo.

Já a expressão do AISC:1993 não se mostrou satisfatória para a avaliação da força resistente em cantoneiras formadas a frio. Deve-se notar que para o modelo L4 cujo todos os elementos estão conectados, o coeficiente redutor da área líquida $(\boldsymbol{U})$, tanto para O AISC:1993 como para o Suplemento nol do AISI:1996 e pela nova norma brasileira $\left(\boldsymbol{C}_{t}\right)$, são todos iguais a unidade.

Para as ligações em perfis U, a expressão da força resistente do AISC:1993 mostrou boa correlação com os resultados experimentais, assim como as do Suplemento nol do AISI:1996, as apresentadas por HOLCOMB et al. (1995)e as de chapa equivalente, com a diferença que enquanto para as duas primeiras a 
força resistente foi sempre abaixo do valor obtido experimentalmente, paras duas últimas este foi em sua maioria superior ao experimental.

Em geral observa-se que a relação entre os resultados experimentais e teóricos aproximam-se mais da unidade para a espessura de 3,0 $\mathrm{mm}$, o que reflete a diminuição da interferência dos efeitos localizados conforme o aumento de espessura.

Os resultados obtidos confirmaram que a especificação de cálculo empregada para os perfis laminados e soldados, apresentada pelo AISC:1993, não pode ser diretamente aplicada para aos perfis formados a frio, principalmente no caso de cantoneiras de abas desiguais, quando a ligação é feita por uma das abas.

O Suplemento no1 do AISI:1996, apesar de aplicar fatores modificadores ao coeficiente redutor da área líquida apresentado pelo AISC:1993, não apresentou também, no geral, boas estimativas para o cálculo da força resistente à ruptura da seção líquida para os casos analisados.

O procedimento de cálculo que considera o perfil como uma chapa equivalente, adotado nas primeiras versões do texto da nova norma brasileira, também apresentou dispersão dos resultados, mas com valores da força resistente superiores aos experimentais, comportamento contrario aos apresentados pelas especificações anteriores.

Por outro lado, a expressão apresentada por HOLCOMB et al. (1995), proveniente de análise estatística de resultados de ensaios, mostrou-se satisfatória para o caso das cantoneiras e com pouca dispersão no caso dos perfis U. 
CAPÍTULO 03

PROCEDIMENTO EXPERIMENTAL 


\subsection{DISPOSIÇÕES GERAIS}

A investigação experimental realizada consistiu no ensaio de ligações parafusadas em chapas finas de aço e perfis formados a frio, submetidas ao cisalhamento simples ou duplo, por meio da aplicação de esforço normal de tração nos elementos de ligação.

Esta foi realizada no Laboratório de Estruturas da EESC-USP, utilizando para aplicação de força a máquina servo-hidráulica INSTRON. Adaptações em suas garras foram feitas para melhor fixação das chapas finas e dispositivos especiais foram confeccionados para fixação dos perfis formados a frio.

Os dados dos ensaios, coletados por um sistema automático de aquisição, consistiram basicamente na força aplicada pela máquina de ensaio, na leitura do deslocamento do seu pistão e de transdutores posicionados na região da ligação.

Os corpos-de-prova, fabricados em empresas de São Carlos, foram calculados com base nas especificações da NBR14762:2001 para apresentarem como modo de falha principal a ruptura da seção líquida, somente em algumas configurações a falha avaliada foi o esmagamento da parede do furo ou furos. Suas configurações se diferenciavam nos seguintes parâmetros:

- espessura do material,

- largura da chapa ou variação da seção transversal do perfil,

- posicionamento dos parafusos na seção transversal,

- quantidade de seções de parafusos normal à solicitação. 
Informações mais detalhadas dos corpos-de-prova ensaiados; denominação, dimensões reais, modo de falha observado ao final do ensaio e a força máxima alcançada $\left(\boldsymbol{F}_{\mathbf{u}}\right)$, são apresentadas nas tabelas do Apêndice $B$.

\subsection{PREPARAÇÃO DOS CORPOS-DE-PROVA}

\subsubsection{Fabricação}

Para a fabricação dos corpos-de-prova foram adquiridas chapas de aço nas espessuras de $1,55 \mathrm{~mm}, 2,00 \mathrm{~mm}, 2,65 \mathrm{~mm}, 3,75 \mathrm{~mm}, 4,75 \mathrm{~mm}$ e $6,30 \mathrm{~mm}$. Para cada uma dessas espessuras o material era proveniente de uma mesma bobina. A classificação dos aços como recebido bem como os valores médios das propriedades mecânicas, obtidos em ensaios de tração conforme ASTM A370:1996, estão apresentadas no Apêndice A.

O corte das chapas foi executado em guilhotina e a dobra dos perfis foi feita em prensa dobradeira, ambas as operações executadas pela empresa ENFER Ind. \& Com. de Produtos Siderúrgicos Ltda. Para satisfazer o afastamento mínimo das garras da máquina de ensaio, bem como providenciar o espaçamento necessário para uniformização das tensões, os corpos-de-prova de chapa tinham o comprimento de $600 \mathrm{~mm}$ e os de perfil $1.000 \mathrm{~mm}$.

Os furos foram feitos por puncionamento, pela empresa SIDERTEC Estruturas Metálicas Ltda. A folga dos furos em relação ao diâmetro do parafuso foi de $1,5 \mathrm{~mm}$ quando da utilização de parafusos de $12,5 \mathrm{~mm}$ e de $2,00 \mathrm{~mm}$ quando os parafusos eram de $16,0 \mathrm{~mm}$, em função da disponibilidade do equipamento.

Os corpos-de-prova foram fabricados em duplicata para cada configuração de ligação, perfazendo um total de 232 corpos-de-prova para ensaio de ligações parafusadas em chapas finas de aço e 164 corpos-deprova para ensaio de ligações parafusadas em perfis formados a frio 


\subsubsection{Montagem dos ensaios}

Uma vez que, na prática, é comum a não utilização de arruelas nas ligações parafusadas em estruturas leves, para o par de corpos-de-prova de ligações parafusadas em chapa fina, que apresentavam a mesma configuração (fabricados em duplicata), um destes foi ensaiado sem arruelas, já no segundo foram empregadas arruelas junto à cabeça do parafuso e à porca. Para as ligações parafusadas em perfis formados a frio todos os corposde-prova foram ensaiados sem a utilização de arruelas.

Em todos os ensaios foram utilizados parafusos de alta resistência ISO 7411 - grau 8.8, com 12,5mm de diâmetro (M12) para os materiais de $1.55 \mathrm{~mm}$, $2,00 \mathrm{~mm}$ e $2,65 \mathrm{~mm}$ de espessura; e $16,0 \mathrm{~mm}$ de diâmetro (M16) para os materiais de $3,75,4,75 \mathrm{~mm}$ e $6,30 \mathrm{~mm}$ de espessura, evitando deste modo a falha por cisalhamento do parafuso.

Para a fixação dos corpos-de-prova de chapa fina na máquina de ensaio, devido a sua pequena espessura, foram fabricadas placas especiais em aço SAE4340 (alta resistência), providos de ranhuras em uma de suas faces de modo a melhorar as condições de atrito (fig. 3.1b), estas eram acopladas às garras hidráulicas da máquina de ensaio. Para o ensaio de ligação em chapa fina, submetida ao corte simples, esta era parafusada a uma outra de igual dimensão, e assim, o conjunto era fixado a máquina de ensaio (fig. 3.1 a).

Já para os corpos-de-prova de perfis formados a frio, estes não puderam ser fixados diretamente nas garras da máquina de ensaio, portanto dispositivos especiais foram fabricados para a fixação das cantoneiras (fig. 3.2b) e perfis $U$ (fig. 3.3b). Estes dispositivos compostos por chapas de aço carbono ASTM A36 com 10mm de espessura, eram fixados nas garras da máquina de ensaio, enquanto os corpos-de-prova de perfis formados a frio eram parafusados internamente a estes (fig. 3.2a e 3.3a).

Para simular o torque empregado na prática e impor aproximadamente o mesmo valor para todos os parafusos, estes foram instalados manualmente na condição de pré-torque, sempre por uma mesma pessoa, utilizando uma chave inglesa comum. Este procedimento conferiu aos parafusos um torque relativamente baixo, permitindo deste modo que a força de atrito entre as chapas fosse superada ainda nas primeiras etapas de carregamento. 


\subsubsection{Instrumentação}

Os deslocamentos relativos na região da ligação, na direção longitudinal dos corpos-de-prova, foram medidos utilizando transdutores de deslocamento, com uma base de medida igual à $375 \mathrm{~mm}$.

Para o caso de chapa fina, foram posicionados dois transdutores simétricos à direção do comprimento (fig 3.1c).

Já para o caso dos perfis formados a frio foi posicionado um transdutor apenas, fixado em uma das abas das cantoneiras (na aba maior no caso das cantoneiras de abas desiguais) ou na alma do perfil $U$ (fig. $3.2 a$ e $3.3 \mathrm{c}$ ). Em ambos casos, os transdutores se encontravam na altura do centro de gravidade destas peças.

A força aplicada foi medida pela célula de carga constante da máquina de ensaio.

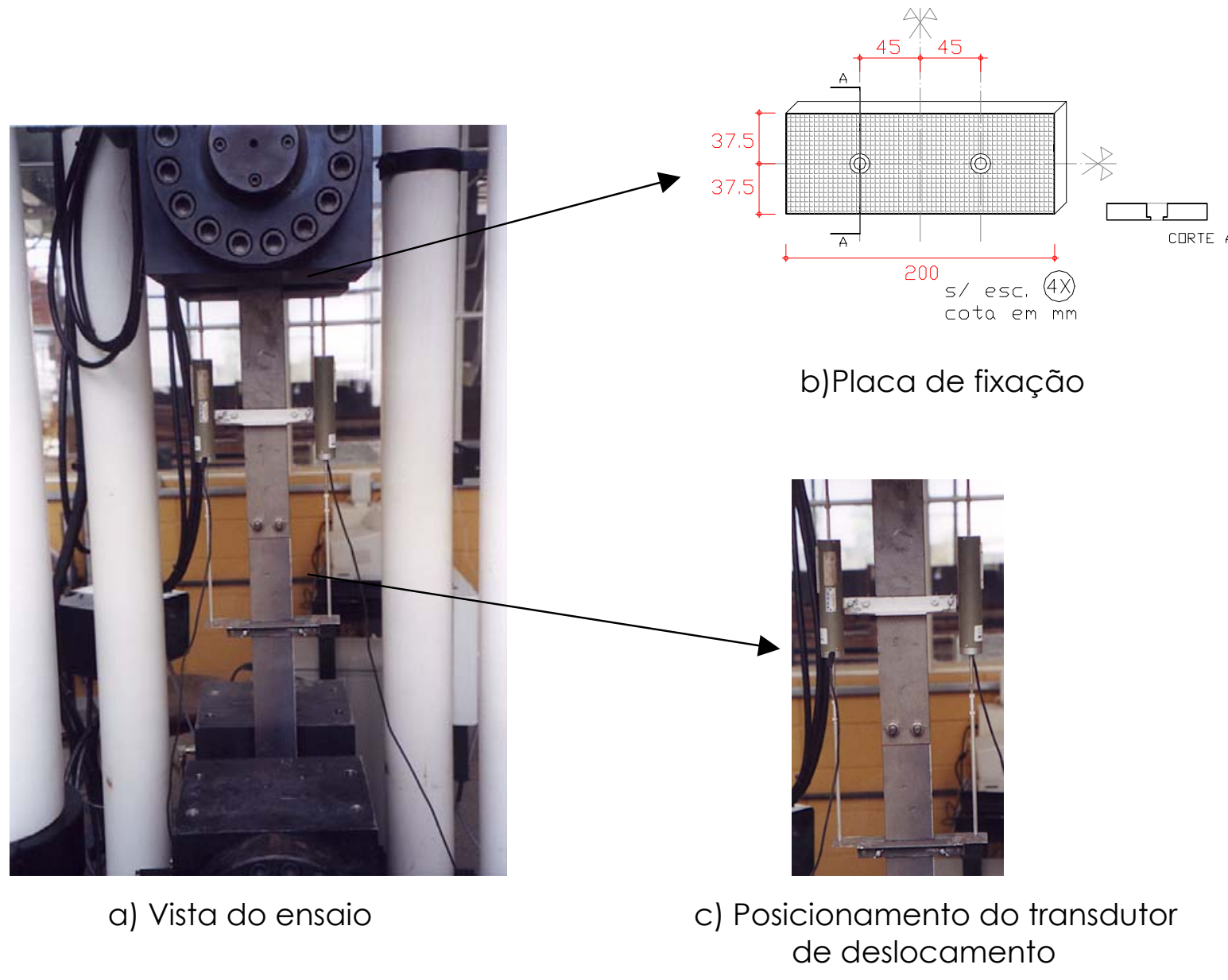

Figura 3.1 - Vista do ensaio de ligação parafusada em chapa fina, chapas de fixação e posicionamento dos transdutores de deslocamento. 

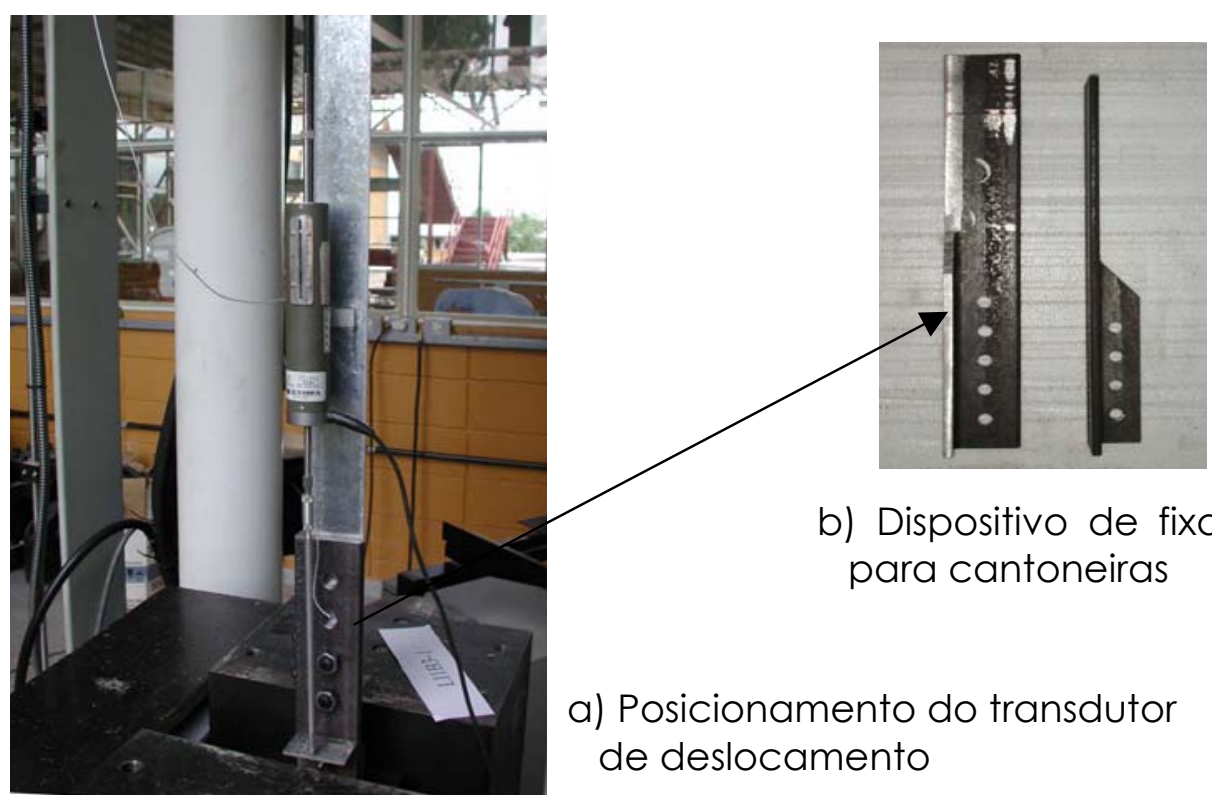
b) Dispositivo de fixação para cantoneiras

a) Posicionamento do transdutor de deslocamento

Figura 3.2 - Ensaio de ligação parafusada em cantoneiras, posicionamento do transdutor de deslocamento e dispositivos de fixação

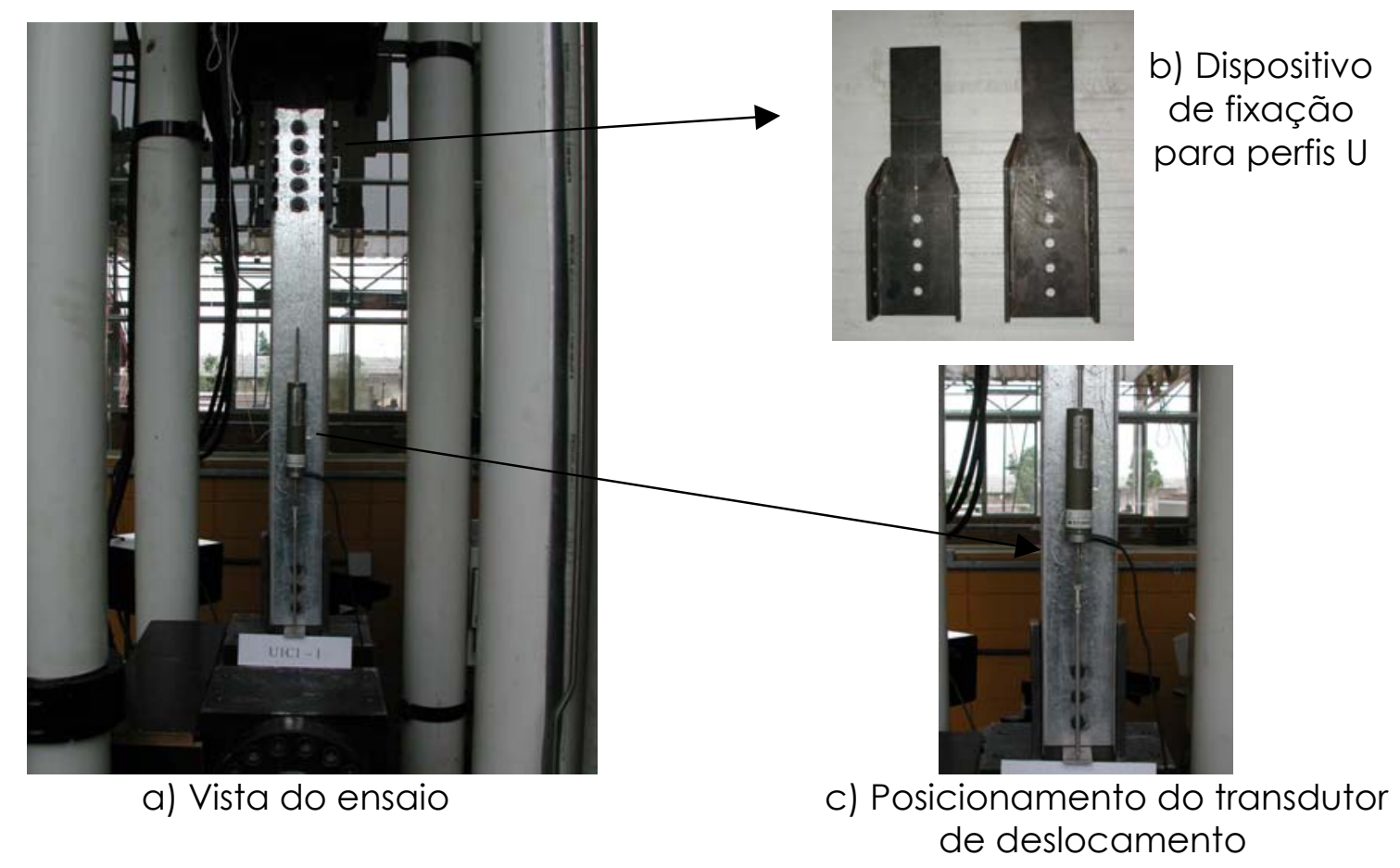

Figura 3.3 - Vista do ensaio de ligação parafusada em perfis U, dispositivos de fixação e posicionamento dos transdutores de deslocamento. 


\subsection{EXECUÇÃO DOS ENSAIOS}

Os corpos-de-prova foram ensaiados na máquina servo-hidráulica INSTRON, pertencente ao Laboratório de Estruturas da EESC-USP. A força de tração foi aplicada com controle de deslocamento do pistão numa taxa de $2,0 \mathrm{~mm} / \mathrm{min}$. As leituras de força e deslocamento relativo foram feitas em períodos de $1 \mathrm{seg}$. usando o sistema automático de aquisição de dados da máquina.

As forças últimas $\left(\boldsymbol{F}_{u}\right)$ registradas ao final de cada ensaio foram obtidas sem a preocupação em se estabelecer um deslocamento máximo, uma vez que a acomodação inicial e a deformação localizada junto aos furos ocasionaram deslocamentos relativos elevados (entre 4,0 $\mathrm{mm}$ e $23,0 \mathrm{~mm}$ no caso de chapas finas), portanto muito acima do deslocamento limite de $6,35 \mathrm{~mm}$ especificado pelo American Institute of Steel Construction (1993), valor este que se respeitado não levaria os corpos-de-prova à ruína (Rogers \& Hancock 1998).

Portanto o modo de falha foi caracterizado visualmente, de acordo com os seguintes parâmetros:

- observada a fratura do material, iniciada geralmente junto as bordas dos furos, juntamente ou não com a estricção da seção transversal, caracterizava-se a falha por ruptura da seção líquida;

- se juntamente a esta fratura houve-se um visível enrugamento do material em frente ao parafuso, caracterizava-se a falha por ruptura associada ao esmagamento da parede do furo ou furos;

- se a partir de um deslocamento relativo limite igual à 12,5mm, mantendo-se a força aplicada constante com evolução dos deslocamentos, caracterizando um patamar de escoamento ou se esta força decaia, caracterizando tendência descendente da curva força x deslocamento, observado o enrugamento do material em frente ao parafuso, caracterizava-se a falha por esmagamento da parede do furo ou furos

- se a partir deste deslocamento relativo limite, com a parede dos furos apresentando enrugamento do material, mas ainda se observando um ganho de força, retardava-se o final do ensaio, até 
a estabilização ou queda desta força. Nestes casos, se ao final do ensaio observava-se o inicio de ruptura da seção líquida, caracterizava-se a falha por esmagamento da parede do furo ou furos com início de ruptura da seção líquida. Caso contrário recaia na hipótese anterior.

\subsection{CONFIGURAÇÃO DOS CORPOS-DE-PROVA}

As configurações dos corpos-de-prova, representando as ligações parafusadas em chapas finas e perfis formados a frio, foram estabelecidos de modo a apresentarem em sua maioria, segundo os critérios de cálculo da NBR14762:2001, o estado limite último correspondente à ruptura da seção líquida, permitindo com isso estabelecer comparações entre os valores experimentais e teóricos do coeficiente de redução da área líquida $\left(\boldsymbol{C}_{t}\right)$, estabelecidos por esta norma.

Para a aplicação das expressões de norma na avaliação da resistência destas ligações, foi considerado que todos os parafusos da ligação sofriam igual solicitação. Condição esta ideal, difícil de ser conseguida na prática, mas admitindo a capacidade de deformação do material (ductilidade), esta propicia a igual distribuição de forças quando da plastificação das seções.

\subsubsection{Ligações parafusadas em chapas finas de aço}

Foram confeccionados duzentos e trinta e dois corpos-de-prova de ligações parafusadas em chapa fina, todos foram submetidos à força de tração, sendo que em 208 desses os parafusos eram solicitados ao corte simples e em 24 solicitados ao corte duplo.

Nestes variaram-se os seguintes parâmetros:

espessura das chapas $\Rightarrow$ com chapas de 2,00mm, 2,65mm, $3,75 \mathrm{~mm}, 4,75 \mathrm{~mm}$ e $6,30 \mathrm{~mm}$, sendo estas de materiais diferentes conforme apresentado no Apêndice A; 
- diâmetro dos parafusos $\Rightarrow$ utilizou-se parafusos de $12,5 \mathrm{~mm}$ e 16,0mm de diâmetro, sendo os primeiros utilizados nas ligações com chapas de $2,00 \mathrm{~mm}$ e $2,65 \mathrm{~mm}$ e os outros no restante;

- $\quad$ relação $\mathbf{d} / \mathbf{g} \Rightarrow$ conforme disposição dos parafusos na seção transversal e de acordo com as recomendações da NBR 14762:2001, obtiveram-se relações de $\mathbf{d} / \mathbf{g}$ iguais à 0,111 ; 0,$161 ; 0,250 ; 0,333$ e 0,500

quantidade de parafusos na seção $\Rightarrow u m$, dois ou quatro;

quantidade de seções de parafusos perpendicular a solicitação $\Rightarrow$ com uma ,duas, três ou quatro seções, distinguindo-se as séries $\boldsymbol{A}, \boldsymbol{B}, \boldsymbol{C}$ e $\boldsymbol{D}$, respectivamente; emprego ou não de arruelas junto a cabeça dos parafusos e a porca.

Esses parâmetros combinados produziram dez diferentes tipos de configurações de ligações parafusadas, ilustradas na figura 3.4 e descritas na tabela 3.1. Para as chapas de $2,65 \mathrm{~mm} ; 3,75 \mathrm{~mm}$ e $6,30 \mathrm{~mm}$ foram confeccionados apenas as configurações tipo 1 e 4 e para ligações solicitadas ao corte duplo as tipo 1, 4 e 6 utilizando chapa de 2,00mm de espessura.

As configurações tipo 1, 4 e 6 apresentavam as distâncias entre furos e furo e borda, perpendicular à direção da solicitação, iguais aos valores mínimos recomendados pela norma brasileira com valor de $\mathbf{d} / \mathbf{g}$ igual a 0,333. As tipo 3 apresentava estas distâncias inferiores as recomendadas, sendo d/g igual a 0,5. As tipos 2 e $5(\operatorname{com} \mathbf{d} / \mathbf{g}=0,167)$, tipos 7 e $8(\operatorname{com} \mathbf{d} / \mathbf{g}=0,250)$ e tipo 9 (com $\mathbf{d} / \mathbf{g}=0,111)$, tinham as distâncias entre furo e borda com valor superior ao mínimo recomendado, de modo que a avaliação da variável $\mathbf{g}$ foi feita como sendo a soma destas distâncias $\left(\mathbf{e}_{1}+\mathbf{e}_{2}\right)$, segundo recomendação da NBR 14762:2001. Para ligação tipo 10 as distâncias entre furos tinham valor superior ao mínimo recomendado por norma, ficando $\mathbf{d / g}$ igual a 0,111.

Com estas configurações foram confeccionadas quatro séries de corpos-de-prova (séries $\boldsymbol{A}$ a $\boldsymbol{D}$ ), feitos em duplicata, ensaiados, cada dupla, com ou sem a utilização de arruelas junto a cabeça do parafuso e a porca.

A nomenclatura utilizada na representação destes corpos-de-prova é apresentada a seguir. 

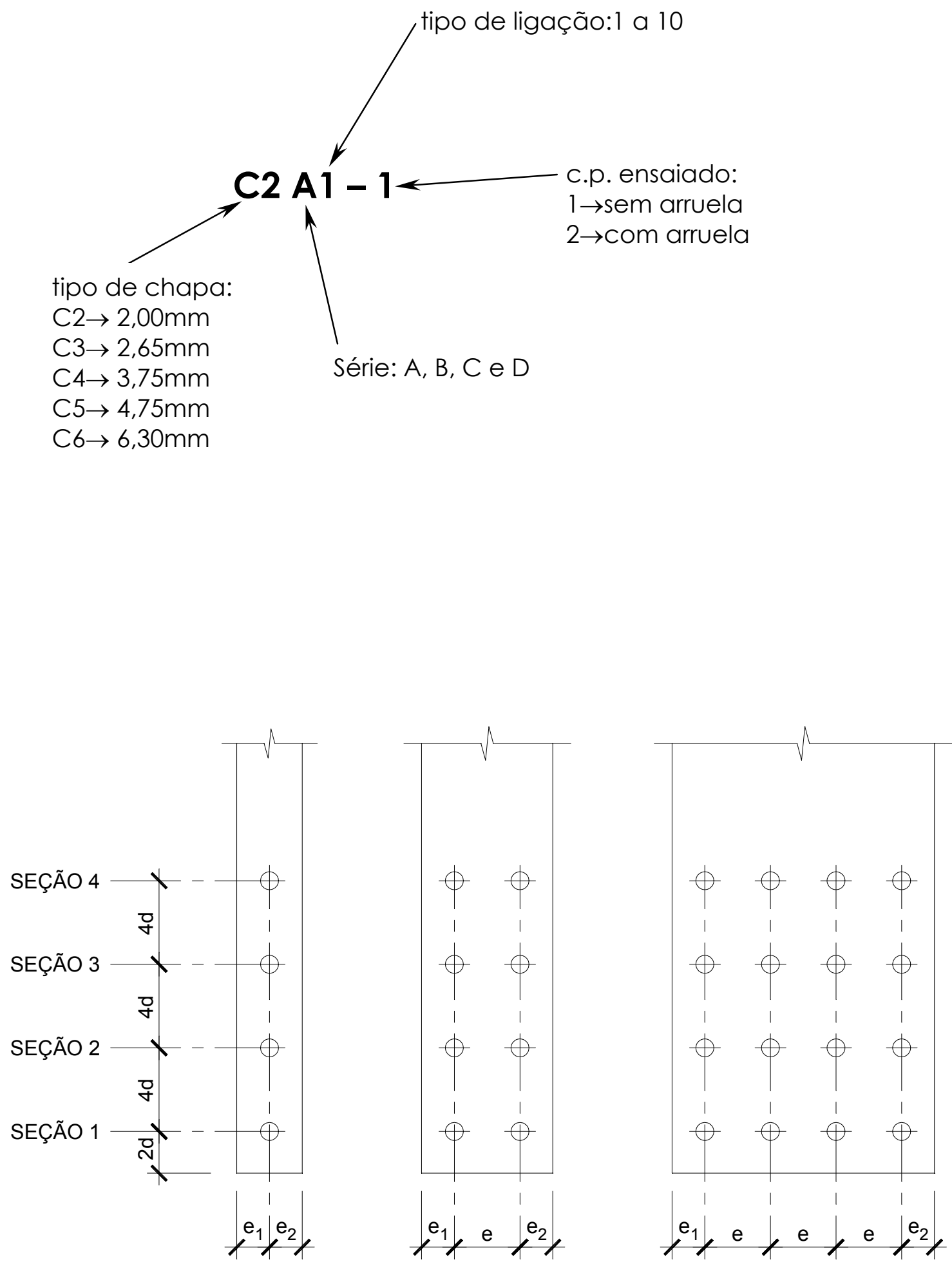

Figura 3.4 - Esquema dos corpos-de-prova de ligações parafusadas em chapa fina 
TABELA 3.1 - Características geométricas dos corpos-de-prova de ligações parafusadas em chapa fina.

\begin{tabular}{|c|c|c|c|c|c|c|}
\hline $\begin{array}{l}\text { Tipo da } \\
\text { ligação }\end{array}$ & $\begin{array}{l}\text { Quantidade } \\
\text { de parafusos } \\
\text { por seção }\end{array}$ & $e_{1}=e_{2}$ & $e$ & $\begin{array}{c}\text { Largura } \\
\text { total }\end{array}$ & $\mathbf{g}^{* * *}$ & $d / g$ \\
\hline $1^{*}$ & 1 & $1,5 d$ & --- & $3 d$ & $3 d$ & 0,333 \\
\hline 2 & 1 & $3 d$ & --- & $6 d$ & $6 d$ & 0,167 \\
\hline $3^{* *}$ & 2 & $d$ & $2 d$ & $4 d$ & $2 d$ & 0,500 \\
\hline $4^{*}$ & 2 & $1,5 d$ & $3 d$ & $6 d$ & $3 d$ & 0,333 \\
\hline 5 & 2 & $3 d$ & $3 d$ & $9 d$ & $6 d$ & 0,167 \\
\hline $6^{*}$ & 4 & $1,5 d$ & $3 d$ & $12 d$ & $3 d$ & 0,333 \\
\hline 7 & 1 & $2 d$ & --- & $4 d$ & $4 d$ & 0,250 \\
\hline 8 & 2 & $2 d$ & $3 d$ & $7 d$ & $4 d$ & 0,250 \\
\hline 9 & 2 & $4,5 d$ & $3 d$ & $12 d$ & $9 d$ & 0,111 \\
\hline 10 & 2 & $1,5 d$ & $9 d$ & $12 d$ & $9 d$ & 0,111 \\
\hline \multicolumn{7}{|c|}{$\begin{array}{l}\text { * Distâncias mínimas estabelecidas no projeto de norma brasileira. } \\
\text { ** Não atende às disposições construtivas estabelecidas no projeto de normo } \\
\text { brasileira. } \\
{ }_{* * *} \text { Avaliado segundo recomendações da NBR 14762:2001 }\end{array}$} \\
\hline
\end{tabular}

\subsubsection{Ligações parafusadas em perfis formados a frio}

Foram confeccionados cento e sessenta e quatro corpos-de-prova de ligações parafusadas em cantoneiras e perfis $U$ formados a frio, divididos em:

36 cantoneiras de abas iguais: sendo, $16 \mathrm{~L} 50 \times 50 \times 1,55 \mathrm{~mm}$ utilizando parafusos de 12,5mm, $16 \mathrm{~L} 75 \times 75 \times 3,75 \mathrm{~mm}$ e $4 \mathrm{~L} 75 \times 75 \times 4,75 \mathrm{~mm}$, com parafusos de $16,0 \mathrm{~mm}$ ligadas por uma aba ou ambas.

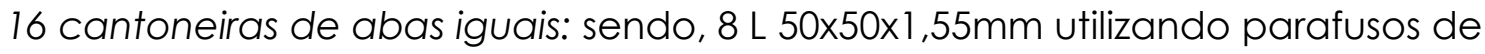
$12,5 \mathrm{~mm}, 8 \mathrm{~L} 75 \times 75 \times 3,75 \mathrm{~mm}$, com parafusos de $16,0 \mathrm{~mm}$, solicitadas ao corte duplo.

52 cantoneiras de abas desiguais: sendo, 24 L60 $\times 40 \times 1,55 \mathrm{~mm}$ utilizando parafusos de 12,5, 24 L80x40x3,75mm e 4 L80x40x4,75mm, com parafusos de 16,0 mm, ligadas pela aba menor, aba maior ou ambas. 


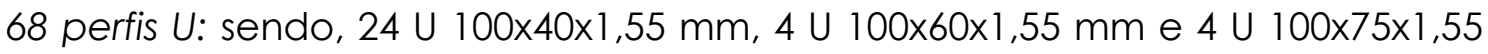

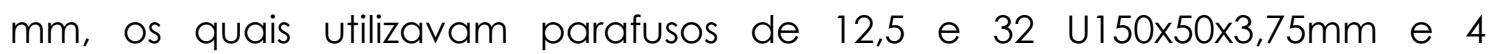
U150x50x4,75mm, utilizando parafusos de $16,0 \mathrm{~mm}$ de diâmetro, ligados pelas mesas, alma ou por ambos os elementos.

Para esses perfis, também fabricados em duplicata, variou-se a distribuição e quantidade de parafusos na seção transversal, conforme configurações apresentadas nas tabelas 3.2 e 3.3, bem como a quantidade de seções com parafusos perpendicular a solicitação, apresentando uma ,duas, três ou quatro seções, distinguindo-se as séries $\boldsymbol{A}, \boldsymbol{B}, \boldsymbol{C} e \boldsymbol{D}$, respectivamente.

Para todos os corpos-de-prova, os furos foram previstos no centro dos elementos conectados e não foi prevista a utilização de arruelas junto a cabeça do parafuso e a porca.

A nomenclatura utilizada na representação destes corpos-de-prova é apresentada a seguir.

Material empregado:

$1 \rightarrow$ ZAR 345 com $1,55 \mathrm{~mm}$

$4 \rightarrow$ SAE 1008 com $3,75 \mathrm{~mm}$

$4 \rightarrow$ CSN COR 420 com $4,75 \mathrm{~mm}$

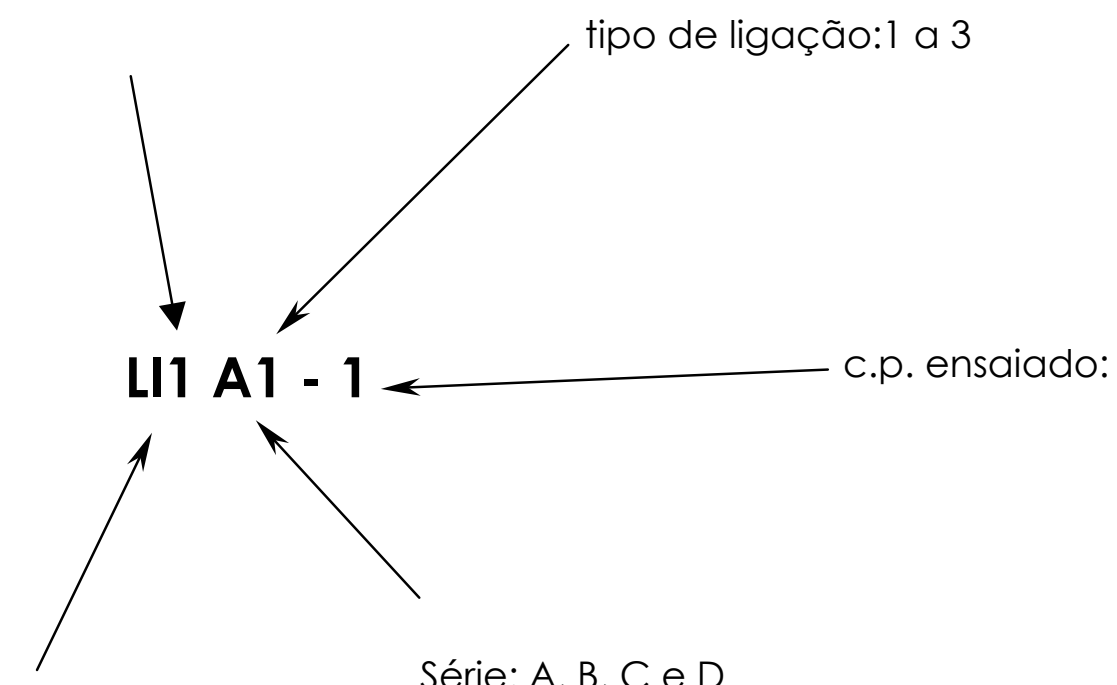

Seção transversal do perfil:

$\mathrm{LI} \rightarrow$ cantoneira de abas iguais

LD $\rightarrow$ cantoneira de abas desiguais

$\mathrm{DL} \rightarrow$ dupla cantoneira

$U \rightarrow$ perfil $U$ 
Tabela 3.2: Configuração das ligações parafusadas em cantoneiras formadas a frio

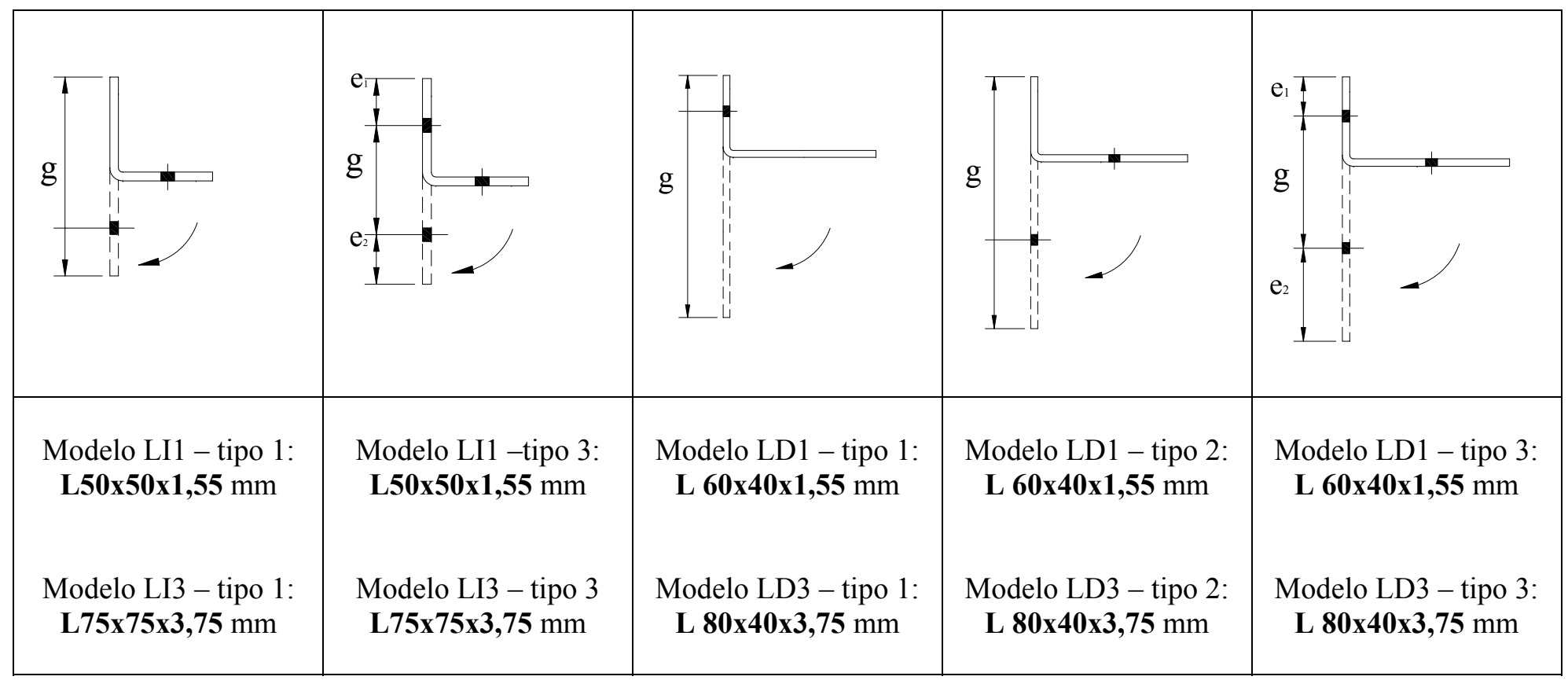


Tabela 3.3: Configuração das ligações parafusadas em perfis U formados a frio.

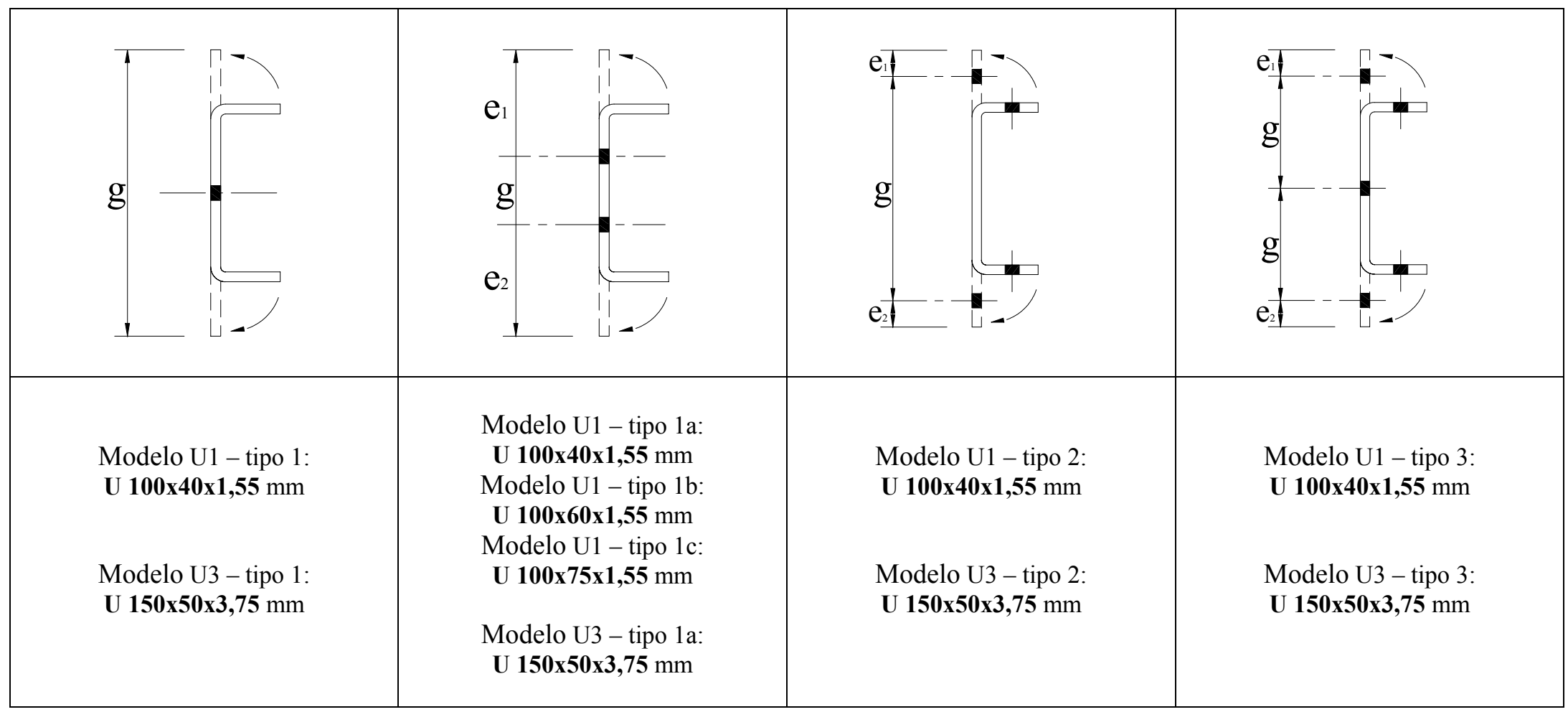


CAPÍTULO 04 ANÁLISE NUMÉRICA 


\subsection{INTRODUÇÃO}

O estudo do comportamento de ligações parafusadas em elementos metálicos tem sido conduzido utilizando-se algumas estratégias de análise, dentre elas inclui-se os modelos matemáticos. Assim, devido às complexidades do problema real, simplificações são introduzidas no problema inicial, criando-se, portanto, modelos para representar os comportamentos dos campos de interesse, representados por relações matemáticas que, em geral, são escritas em termos de equações diferenciais parciais(EDP), definidas sobre um domínio.

As soluções analíticas para as EDPs desses problemas não estão disponíveis ou até mesmo possíveis na maioria dos casos. Assim, uma alternativa é partir para a discretização do meio contínuo e sistematizar o problema discreto, obtendo-se soluções aproximadas via análises numéricas. Dentre as técnicas numéricas conhecidas, utilizou-se, neste trabalho, o Método dos Elementos Finitos(MEF) que, devido à versatilidade de suas formulações, se tornou uma técnica quase 'onipresente' em muitas áreas da mecânica dos sólidos.

A tentativa de representação da estrutura real pode assumir inúmeras possibilidades de modelagem, afetadas pela precisão estipulada e custo operacional (homem-tempo, recursos computacionais), assim cabe ao analista o balanceamento destes dois fatores que estão freqüentemente em conflito. Portanto, os objetivos de uma análise têm influência relevante na escolha apropriada da modelagem. 
Neste trabalho, buscou-se fazer uma investigação numérica simulando o comportamento estrutural das ligações parafusadas em chapas finas e perfis formados a frio, utilizando o programa de análise por elementos finitos ANSYS, versão 5.5. Os resultados numéricos obtidos foram comparados com os resultados experimentais, aferindo, desse modo, a validade desses modelos, buscando incluir neles algumas características da estrutura real.

Deste modo, iniciou-se a análise por meio de um modelo mais simples tanto na concepção geométrica como na representação dos materiais, sendo que os conceitos das não-linearidades físicas (modelo elasto-plástico perfeito) e geométricas, bem como características especificas da tipologia estrutural em estudo, foram incorporadas ao modelo progressivamente, tendo com objetivo obter a representatividade do modelo numérico. Nesta primeira etapa da análise, foram obtidos bons resultados para a relação forçadeslocamento no regime linear, quando comparado aos resultados experimentais.

Numa segunda etapa, buscaram-se estratégias para o enriquecimento desta modelagem inicial visando a melhora dos resultados. Dessa forma, procurou-se identificar quais fatores têm influência relevante no comportamento de cada uma das estruturas analisadas e que não podem ser negligenciadas na sua modelagem.

Desta forma, aumentou-se o número de elementos da malha, principalmente nos pontos críticos, aplicaram-se relações constitutivas mais apropriadas com aquelas da caracterização do material, melhoraram-se as condições de contorno, etc. Mas, com o conseqüente elevação do custo operacional.

Na geração do modelo não foi contemplada a introdução de imperfeições geométricas iniciais, uma vez que estas não foram quantificadas nos modelos experimentais e, se tratando de carregamento por tração, não se tornam tão significativas. As tensões residuais ao redor dos cantos dos perfis formados a frio, oriundas do trabalho de dobramento, também não foram incluídas no modelo. 


\subsection{MODELAGEM NUMÉRICA}

\subsubsection{Parâmetros para a avaliação dos modelos numéricos}

Para avaliar o comportamento do modelo numérico gerado, bem como verificar a influência do enriquecimento aplicado a estes, os resultados obtidos numericamente foram comparados com os experimentais, tanto para o caso de chapa fina como para os perfis formados a frio. Para tanto, foram escolhidas duas configurações representativas destas ligações, apresentadas a seguir:

Para o caso de ligação em chapa fina escolheu-se para modelagem a configuração C2C4-14.1 (fig. 4.1 a), que experimentalmente apresentou modo de falha por ruptura da seção líquida com força última de $48,8 \mathrm{kN}$ e deslocamento total incluindo acomodação dos parafusos nos furos de $8,4 \mathrm{~mm}$, conforme apresentado na figura 4.1b.

Tornou-se indiferente, na escolha da ligação, a utilização ou não de arruelas junto a cabeça e $\circ$ corpo do parafuso uma vez que 0 puncionamento do parafuso na chapa de aço, o qual foi facilitado pela ausência destas, foi predominante nas configurações com uma seção de parafusos apenas.

Já para a modelagem do perfil formado a frio escolheu-se uma cantoneira de abas iguais $\mathrm{L} 50 \times 50 \times 1,55 \mathrm{~mm}$ (LIIC1-1).1.1 (fig. 4.2a) conectada por uma das abas, que experimentalmente apresentou modo de falha por ruptura da seção líquida com força última de $36,5 \mathrm{kN}$ e deslocamento total incluindo acomodação dos parafusos nos furos de $10,7 \mathrm{~mm}$, conforme apresentado na figura 4.2b.

Durante o ensaio, uma vez vencido o atrito entre as chapas ou entre 0 perfil e o dispositivo de fixação, ocorreu a acomodação do parafuso no furo padrão. Como esse fenômeno não foi representado pelos modelos em análise, na comparação com os resultados experimentais o trecho de deslocamento, correspondente à acomodação do parafuso, foi suprimido dos gráficos força $\mathrm{x}$ deslocamento, conforme apresentado nos gráficos das figuras $4.1 \mathrm{~b}$ e $4.2 \mathrm{~b}$.

4.1 Para maiores detalhes da citada configuração ver capítulo 3 subitem 3.4 


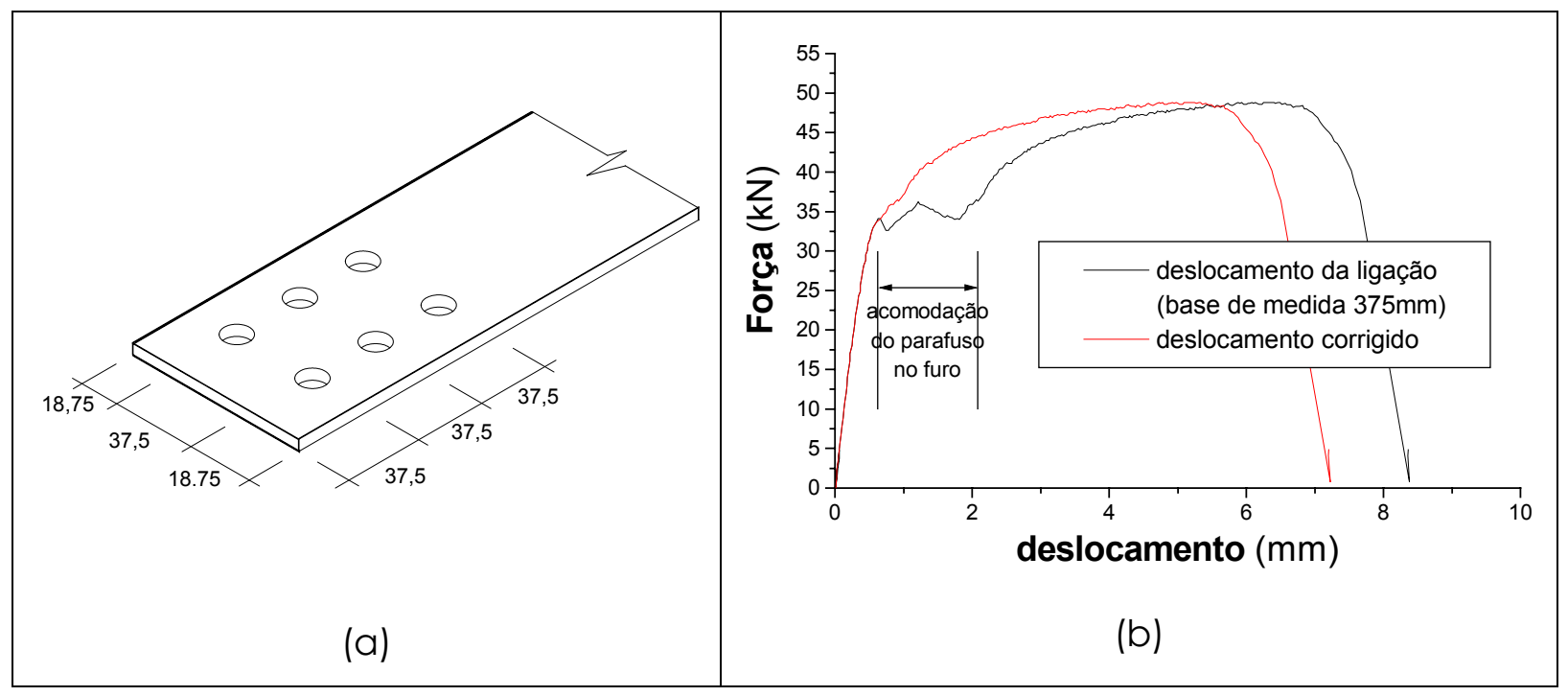

FIGURA 4.1 - Modelo de chapa fina (C2C4-1), analisado numericamente

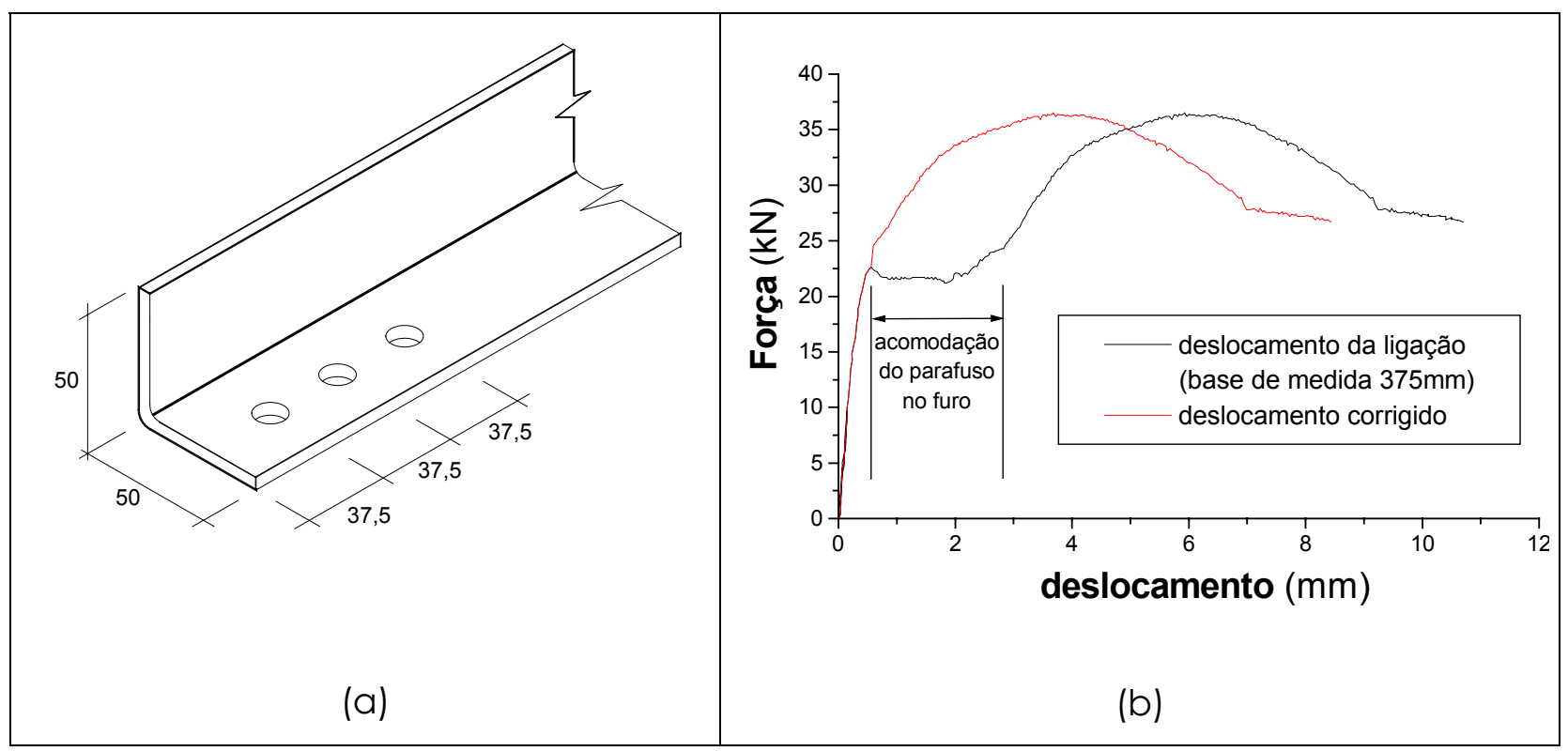

FIGURA 4.2 - Modelo de perfil formado a frio (LIIC 1-1), analisado numericamente 


\subsubsection{Geração e avaliação do modelo numérico}

\subsubsection{Elemento tipo e malha utilizados}

Em principio, as estruturas de paredes finas como: painéis, chapas ou até mesmo superfícies curvas são definidos no espaço tridimensional. Contudo, devido á pequena relação entre a espessura e as demais dimensões desses elementos, estes podem ser analisados mediante a utilização da teoria de cascas. Uma das prescrições usualmente encontradas na literatura como recomendação para a utilização de elementos de casca é que, para sua aplicação, deve-se ter a menor dimensão de cada painel que compõe a estrutura modelada maior do que 10 vezes sua espessura.

Satisfeita esta condição pelos modelos a serem analisados, utilizou-se em todas as modelagens o elemento de casca de quatro nós SHELL43 (Plastic Large Strain Shell - ANSYS 5.5), esquematizado na figura 4.3. Este permite a translação em ambas direções do plano da casca e num terceiro definido transversalmente a este plano, podendo descrever comportamento plástico e grandes deformações. Para um dos seus nós apresenta seis graus de liberdade:

- translações nas direções locais x, y e z;

- rotações em torno dos eixos x, y e z.

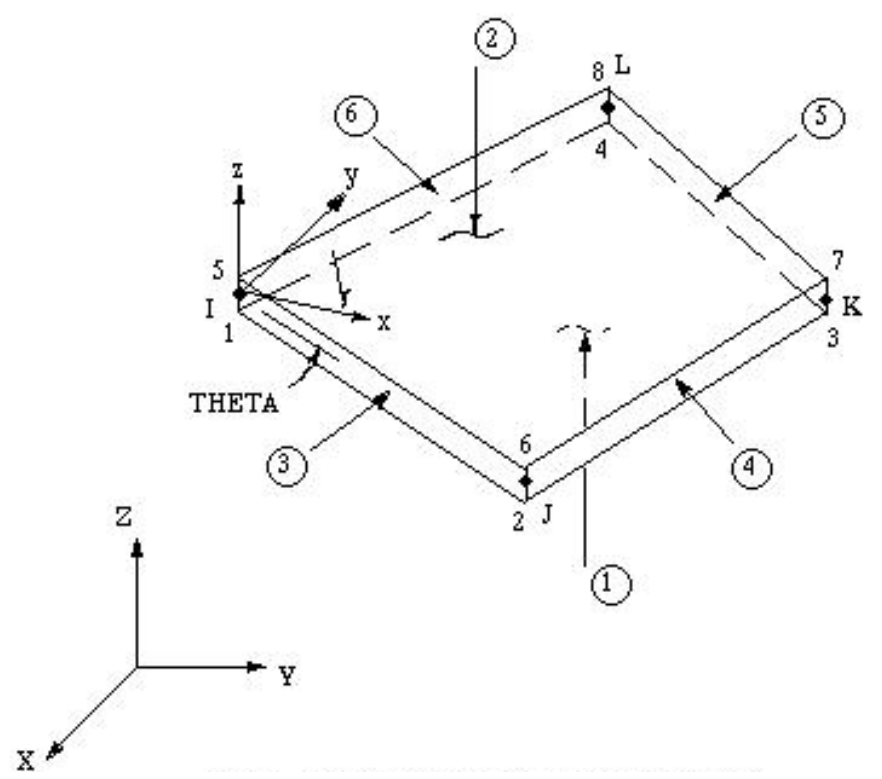

FIGURA 4.3 - Representação do elemento SHELL43 (ANSYS 1996) 
As malhas de elementos finitos utilizadas na modelagem foram investigadas variando-se o tamanho dos elementos, consequentemente, o seu número, tanto numa abordagem global como em pontos específicos, citados a seguir:

- nas regiões adjacentes aos furos; tentado desse modo melhor representar as concentrações de tensões que usualmente ocorrem nesses locais.

- nos cantos dos perfis; pois o diferente posicionamento dos elementos adjacentes a um canto podem causar grandes variações na distribuição das tensões, principalmente quando se trata de peças fletidas, segundo HOFMEYER (2000), que tendo estudado vigas em perfis $U$, relata que especial atenção deve ser dada a esta região,.

Numa primeira tentativa utilizou-se, para a modelagem da ligação em chapas finas, uma malha pobre com 740 elementos (malhaCH1), numa segunda modelagem (malhaCH2) enriqueceu-se esta malha gerando 1705 elementos. Já para a modelagem malhaCH3 aumentou-se o número de elementos utilizando uma discretização com 3710 elementos.

Já para as modelagens de perfis formados a frio, iniciou-se com a malha pobre contendo 451 elementos (malhaP1), numa segunda modelagem (malhaP2) enriqueceu-se esta malha gerando 1582 elementos. Já para a modelagem malhaP3 aumentou-se o número de elementos utilizando uma discretização com 4099 elementos. Evidentemente, o tempo de processamento aumentou conforme aumentou-se o número de elementos das malhas. Ressalta-se que a geração destas malhas foi realizada automaticamente pelo processador do programa.

Nos gráficos da figura 4.4 observa-se que a variação do número de elementos utilizados na confecção das malhas teve pouca influência nos resultados, tanto para o caso das ligações em chapas finas quanto para os perfis formados a frio, sendo portanto utilizado no decorrer do trabalho as modelagens malhaCH $\mathbf{l}$ para as chapas e a malhaP1 para os perfis.

Destaca-se também, na figura 4.4a, que os modelos para ligação em chapa fina tiveram problemas de convergência no início da fase de 
plastificação, apresentando melhora com a adoção de modelos constitutivos trilineares, conforme demonstrado adiante.

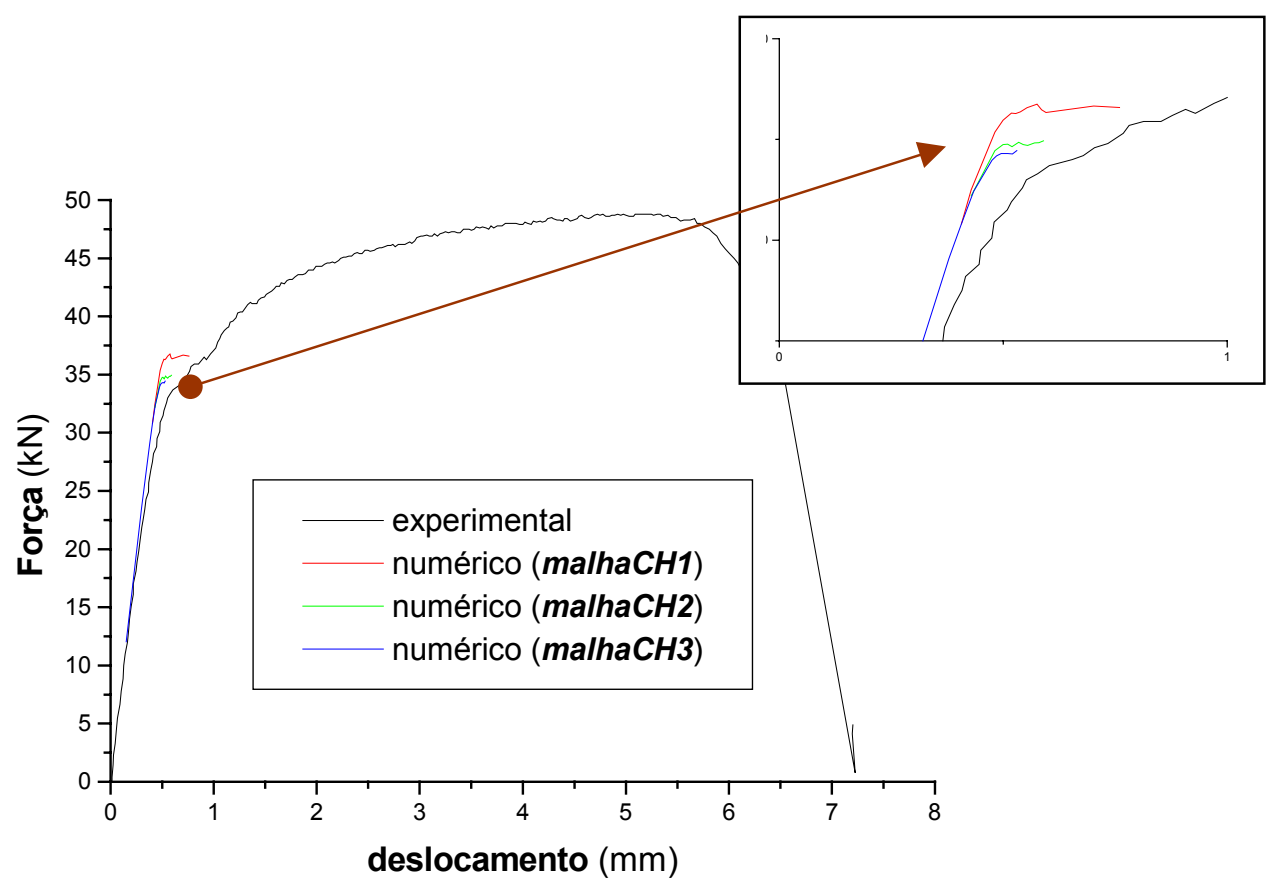

a) chapas finas

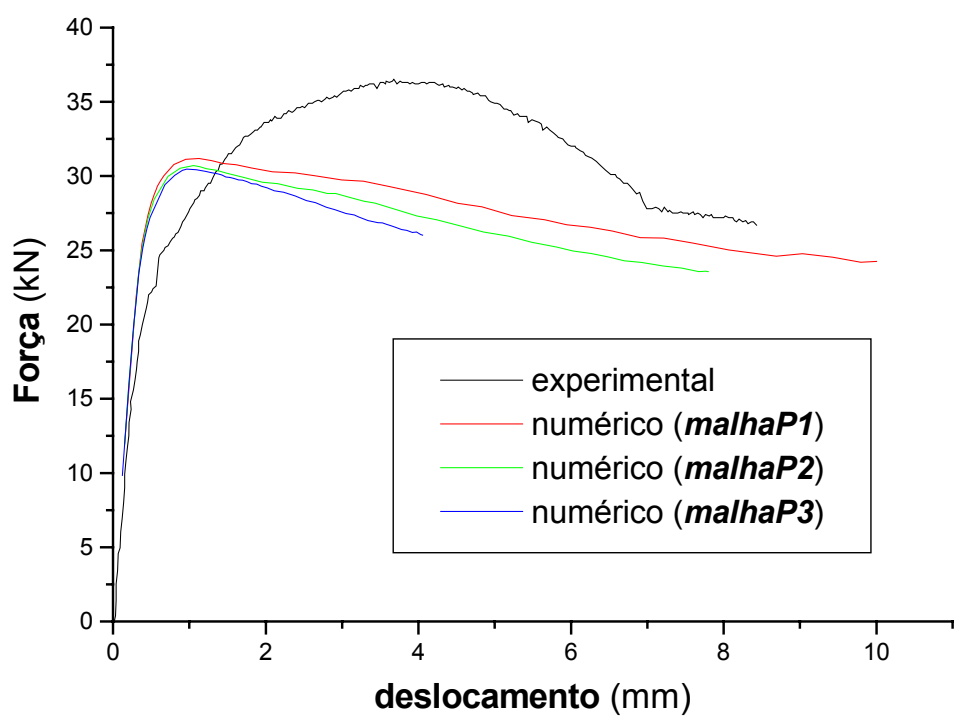

b) cantoneira

FIGURA 4.4 - Estudo do enriquecimento da malha de elementos finitos (material elasto-plástico perfeito) 
A partir do modelo para cantoneira malhaP1 procedeu-se a um enriquecimento da malha somente nos pontos considerados críticos, ou seja, ao redor dos furos e na região dos cantos.

Portanto, para o modelo malhaPlc, houve o aumento no número de elementos na região do canto, passando de um elemento da malha original para nove elementos, conforme apresentado na figura 4.5, gerando um aumento de 304 elementos (67\%). Para o modelo malhaPlf o enriquecimento ocorreu na região do furo, sendo criados 1142 novos elementos nesta região (aumento de 253\%).
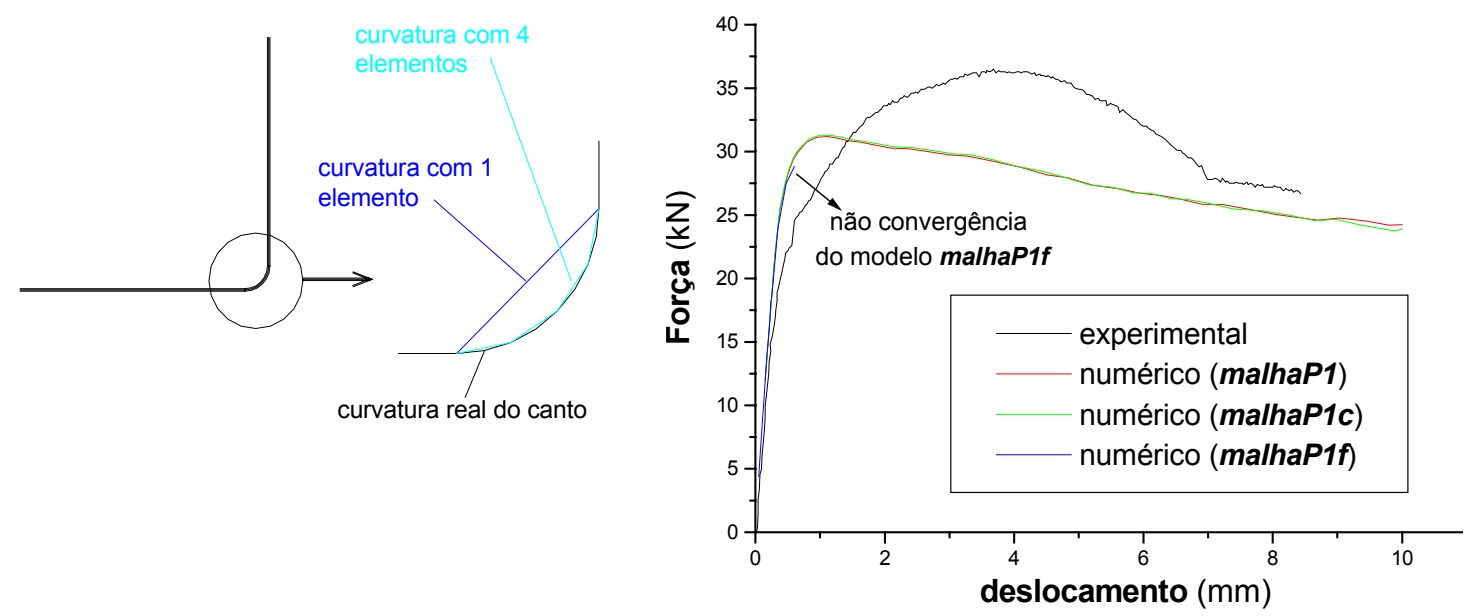

FIGURA 4.5 - Influência do enriquecimento da malha na região dos cantos e furos (material elasto-plástico perfeito)

Como ilustrado no gráfico da figura 4.5, o enriquecimento da malha de elementos finitos nas regiões consideradas críticas dos corpos-de-prova não resultou em melhora dos resultados numéricos, principalmente quando este foi feito na região dos furos, o que acarretou a não convergência da análise logo após a fase elástica. Já para a região dos cantos, este refinamento só é satisfatório para os casos em que há uma grande variação na distribuição de tensões nos elementos adjacentes ao canto, exemplo de peças fletidas, não sendo este o caso em questão. 


\subsubsection{Condições de contorno}

Nos ensaios realizados, a base de medida inicial para o posicionamento dos transdutores de deslocamento foi de $375 \mathrm{~mm}$, conforme apresentado nas figuras $4.6 \mathrm{~d}$ e 4.7d. Com vista nisso, os modelos numéricos analisados apresentavam comprimento de $375 \mathrm{~mm}$, conforme apresentado nas figuras 4.6c e 4.7c, de modo a facilitar a comparação dos resultados experimentais de deslocamento.

$\mathrm{Na}$ concepção do modelo numérico, elementos como parafusos, arruelas e os dispositivos de fixação não foram incluídos. Sendo que a ação deste primeiro na ligação foi representada através das restrições dos graus de liberdade impostos pelo parafuso ao modelo.

Na simulação do ensaio de chapa fina, foram modeladas duas chapas posicionadas como no ensaio a corte simples (figura 4.6c). Os nós da região dos furos localizados nas metades opostas destes para cada chapa (região comprimida) tiveram os seus graus de liberdade acoplados de modo a terem os mesmos deslocamentos e rotações, simulando a ação do parafuso.

Na região dos apoios, os nós da extremidade inferior do modelo tiveram todos os deslocamentos restritos (tanto translações como rotações), já para os nós da extremidade superior foi aplicada uma translação de 10mm, em pequenos incrementos, na direção y (longitudinal) enquanto os graus de liberdade restantes foram restringidos (figura $4.6 \mathrm{~b}$ e $4.6 \mathrm{a}$ ).

Para a cantoneira, na simulação da extremidade fixa, a condição de contorno foi aplicada restringindo os deslocamentos e rotações dos nós localizados na metade inferior dos furos (região comprimida pela ação do parafuso), figura 4.7b. Na outra extremidade, restringiram-se as rotações e os deslocamentos dos nós nas direções transversais ao perfil e aplicou-se um deslocamento de $10 \mathrm{~mm}$, em pequenos incrementos, na direção longitudinal a este (direção z), figura 4.7a. 


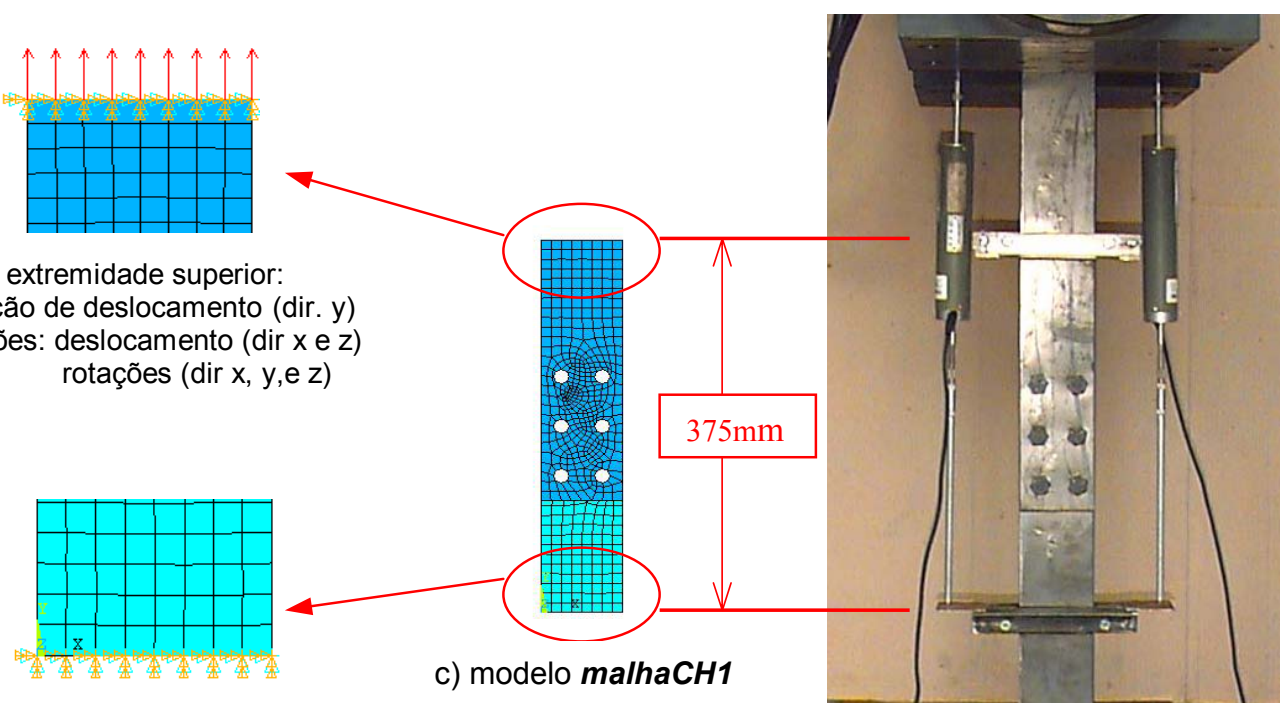

b) extremidade inferior:

- restrições: deslocamento (dir. $x, y$ e z)

d) vista do ensaio: c.p. C2C4-1 rotações (dir. $x, y$ e z)

Figura 4.6 - Condições de contorno do modelo malhaCHI e vista do ensaio C2C4-1

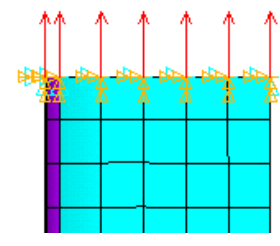

a) extremidade superior: - aplicação de deslocamento (dir. y) - restrições: deslocamento (dir x e z) rotações (dir $x, y, e z)$

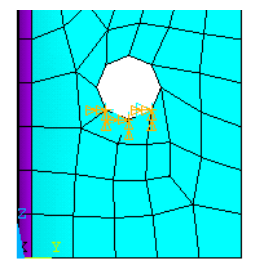

b) região dos furos:

- restrições: deslocamento (dir. $x, y$ e z) rotações (dir. $x, y$ e z)

Figura 4.7 - Condições de contorno do modelo malhaPl e vista do ensaio $\mathrm{LIICl-1}$ 


\subsubsection{Método de carregamento}

O carregamento foi aplicado por meio de deslocamentos longitudinais controlados, procedimento similar ao utilizado nos ensaios. Estes deslocamentos foram aplicados nos nós da extremidade superior do modelo (chapa ou perfil), em pequenas etapas, definidas automaticamente pelo programa conforme convergência, até o limite de $10 \mathrm{~mm}$, podendo não haver convergência para valores inferiores a este.

Após análise, o valor do carregamento aplicado, em cada passo de deslocamento, era obtido pela somatória das reações de apoio destes nós extremos.

\subsubsection{Não linearidade geométrica}

Para a análise da não linearidade geométrica foi utilizada a formulação lagrangeana atualizada e a solução dos sistemas de equações não lineares foi obtida utilizando o processo incremental-iterativo de NEWTON-RAPHSON, disponível no programa ANSYS.

\subsubsection{Não linearidade física}

Existem, na literatura, várias propostas de diagrama tensão $x$ deformação para aplicação na análise numérica das chapas finas e perfis formados a frio, como as adotadas por CHUNG \& IP (2000) para análise da resistência ao esmagamento de chapas finas de aço conectadas por parafusos, apresentados na figura 4.8. Segundo Chung, dos modelos constitutivos utilizados o que apresentou melhores resultados foi o FEA-pr. 


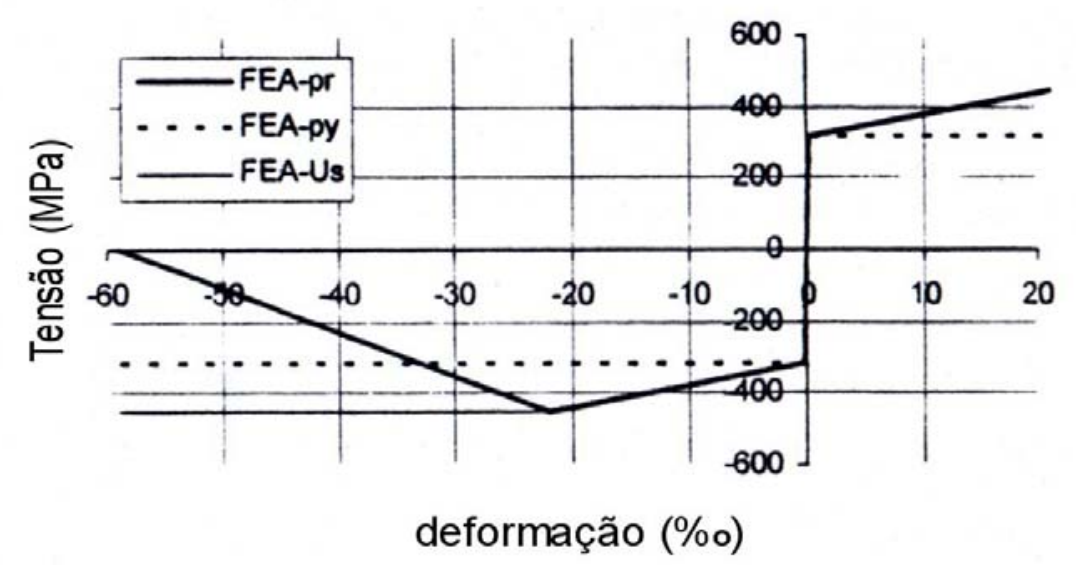

FIGURA 4.8 - Curvas tensão x deformação propostas por CHUNG \& IP (2000) para tração e compressão.

Como se pode observar na figura anterior o modelo constitutivo FEA-pr de Chung apresenta comportamento diferente na tração e compressão, considerando um modelo bilinear com encruamento positivo para a tração; e um trilinear com encruamento negativo para a compressão. A parte descendente da curva pode ser considerado como fisicamente impossível para materiais comprimidos, podendo ser uma tentativa de representar 0 efeito de flambagem local de chapa fina ou da fratura do material para $o$ modelo em elemento finito.

No entanto, o programa ANSYS - versão 5.5 só admite, para os elementos utilizados, diagramas tensão x deformação simétricos na tração e compressão e impede também a utilização de encruamento negativo, como o que ocorre na compressão do modelo de FEA-pr de Chung.

Nesta análise, no primeiro estágio admitiu-se para o material um diagrama tensão x deformação elasto-plástico perfeito, com plastificação iniciando quando o material atingir a tensão de escoamento obtida em ensaios de tração $\left(34,6 \mathrm{kN} / \mathrm{cm}^{2}\right)$, modelo malhaCH $\mathbf{l}$ para chapa e malhaPl no caso da cantoneira. Num segundo estágio evolviu-se para um modelo bilinear com encruamento positivo (malhaCHIbl e malhaPlbl) e em seguida um trilinear também com encruamento positivo e início da plastificação para níveis de tensões correspondentes a resistência do aço $\left(46,8 \mathrm{KN} / \mathrm{cm}^{2}\right)$ modelo malhaCHItl e malhaPltl para chapa e cantoneira, respectivamente. Na figura 4.9 são representados estes modelos constitutivos do material, e os resultados da análise numérica comparados com os obtidos nos ensaios são 
apresentados nos gráficos das figuras 4.10 e 4.11 , para o caso do modelo de chapas e de cantoneira, respectivamente.

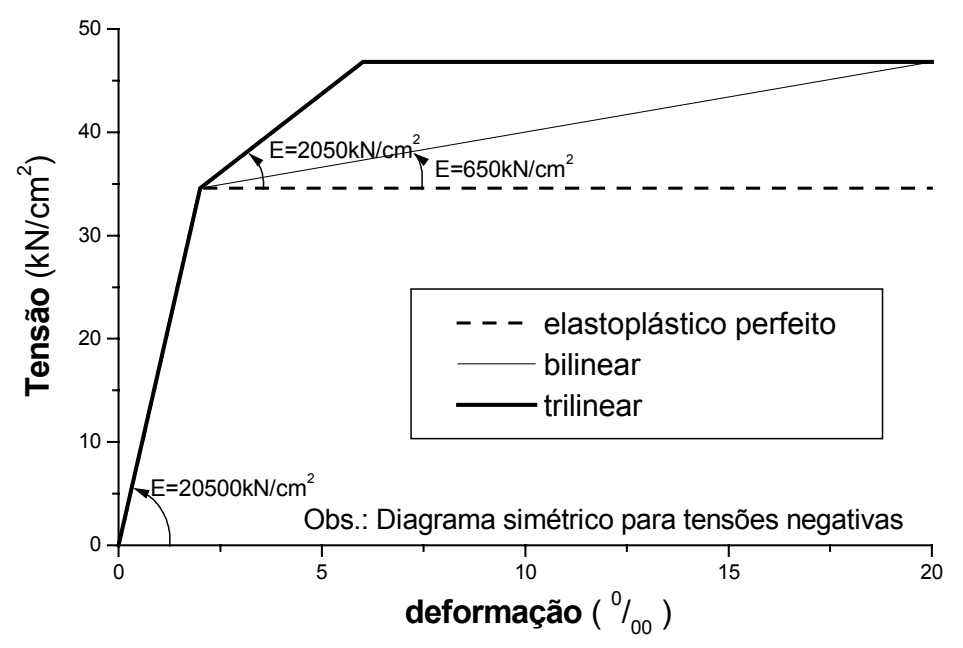

FIGURA 4.9 - Curvas tensão x deformação utilizadas na análise numérica

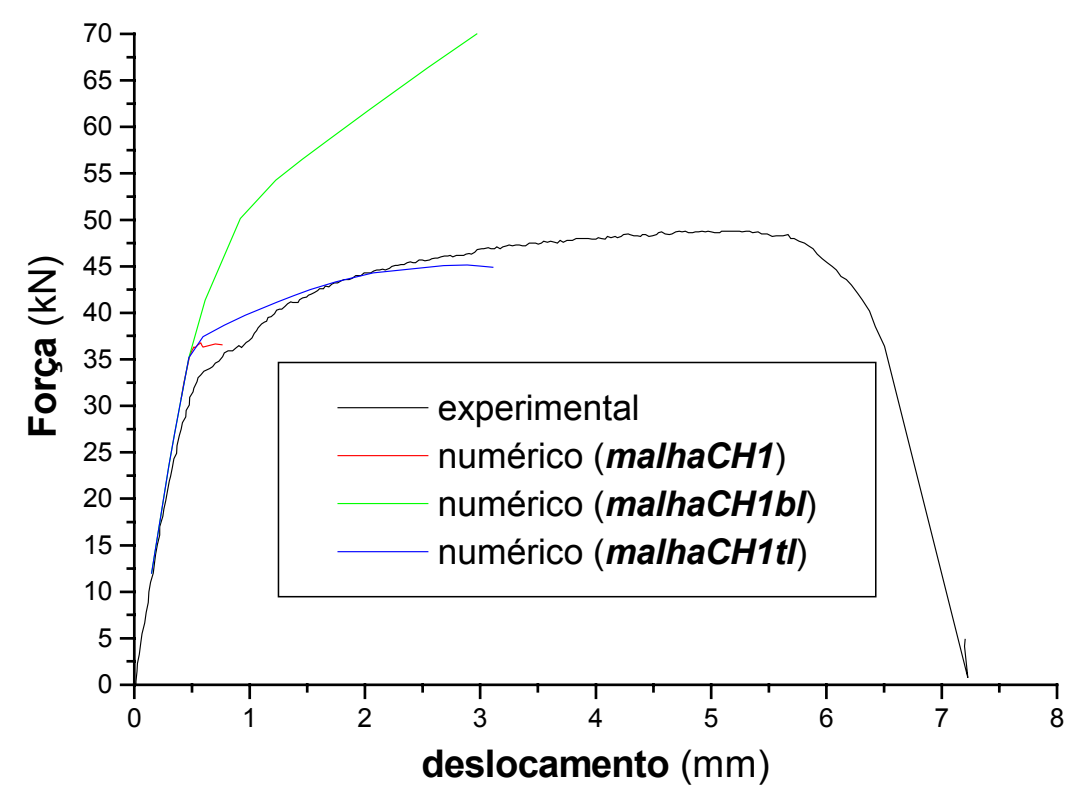

FIGURA 4.10 - Estudo da modelagem das relações constitutivas do material aplicada as chapas 


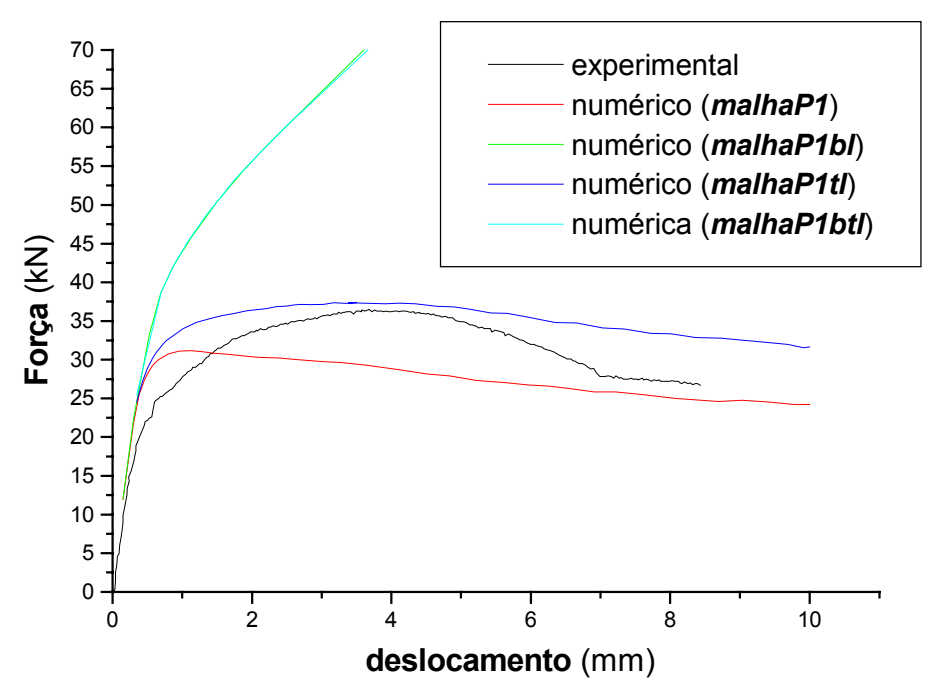

FIGURA 4.11 - Estudo da modelagem das relações constitutivas do material aplicada aos perfis

Para o modelo de chapa (figura 4.10), observa-se melhora na convergência acarretada pela adoção do modelo constitutivo trilinear em comparação com o elasto-plástico perfeito, mas no entanto esta ainda não apresentou deslocamentos finais compatíveis com o modelo real, obtendo força última 7,4\% menor.

Já os modelos com relação constitutiva bilinear, tanto para chapa como para cantoneira (malhaCHibl e malhaPlbl, nas figuras 4.10 e 4.11) apresentaram uma resistência infinita, representada pelo ganho de força sempre ascendente.

Com a aplicação da relação constitutiva trilinear do material para o modelo de cantoneira, obtiveram-se resultados satisfatórios de força última, ficando esta $2,4 \%$ acima do modelo real.

O modelo malhap1bfl (figura 4.11) foi uma tentativa de aplicar uma relação constitutiva trilinear na região do canto (simulando o trabalho a frio) e no restante do modelo uma relação bilinear. Entretanto, tal solução não conduziu a resultados satisfatórios. 


\subsection{RESULTADOS DA ANÁLISE NUMÉRICA}

Nesse item são apresentados os resultados finais obtidos, após todos refinamentos, para a simulação numérica de ligações parafusadas em chapa fina e cantoneira formada a frio, comparados com os resultados reais obtidos nos ensaios realizados.

Comparando o comportamento força $x$ deslocamento, observa-se o ótimo comportamento de força última para o modelo da cantoneira, ficando este $2,4 \%$ acima do experimental. Já o modelo de chapa apesar de ter obtido um valor de força última 7,4\% abaixo do experimental apresentou problemas de convergência, o que fez com que o deslocamento último fosse $50 \%$ menor que o experimental. Estes comportamentos estão representados nas figuras $4.12 a$ e $4.13 a$.

Quanto ao aspecto das deformadas obtidas numericamente estas são condizentes com as experimentais. Como pode ser observado na figura 4.12c, para o caso da ligação em chapa fina, a configuração em estudo não apresentou, no ensaio, flexão acentuada da região conectada, e o início da ruptura da seção líquida se deu entre os parafusos para, em seguida, se propagar para os cantos. Numericamente este comportamento pode ser traduzido pelas máximas tensões de tração localizadas inicialmente nas bordas dos furos (entre estes), as quais com a evolução da análise também se propagavam para as bordas (figura 4.12b).

A mesma análise pode ser feita para o caso da cantoneira (figura 4.13b), onde observa-se o início da ruptura ao redor dos furos (máximas tensões de tração), só que, para este caso, na estrutura real houve ao final do ensaio a flexão da aba não conectada (instabilidade local), representada na figura 4.13c, o mesmo ocorrendo na análise numérica, acompanhada da deformação do furo. 
Ligações parafusadas em chapa fina de aço
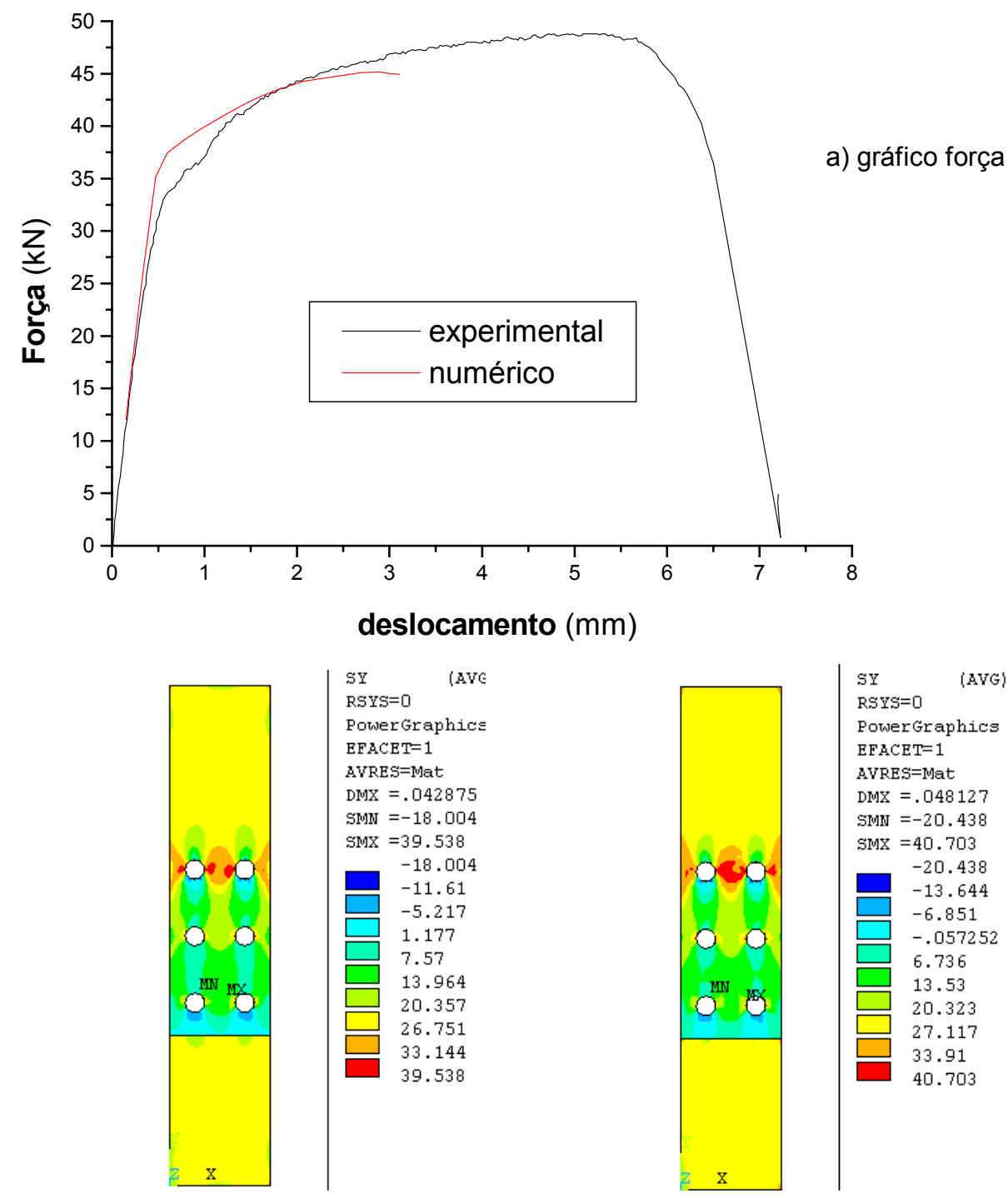

b) curvas de isotensões
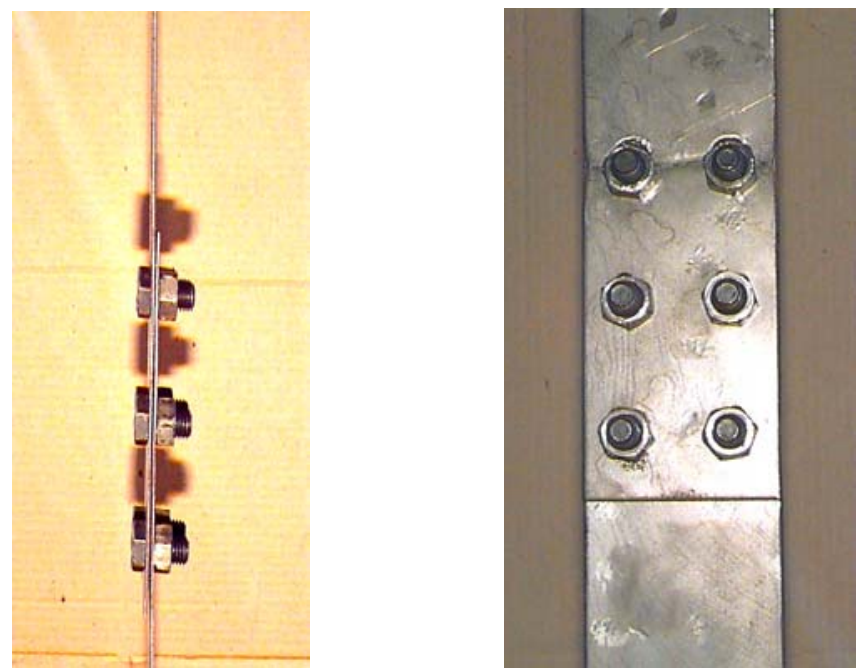

c) vistas da flexão e do ensaio c.p. C2C4-1

FIGURA 4.12 - Resultados da análise numérica para o modelo de chapa fina 


\section{Ligações parafusadas em cantoneira de aço formada a frio}
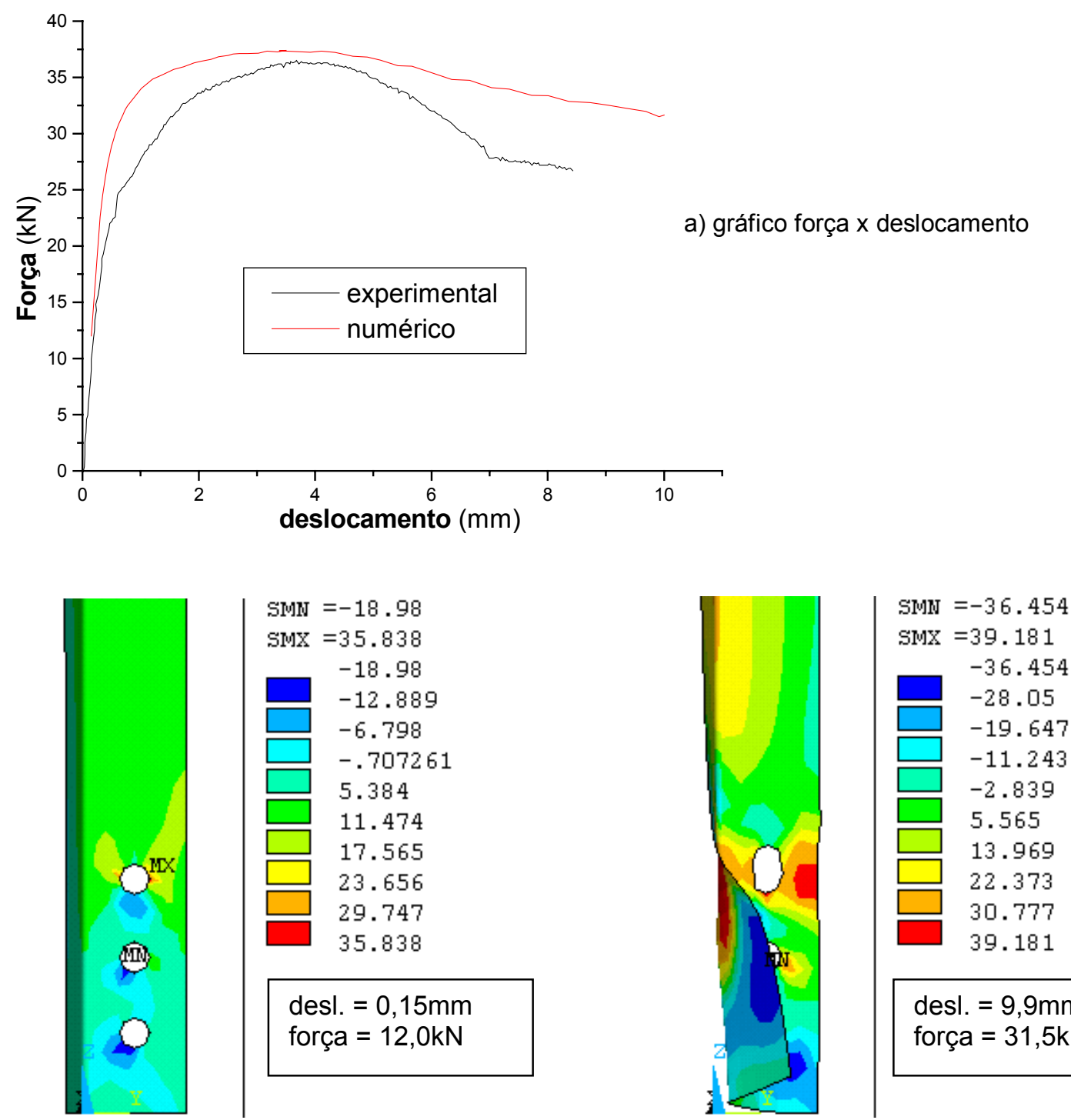

desl. $=9,9 \mathrm{~mm}$ força $=31,5 \mathrm{kN}$

b) curvas de isotensões e configuração da deformada

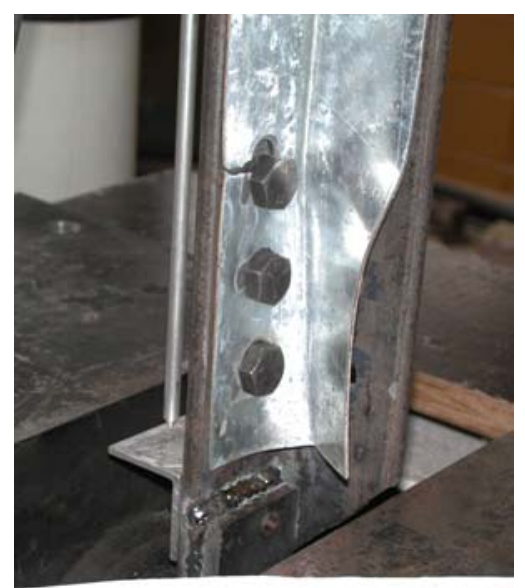

c) deformada real

LI $1 \subset 1-1$

FIGURA 4.13 - Resultados da análise numérica para o modelo de cantoneira 
CAPÍTULO 05

RESULTADOS E DISCUSSÃO 


\subsection{INTRODUÇÃO}

Neste capitulo serão apresentados os resultados da análise experimental realizada nas ligações parafusadas em chapas finas e perfis formados a frio, e sua comparação com os valores teóricos apresentados pela especificação NBR14762:2001 e também pelo AISI em suas edições de 1996 e 2001.

Nos ensaios realizados foi observada a ocorrência de dois modos de falha predominantes. $O$ primeiro foi caracterizado pelo esmagamento da parede do furo ou furos. O segundo caracterizou-se pela ruptura da seção líquida.

Um terceiro modo de falha, observado em alguns dos corpos-de-prova, foi a associação dos anteriores, ou seja, ao final do ensaio, ocorrida a ruptura da seção líquida, a parede do furo (ou furos) se encontravam com deformação excessiva. Para estes, os resultados foram analisados tanto nos casos de esmagamento quanto para os de ruptura da seção líquida.

No total foram ensaiadas 208 ligações de chapas finas submetidas à corte simples, 24 submetidas a corte duplo e 164 ligações em perfis formados a frio, sendo 88 cantoneiras simples de abas iguais e desiguais, 8 duplas cantoneiras de abas iguais e 68 perfis $U$. 


\subsection{LIGAÇÕES PARAFUSADAS EM CHAPAS FINAS DE AÇO}

\subsubsection{Esmagamento}

A falha por esmagamento da parede do furo foi caracterizada pela incapacidade da ligação de suportar acréscimos de força, apresentando grandes deslocamentos e elevada deformação na região do furo.

Observa-se nos gráficos força $\mathrm{x}$ deslocamento na figura 5.1, que os corpos-de-prova que tiveram a falha por esmagamento da parede do furo, representados pelas ligações C2B2-1 e C2B2-2, apresentaram três trechos distintos: o inicial representado por pequenas deformações elásticas, seguido de um pequeno patamar ocorrido devido ao escorregamento entre chapas e a conseqüente acomodação dos parafusos e uma fase final apresentando um encruamento positivo que se estende até o final do ensaio, ultrapassando os $12,5 \mathrm{~mm}$ (1/2") de deslocamento relativo, valor este estipulado como limite convencional para caracterizar a falha por esmagamento.

Quando o modo de falha foi caracterizado como a ruptura da seção líquida, houve alteração de comportamento força $x$ deslocamento dos corpos-de-prova somente na fase final do ensaio, caracterizada pela queda acentuada da força, ocorrida antes do deslocamento relativo limite de 12,5mm (gráficos C2B4-1 e C2B4-2, fig 5.1).

Para os corpos-de-prova que tiveram como falha a ruptura da seção líquida, mas apresentavam deformação excessiva dos furos, característica de esmagamento, observa-se uma queda acentuada da força na fase final do ensaio após a este deslocamento relativo limite (gráficos C2B10-1 e C2B10-2, fig.5.1). 


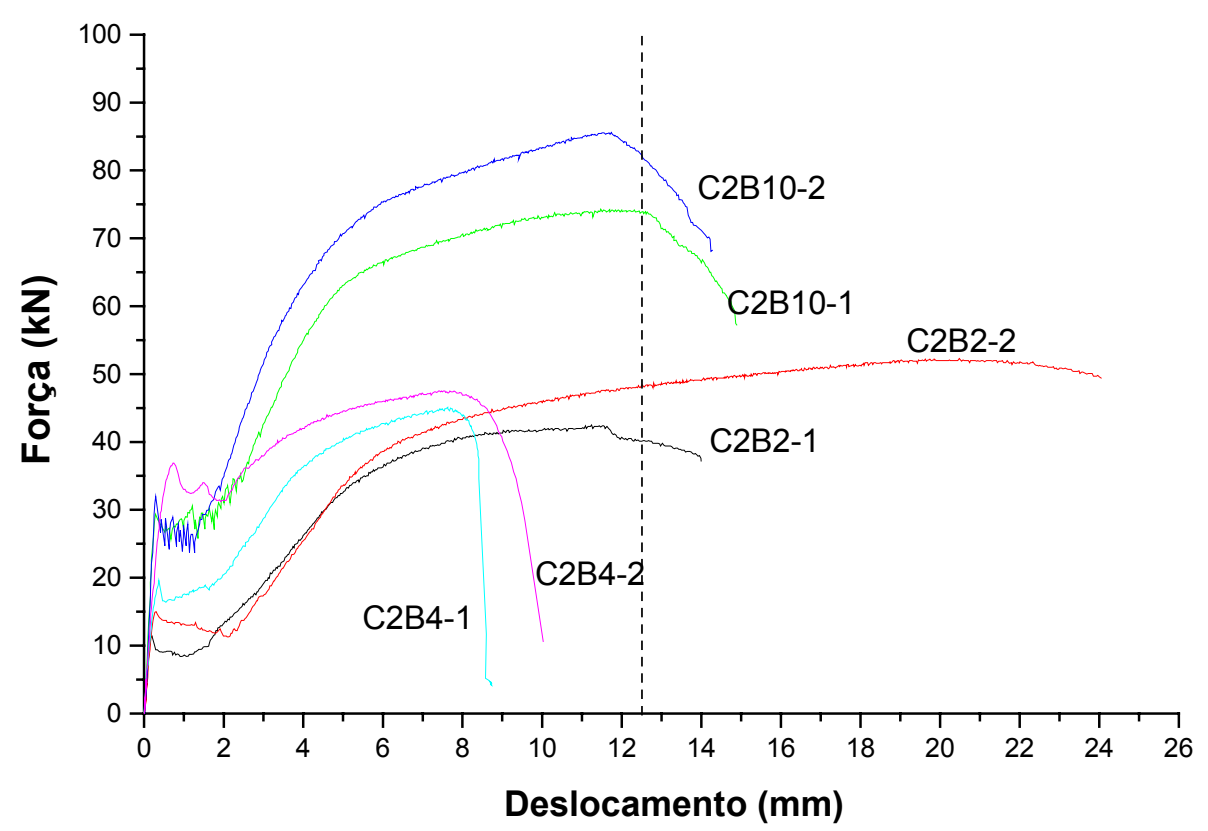

FIGURA 5.1 - Comportamento força $x$ deslocamento para os três modos de falha observados (ensaio de chapa).

A falha por esmagamento ocorreu somente nas ligações submetidas ao cisalhamento simples, e foi predominante nos corpos-de-prova da Série A, onde todos os parafusos da ligação foram posicionados em uma única seção perpendicular à direção da força, ocorrendo, portanto, elevada concentração de tensão (pressão de contato) junto aos furos.

Esta situação foi agravada pela flexão excessiva da borda das chapas, na extremidade ligada (figura 5.2a), observada na fase final do ensaio, a qual fez com que o parafuso passasse a ser solicitado também à tração, acarretando o puncionamento da chapa pela cabeça do parafuso e/ou sua porca, facilitado pela deformação excessiva do furo (figura 5.2b).

A presença de arruelas junto a cabeça do parafuso e a porca, diminuiu os afeitos do puncionamento, acarretando um aumento da força última (fig 5.4) e na ductilidade da ligação, esta última pode ser demonstrada na figura 5.3 pelo acréscimo de $20 \%$, em média, nos deslocamentos relativos, no entanto esta não pôde ser conclusiva uma vez que foi estipulado um deslocamento limite no ensaio. 


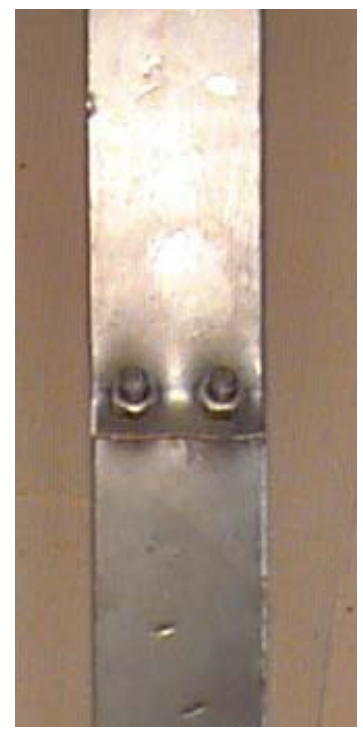

Série A (tipo 4)

(a)

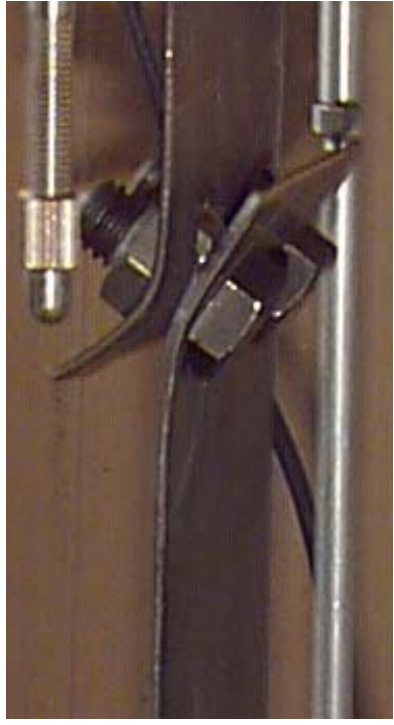

Série A (tipo 4)

(b)

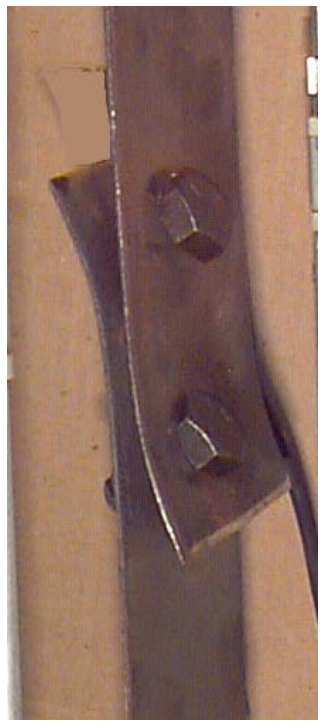

Série B (tipo 2)

(c)

FIGURA 5.2 - Configuração última das ligações que apresentaram falha por esmagamento.

Nas configurações da série $B$, com duas seções de parafusos, também houve a flexão da borda das chapas na extremidade ligada, com início de puncionamento nas ligações sem arruelas, no entanto com menor intensidade que nas ligações da série A (figura 5.2c). Essa flexão de borda foi se tornando menos pronunciada a medida em que se aumentou o número de seções de parafusos perpendicular à solicitação, ou seja, aumentou-se o comprimento da ligação. Isto se deveu à criação de um binário resistente formado pelas seções de parafusos extremas.

Outro fator que minimizou a influência desta flexão de borda foi o aumento da seção entre o furo e a borda na direção perpendicular a solicitação, comprimentos $\mathbf{e}_{1}$ e $\mathbf{e}_{2}$. Isto pode ser comprovado nos gráficos da figura 5.3, onde estão apresentados o comportamento força $x$ deslocamento de ligações com mesmo número de parafusos, porém distribuídos de modo diferente na seção transversal. Com dois parafusos dispostos em uma única seção perpendicular a solicitação para as ligações C2A4 e C2A5 porém apresentado as distâncias $\boldsymbol{e}_{1}$ e $\mathbf{e}_{2}$ iguais à $\mathbf{1 , 5} \mathbf{d}$ e $\mathbf{3} \boldsymbol{d}$, respectivamente, e em duas seções perpendiculares a solicitação, com um parafuso em cada, para a ligação C2B2 com distâncias $\mathbf{e}_{1}$ e $\mathbf{e}_{2}$ iguais à $\mathbf{3} d$. 
Assim comparando o comportamento da ligação C2B2 cujo a flexão foi minimizada pelo binário resistente formado pelas duas seções de parafusos, observa-se que o comportamento da ligação C2A5, na fase final do ensaio, foi similar a este, enquanto o da ligação C2A4 alcançou nesta fase forças sempre abaixo das duas ligações anteriores, o que pode ser confirmado nos gráficos da figura 5.4 tanto para ligações com ou sem arruelas.

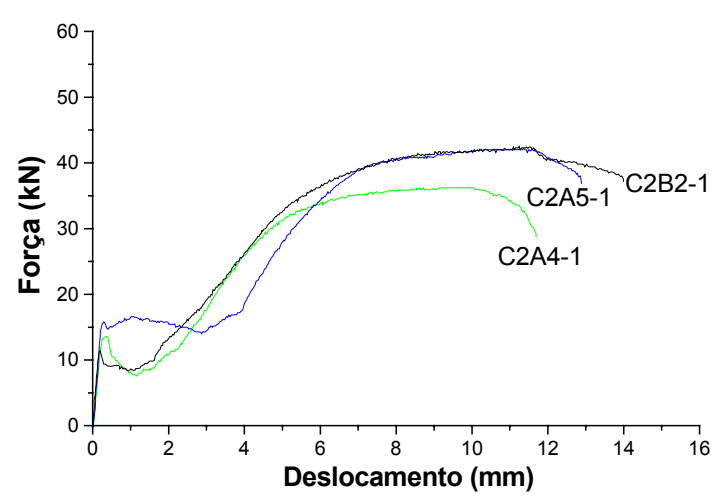

chapa $2,00 \mathrm{~mm}-\mathrm{s} /$ arruelas

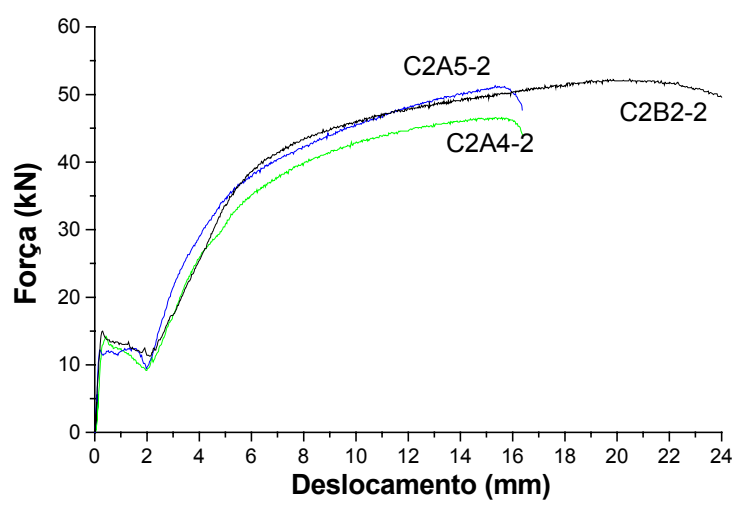

chapa $2,00 \mathrm{~mm}-\mathrm{c} /$ arruelas

FIGURA 5.3 - Influência das distâncias entre furo e borda na direção perpendicular a solicitação para a falha por esmagamento

ligações da série A

Nos gráficos da figura 5.4 são comparadas as forças últimas de ensaio $\left(\boldsymbol{F}_{u}\right)$, para os corpos-de-prova da série A que apresentaram falha por esmagamento, com a força teórica resistente, tomada como sendo a área resistente, formada pela distância entre o centro do furo à borda na direção da solicitação (2d) pela espessura da chapa (t), multiplicada pela resistência do material $\left(\boldsymbol{f}_{\mathbf{u}}\right)$.

Nestes pode-se comprovar que a concentração de tensões juntos aos furos, devida ao fato de se estar trabalhando com uma única seção de parafusos, somada com a flexão da extremidade da chapa, realmente influenciaram na força última da ligação, ficando esta em média $20 \%$ abaixo da teórica para as ligações do tipo 1, 4 e 6, cujos espaçamentos entre furo e borda são iguais ao mínimo recomendado por norma, e 10\% em média abaixo desta para ligações tipo 2, 5, 7, 8, 9 e 10 cujos estes espaçamentos são maiores 
do que os recomendado por norma. Isto para as ligações parafusadas sem a utilização de arruelas (fig 5.4a).

O que vem a confirmar também a melhora no comportamento destas ligações quando aumenta-se a distância entre furo e borda na direção perpendicular á solicitação.

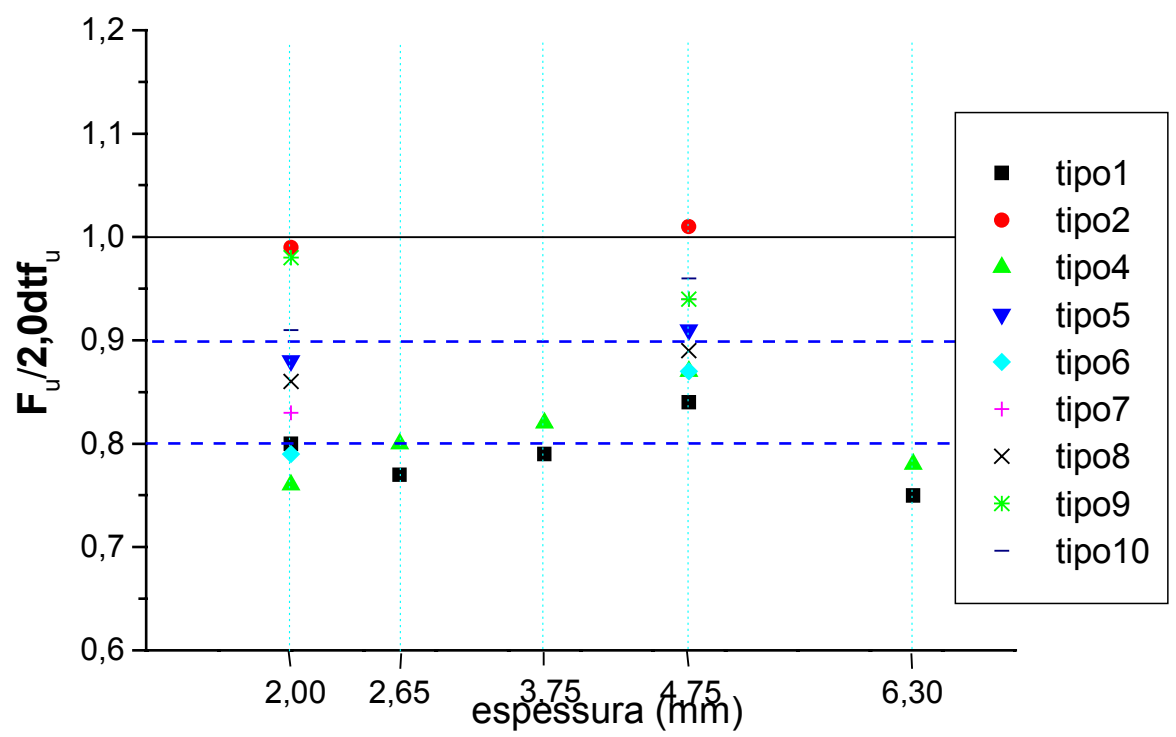

a) configurações sem a utilização de arruelas

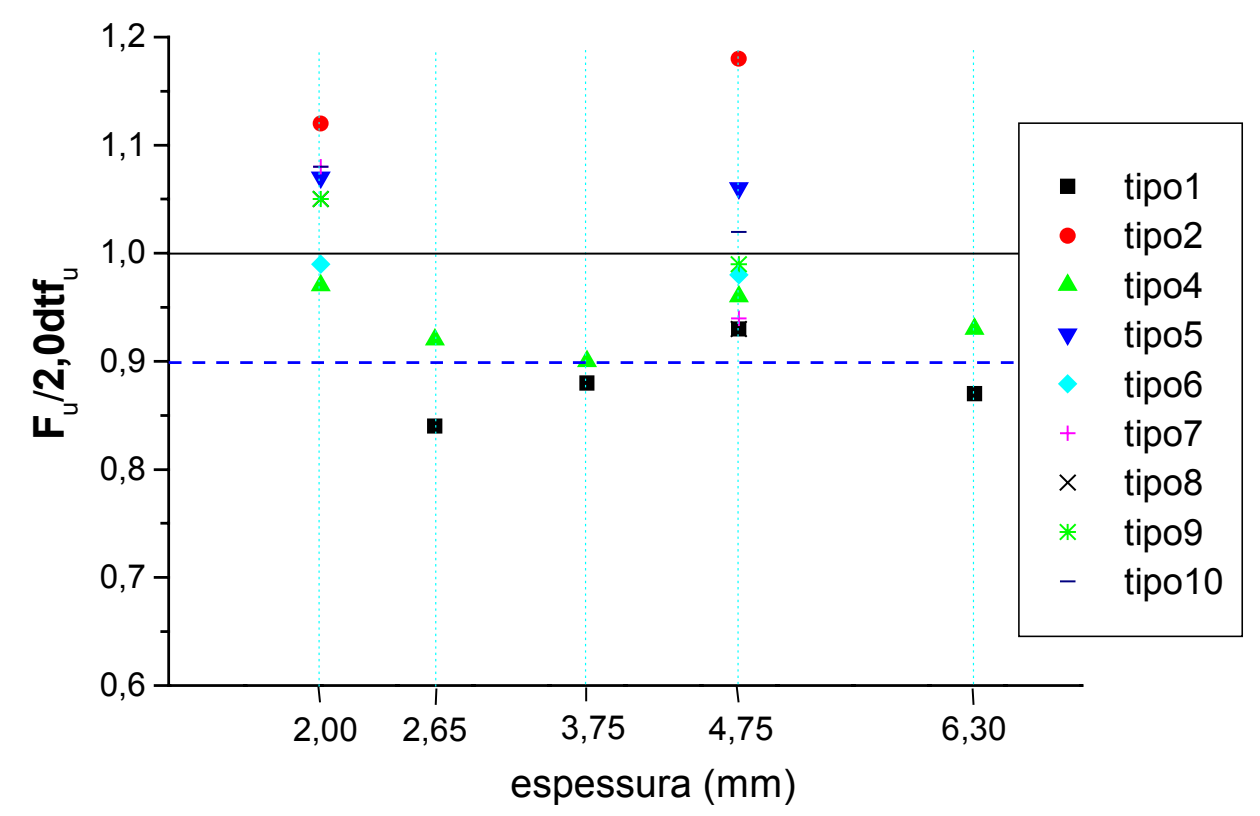

b) configurações com a utilização de arruelas

FIGURA 5.4 - Resultados experimentais para as chapas que apresentaram falha por esmagamento - série A-. 
No gráfico da figura 5.4b, onde estão representadas as ligações parafusadas em chapa fina da série A utilizando arruelas, comprova-se que a presença de arruelas (junto à cabeça do parafuso e a porca), melhorou o comportamento da ligação fazendo com que a flexão da borda juntamente com o puncionamento da chapa pela cabeça do parafuso e/ou pela porca fosse menos pronunciada. Nestes casos, tomando como parâmetro as ligações do tipo 1, 4 e 6, cujos espaçamentos entre furo e borda são iguais ao mínimo recomendado por norma, observa-se que para as duas primeiras tipologias a força última experimental ficou em média 10\% abaixo dos estimados teoricamente, enquanto que para a última, tipo 6, esta relação ficou em torno da unidade. Para os tipos de ligações restantes a força última experimental ficou em sua maioria acima da teórica.

- ligações da série B, C e D

Houve também ligações da série B que apresentaram como modo de falha o esmagamento da parede do furo e das séries C e D que apresentaram como modo de falha o esmagamento acentuado nas paredes dos furos seguido da ruptura da seção líquida cujos resultados também são apresentados neste item. Isso ocorreu nas configurações que apresentavam espaçamento entre furo e borda (tipos 2, 5 e 9) ou entre furos (tipo 10) maiores do que o mínimo recomendado em norma, o que veio a acarretar uma maior área de aço na seção transversal, dificultando a falha por ruptura da seção líquida estimada teoricamente.

Lembra-se que segundo hipótese de cálculo adotada, admite-se que todos os parafusos da ligação sofrem igual solicitação, isto é válido uma vez que a capacidade de deformação do material (ductilidade) propicia essa igual distribuição de forças, quando da plastificação das seções.

Os resultados experimentais destas ligações, representados pela força última obtida nos ensaios $\left(\boldsymbol{F}_{\mathbf{u}}\right)$ dividida pela força teórica resistente ao

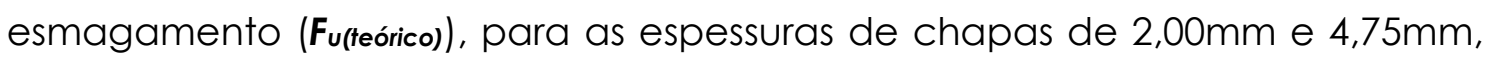
são apresentados na figura 5.5. Sendo a força teórica resistente, representada

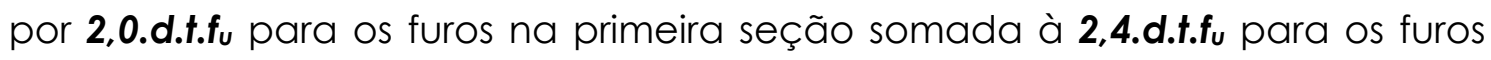


das seções subsequentes, sendo este último o valor limite apresentado pela NBR 14762:2001.

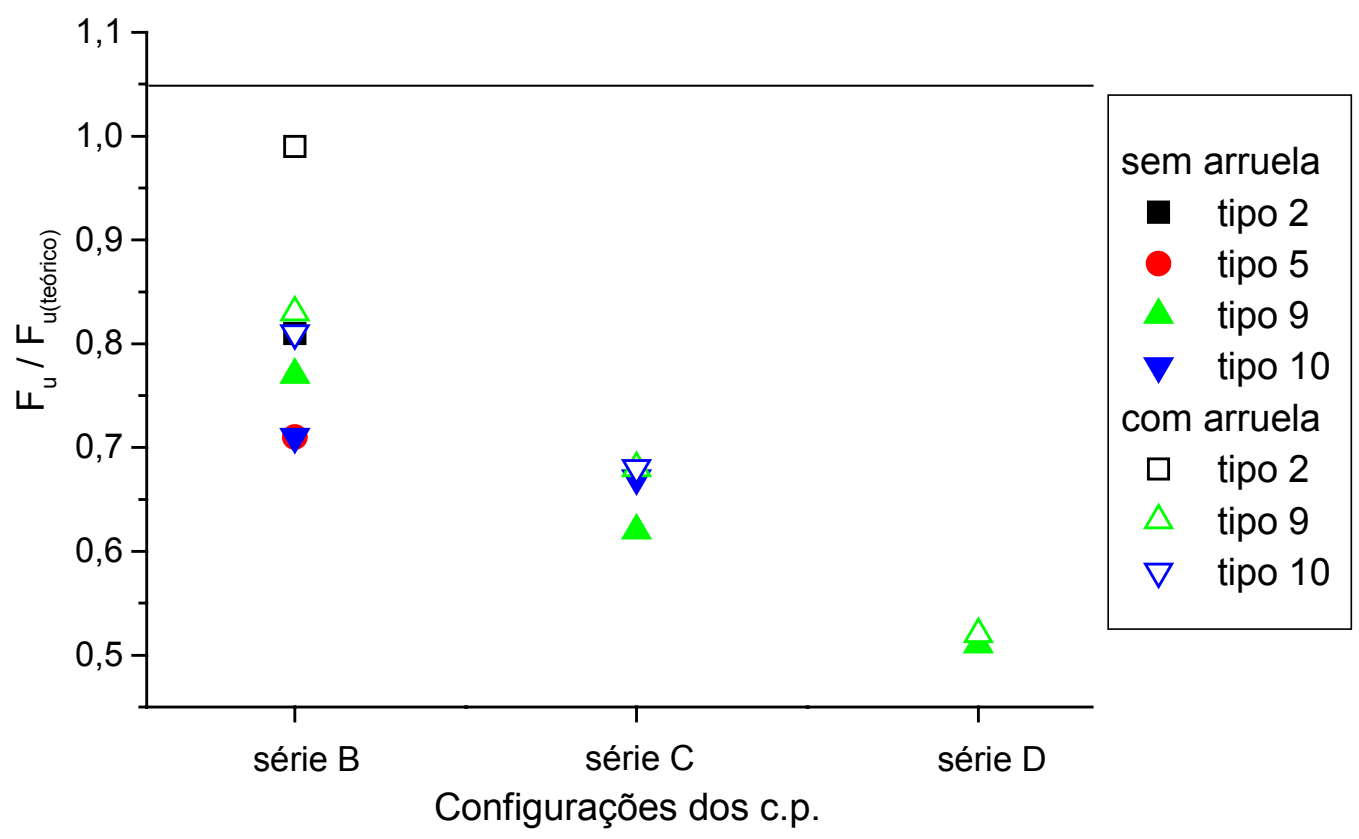

a) chapa de $2,00 \mathrm{~mm}$

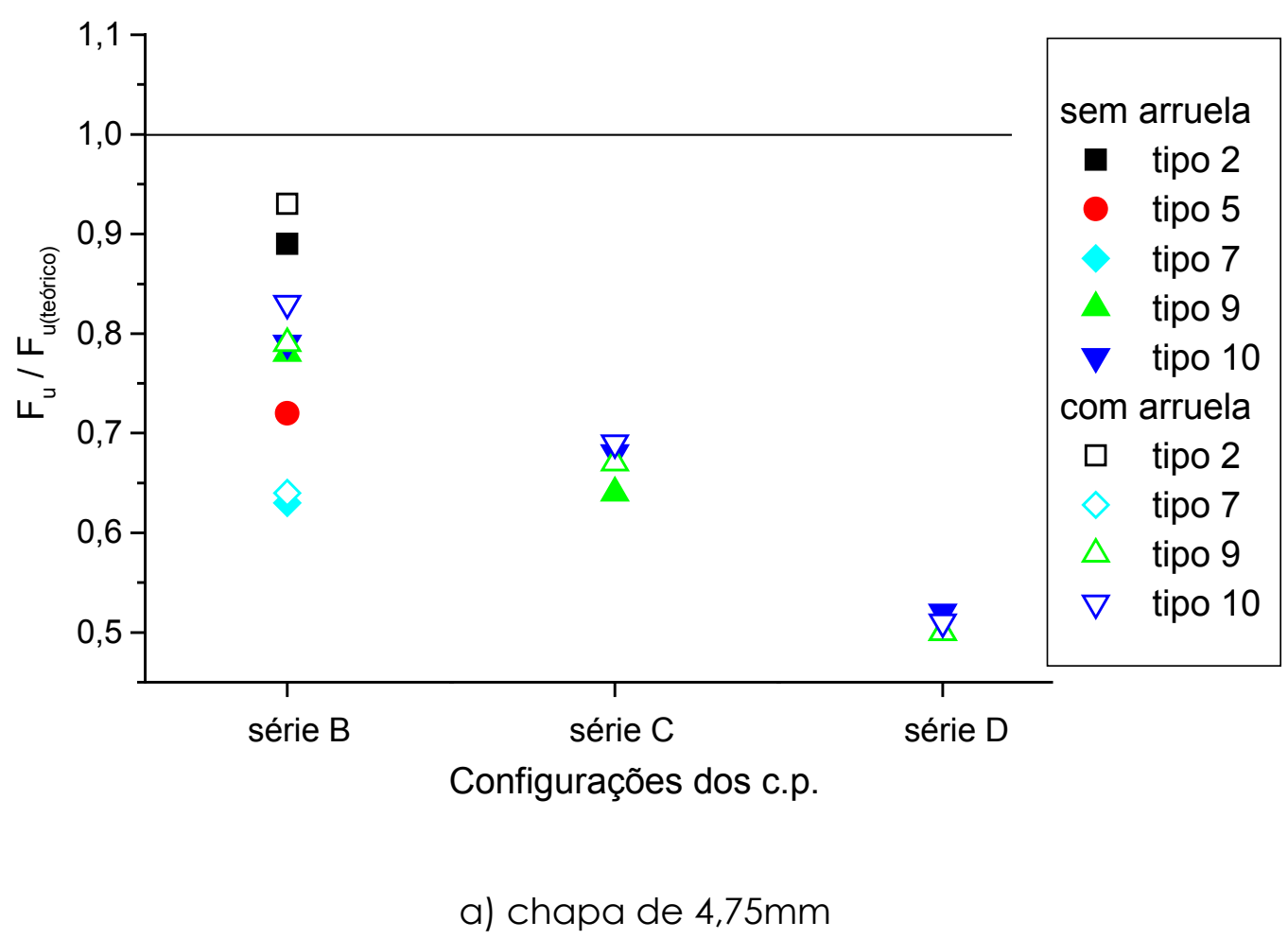

FIGURA 5.5 - Resultados experimentais para as chapas que apresentaram falha por esmagamento - série B, C e D. 
Nos gráficos anteriores, pode-se observar a diminuição da dispersão dos resultados a medida em que se aumenta o comprimento da ligação, ou seja, quando há o aumento nas seções de parafusos, o que comprova a diminuição da influência da flexão de borda na região da ligação com este aumento de seções de parafusos.

Nota-se também que a influência acarretada pela adoção ou não de arruelas, observada nos ensaios da série A, também diminui com o aumento do comprimento da ligação.

Observa-se também que as forças últimas obtidas nos ensaios ficaram sempre abaixo das calculadas teoricamente. Sendo para as ligações da série B estas foram em média $25 \%$ menores do que as teóricas para as chapas de 2,00mm e $17 \%$ menores para as chapas de $4,75 \mathrm{~mm}$, para as ligações da série $C$ e $D$ essa diferença ficou em torno de $33 \%$ e $49 \%$, respectivamente, tanto para as chapas de $2,00 \mathrm{~mm}$ quanto para as de $4,75 \mathrm{~mm}$.

Se estas forças últimas fossem comparadas com a força teórica resistente ao esmagamento tomada igual à 2,0.t.d... $\boldsymbol{f}_{\mathbf{u}}$ para todas as seções de parafusos, ou seja, se diminui-se o limite da força resistente para ocorrência do esmagamento, as diferenças entre a força última experimental e a força teórica resistente diminuiriam para $17 \%$ e $8 \%$ para série $B$, utilizando ou não arruelas, respectivamente, e $15 \%$ e $41 \%$ paras as séries C e D, respectivamente.

\section{Comentários}

Conclui-se, portanto, que as ligações parafusadas em chapa fina de aço, submetidas à uma força normal de tração, quando apresentam apenas uma seção de parafusos perpendicular à solicitação, sofrem grande influência da concentração de tensões junto aos seus furos e também da flexão da extremidade da chapa na região da ligação. Nestas o modo de falha predominante foi o esmagamento da parede do furo ou furos, com resultados experimentais de força última inferiores aos estimados teoricamente. Observou-se uma melhora no desempenho dessas ligações quando da utilização de arruelas junto à cabeça dos parafusos e da porca. 
Conforme aumentou-se as seções de parafusos houve uma diminuição da influencia da flexão da extremidade das chapas e também da utilização ou não de arruelas, no entanto não observou-se melhora nos resultados experimentais quando comparados com os teóricos.

Observa-se na figura 5.6 que o limite teórico para o espaçamento entre centro de furo e borda na direção da solicitação, utilizado pela NBR 14762:2001 como divisor entre da falha por rasgamento e o esmagamento da parede do furo é $\mathbf{2 , 4 d}$. No entanto, observou-se nos ensaios a ocorrência da falha por esmagamento para valor inferior a este $(\mathbf{2}, \mathbf{0 d})$. Mesmo quando havia duas seções de parafusos (série B) e o espaçamento entre furos era igual á 2,5d, o cálculo utilizando o valor limite igual à 2,0d se mostrou satisfatório. Para as configurações com três ou mais seções de parafusos, a área resistente para este modo de falha é elevada o que torna improvável a sua ocorrência, tanto que os poucos corpos-de-prova das séries $C$ e $D$ apresentados neste item tiveram a falha por esmagamento seguido de ruptura da seção líquida.

Com base nestes resultados sugere-se alterar a expressão para a avaliação da força nominal para a falha por esmagamento da parede do furo ou furos em ligações parafusadas em chapas finas de aço para:

$$
F_{R}=2,0 . d . t . f_{U}
$$

Diminuindo com isso o valor limite do espaçamento entre furo e borda (e) que separa a estimativa teórica de ocorrência da falha por rasgamento e esmagamento, que passaria de $2,4 d$ para $2 d$, conforme figura 5.6 .

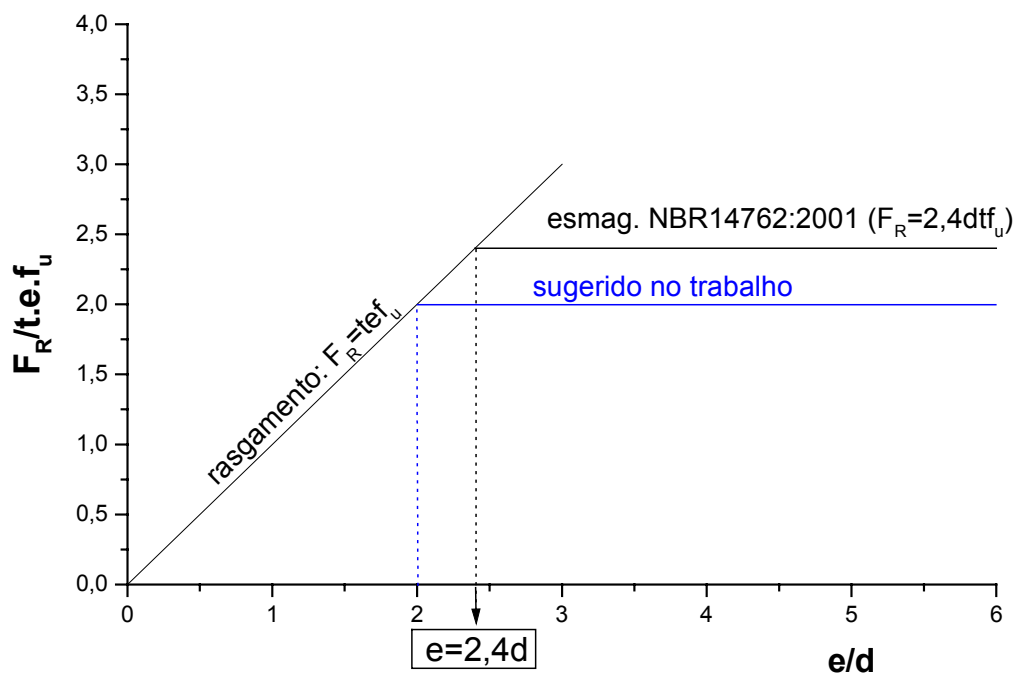

FIGURA 5.6 - Proposta de um novo valor para resistência ao esmagamento 
Ainda para o caso de ligações com apenas uma seção de parafusos perpendicular à solicitação, utilizando nenhuma ou apenas uma arruela junto a cabeça do parafuso ou a porca, aplicar-se-ía um coeficiente redutor de $20 \%$, ficando a expressão igual à:

$$
F_{R}=0,8\left(2,0 . d \cdot . f_{U}\right)
$$

Comparando estes valores com os adotados pelo AlSI:2001, para avaliação da força nominal resistente para falha por esmagamento de ligações parafusadas em chapas submetidas ao cisalhamento simples, apresentados a seguir:

$$
F_{R}=\text { 3, 0.d.t.f } f_{U}
$$

(para o caso da utilização de arruelas)

$$
F_{R}=2,22 . \text { d.t.f } f_{u}
$$

(para o caso da utilização de nenhuma ou apenas uma de arruela)

Observa-se que para o caso mais crítico, ou seja, quando da utilização de uma arruela ou da não utilização destas, uma vez que a norma brasileira não faz esta distinção, o valor sugerido anteriormente é $11 \%$ menor do que o apresentado pela norma americana, para as ligações com mais de uma seção de parafusos e 39\% menor quando utiliza-se apenas uma seção de parafusos.

Fazendo a mesma comparação mas agora para a avaliação da força de cálculo estas diferenças ficariam em 10,3\% maior e 12,0\% menor, respectivamente. 


\subsection{2 - Ruptura da seção líquida}

A falha por ruptura da seção líquida foi caracterizada pela estricção da seção seguida da fratura do material iniciada junto às bordas do furo ou furos, propagando-se em seguida para as extremidades da chapa, no caso de um furo por seção, ou propagando-se inicialmente para os furos adjacentes para em seguida iniciar a fratura em direção às extremidades das chapas, no caso de dois ou mais furos por seção (figura 5.7).

Na realidade, este modo de falha não ocorreu de maneira isolada, sendo que, nos casos onde houve a ruptura da seção líquida, pôde-se observar um avançado esmagamento na parede dos furos, tanto maior quanto menor a quantidade de seções com parafusos (maior concentração de tensões). Exceção é feita para as ligações do tipo 3, onde as distâncias transversais entre furos (2d) e entre furo e borda (d) eram inferiores às mínimas recomendadas pela norma brasileira ( $3 \boldsymbol{d}$ e $\mathbf{1 , 5} \mathbf{d}$, respectivamente), nesse caso, observou-se a falha prematura da ligação por ruptura da seção líquida.
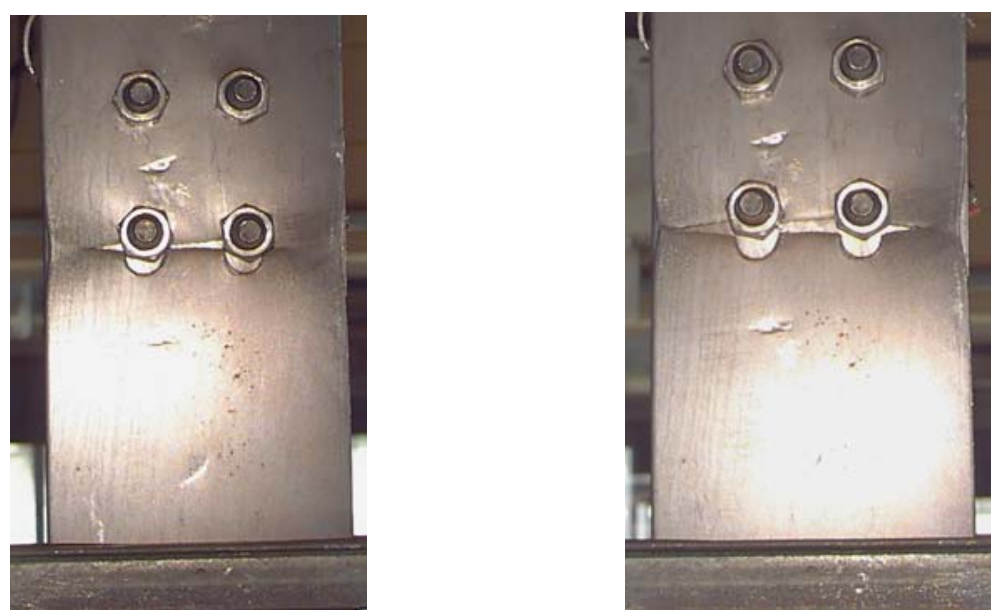

FIGURA 5.7 - Evolução da falha por ruptura da seção líquida 


\subsubsection{Avaliação do coeficiente $\boldsymbol{C}_{t}$}

Os valores experimentais do coeficiente redutor da área líquida $\boldsymbol{C}_{t}$, representados como sendo a relação da força última obtida nos ensaios pela força teórica resistente da seção líquida $\left(\boldsymbol{F}_{\mathbf{u}} / \boldsymbol{A}_{\boldsymbol{n}} \boldsymbol{f}_{\mathbf{u}}\right)$, juntamente com suas curvas teóricas apresentadas pela NBR 14762:2001, e as curvas do coeficiente redutor das tensões $(\boldsymbol{U})$ apresentadas pelo AISI:1996, quando da utilização de arruelas junto aos parafusos, são mostrados nos gráficos das figuras 5.8, 5.9, 5.10 e 5.11 para os corpos-de-prova que apresentaram como modo de falha a ruptura da seção líquida das séries $A, B, C$ e D, respectivamente. Nestes gráficos, o coeficiente $\boldsymbol{C}_{\boldsymbol{t}}$ varia em função da relação do diâmetro do parafuso com o espaçamento entre furos $(\mathbf{d} / \mathbf{g})$.

Vale ressaltar que as expressões da NBR 14762:2001 coincidem com a do AISI:1996 para o caso de ligações sem arruelas ou com apenas uma arruela. No entanto, observando os gráficos das figuras 5.9, 5.10 e 5.11 em cujos são apresentados os resultados experimentais dos corpos-de-prova das séries $B, C$ e $D$, com duas, três e quatro seções de parafusos perpendiculares à solicitação, respectivamente, pode-se concluir que a utilização de arruelas junto à cabeça do parafuso e a porca não ocasionou grandes variações de resultado na avaliação do coeficiente $\boldsymbol{C}_{\boldsymbol{t}}$. Para a série A (figura 5.8), os dados foram insuficientes para se fazer uma análise conclusiva a este respeito.

Numa visão geral, observa-se nestes gráficos que na maioria dos casos os valores experimentais de $\boldsymbol{C}_{\boldsymbol{t}}$ resultaram superiores aos valores teóricos obtidos segundo a NBR 14762:2001. Exceto para as ligações do tipo 3 (d/g = $0,5)$, principalmente quando estas não utilizavam arruelas, ficando os valores experimentais até15\% abaixo do valor teórico (fig 5.9 para as chapas de 2,0 mm). Entretanto é importante lembrar que nesse caso o gabarito de furação não respeitou as recomendações de norma, portanto estas configurações não são recomendadas para utilização na prática, o que foi confirmado nos ensaios. E também, que os valores experimentais de $\boldsymbol{C}_{\boldsymbol{t}}$ se aproximaram dos teórico a medida em que se aumentaram o número de seções de parafusos perpendicular à solicitação tendendo a um valor unitário.

Estes resultados são analisados a seguir para cada série ensaiada e sugestões para a calibração do coeficiente $\boldsymbol{C}_{\boldsymbol{t}}$ são apresentadas. 
Ligações da Série A (fig. 5.8);

Como mostrado anteriormente, para as ligações parafusadas em chapa fina com apenas uma seção de parafusos perpendicular a solicitação (série A) a falha por esmagamento foi predominante. Destas, além das ligações do tipo 3 comentadas anteriormente, apenas as ligações do tipo 2 para chapa de $2 \mathrm{~mm}$ e tipo 1 e 4 para chapa de $4,75 \mathrm{~mm}$, utilizando arruelas, tiveram a falha caracterizada pelo esmagamento da parede do furo lou furos), seguida ruptura da seção líquida.

Os resultados experimentais do coeficiente $\boldsymbol{C}_{\boldsymbol{t}}$ ficaram, respectivamente, (descartando as ligações tipo 3), $8 \%, 11 \%$ e 15\% acima da curva teórica apresentada pela NBR 14762:2001. Comparando estes valores com a curva do AISI:1996, prevendo a utilização de arruelas, eles ficaram 26\%, $8 \%$ e $4 \%$ abaixo desta, respectivamente.

Para comparar estes resultados com os valores de cálculo apresentados pela AISI:2001, temos que definir os valores de $d / s$, sendo $s$ a largura da chapa dividida pelo número de furos, assim para ligações tipo 1, 2, 3 e 4, os valores de $d / s$ são, respectivamente, $0,333,0,167,0,25$ e 0,167, o que conduzem a valores teóricos de $\boldsymbol{C}_{t}$ iguais à $\mathbf{0 , 6 2 5}$ para o caso da ligação tipo 3 sem arruela, e 1,0, 0,6, 0,85 e 0,6 para os casos de ligações 1, 2, 3 e 4 com arruelas, respectivamente.

Deste modo os resultados experimentais do coeficiente $\boldsymbol{C}_{\boldsymbol{t}}$ ficaram, em relação a curva teórica apresentada pelo AISI:2001, 7\% abaixo para a ligação tipo 1, 25\% abaixo para a ligação do tipo 2,32\% e 11,6\% acima para as

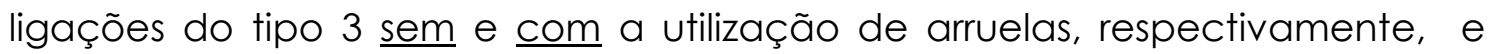
$37,5 \%$ acima para a ligação tipo 4 .

Apesar do número reduzido de corpos-de-prova a apresentar este modo de falha para esta série, observa-se, na análise dos resultados, uma melhor concordância dos valores experimentais de $C_{\dagger}$ com os teóricos apresentados pela NBR14762:2001, portanto sugere-se que estes sejam mantidos, ou seja: 
- para todos os parafusos da ligação contidos em uma única seção transversal:

$$
C_{t}=2,5(d / g) \leq 1,0
$$

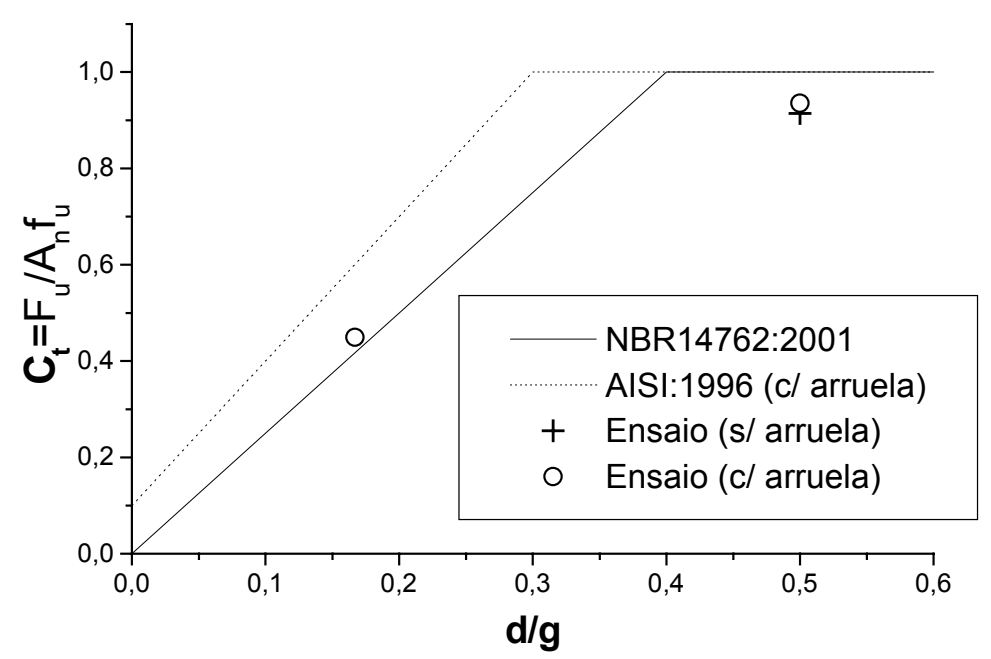

chapa $2,00 \mathrm{~mm}$

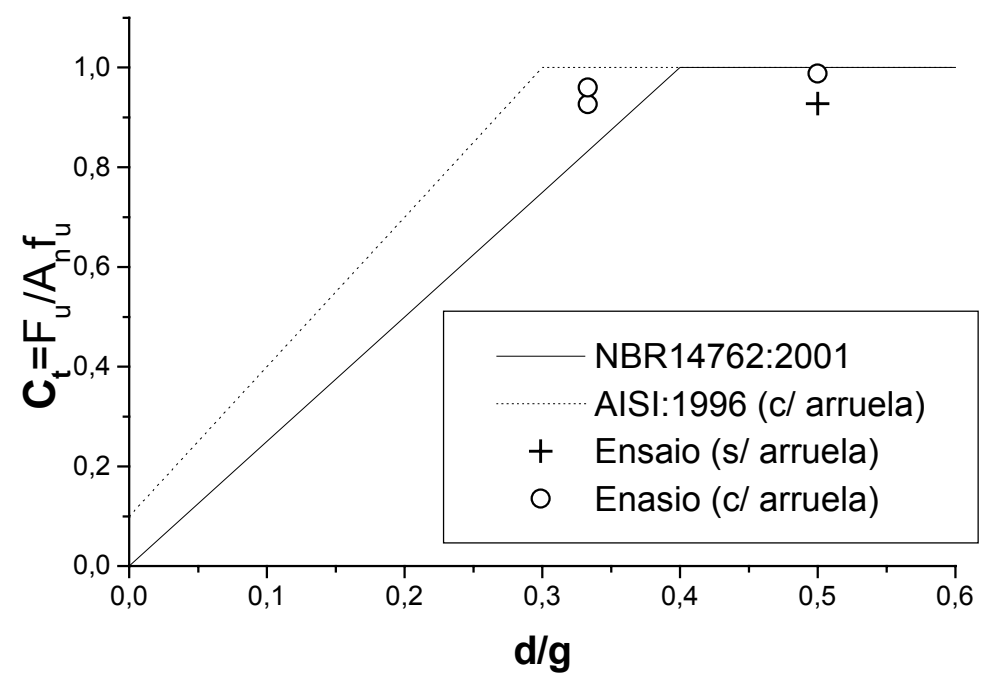

chapa $4,75 \mathrm{~mm}$

FIGURA 5.8 - Resultados experimentais para os ensaios da Série A (c.p. que apresentaram ruptura da seção líquida) 
Ligações da Série B (fig. 5.9);

Nesta série as ligações cuja relação $\mathbf{d} / \mathbf{g}$ estavam acima de $\mathbf{0 . 2 5}$ apresentaram em média valores experimentais de $C_{t}$ bem próximos a unidade, exceto a ligação tipo $3(\boldsymbol{d} / \mathbf{g}=\mathbf{0 , 5})$ para chapa de $2,0 \mathrm{~mm}$ sem arruela que ficou $10,6 \%$ abaixo e as ligações com $\mathbf{d} / \mathbf{g}$ igual a $\mathbf{0 , 3 3 3}$ para chapa de 2,0 $\mathrm{mm}$ sem arruela que ficaram na média $5 \%$ abaixo.

Para relações $\mathbf{d} / \mathbf{g}$ abaixo de $\mathbf{0 , 2 5}$, notou-se uma tendência de queda no valor experimental de $\boldsymbol{C}_{t}$, estando este, em sua maioria, acima da curva teórica apresentada pelo AISI:1996 quando da não utilização de arruelas, exceto para as ligações com $\mathbf{d} / \mathbf{g}$ igual a $\mathbf{0 , 1 1 1}$ para chapa de 2,0mm sem arruela cuja média dos valores experimentais de $\boldsymbol{C}_{t}$ ficou $8,3 \%$ abaixo do apresentado pelo AISI:1996 e 2,8\% acima do apresentado pela NBR 14762:2001.

Portanto, de acordo com os resultados analisados acima e mais os apresentados nos gráficos da figura 5.9, sugere-se a manutenção da expressão apresentada pela NBR14762:2001, para a avaliação do coeficiente $\boldsymbol{C}_{t}$, uma vez que esta não faz distinção quanto da utilização de arruelas ou não junto ao parafuso, ou seja:

- para dois parafusos na direção da solicitação, alinhados ou em zig-zag:

$$
C_{t}=0,5+1,25(d / g) \leq 1,0
$$

Observa-se que para as ligações tipo 5 (com d/g igual à 0,167), o valor experimental de $\boldsymbol{C}_{\boldsymbol{t}}$ foi de $\mathbf{0 , 9 7}$ e $\mathbf{0 , 9 5}$ para as chapas de $2,00 \mathrm{~mm}$ e $4,75 \mathrm{~mm}$, respectivamente, utilizando arruelas, enquanto que para as ligações tipo 9 e 10 (com $\mathbf{d} / \mathbf{g}$ igual à $\mathbf{0 , 1 1} \mathbf{1}$ ), os valores experimentais de $\boldsymbol{C}_{\boldsymbol{t}}$ ficaram em média iguais à $\mathbf{0 , 6 8}$ e $\mathbf{0 , 7 0}$, para as chapas de $2,00 \mathrm{~mm}$ e $4,75 \mathrm{~mm}$, respectivamente.

Estes resultados são suficientes para invalidar a nova formulação adotada pelo AISI:2001, onde considera para essa situação a adoção de um valor unitário para $\boldsymbol{C}_{\boldsymbol{t}}$, agora não mais dependente da relação $\mathbf{d} / \mathbf{s}$, conforme se pode observar nos gráficos da figura 5.9 . 


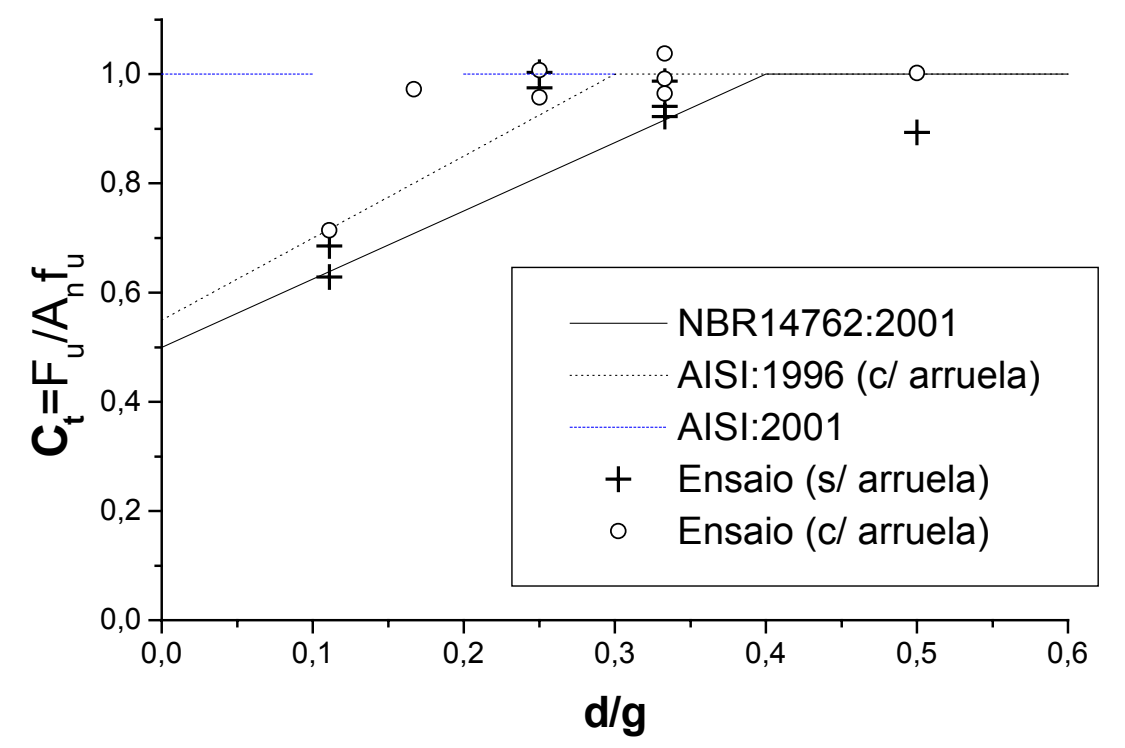

chapa $2,00 \mathrm{~mm}$

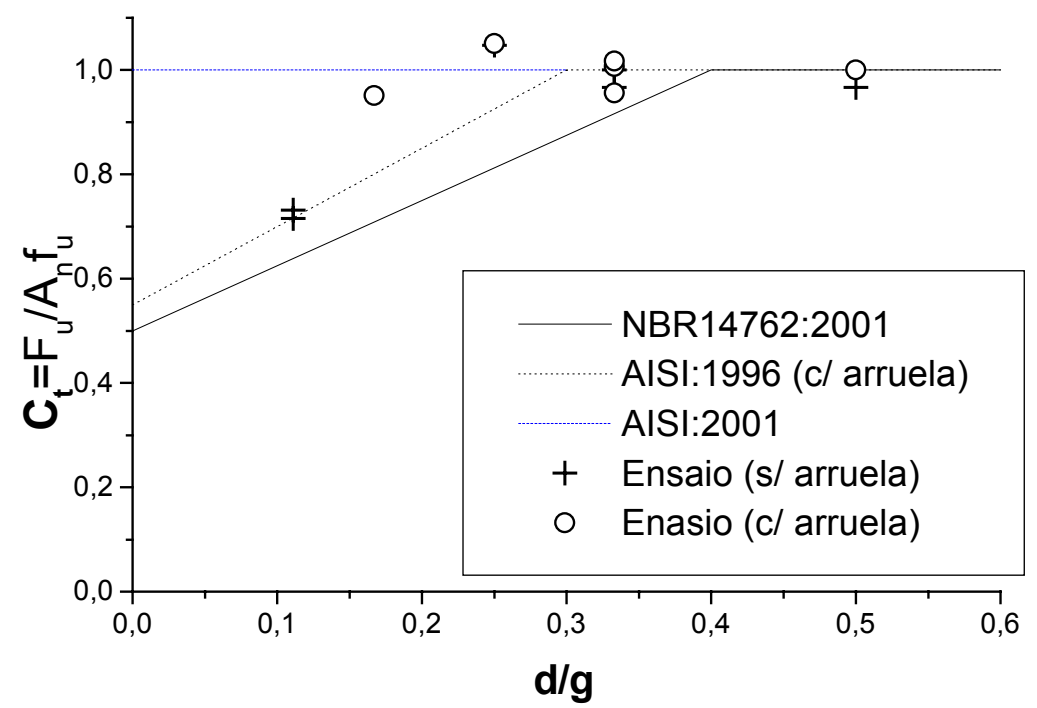

chapa $4,75 \mathrm{~mm}$

FIGURA 5.9 - Resultados experimentais para os ensaios da Série B (c.p. que apresentaram ruptura da seção líquida) 
Para uma visualização global destes resultados, estes foram agrupados no gráfico da figura 5.10, juntamente com as curvas teóricas apresentadas pela NBR14762:2001 e pelo AISI:1996 quando da não utilização de arruelas.

Realizada análise de dispersão, são apresentadas na tabela 5.1 , os valores da média, desvio padrão e coeficiente de variação desses resultados

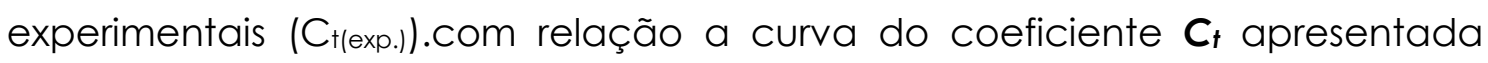
pela NBR 14762:2001 (C+(NBR)).

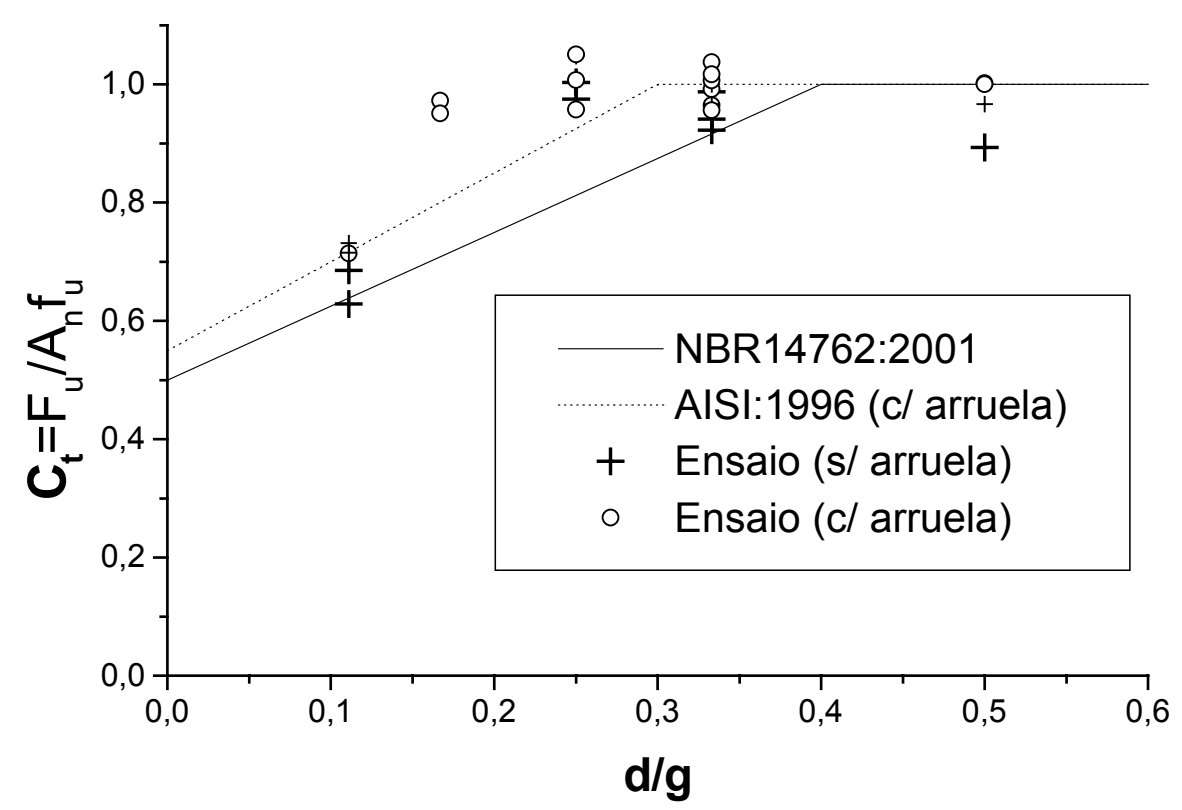

FIGURA 5.10 - Resultados experimentais globais para os ensaios da Série B

TABELA 5.1 - Análise de dispersão para dados da séria B

\begin{tabular}{|c|c|c|}
\hline & $\frac{C_{t(\text { exp. })}}{C_{t(\text { NBR })}}$ & $\frac{C_{t(\text { exp. })}}{C_{t(\text { prop. })}}$ \\
\hline média & 1,138 & $\begin{array}{c}-- \\
\end{array}$ \\
\hline desvio padrão & 0,102617 & --- \\
\hline coeficiente de variação & $9 \%$ & --- \\
\hline
\end{tabular}


Ligações da Série C (fig 5.11);

Nesta série a variação dos valores experimentais de $C_{t}$ foram similares a da série $B$, ou seja, para valores de $\mathbf{d} / \mathbf{g}$ acima de $\mathbf{0 , 2 5}$, estes ficaram em média próximos à unidade, quando abaixo de 0,25 houve uma tendência de queda destes valores experimentais. Ou seja, para as ligações que apresentavam $\mathbf{d} / \mathbf{g}$ igual à 0,167 os valores experimentais de $\boldsymbol{C}_{\boldsymbol{t}}$ ficaram em média iguais à $\mathbf{0 , 9 3} \mathrm{e}$ 0,95, para as chapas de $2,00 \mathrm{~mm}$ e $4,75 \mathrm{~mm}$, respectivamente, enquanto que para as ligações com $\mathbf{d} / \mathbf{g}$ igual à $\mathbf{0 , 1 1 1}$, os valores experimentais de $\boldsymbol{C}_{\boldsymbol{t}}$ ficaram em média iguais à $\mathbf{0 , 9 0}$ e $\mathbf{0 , 9 5}$, para as chapas de 2,00 mm e 4,75mm, respectivamente. Valores estes acima das curvas de $\boldsymbol{C}_{\boldsymbol{t}}$ apresentadas pela NBR14762:2001 e pelo AISI:1996 utilizando arruelas, mas ainda estando abaixo da unidade, contrariando mais uma vez a nova formulação de AISI:2001.

Deste modo sugere-se um ajuste na curva de $\boldsymbol{C}_{t}$, partindo-se de $\mathbf{d} / \mathbf{g}$ igual a zero adota-se para $\boldsymbol{C}_{t} \circ$ valor 0,7 , esta variaria linearmente até o ponto de $\mathbf{d} / \mathbf{g}$ igual a 0,25 a partir do qual $\boldsymbol{C}_{\boldsymbol{t}}$ passaria a ter valor constante igual a unidade. Esta nova expressão seria portanto:

- para três parafusos na direção da solicitação, alinhados ou em zig-zag:

$$
C_{t}=0,7+1,2(d / g) \leq 1,0
$$




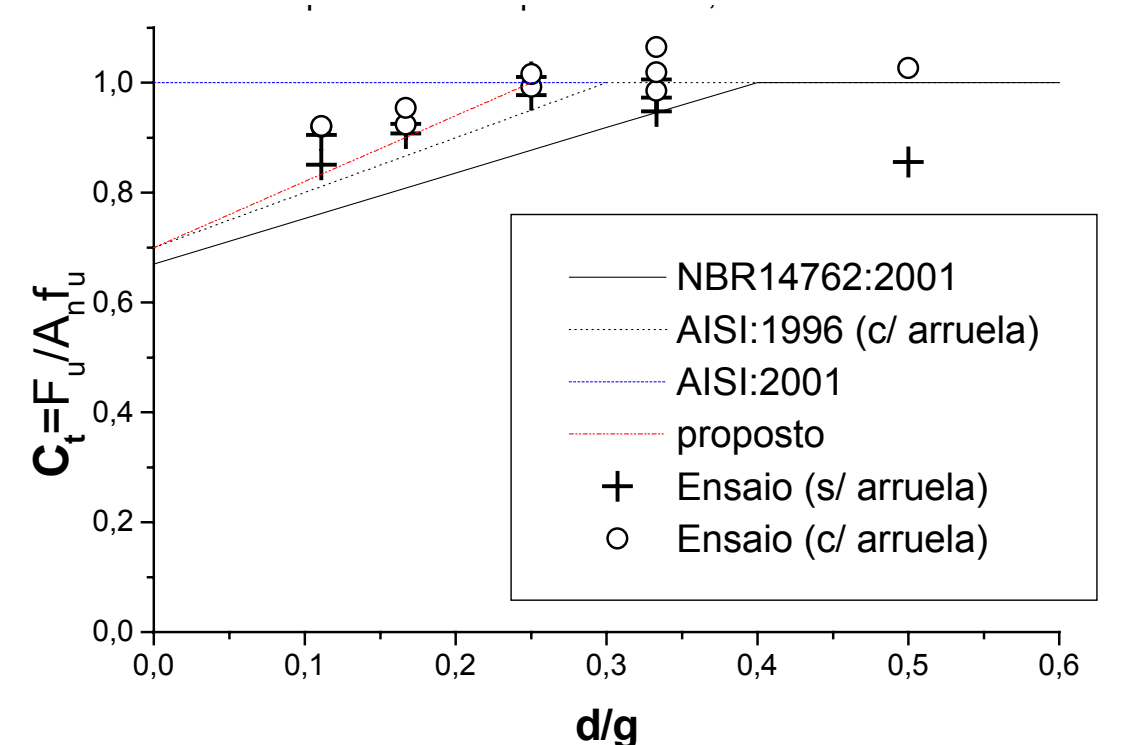

chapa $2,00 \mathrm{~mm}$

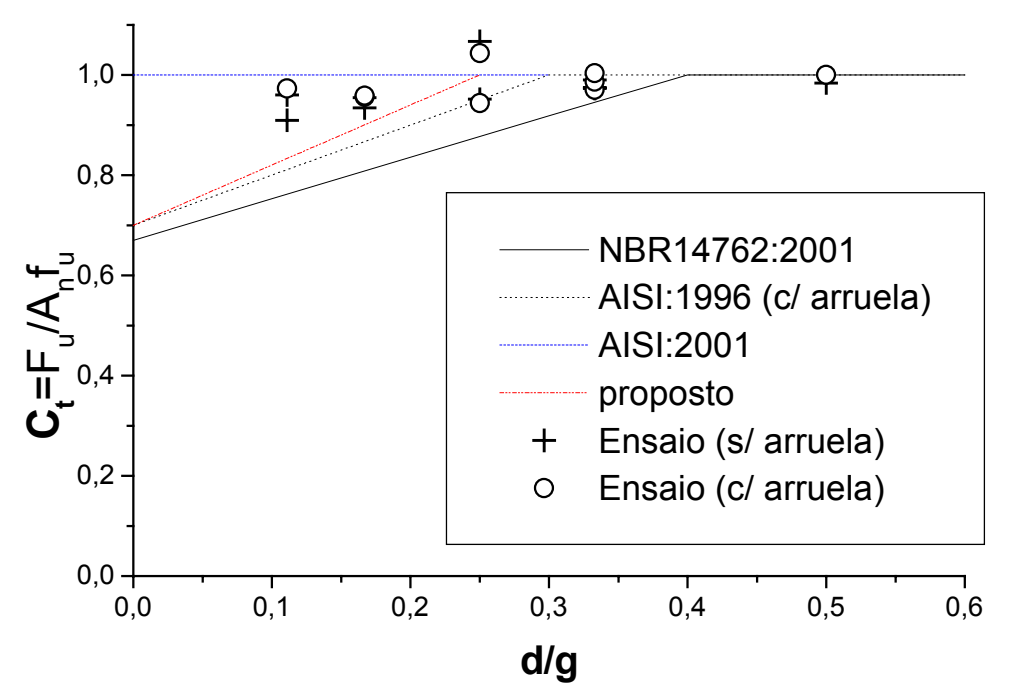

chapa $4,75 \mathrm{~mm}$

FIGURA 5.11 - Resultados experimentais para os ensaios da Série C (c.p. que apresentaram ruptura da seção líquida) 
Para uma visualização global destes resultados, estes foram agrupados no gráfico da figura 5.12, juntamente com as curvas teóricas apresentadas pela NBR14762:2001 e pelo AISI:1996 quando da não utilização de arruelas e a curva proposta neste trabalho.

Realizada análise de dispersão, são apresentadas na tabela 5.2 , os valores da média, desvio padrão e coeficiente de variação desses resultados experimentais $\left(C_{t(\text { exp.) }}\right)$ com relação a curva do coeficiente $C_{t}$ apresentada pela NBR14762:2001 (C+(NBR))e a curva proposta (C+(prop.)).

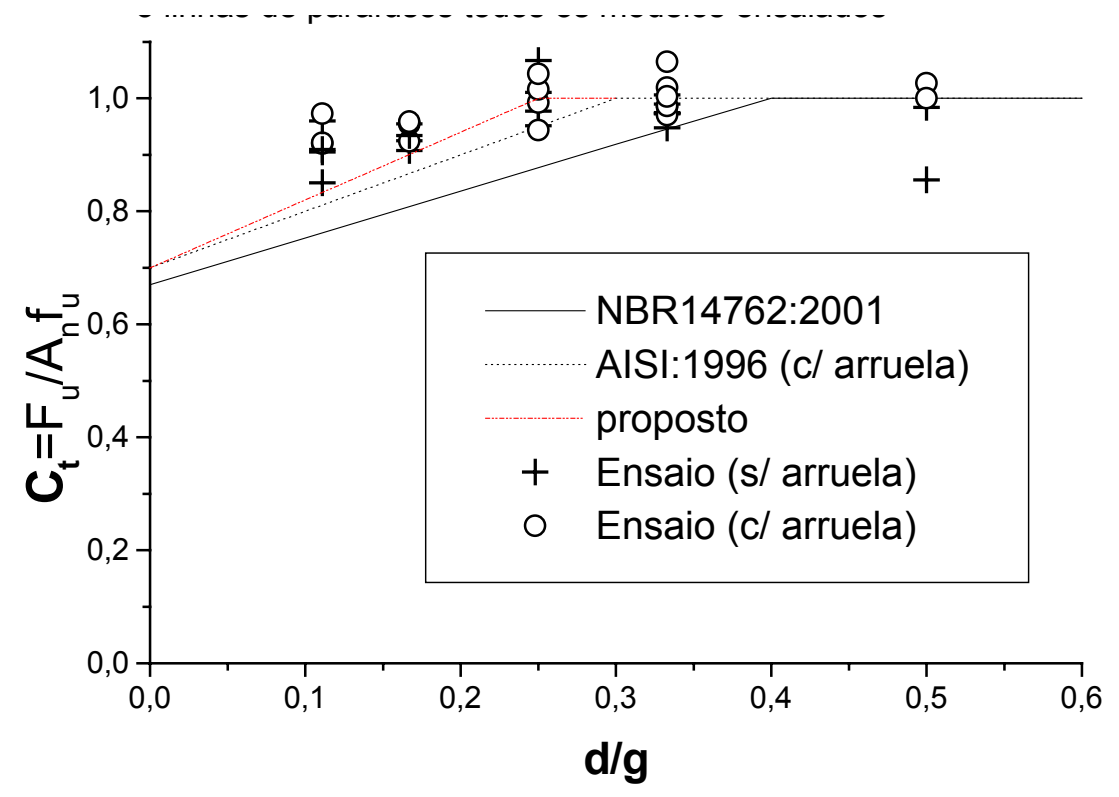

FIGURA 5.12 - Resultados experimentais globais para os ensaios da Série C

TABELA 5.2 - Análise de dispersão para dados da séria C

\begin{tabular}{|c|c|c|}
\hline & $\frac{\mathrm{C}_{\mathrm{t}(\text { exp. })}}{\mathrm{C}_{\mathrm{t}(\mathrm{NBR})}}$ & $\frac{\mathrm{C}_{\mathrm{t}(\text { exp. })}}{\mathrm{C}_{\mathrm{t}(\text { prop. })}}$ \\
\hline média & (1,127 & 1,028 \\
\hline desvio padrão & 0,071666 & 0,054652 \\
\hline coeficiente de variação & $6,4 \%$ & $5,3 \%$ \\
\hline
\end{tabular}


> Ligações da Série D (fig 5.13);

Conforme observado nos gráficos das figuras 5.10 , 5.12 e 5.14, realmente há uma tendência de convergência para um valor unitário do coeficiente $\boldsymbol{C}_{\boldsymbol{t}}$, conforme aumento-se o número de seções de parafusos perpendicular à solicitação. No entanto, observa-se na figura 5.13 que a partir de quatro seções de parafusos a adoção deste valor para $\boldsymbol{C}_{t}$, ainda não é a melhor solução.

Pois conforme resultados experimentais, a maior dispersão do valor médio de $\boldsymbol{C}_{\boldsymbol{t}}$ nesta série, com relação a unidade, ocorreu para as ligações com $\mathbf{d} / \mathbf{g}=\mathbf{0}, \mathbf{1 6 7}$, apresentando valores experimentais médios de $\boldsymbol{C}_{\boldsymbol{t}}$ iguais a 0,92 e $\mathbf{0 , 9 5}$, para as chapas de $2,0 \mathrm{~mm}$ e $4,75 \mathrm{~mm}$, respectivamente, estando estes $7,7 \%$ e $11,2 \%$ acima da curva teórica de $\boldsymbol{C}_{t}$ apresentada pela NBR1 4762:2001 e 1,5\% abaixo e 1,8\% acima da curva proposta neste trabalho, respectivamente, como pode ser observado nos gráficos da figura 5.13.

Para os outros resultados do coeficiente $\boldsymbol{C}_{t}$, fazendo-se a média das configurações de ligações que apresentavam a mesma relação $\mathbf{d} / \mathbf{g}$, observase na figura 5.13, que estes tiveram uma boa concordância com a curva proposta, quando não ficaram acima desta.

Deste modo, sugere-se como nova expressão para avaliação do coeficiente $\boldsymbol{C}_{\boldsymbol{t}}$, a seguinte:

- para quatro ou mais parafusos na direção da solicitação, alinhados ou em zig-zag:

$$
C_{t}=0,8+0,8(d / g) \leq 1,0
$$




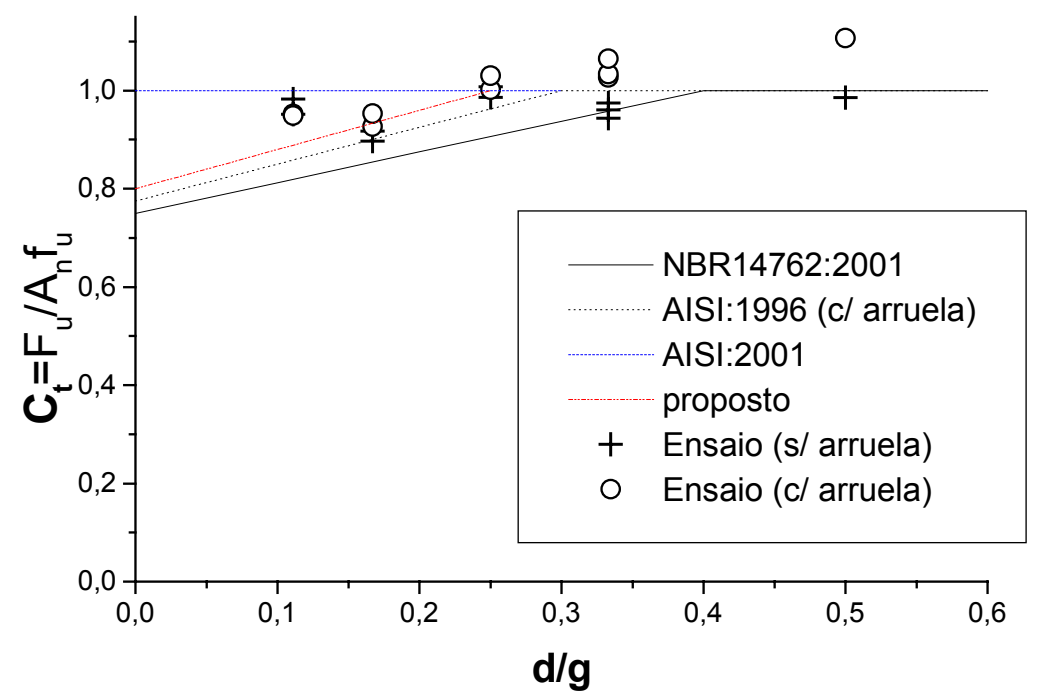

chapa $2,00 \mathrm{~mm}$

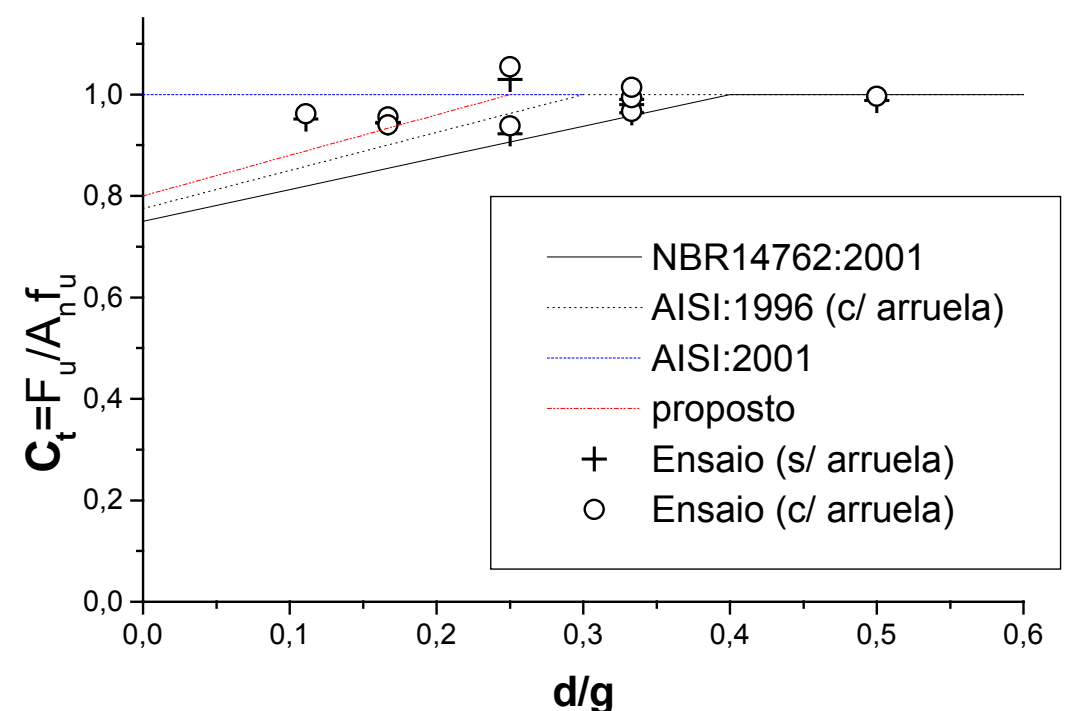

chapa $4,75 \mathrm{~mm}$

FIGURA 5.13 - Resultados experimentais para os ensaios da Série D (c.p. que apresentaram ruptura da seção líquida) 
Para uma visualização global destes resultados, estes foram agrupados no gráfico da figura 5.14, juntamente com as curvas teóricas apresentadas pela NBR14762:2001 e pelo AISI:1996 quando da não utilização de arruelas e a curva proposta neste trabalho.

Realizada análise de dispersão, são apresentadas na tabela 5.3 , os valores da média, desvio padrão e coeficiente de variação desses resultados experimentais $\left(C_{\dagger(\exp .)}\right)$ com relação a curva do coeficiente $\boldsymbol{C}_{\boldsymbol{t}}$ apresentada pela NBR14762:2001 (C+(NBR))e a curva proposta (C+(prop.)).

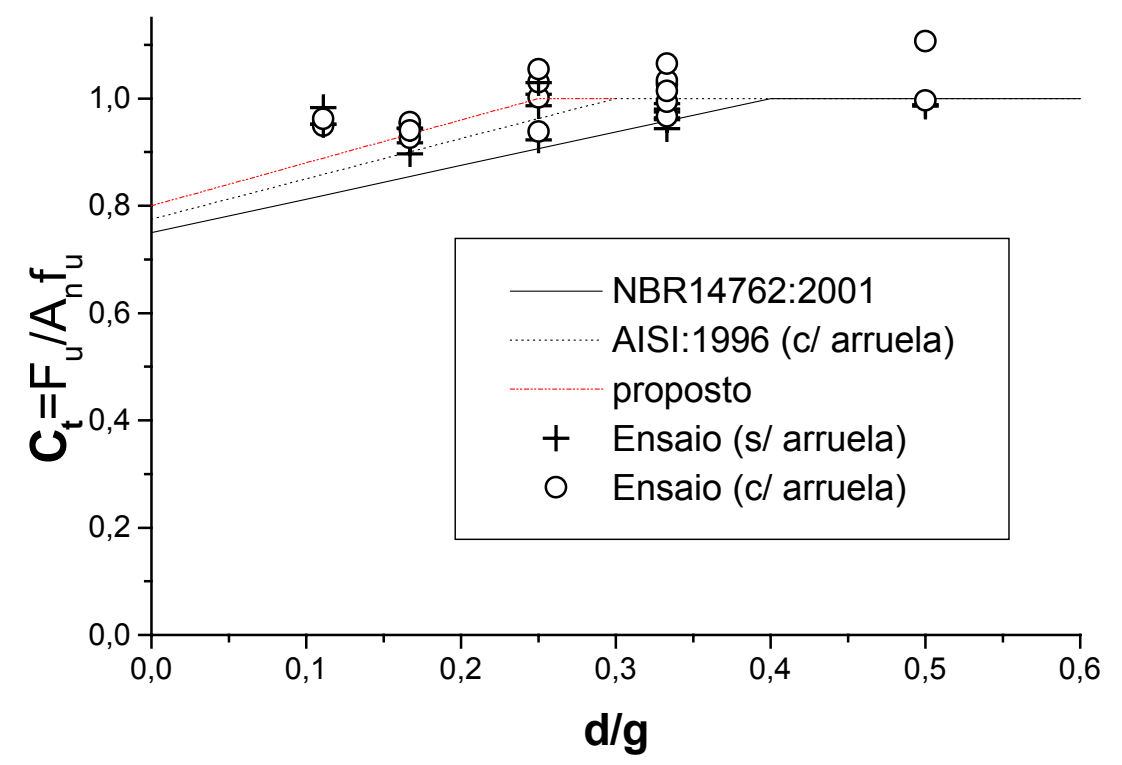

FIGURA 5.14 - Resultados experimentais globais para os ensaios da Série D

TABELA 5.3 - Análise de dispersão para dados da séria D

\begin{tabular}{|c|c|c|}
\hline & $\frac{C_{t(\text { exp. })}}{C_{t(\text { NBR })}}$ & $\frac{C_{t(\text { exp. })}}{C_{t(\text { prop. })}}$ \\
\hline média & 1,086 & 1,009 \\
\hline desvio padrão & 0,058138 & 0,044165 \\
\hline coeficiente de variação & $5,4 \%$ & $4,4 \%$ \\
\hline
\end{tabular}




\subsubsection{Determinação do parâmetro $\mathbf{g}$}

As expressões do coeficiente redutor da área líquida $\left(\boldsymbol{C}_{t}\right)$ são função apenas da relação $\mathbf{d} / \mathbf{g}$, que avalia a "intensidade da concentração de tensão". Portanto o valor adequado de $\boldsymbol{C}_{\boldsymbol{t}}$ depende de uma avaliação racional da grandeza $\mathbf{g}$, o que implica cuidados ao se estabelecer esse valor.

Nas ligações com mais de uma linha de parafusos, projetadas de maneira que os parafusos sejam dispostos uniformemente na região da ligação, o que é desejável tendo em vista amenizar a concentração de tensão, o espaçamento entre os furos assume valor constante e é da ordem do dobro do espaçamento entre furo e borda (caso das ligações tipo 4 e 6), portanto g será o próprio espaçamento entre parafusos, conforme a definição da norma brasileira.

Nos casos em que o espaçamento entre furos $\mathbf{g}$, difere da soma dos espaçamentos entre furo e borda $\left(\mathbf{e}_{1}+\mathbf{e}_{2}\right)$, tomados todos na direção perpendicular à solicitação, caso das ligações tipo 5, 8, 9 e10, a NBR 14762:2001 prevê que o valor de $\boldsymbol{C}_{t}$ deva ser calculado adotando-se o

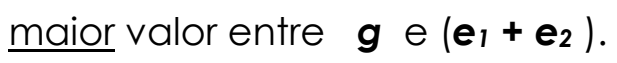

O EUROCODE 3 part 1.3:1996 prevê o contrário para esta situação, ou seja, para o cálculo do coeficiente $\boldsymbol{C}_{\boldsymbol{t}}$ adota-se o menor valor entre $\mathbf{g}$ e $\left(\mathbf{e}_{1}+\right.$ e2).

Para avaliar qual dos procedimentos de obtenção do parâmetro $\mathbf{g}$ apresentados anteriormente para as ligações tipo 5, 8, 9 e 10 leva a resultados mais satisfatórios do coeficiente $\boldsymbol{C}_{\boldsymbol{t}}$, comparou-se, nos gráficos da figura 5.15 , a força última obtida em ensaio $\left(\boldsymbol{F}_{\mathrm{u}}\right)$ com a força resistente teórica apresentada pela NBR 14762:2001 $\left(\boldsymbol{F}_{\boldsymbol{R}}=\boldsymbol{C}_{\boldsymbol{t}} \boldsymbol{A}_{\boldsymbol{n}} \boldsymbol{f}_{\boldsymbol{u}}\right)$, tomando para o cálculo de $\boldsymbol{C}_{\boldsymbol{t}}$ valores de $\boldsymbol{g}$ avaliados segundo procedimento da NBR14762:2001 (NBR) e o EUROCODE 3 part 1.3:1996 (EUR). 


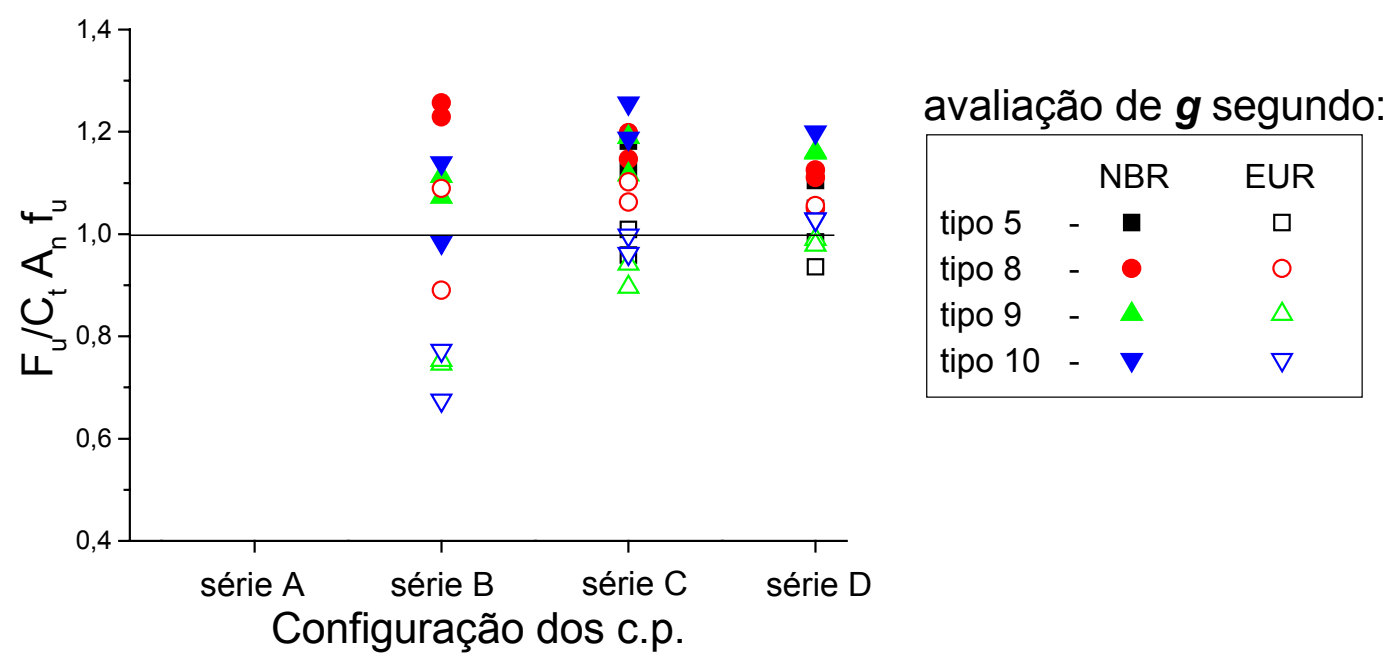

FIGURA 5.15 - Avaliação do parâmetro g para ligações parafusadas em chapas finas de aço

Com o aumento das seções de parafusos na ligação, diminui-se a Influência do coeficiente $\boldsymbol{C}_{\boldsymbol{t}}$, ou seja, este tende a um valor unitário conforme conclusão do item 5.2.2.1, assim pode-se observar a tendência dos valores de força última experimentais se igualarem com os teóricos, independente da forma de avaliação de $\mathbf{g}$.

Analisando as ligações da série B (duas seções de parafusos), observase que o procedimento adotado pela NBR14762:2001 para a determinação dos valores de $\mathbf{g}$, mostrou-se mais satisfatório para avaliação o coeficiente $\boldsymbol{C}_{\boldsymbol{t}}$, principalmente para as ligações tipo 9 e 10. Para as ligações do tipo 8, este procedimento conduziu a resultados bem acima dos teóricos, mas estando a favor da segurança. 


\subsubsection{Ligações submetidas ao corte duplo}

O ensaio a corte duplo consistiu basicamente no arranjo das chapas ligadas pelos parafusos, de modo que estes ficassem submetidos ao corte duplo. Deste modo, e uma vez que as chapas do conjunto ensaiado tinham a mesma espessura, o caso analisado foi o da chapa interna submetida a uma força centrada de tração.

Os 24 corpos-de-prova ensaiados representavam as configurações cujos espaçamentos entre furos e entre furo e borda na direção perpendicular à solicitação eram iguais aos mínimos recomendados por norma, tipos 1, 4 e 6, apresentando uma, duas e quatro linhas de parafusos por seção, respectivamente, e relação $\mathbf{d} / \mathbf{g}$ igual a 0,333. Estes foram confeccionados em duplicata, com material de 2,0mm de espessura, sendo o primeiro da dupla ensaiado sem a utilização de arruelas enquanto para o segundo utilizou-se arruelas junto a cabeça do parafuso e a porca.

O modo de falha observado em todos corpos-de-prova foi a ruptura da seção líquida efetiva e os resultados do coeficiente $\boldsymbol{C}_{\boldsymbol{t}}$ para os casos analisados são apresentados nos gráficos da figura 5.16.

Nestes observa-se que os corpos-de-prova das séries $B, C$ e D apresentaram valores experimentais de $\boldsymbol{C}_{\boldsymbol{t}}$ próximos a unidade, igual ao ocorrido nos ensaio à corte simples. Mas agora devido a força ter sido aplicada de forma centrada e a chapa interna se encontrar contida pelas externas, não criando desta forma condições para que houve-se a flexão da extremidade ligada, também os corpos-de-prova da série A apresentaram valores experimentais de $\boldsymbol{C}_{\boldsymbol{t}}$ próximos a unidade, com exceção da tipo 6 , e não houve influência significativa da não utilização das arruelas. 


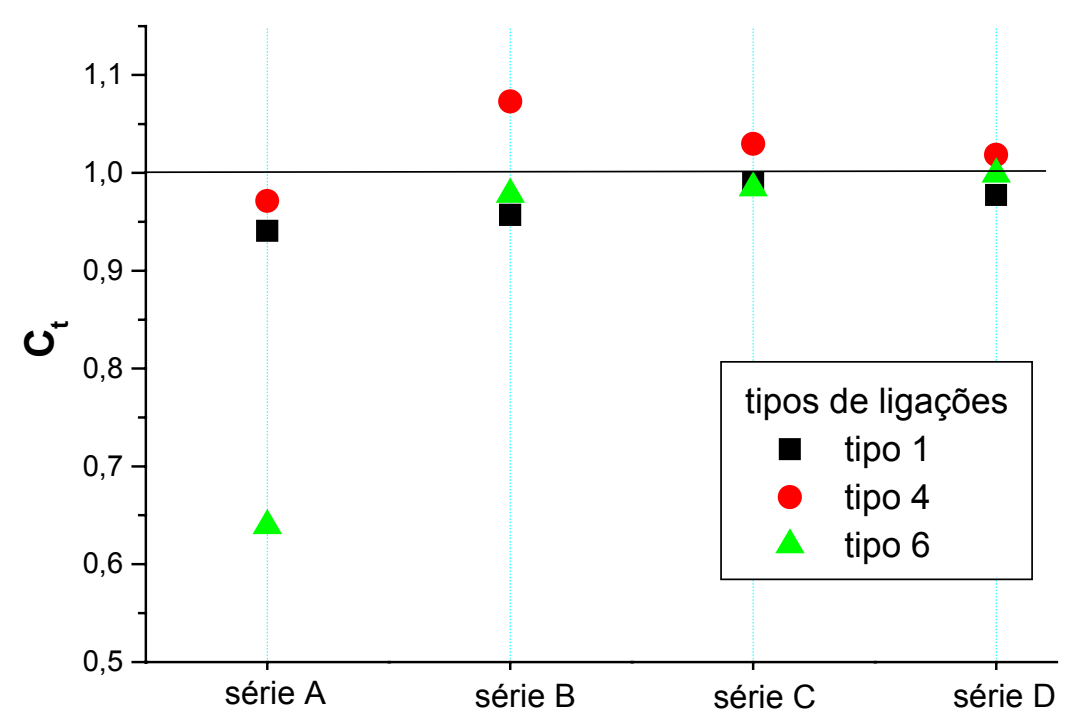

a) sem a utilização de arruelas

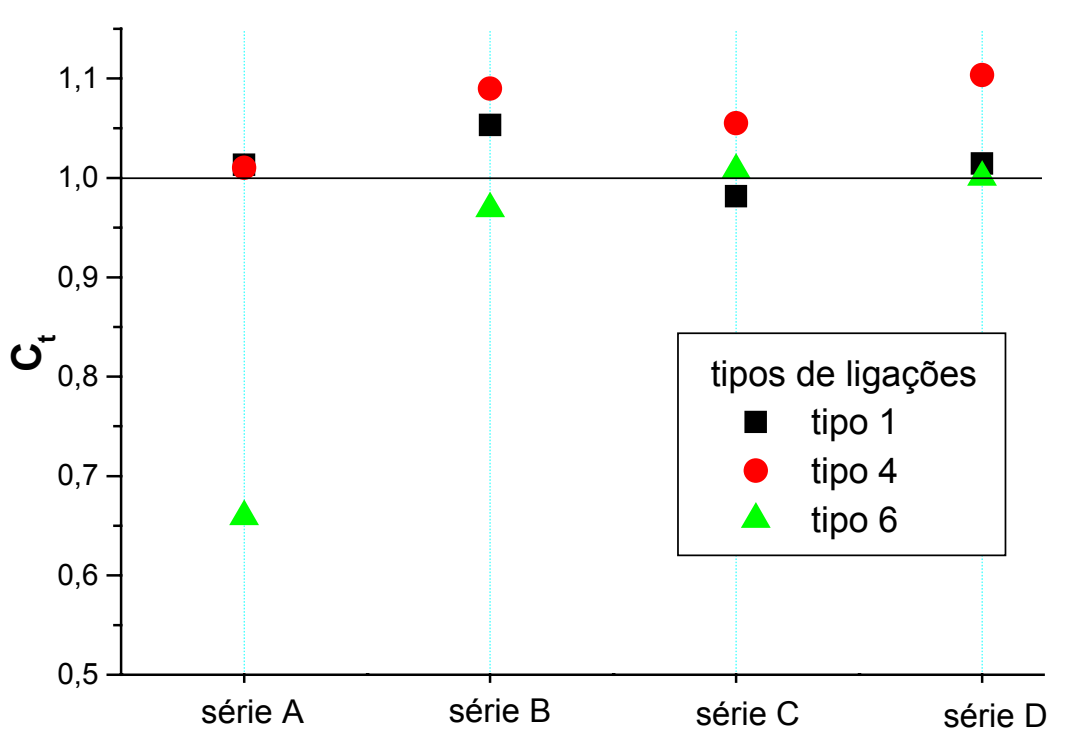

b) com a utilização de arruelas

FIGURA 5.16 - Avaliação de $\boldsymbol{C}_{t}$, para ligação parafusada em chapa, submetida a corte duplo 


\subsection{LIGAÇÕES PARAFUSADAS EM PERFIS DE AÇO FORMADOS A FRIO}

\subsubsection{Esmagamento}

A falha por esmagamento nas ligações parafusadas em perfis formados a frio foi predominante nos corpos-de-prova da Série $\mathbf{A}$, onde todos os parafusos da ligação foram posicionados em uma única seção perpendicular a direção da solicitação (fig. 5.17), isto ocorreu principalmente devido à elevada concentração de tensão na região dos furos (pressão de contato).

Ao contrário das ligações em chapas finas não houve flexão da borda destes perfis na região da ligação ao final do ensaio, isto se deveu a maior rigidez à flexão dos seus elementos, pois estes apresentavam pelo menos uma de suas extremidades enrijecidas.

Houve também ligações com mais de uma seção de parafusos na direção perpendicular à solicitação (séries B, C e D), que apresentaram como modo de falha o esmagamento da parede do furo, isso ocorreu basicamente nas ligações de perfis U conectados pela alma, pois estes além de apresentar uma maior área de aço na seção transversal, o elemento ligado se encontrava duplamente enrijecido, fatores que dificultaram a falha por ruptura da seção líquida estimada teoricamente.

No entanto, nos corpos-de-prova citados anteriormente, foi observado ao final do ensaio o início de ruptura da seção líquida junto as bordas laterais dos furos, mesmo para os corpos-de-prova da série A, onde a elevada pressão de contato indicava ser improvável a ocorrência deste tipo de falha.

Por este motivo os resultados experimentais apresentados neste item serão também comparados com o coeficiente redutor da área líquida $\boldsymbol{C}_{t}$, nas figuras 5.20 no caso de ligações da série A e no item 5.3.2 para outras séries. 

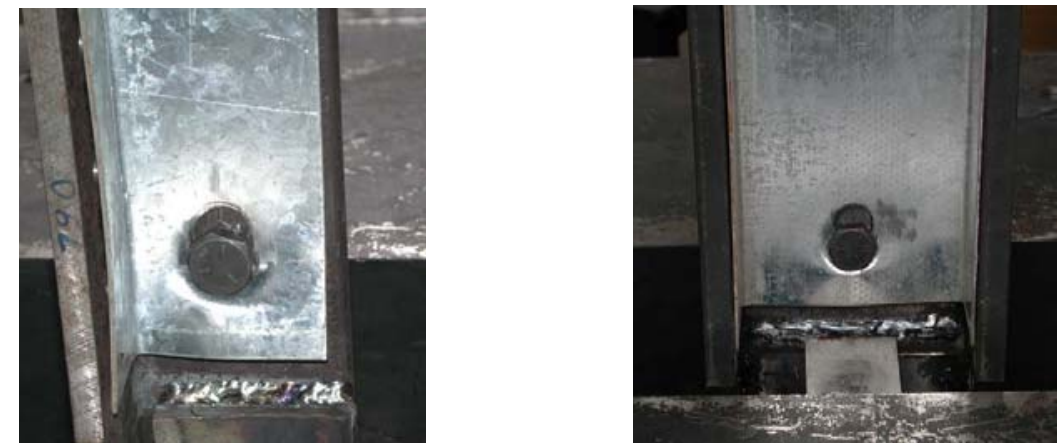

Figura 5.17 - Esmagamento da parede do furo (série A).

ligações da série A

A comparação dos resultados experimentais com os teóricos referentes ao esmagamento, conforme apresentado pela NBR14762:2001, se encontram nas figuras 5.18 e 5.19, onde foram traçados os gráficos da força última

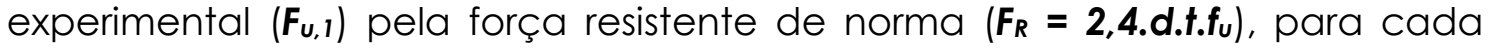
furo.

Nestes gráficos observa-se, de forma geral, que as forças últimas experimentais, ficaram abaixo dos valores teóricos avaliados pela expressão da norma para os perfis com 1,55mm de espessura e acima destes para os perfis com $3,75 \mathrm{~mm}$ de espessura.

Exceção feita para as ligações que apresentavam todos os elementos conectados (tipo 3), das quais, para as cantoneiras de abas desiguais os resultados experimentais foram 15\% abaixo dos teóricos para a espessura de $3,75 \mathrm{~mm}$. Para esta mesma cantoneira, juntamente com as cantoneiras de abas iguais e perfil $U$, confeccionados com material de menor espessura $(1,55 \mathrm{~mm})$, os resultados experimentais, para este tipo de ligação, mostraram boa concordância com os teóricos. Já para as cantoneiras e perfis U com $3,75 \mathrm{~mm}$ de espessura que apresentavam este mesmo tipo de ligação, não se pôde chegar a mesma conclusão devido a dispersão dos resultados.

No caso das cantoneiras, quando a ligação foi feita por apenas um elemento da seção transversal, pela aba menor no caso de cantoneiras de abas desiguais, ou seja ligação tipo 1, houve as maiores diferenças entre os resultados teóricas e experimentais. Reduziu-se esta diferença no caso desta 
ligação se dar na aba maior das cantoneiras de abas desiguais (ligação tipo 2), conforme apresentado na figura 5.18.

Observação semelhante pode ser feita no caso dos perfis $U$ de maior espessura, conectados pela alma, onde houve também as maiores diferenças entre os resultados teóricas e experimentais, já para o caso da ligação tipo 2 representando a conexão das mesas, esta ficou 10\% acima da teórica. Já para os perfis $U$ com $1,55 \mathrm{~m}$ de espessura os resultados experimentais para todos os tipos de ligações ficaram em média 5\% abaixo dos teóricos, demonstrando boa concordância com estes. (figura 5.19)

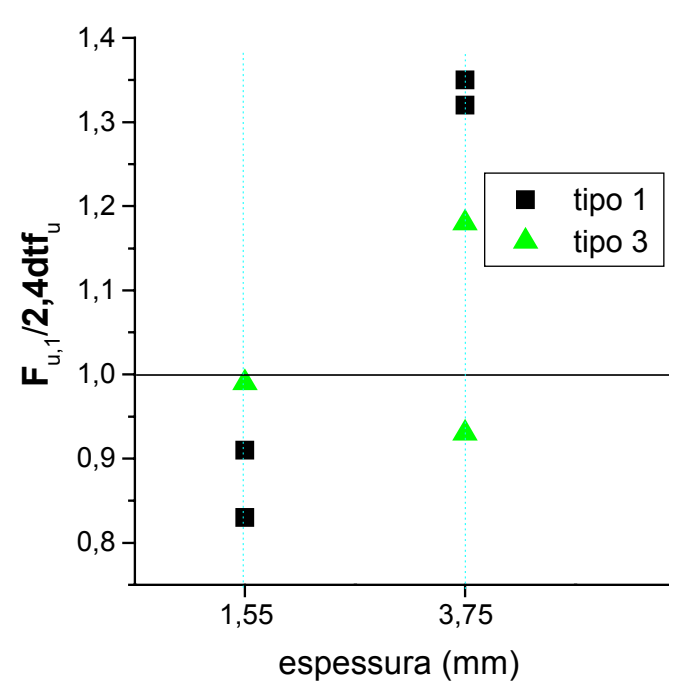

a) cantoneiras de abas iguais

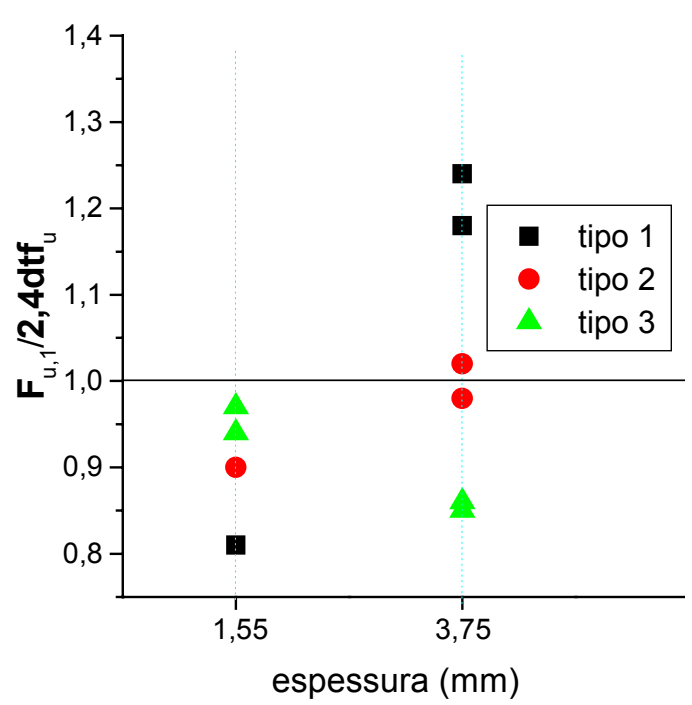

b) cantoneiras de abas desiguais

Figura 5.18 - Resultados experimentais da série A: falha por esmagamento (cantoneiras)

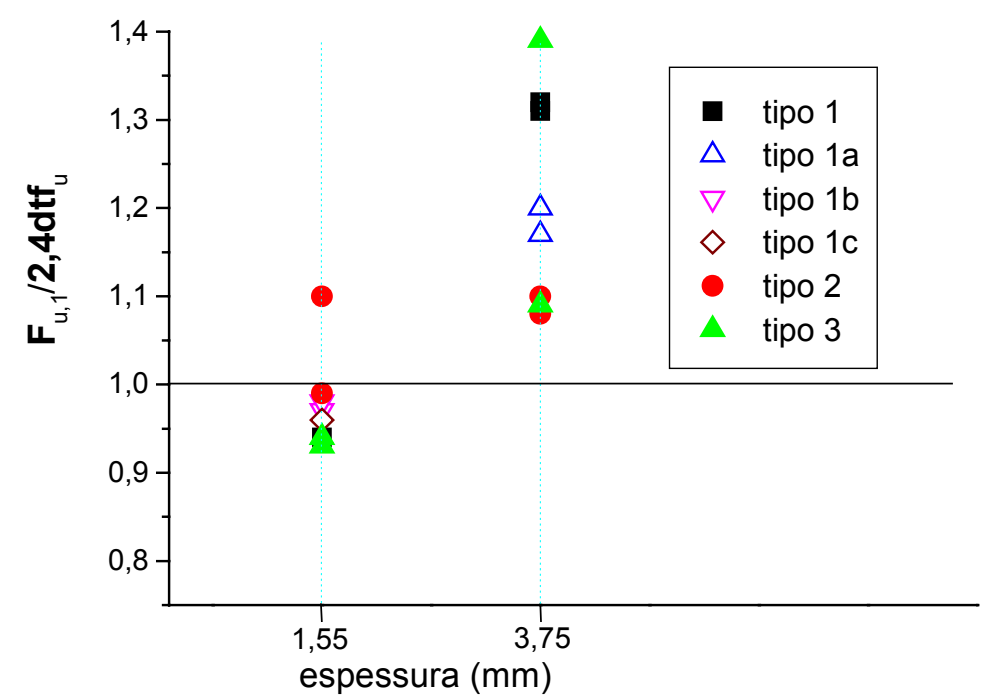

Figura 5.19 - Resultados experimentais da série A: falha por esmagamento (perfis U) 
De acordo com os resultados apresentados anteriormente, nota-se que o principal fator que influenciou o comportamento destas ligações foi a concentração de tensões junto a borda do furo, ou furos. Isto pode ser comprovado nas ligações em cantoneiras, onde observa-se a maior dispersão dos resultados quando a ligação se dava por um único parafuso (ligação tipo 1 - fig 5.18), esta dispersão diminuía e os resultados experimentais convergiam para os valores estimados teoricamente quando se conectava a aba maior da cantoneira de abas desiguais (ligação tipo 2 - fig 5.18b), pressupondo deste modo uma melhor distribuição de tensões devido a maior área de aço.

Observação semelhante pode ser feita no caso dos perfis U ligados pela alma (fig 5.19), sendo, para aqueles que utilizavam apenas um parafuso (tipo 1), dispersão dos resultados maior do que quando se utilizava dois parafusos (tipo la).

Outro fator que influenciou nos resultados foi a variação de espessura do material, apresentando o material de menor espessura (1,55mm), um melhor comportamento com menor dispersão dos resultados. Com a variação da espessura houve também a mudança de material, acarretando diferenças nas características físicas (ver Apêndice A), o que pode ter acarretado esta diferença de comportamento, no entanto, a diferença nas suas resistências são levadas em conta nas expressões de cálculo, e a diferença de ductilidades não é significativa, a ponto de ambos materiais serem considerados dúcteis. Portanto, não justificando, tão somente, ter sido as diferenças nas características físicas a influenciar nos resultados.

Assim, devido a dispersão apresentada nos ensaios, não possibilitando a adoção de uma expressão única para representar satisfatoriamente o comportamento dos casos analisados e sendo inviável a adoção de expressões diversas, uma para cada caso, e tendo em vista também o fato de que para os casos analisados cujas forças teóricas ficaram abaixo das experimentais, essa diferença foi em média de 10\%, admiti-se como boa estimativa de avaliação da força resistente para a falha por esmagamento da parede do furo ou furos, para os perfis formados a frio a expressão apresentada pela NBR 14762:2001. 
Nos gráficos da figura 4.20 são apresentados os valores experimentais do coeficiente $\boldsymbol{C}_{\boldsymbol{t}}$, para as ligações dessa série, comparados aos valores teóricos avaliados com base no procedimento de chapa equivalente. Nestes pode se notar que os valores experimentais resultaram, em geral, acima dos valores teóricos, com boa concordância tanto para as cantoneiras como para os perfis U. Portanto, embora o modo de falha tenha sido caracterizado como esmagamento da parede do furo, muitos corpos-de-prova apresentaram, ao final do ensaio, o início de ruptura da seção líquida. Deste modo, pode-se constatar que o procedimento de chapa equivalente permite avaliar satisfatoriamente a capacidade da barra na região da ligação.

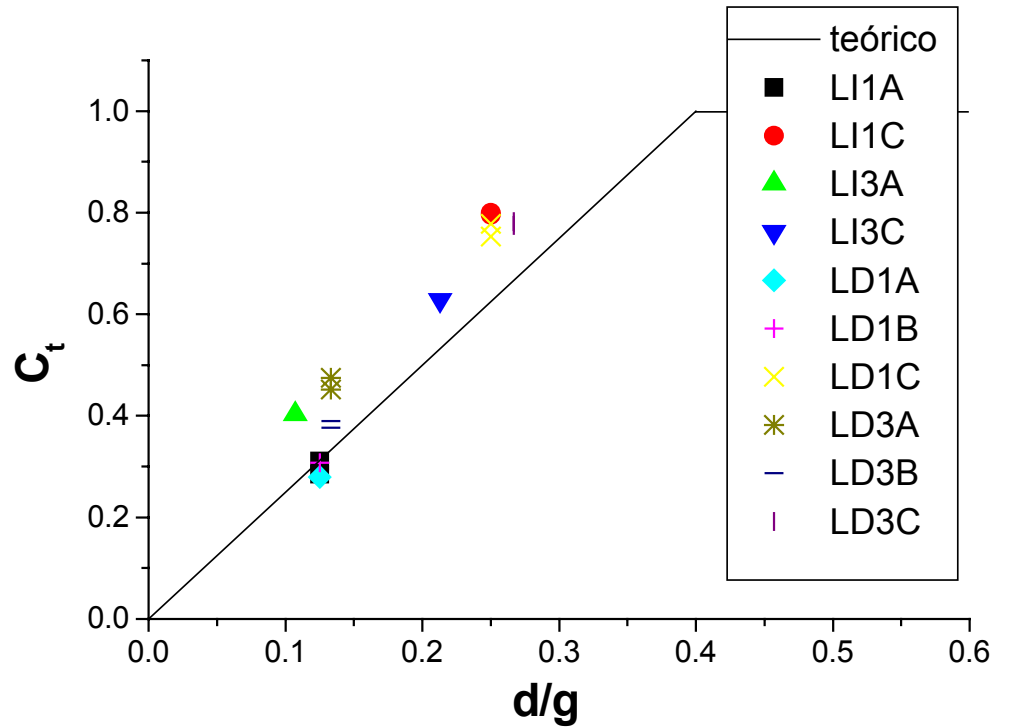

a) cantoneira

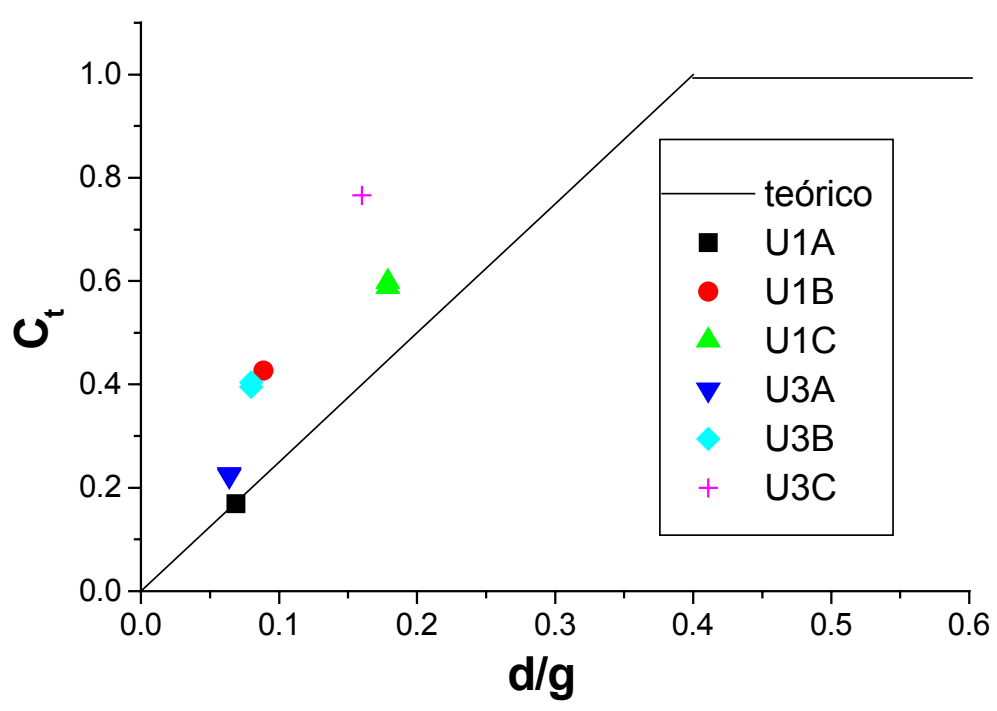

b) perfil U

Figura 5.20 - Resultados experimentais da série A, comparados com o procedimento de chapa equivalente 
- ligações da série B, C e D

Para estas séries o esmagamento ocorreu basicamente para os perfis U conectados pela alma, deste modo os resultados experimentais destas ligações, representados pela força última por parafuso obtida nos ensaios $\left(\boldsymbol{F}_{u, 1}\right)$ dividida pela força teórica resistente ao esmagamento para cada furo (2,4.d.t.fu), segundo a NBR14762:2001, são apresentados na figura 5.21.

Observa-se, nesta figura, que as forças últimas obtidas nos ensaios ficaram, no geral, sempre abaixo das calculadas teoricamente, aumentando esta diferença a medida em que se aumentou o número de parafusos da ligação. Como pode ser comprovado na série B, onde as ligações tipo 1, com apenas um furo por seção (num total de 2), apresentaram força última experimental em média 5\% abaixo da teórica, enquanto para as ligações do tipo 1a, com 2 furos por seção (totalizando 4 furos), esta diferença ficou em média $19 \%$ abaixo da teórica. Seguindo este raciocínio, para a série C, estas diferenças foram em média de $10 \%$ e $36 \%$ e, para a série D, foram de $17 \%$ e $47 \%$, para as ligações tipo 1 e la, respectivamente.

Outro fator a se destacar é que a dispersão dos resultados, devido a variação de espessura do material, diminui a medida em que se aumentou o número de seções de parafusos ou, conseqüentemente, à medida em que se aumentou o número de furos.

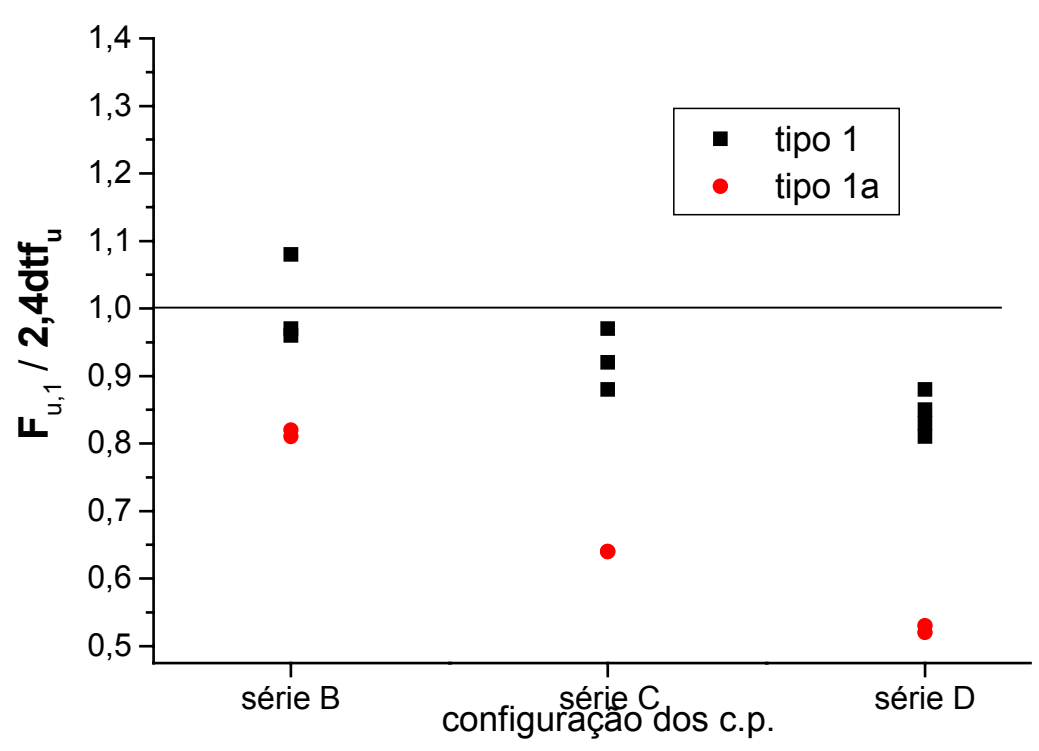

Figura 5.21 - Resultados experimentais das séries B, C e D : falha por esmagamento 


\subsection{2 - Ruptura da seção líquida}

Para os corpos-de-prova que apresentavam duas ou mais seções com parafusos na direção perpendicular à solicitação, o modo de falha predominante foi a ruptura da seção líquida conforme representado na figura 5.22, muitas vezes associada ao esmagamento, ou seja, a ruptura da seção líquida ocorreu sob deformação excessiva da parede do furo (ou furos).
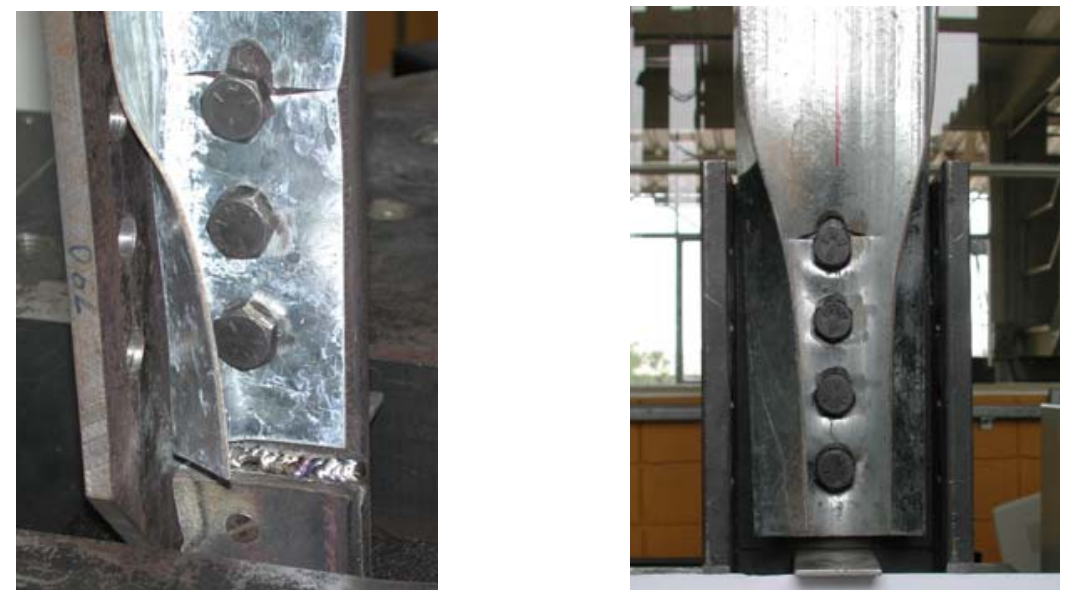

Figura 5.22 - Ruptura da seção líquida.

Neste item, os resultados obtidos nos ensaios são comparados com as curvas teóricas do coeficiente de redução da área líquida $\left(\boldsymbol{C}_{\boldsymbol{t}}\right)$ apresentadas pela NBR14762:2001 e pelo AISI:2001. Os valores experimentais do coeficiente $C_{f}$ foram obtidos a partir da força última de ensaio, dividida pela força resistente da seção líquida $\left(\boldsymbol{C}_{t}=\boldsymbol{F}_{v} / \boldsymbol{A}_{n} \boldsymbol{f}_{u}\right)$, e são apresentados nos gráficos a seguir em função da variação da relação $\overline{\boldsymbol{x}} / \mathbf{L}$.

\subsubsection{Ligações onde nem todos os elementos estavam conectados}

Nos gráficos das figuras a seguir são apresentados apenas os resultados para os corpos-de-prova que não possuíam todos os elementos conectados.

cantoneiras

Para as cantoneiras (fig. 5.23), os valores experimentais do coeficiente $\boldsymbol{C}_{t}$ resultaram em média de $15 \%$ abaixo dos valores teóricos, exceto para as 
cantoneiras de abas desiguais com espessura de $3,75 \mathrm{~mm}$ ligada pela aba maior (ligação do tipo 2 para configuração LD3) as quais apresentaram boa concordância com estes. Observa-se a diminuição desta diferença para valores acima de 0,4 da relação $\overline{\boldsymbol{x}} / \mathbf{L}$.

De acordo com estes resultados experimentais, sugere-se o seguinte ajuste da curva de $\boldsymbol{C}_{\boldsymbol{t}}$ aplicada as cantoneiras:

- abaixar o limite superior para o valor de $\boldsymbol{C}_{\boldsymbol{t}}$, para 0,8;

- adotar para limite inferior o valor de 0,5;

- manter a mesma inclinação para o trecho com variação linear, porém com valores $15 \%$ inferiores.

Obtém-se, portanto, a seguinte expressão para o coeficiente de redução da área líquida no caso de cantoneiras:

- para cantoneiras com duas ou mais seções de parafusos na direção perpendicular a solicitação:

$$
\boldsymbol{C}_{\boldsymbol{t}}=\mathbf{0 , 8 5}-\mathbf{1 , 2} \cdot \overline{\boldsymbol{x}} / \boldsymbol{L}<\mathbf{0 , 8} \quad \text { (porém não menor que 0,5) }
$$

Esta expressão está representada na figura 5.23, com a denominação da curva como 'proposto', onde pode-se observar a boa concordância desta com os resultados experimentais.

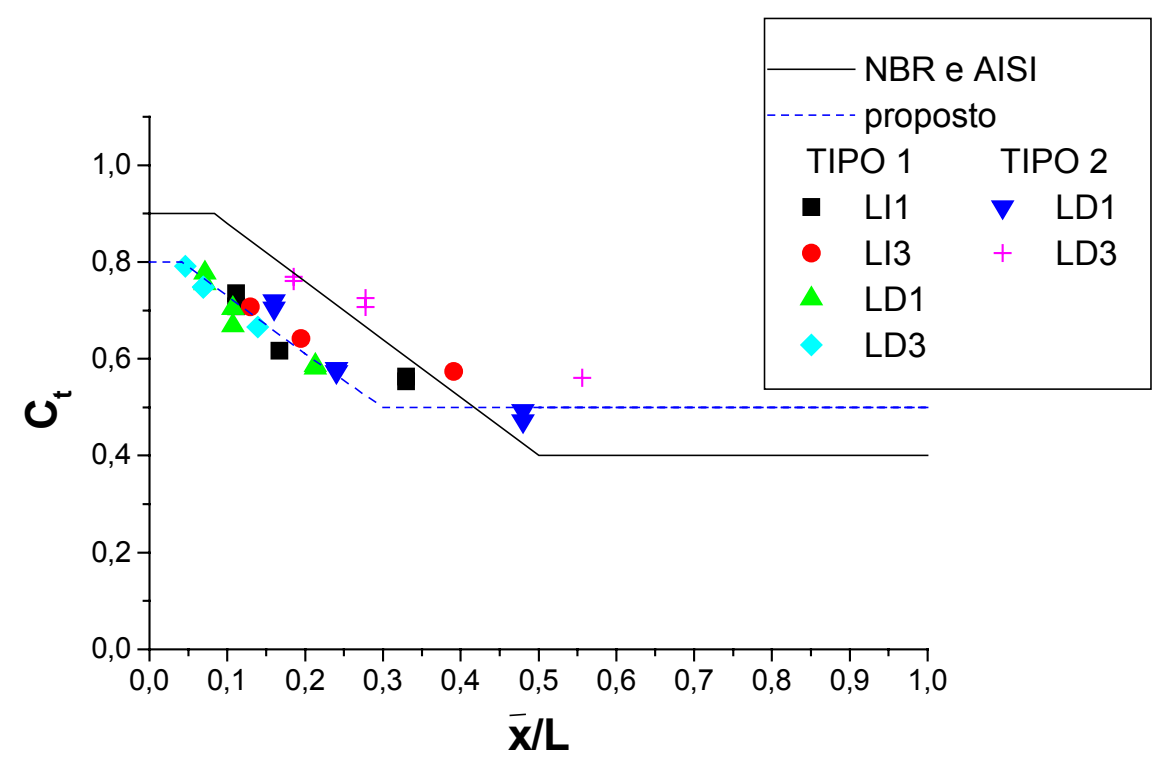

Figura 5.23 - Resultados experimentais de $\boldsymbol{C}_{\boldsymbol{t}}$ para as ligações parafusadas em cantoneiras com duas ou mais seções com parafusos 
Realizada análise de dispersão, são apresentadas na tabela 5.4 , os valores da média, desvio padrão e coeficiente de variação desses resultados experimentais $\left(C_{t(\exp .)}\right)$ com relação a curva do coeficiente $C_{t}$ apresentada

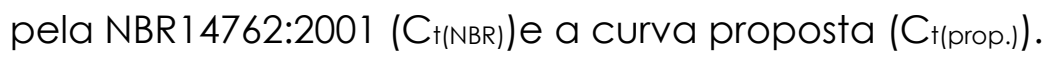

TABELA 5.4 - Análise de dispersão para dados do ensaio de cantoneiras

\begin{tabular}{r|c|c|c|}
\cline { 2 - 4 } \multicolumn{1}{c|}{} & $\frac{\mathrm{C}_{\mathrm{t}(\text { exp. })}}{\mathrm{C}_{\mathrm{t}(\mathrm{NBR})}}$ & $\frac{\mathrm{C}_{\mathrm{t}(\text { exp. })}}{\mathrm{C}_{\mathrm{t} \text { (prop. })}}$ & $\frac{\mathrm{C}_{\mathrm{t}(\text { (exp.) }}}{\mathrm{C}_{\mathrm{t}(\text { (prop. })}}$ \\
\hline \hline média & 0,915 & 1,057 & 1,015 \\
\hline desvio padrão & 0,151592 & 0,114311 & 0,056053 \\
\hline coeficiente de variação & $16,6 \%$ & $10,8 \%$ & $5,5 \%$ \\
\hline $\begin{array}{l}\text { (a) considerando todos os C.p. ensaiados; } \\
\text { (b) desconsiderando os C.p. LD3 (tipo 2) }\end{array}$
\end{tabular}

O coeficiente de variação para a curva proposta considerando todos os c.p. ensaiados (caso a da tabela 5.4), apresentou valor menor do que o apresentado pela curva da norma. Nesta mesma tabela, retirando da análise os dados das cantoneiras de abas desiguais com $3,75 \mathrm{~mm}$ de espessura, conectadas pela aba maior (caso $\underline{b}$ ), os quais apresentaram valores experimentais de $\boldsymbol{C}_{\boldsymbol{t}}$ maiores do que os demais c.p., mas a favor da segurança, observa-se melhora deste coeficiente, de $10,8 \%$ para $5,5 \%$.

No entanto, o procedimento da NBR14762:2001, ou seja, apresentando uma expressão única de $\boldsymbol{C}_{t}$ para o caso de cantoneiras, satisfaz os casos analisados, uma vez que esta dispersão se encontra a favor da segurança. Evitando desta forma a criação de várias curvas.

perfis $U$

Para os perfis $U$, quando as ligações foram feitas pelas mesas (tipo 2), e a variável $\overline{\boldsymbol{x}}$ foi avaliada como sendo a metade da altura do perfil, procedimento descrito no item 2.4.1 e demonstrado na figura 2.10. Os valores experimentais de $\boldsymbol{C}_{\boldsymbol{t}}$ demonstraram uma boa concordância com os teóricos, conforme pode ser visto na figura 5.24.

Quando esta ligação era feita pela alma, a falha predominante foi o esmagamento da parede dos furos. Entretanto, para as ligações tipo U1B lb e 
U1BlC (representadas na figura 5.24 pela sigla U1 nas ligações tipo lb e 1c, respectivamente), apresentando duas seções de parafusos dispostos na alma em duas linhas, para os perfis $U 100 \times 60 \times 1,55 \mathrm{~mm}$ e $U 100 \times 75 \times 1,55 \mathrm{~mm}$, respectivamente (ver tabela 3.3), o modo de falha foi a ruptura da seção líquida. Analisando os resultados experimentais de $\boldsymbol{C}_{\boldsymbol{t}}$ para estes corpos-deprova, observa-se que estes ficaram em média $50 \%$ abaixo dos valores teóricos, portanto pode-se concluir que a atual curva da norma não é adequada para avaliar o $C_{t}$ nesses casos.

Diante destes resultados, uma solução razoável para avaliação do coeficiente $\boldsymbol{C}_{\boldsymbol{t}}$ para perfis $U$ formados a frio, seria a criação de duas curvas, uma para ligação feita pelas mesas do perfil, já apresentada em norma e a outra quando a ligação se desse pela alma.

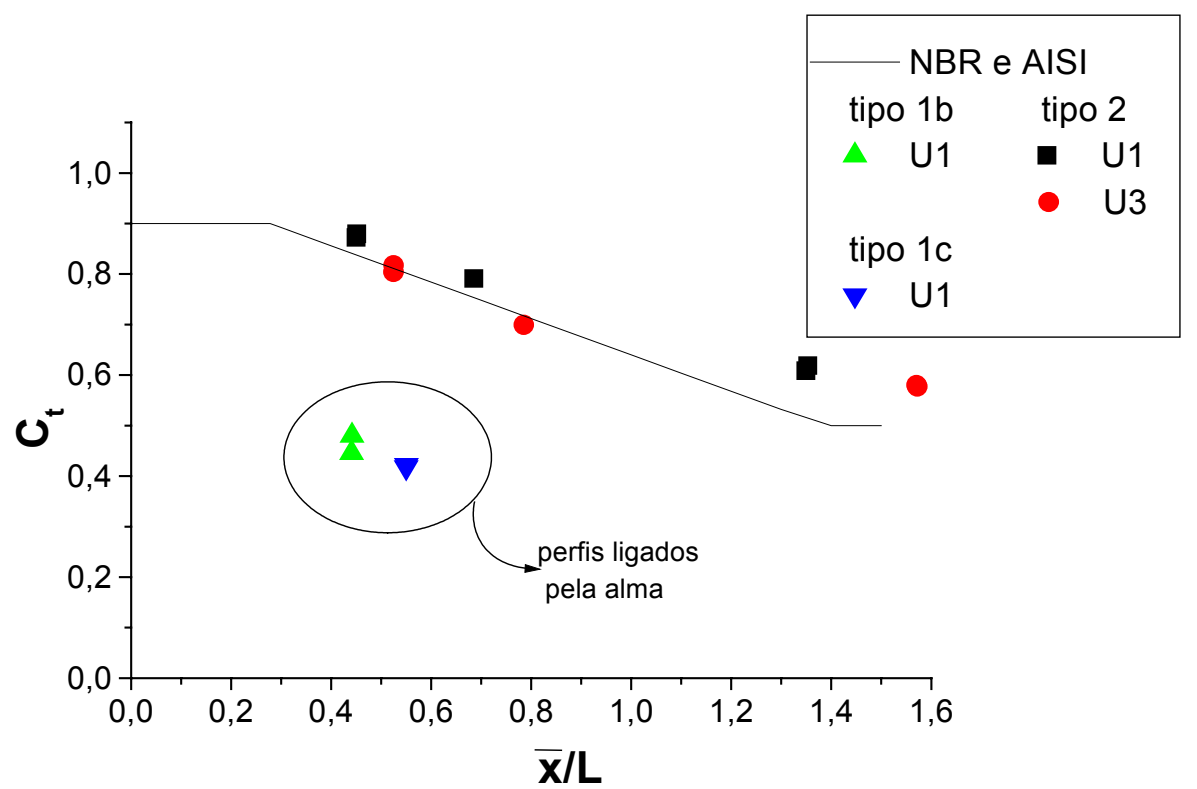

Figura 5.24 - Resultados experimentais de $\boldsymbol{C}_{\boldsymbol{t}}$ para as ligações parafusadas em perfis $U$ com duas ou mais seções com parafusos - procedimento 01.

Outra solução seria avaliar a variável $\overline{\boldsymbol{x}}$, no caso das ligações se darem pelas mesas do perfil, do modo sugerido pelo AISC:1993, ou seja, dividir o perfil ao meio, considerando duas cantoneiras $e$, conseqüentemente, tomando a excentricidade da ligação em relação a uma destas cantoneiras (ver fig 2.9 no item 2.4.1). Assim, conforme demonstrado no gráfico da figura 5.25, os perfis U com ligações do tipo 2 (pelas mesas) cujo valor de $\overline{\boldsymbol{x}}$ foi avaliado deste modo, e as ligações tipo lb e 1c (ligações pela alma), apresentaram valores experimentais do coeficiente $\boldsymbol{C}_{\boldsymbol{t}}$ próximos à curva teórica para cantoneiras dada pela NBR14762:2001, a qual está indicada neste gráfico, ou seja: 
- para perfis U com duas ou mais seções de parafusos na direção perpendicular a solicitação:

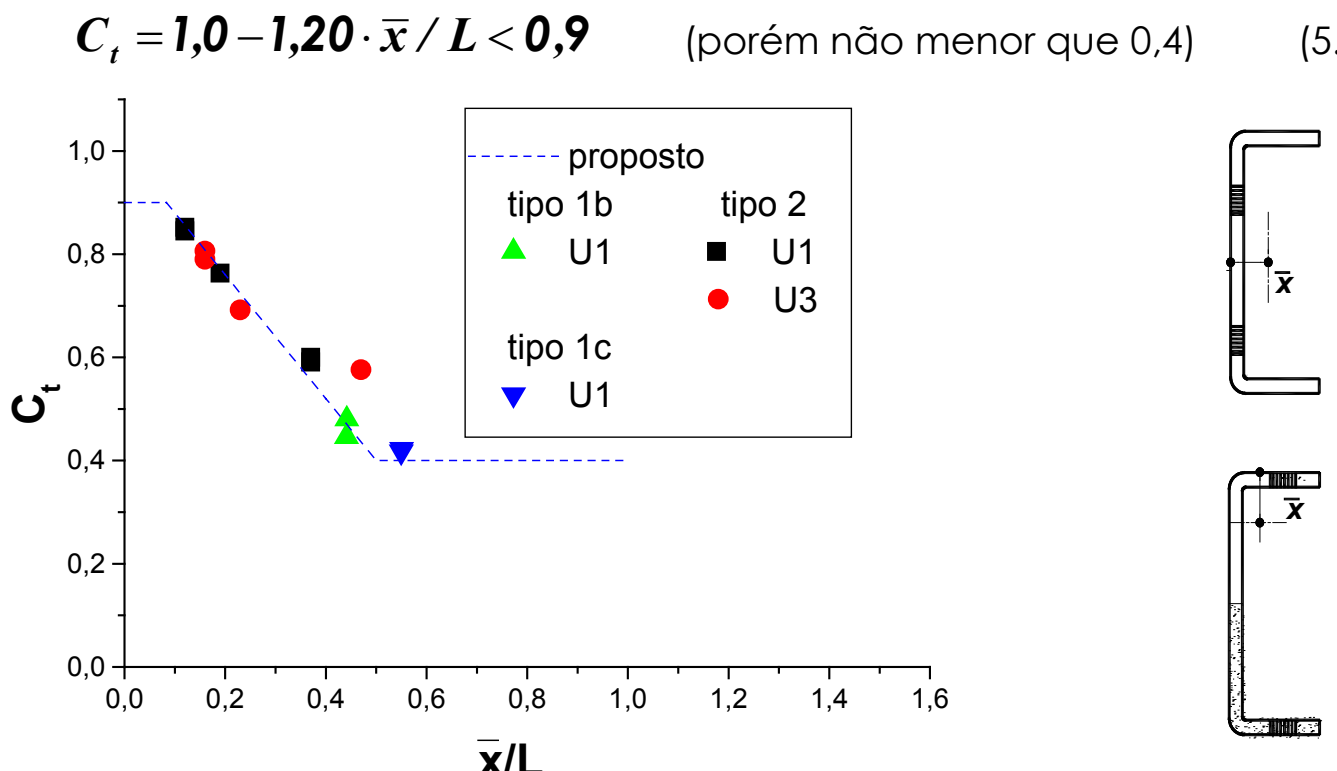

Figura 5.25 - Resultados experimentais de $C_{\boldsymbol{t}}$ para as ligações parafusadas em perfis $U$ com duas ou mais seções com parafusos - procedimento 02.

Realizada análise de dispersão, são apresentadas na tabela 5.5 , os valores da média, desvio padrão e coeficiente de variação desses resultados

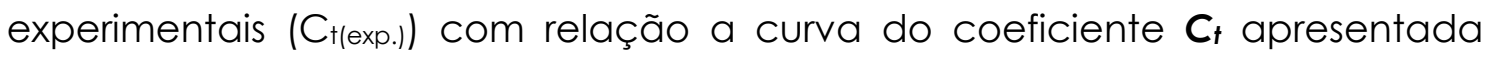
pela NBR14762:2001 (C+(NBR))e a curva proposta (C+(prop.)).

TABELA 5.5 - Análise de dispersão para dados do ensaio de perfis U

\begin{tabular}{|c|c|c|c|}
\hline & $\frac{C_{t(\text { exp. })}}{C_{t(\text { NBR })}}$ & $\frac{\mathrm{C}_{\mathrm{t}(\exp .)}}{\mathrm{C}_{\mathrm{t}(\mathrm{NBR})}}$ & $\frac{\mathrm{C}_{\mathrm{t}(\text { exp. })}}{\mathrm{C}_{\mathrm{t}(\text { prop. })}}$ \\
\hline média & 0,891 & 1,049 & 1,033 \\
\hline desvio padrão & 0,245317 & 0,077765 & 0,091974 \\
\hline coeficiente de variação & $27,5 \%$ & $7,4 \%$ & $8,9 \%$ \\
\hline
\end{tabular}

Observa-se na tabela 5.5, que excluindo os valores experimentais de $\boldsymbol{C}_{t}$ para os perfis $U$ conectados pela alma com dois parafusos por linha, tipos la $e$ lb (caso a), há uma melhora no coeficiente de variação, comparando com as expressões da NBR, mas deste modo, não ficaram cobertos todos possíveis tipos de ligação, necessitando de mais de uma expressão de $\boldsymbol{C}_{\boldsymbol{t}}$. 


\subsubsection{Ligações com todos os elementos conectados}

$\mathrm{Na}$ figura 5.26 são apresentados os resultados experimentais das ligações com duas ou mais seções de parafusos onde todos os elementos se encontravam conectados. Pode-se observar que o valor do coeficiente $\boldsymbol{C}_{\boldsymbol{t}}$ na maioria dos casos resultou inferior ao valor teórico recomendado pela NBR 14762:2001 $\left(\boldsymbol{C}_{\boldsymbol{t}}=\mathbf{1}, \mathbf{0}\right)$, que também é o adotado no projeto de perfis laminados.

Para as cantoneiras de maior espessura ensaiada $(4,75 \mathrm{~mm})$ realmente se observou uma tendência para que o coeficiente $\boldsymbol{C}_{t}$ se aproxima da unidade, ficando acima deste no caso do perfil $U$ de $4,75 \mathrm{~mm}$.

De acordo com os resultados apresentados na tabela 5.6, observa-se que a média geral dos valores experimentais de $\boldsymbol{C}_{t}$ foi igual a 0,935 , sugere-se que este coeficiente para o caso de perfis formados a frio quando todos os elementos estejam ligados seja considerado igual à 0,95.

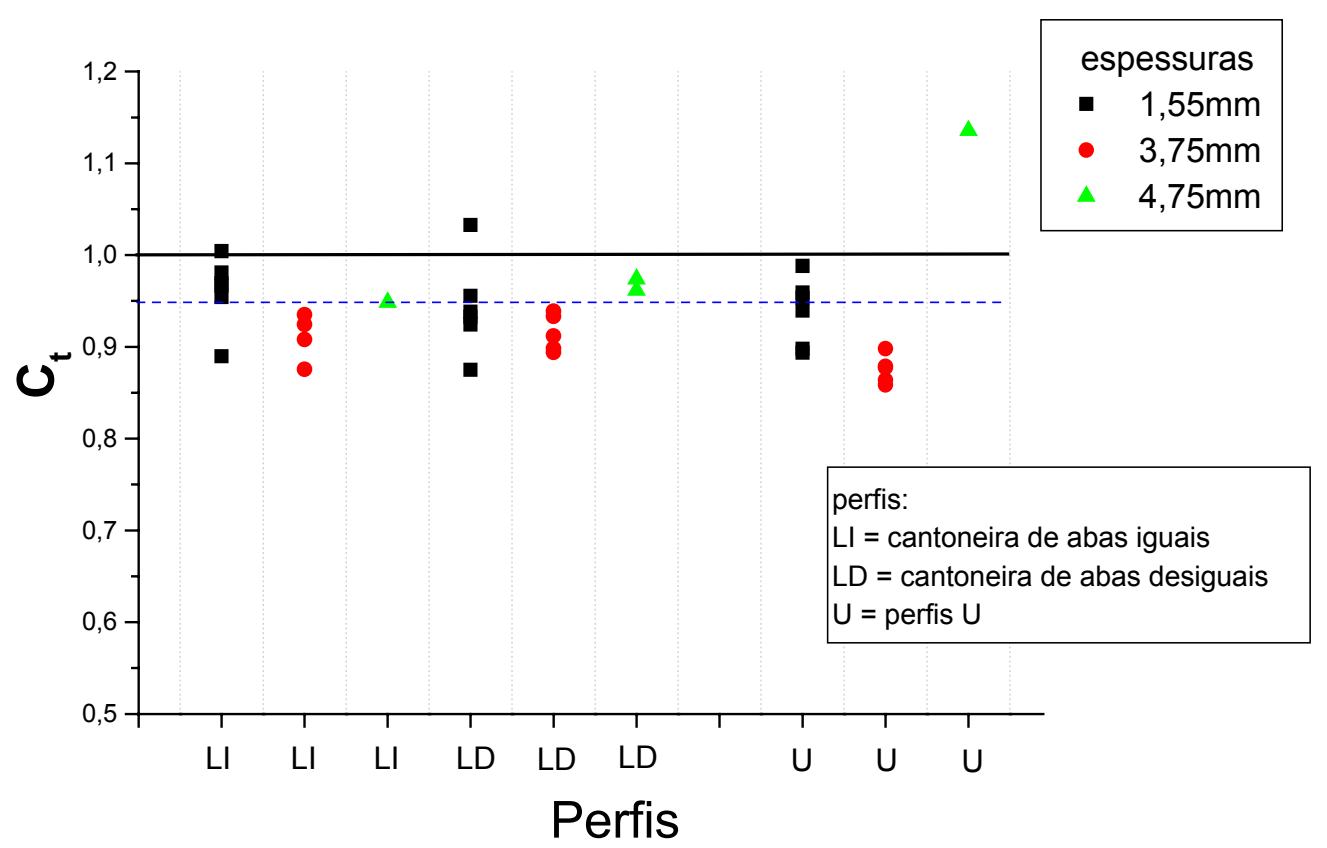

Figura 5.26 - Resultados experimentais de $\boldsymbol{C}_{\boldsymbol{t}}$ para as ligações parafusadas com todos os elementos conectados

TABELA 5.6 - Análise de dispersão para todos os elementos conectados

\begin{tabular}{|r|c|}
\cline { 2 - 2 } \multicolumn{1}{c|}{} & $\boldsymbol{C}_{\boldsymbol{t}}$ \\
\hline \hline média & 0,935 \\
\hline desvio padrão & 0,053087 \\
\hline coeficiente de variação & $5,7 \%$ \\
\hline
\end{tabular}




\subsubsection{Ligações em duplas cantoneiras}

O ensaio de dupla cantoneira consistiu basicamente no arranjo destas externamente ao dispositivo de ligação, de modo que estes ficassem submetidos ao corte duplo.

Uma vez que a chapa do dispositivo de ligação apresentava resistência superior à soma das resistências das cantoneiras ligadas, a estimativa era que a falha ocorre-se nestas últimas.

Os 8 corpos-de-prova ensaiados apresentavam configurações da

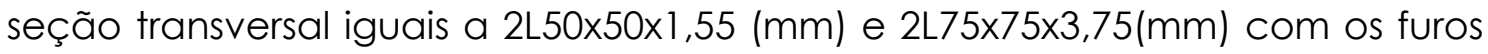
em uma das abas (tipo 1), dispostos no centro desta em uma ou três seções (LD1 e LD3, respectivamente), apresentando relações $\overline{\boldsymbol{x}} / \boldsymbol{L}$ iguais a 0,167 e 0,195, respectivamente. Estes foram confeccionados em duplicata, sendo ambos ensaiados sem a utilização de arruelas.

O modo de falha observado foi o esmagamento da parede do furo para ligações com uma seção de parafusos e a ruptura da seção líquida efetiva para as ligações com três seções de parafusos, para estes últimos os resultados experimentais do coeficiente $\boldsymbol{C}_{\boldsymbol{t}}$ são apresentados na figura 5.27.

Apesar do número reduzido de ligações parafusadas em dupla cantoneira a apresentarem a ruptura da seção líquida, os resultados obtidos indicam o bom desempenho deste tipo de ligação, apresentando valores experimentais de $\boldsymbol{C}_{\boldsymbol{t}}$ em média iguais à 1,20.

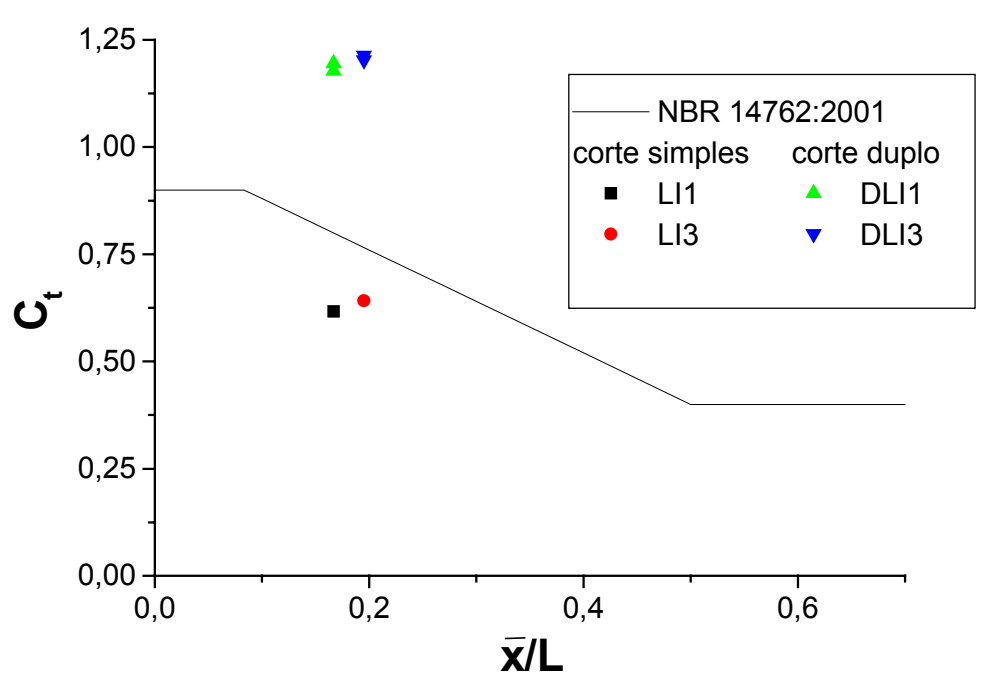

FIGURA 5.27 - Avaliação de $\boldsymbol{C}_{t}$, para ligação parafusada em dupla cantoneira 
CAPÍTULO 06

\section{CONCLUSÃO}




\section{CONCLUSÕES}

Apesar da grande aceitação dos perfis formados a frio no mercado brasileiro, as pesquisas com nesse campo somente receberam um impulso com o desenvolvimento da norma brasileira NBR14762:2001 "Dimensionamento de Estruturas de Aço Constituídas por Perfis Formados a Frio". Portanto, são poucos os trabalhos desenvolvidos neste campo da engenharia estrutural em nosso país. Internacionalmente vê-se a contínua pesquisa sobre este assunto, mas, especificamente com relação às ligações parafusadas observou-se que a maioria dos estudos ocorreu entre as décadas de 50 e 70, onde foram desenvolvidas as primeiras expressões para cálculo das ligações parafusadas em chapas finas e no final da década de 90 e início deste século onde se iniciaram os estudos sobre ligações parafusadas em perfis formados a frio.

Inseridas neste contexto, as análises experimentais de ligações parafusadas em chapas finas de aço e perfis formados a frio, desenvolvidas neste trabalho, permitiram algumas conclusões quanto aos procedimentos de cálculo adotados.

A primeira delas, diz respeito ao fato de que estas ligações são singulares e afetadas por uma série de variáveis e, como não existe a possibilidade de se recomendar procedimentos específicos para cada configuração estudada, foram propostas expressões gerais de modo que atendessem casos os mais abrangentes possíveis, respeitando os níveis de segurança, como segue. 


\section{- Ligações parafusadas em chapas finas de aço}

Esmagamento (pressão de contato)

A falha por esmagamento foi predominante nas ligações onde todos os parafusos da ligação foram posicionados em uma única seção perpendicular à solicitação (Série A), esta situação foi agravada pela flexão excessiva da borda das chapas na extremidade ligada observada na fase final do ensaio (fig. 5.2a).

Essa flexão de borda se tornou menos pronunciada a medida em que se aumentou o número de seções de parafusos perpendicular à solicitação, ou seja, aumentou-se o comprimento da ligação. A presença de arruelas junto a cabeça do parafuso e a porca, diminuiu os efeitos do puncionamento, acarretado por esta flexão de borda, observou-se, portanto, uma melhora no desempenho dessas ligações quando da utilização de arruelas.

Observou-se experimentalmente a ocorrência da falha por esmagamento quando da adoção de espaçamentos entre centro de furo e borda na direção da solicitação iguais a $\mathbf{2 , 0 d}$.

Com base nestes resultados, sugere-se alterar a expressão para a avaliação da força nominal resistente para a falha por esmagamento da parede do furo ou furos em ligações parafusadas em chapas finas de aço, conforme apresentado a seguir.

E para os casos de ligações com apenas uma seção de parafusos perpendicular à solicitação, na qual não se utilizem arruelas, sugere-se a aplicação de um coeficiente redutor de $20 \%$, como segue:

\begin{tabular}{|c|c|}
\hline NBR 1 4762:2001 & proposto \\
\hline \multirow{2}{*}{$\begin{array}{l}\text { - para qualquer configuração: } \\
\qquad F_{R}=\mathbf{2} \text {, } \mathbf{4} \text {.d.t.f }\end{array}$} & $\begin{array}{l}\text { - para uma seção de parafusos sem } \\
\text { arruelas ou com apenas uma arruela: } \\
\qquad F_{R}=\mathbf{0 , 8}\left(\mathbf{2}, \mathbf{0 . d . t . f _ { U } )}\right.\end{array}$ \\
\hline & $\begin{array}{l}\text { - para os demais casos: } \\
\qquad \boldsymbol{F}_{R}=\mathbf{2}, \mathbf{0 . d . t .} \boldsymbol{f}_{U}\end{array}$ \\
\hline
\end{tabular}


Ruptura da seção líquida efetiva

Esse modo de falha não ocorreu de maneira isolada, sendo que, nos casos onde houve a ruptura da seção líquida pôde-se observar um avançado esmagamento na parede dos furos, tanto maior quanto menor a quantidade de seções com parafusos (maior concentração de tensões). Exceção é feita para as ligações do tipo 3, nas quais observou-se a falha prematura da ligação por ruptura da seção líquida, nestas o gabarito de furação não respeitava as recomendações mínimas de norma, confirmando deste modo que tais configurações não devem ser empregadas na prática.

De acordo com os resultados experimentais, observou-se para a maioria dos casos que os valores médios experimentais de $\boldsymbol{C}_{\boldsymbol{t}}$ resultaram superiores aos valores teóricos obtidos segundo a NBR 14762:2001 (exceto as ligações do tipo 3). Para ligações com mais de duas seções de parafusos cujas configurações apresentavam relação $\mathbf{d} / \mathbf{g}$ acima de $\mathbf{0 , 2 5}$ os valores de $\boldsymbol{C}_{\boldsymbol{t}}$ mostraram boa concordância com a unidade, para as relações abaixo de 0,25 estes ficaram abaixo da unidade, o que vêm a invalidar a nova recomendação adotada pelo AISI:2001, onde considera para essa situação a adoção de um valor unitário para $\boldsymbol{C}_{\boldsymbol{t}}$. Assim com base nestes resultados são propostos ajustes nas curvas de $\boldsymbol{C}_{\boldsymbol{t}}$ para o caso de ligações parafusadas em chapas finas, como segue: 
NBR 14762:2001

proposto

- quando todos os parafusos da ligação estão contidos em uma única seção transversal:

$$
\begin{array}{c||c}
C_{t}=2,5(d / g) \leq 1,0 & C_{t}=2,5(d / g) \leq 1,0
\end{array}
$$

- quando existem duas seções de parafusos perpendiculares à direção da solicitação, alinhados ou em zig-zag:

\begin{tabular}{|c|c|}
\hline$C_{t}=0,5+1,25(d / g) \leq 1,0$ & $C_{t}=0,5+1,25(d / g) \leq 1,0$ \\
\hline \multicolumn{2}{|c|}{$\begin{array}{l}\text { - quando existem três seções de parafusos perpendiculares à direção da solicitação, } \\
\qquad \text { alinhados ou em zig-zag: }\end{array}$} \\
\hline$C_{t}=0,67+0,83(d / g) \leq 1,0$ & $C_{t}=0,7+1,2(d / g) \leq 1,0$ \\
\hline \multicolumn{2}{|c|}{$\begin{array}{l}\text { - quando existem quatro ou mais seções de parafusos perpendiculares à direção d } \\
\text { solicitação, alinhados ou em zig-zag: }\end{array}$} \\
\hline$C_{t}=0,75+0,625(d / g) \leq 1,0$ & $C_{t}=0,8+0,8(d / g) \leq 1,0$ \\
\hline
\end{tabular}

\section{- Ligações parafusadas em perfis formados a frio}

Esmagamento (pressão de contato)

A falha por esmagamento nas ligações parafusadas em perfis formados a frio foi predominante nos corpos-de-prova da Série A, onde todos os parafusos da ligação foram posicionados em uma única seção perpendicular a direção da solicitação (fig. 5.16), isto ocorreu principalmente devido à elevada concentração de tensão na região dos furos (pressão de contato).

Para as séries B, C e D o esmagamento ocorreu basicamente para os perfis U conectados pela alma, nos quais a elevada área da seção transversal dificultou a falha por ruptura da seção líquida efetiva estimada teoricamente. 
Nesse caso as forças últimas experimentais ficaram sempre abaixo das calculadas segundo a NBR 14762:2001 para a falha por esmagamento, ou seja:

\section{$F_{R}=2,4$. d.t. $f_{U}$}

Esta diferença aumentou a medida em que se aumentou o número de parafusos da ligação. Quando, para esta avaliação da força teórica, utilizou-se como espaçamento limite entre centro de furo e borda o valor de $\mathbf{2 , 0}$, houve uma melhor concordância com os resultados experimentais.

Para o caso de ligações parafusadas em perfis formados a frio com apenas uma seção de parafusos na direção transversal à solicitação, observouse a ocorrência de forças últimas experimentais 10\% abaixo das avaliadas teoricamente pela NBR14762:2001.

De acordo com o exposto anteriormente, admite-se como estimativa satisfatória de avaliação da força resistente para a falha por esmagamento da parede do furo ou furos para os perfis formados a frio, a seguinte expressão:

\section{$F_{R}=2,0$. d.t. $f_{U}$}

Ruptura da seção líquida efetiva

Para as ligações parafusadas em perfis formados a frio apresentando duas ou mais seções com parafusos na direção perpendicular à solicitação, o modo de falha predominante foi a ruptura da seção líquida, muitas vezes associada ao esmagamento, ou seja, a ruptura da seção líquida ocorreu sob deformação excessiva da parede do furo (ou furos). Este ocorreu muitas vezes para valores experimentais de $\boldsymbol{C}_{\boldsymbol{t}}$ abaixo dos estimados teoricamente, portanto de acordo com estes resultados experimentais, sugere-se os seguintes ajustes da curva de $\boldsymbol{C}_{\boldsymbol{t}}$ aplicada as cantoneiras e perfis $U$ formados a frio. 
-para cantoneiras com duas ou mais seções de parafusos na direção perpendicular a solicitação:

\begin{tabular}{c|c}
\hline $\begin{array}{c}\boldsymbol{C}_{\boldsymbol{t}}=\mathbf{1 , 0}-\mathbf{1 , 2 0} \cdot \overline{\boldsymbol{x}} / \boldsymbol{L}<\mathbf{0 , 9} \\
\text { (porém não menor que 0,4) }\end{array}$ & $\begin{array}{c}\boldsymbol{C}_{\boldsymbol{t}}=\mathbf{0 , 8 5}-\mathbf{1 , 2} \cdot \overline{\boldsymbol{x}} / \boldsymbol{L}<\mathbf{0 , 8} \\
\text { (porém não menor que 0,5) }\end{array}$ \\
\hline \hline - para perfis U com duas ou mais seções de parafusos na direção perpendicular a \\
solicitação:
\end{tabular}

- para cantoneiras e perfis U com duas ou mais seções de parafusos na direção perpendicular a solicitação, quando todos os elementos estão conectados:

$$
\begin{array}{l|l}
C_{t}=1,0 & C_{t}=0,95
\end{array}
$$

\footnotetext{
* Avaliando a variável $\overline{\boldsymbol{x}}$, no caso das ligações se darem pelas mesas do perfil, do modo sugerido pelo AISC:1996, ou seja, dividindo o perfil ao meio, criando duas cantoneiras e avaliando a excentricidade da ligação em relação a uma destas cantoneiras (fig 2.9 item 2.4.1).
}

\section{- Análise numérica realizada}

Na análise numérica realizada conseguiu-se boa representação de força última quando comparada com os resultados experimentais das ligações modeladas. No entanto ainda existem problemas de instabilidades locais acarretados pela concentração de tensões junto as bordas dos furos, os quais podem ser resolvidos com um enriquecimento adequado da malha de elementos finitos. Pode-se também conseguir uma melhora no comportamento força $x$ deslocamento avaliado numericamente, com a adoção de relações constitutivas do material que contemplem a fase de ruptura do mesmo, ou seja, que apresente a possibilidade de implementação de um trecho de encruamento negativo na fase final dessa relação. 


\section{- Sugestões para pesquisas futuras}

Na montagem dos ensaios de ligação em perfis formados a frio, realizou-se a fixação destes com a máquina de ensaio por intermédio de um dispositivo de fixação de rigidez elevada (espessura superior à da peça ensaiada), se procedeu desta maneira de modo a se ter uma melhor concordância com os ensaios realizados por HOLCOMB et al (1995), ensaios estes que deram origem as expressões adotados pelo AISI:2001 para verificação da ruptura da seção líquida efetiva de ligações parafusadas em perfis formados a frio, promovendo deste modo a possibilidade de comparação de resultados.

Na continuidade do trabalho, caberia a verificação da validade das conclusões aqui apresentadas, para ensaios de perfis ligados a outros perfis ou ligados a chapas de fixação de rigidez equivalente a da peça ensaiada (de espessura similares).

Quanto ao caso da análise de ligações parafusadas que apresentaram a falha por esmagamento, sugere-se o aprofundamento deste estudo, de moda a identificar o limite para o espaçamento entre centro de furo e borda na direção da solicitação, que separaria as ocorrências do estado limite último de esmagamento (ou pressão de contato) do estado limite último de rasgamento entre furos ou entre furo e borda. 


\section{7 - REFERÊNCIAS}

ABDEL-RAHMAN, N.; SIVAKUMARAN, K. S. (1997). Material properties models for analysis of cold-formed steel members. Journal of Structural Enginnering, ASCE, v.123, n.9, p.1135-1143, Sept 1997

AMERICAN INSTITUTE OF STEEL CONSTRUCTION (1993). LRFD -Manual of steel construction. Washington, DC.

AMERICAN IRON AND STEEL INSTITUTE (1996). LRFD - Load and resistance factor design specification for cold-formed steel structural members. Washington, DC.

AMERICAN IRON AND STEEL INSTITUTE (1999). Supplement $n^{\circ} 1$ to the specification for the design of cold-formed steel structural members. Washington, DC.

AMERICAN IRON AND STEEL INSTITUTE (2001). LRFD - Load and resistance factor design specification for cold-formed steel structural members. Washington, DC.

AMERICAN SOCIETY FOR TESTING AND MATERIALS (1992). $A-370$ Standard test methods and definitions for mechanical testing of steel products. Philadelphia.

AMERICAN SOCIETY FOR TESTING AND MATERIALS (1995). F-606-95b Standard test methods for determining the mechanical properties of externally and internally threaded fasteners, washers, and rivets. Philadelphia.

ANSYS (1995). Structural nonlinearities: user's guide for revision 5.1. Houston. v.1.

ASSOCIAÇÃO BRASILEIRA DE NORMAS TÉCNICAS (1967). N NB 143 - Cálculo de estruturas de aço, constituídas por perfis leves. Rio de Janeiro, ABNT.

ASSOCIAÇÃO BRASILEIRA DE NORMAS TÉCNICAS (1980). NBR 6355. Perfis estruturais, de aço, formados a frio. Rio de Janeiro, ABNT.

ASSOCIAÇÃO BRASILEIRA DE NORMAS TÉCNICAS (1986). NBR-8800 - Projeto e execução de estruturas de aço de edifícios: método dos estados limites. Rio de Janeiro.

ASSOCIAÇÃO BRASILEIRA DE NORMAS TÉCNICAS (2001). NBR 14762 Dimensionamento de estruturas de aço constituídas por perfis formados a frio. Rio de Janeiro, ABNT.

BLAKE, A. (1986). What every engineer should know about threaded fasteners materials and design. New York, Marcel Dekker, Inc.

BS5950 (1987). Structural use of steelwork in buildings: part 5 code of practice for the design of cold formed sections. British Standards Institution, London, 1987 
CHONG, K. P.; MATLOCK, R. B. (1975). Light-gage steel bolted connections without washers. Journal of the Structural Division. v.101, n.ST7, p.1381-1391, July 1975

CHUNG, K. F.; IP, K. H. (2000). A general design rule for bearing failure of bolted connections between cold-formed steel strips. In: INTERNATIONAL SPECIALTY CONFERENCE ON COLD-FORMED STEEL STRUCTURES, 15., St. Louis, Missouri, U.S.A., Octuber 19-20, 2000. Proceedings. Rolls, University of Missouri

COLD-FORMED STEEL IN TALL BUILDINGS. (1993). Council on Tall Buildings and Urban Habitat, Committee S37 ; [Colab] Rolf Baehre,Ton Toma. New York : Mcgraw-Hill, 1993.

CRAWFORD, S.F.; KULAK, G.L. (1971). Eccentrically loaded bolted connections. Journal of the Structural Division. vol. 97, Mar. 1971.

EUROPEAN COMMITTEE FOR STANDARDISATION (1996). Eurocode 3 - Design for steel structures: part 1.3 - general rules: supplementary rules for cold-formed thin gauge members and sheeting, Brussels.

GAYLORD, H. E.; GAYLORD, C. N; STALLMEYER, J. E. (1992). Design of steel structures. 3.ed. New York, McGraw-Hill.

GILCHRIST, R. T.; CHONG, K. P. (1979). Thin light-gage bolted connections without washers. Journal of the Structural Division. v.105, n.ST1, p. 175-183, January 1979

JAVARONI, C. E. (1999). Perfis de aço formados a frio submetidos à flexão: análise teórico-experimental. São Carlos. Tese (Doutorado) - Escola de Engenharia de São Carlos - Universidade de São Paulo.

KULAK, G. L.; FISHER, J. W.;STRUIK, J.H.A. (1987). Guide to design criteria for bolted and riveted joints. New York, John Wiley \& Sons.

LABOUBE, R. A.; YU, W. W. (1998a). Recent research and developments in cold-formed steel framing. Thin-Walled Structures. v.32, p. 19-39, 1998

MALITE, M. (1993a). Análise do comportamento estrutural de vigas mistas aço-concreto constituídas por perfis de chapa dobrada. São Carlos. Tese (Doutorado) - Escola de Engenharia de São Carlos - Universidade de São Paulo.

MALITE, M. (1993b). Estruturas de aço constituídas por perfis de chapa dobrada: dimensionamento de ligações. São Carlos, EESC-USP, 1993. 49p. (publ. 022/93).

MALITE, M.; SÁLES, J.J.; GONÇALVES, R. M. (1998). Algumas considerações sobre a nova norma brasileira de estruturas de aço em perfis formados a frio. Artigo Técnico, Revista Construção Metálica, n.33, p.22-26, 1998. 
McGUIRE, W. (1988). Introduction. In: CHEN, W. F., Ed. Steel beam-to-column building connections. London, Elsevier, P. 1-35.

OLIVEIRA, N. C. G. (1980). Roscas e parafusos. 2 ed. São Paulo. Grêmio Politécnico, 1980.

PEDRESCHI, R. F.; SINHA, B. P. (1996). The potential of press-joining in cold-formed steel structures. Construction and Building Materials, v.10, n.4, p.243-250, 1996

PERFIS SOLDADOS DE AÇO. (1997). Revista Construção Metálica, ABCEM, v.7, n.29, p.12-14, 1997.

ROGERS, C. A.; HANCOCK, G. J. (1998). Behaviour of thin G550 sheet steel bolted connections. In: INTERNATIONAL SPECIALTY CONFERENCE ON COLD-FORMED STEEL STRUCTURES, 14., St. Louis, Missouri, U.S.A., Octuber 15-16, 1998. Proceedings. Rolls, University of Missouri.

SCHAFER, B.W.; PEKÖZ, T. (1998). Computational modeling of cold-formed steel: characterizing geometric imperfections and residual stresses. Journal of Constructional Steel Research, v.47, p. 193-210, 1998

SELEIM, S.; LABOUBE, R. (1996). Bahavior of low ductility steels in cold-formed steel connections. Thin-Walled Structures. v. 25, n.2, p. 135-151, 1996

SIVAKUMARAN, K. S.; ABDEL-RAHMAN, N. (1998). A finite element analysis model for the behaviour of cold-formed steel members. Thin-Walled Structures, v.31, p. 305-324, 1998

STANDARDS AUSTRALIA/STANDARDS NEW ZEALAND (1996), AS/NZS 4600: Cold formed steel structures. 1996

VALENCIANI, V. C. (1997). Ligações em estruturas de aço. Dissertação (Mestrado). Escola de Engenharia de São Carlos - Universidade de São Paulo.

WINTER, G. (1956). Test on bolted connections in light gage steel. Journal Structural Division. v.82, n.ST2, March 1956

WINTER, G. (1959). Cold-formed, light-gage steel construction. Journal Structural Division. v.85, n.ST9, November 1959

YU, W.W. (1982). AISI design criteria for bolted connections. In: INTERNATIONAL SPECIALTY CONFERENCE ON COLD-FORMED STEEL STRUCTURES, 6., St. Louis, Missouri, U.S.A., Octuber 15-16, 1998. Proceedings. Rolls, University of Missouri.

YU, W. W.; LaBOUBE, R. A. (1997). University of Missouri-Rolla research on coldformed steel structures. Thin-Walled Structures. v.28, n.3/4, p. 213-223, 1997

YU, W.W. (2000). Cold-formed steel design. New York, John Wiley \& Sons. 


\section{APENNDICE A}

\section{CARACTERIZAÇÃO DO MATERIAL}

\section{- Ensaio de tração}

A caracterização mecânica do aço utilizado na confecção das peças de chapa fina e perfis formados a frio foi feita mediante ensaios de tração, conforme a especificação norte-americana: AMERICAN SOCIETY FOR TESTING AND MATERIALS A-370 'Standard test methods and definitions for mechanical testing of steel products' (ASTM A370-96).

Os corpos-de-prova (figura A.1), foram extraídos das chapas adquiridas para execução dos ensaios, sendo extraídos três corpos-de-prova para cada máterial utilizado, destes foram ensaiados apenas dois, o terceira ficou reservada para uma eventual contra prova.

Os corpos-de-prova foram ensaiados à tração em máquina de ensaio mecânica INSTRON, as deformações foram obtidas a partir de extensômetro removível (clip-gage), com base de medida de $25 \mathrm{~mm}$, posicionado no trecho central destes. Utilizou-se como taxa de deslocamento relativo entre garras, $2 \mathrm{~mm} / \mathrm{min}$ no trecho inicial (que corresponde aproximadamente ao início da fase de escoamento, ultrapassando a deformação 0,2\%) e $5 \mathrm{~mm} / \mathrm{min}$ no trecho final (início de escoamento até a ruptura), sendo que nesse último trecho foi retirado o extensômetro removivel.

dimensões em mm

FIGURA A.1 - Dimensões dos corpos-de-prova para o ensaio de tração do aço 
Os resultados dos ensaios de tração para os materiais utilizados na confecção dos ensaios estão listados na tabela A.1, divididos em lotes de uma mesma corrida, designados pela sua denominação comercial e espessura nominal $\left(t_{n}\right)$, conforme recebidos.

Tabela A.1 - Resultados do ensaio de tração do aço

\begin{tabular}{|l|c|c|c|c|c|}
\hline \multicolumn{1}{|c|}{ Material } & $\begin{array}{c}f_{n} \\
(\mathrm{~mm})\end{array}$ & $\begin{array}{c}A \\
(\%)\end{array}$ & $\begin{array}{c}f_{y} \\
(\mathrm{MPa})\end{array}$ & $\begin{array}{c}f_{u} \\
(\mathrm{MPa})\end{array}$ & $f_{u} / f_{y}$ \\
\hline Chapa zincada ZAR 345 & 1,55 & 28 & 346 & 468 & 1,35 \\
\hline AçO patinável ĆSN COR 420 & 2,00 & 30 & 331 & 479 & 1,45 \\
\hline AçO carbono SAE 1008 & 2,65 & 46 & 215 & 325 & 1,51 \\
\hline AçO carbono SAE 1008 (1) & 3,75 & 36 & 287 & 399 & 1,39 \\
\hline AçO carbono SAE 1008 (2) & 3,75 & 39 & 286 & 372 & 1,30 \\
\hline AçO patinável CSN COR 420 & 4,75 & 30 & 371 & 490 & 1,32 \\
\hline AçO carbono (3) & 6,30 & 28 & 356 & 457 & 1,28 \\
\hline
\end{tabular}

Onde:

$t_{n}=$ espessura nominal

A = alongamento na ruptura (base de medida $50 \mathrm{~mm}$ )

$f_{y}=$ resistência ao escoamento

$f_{u}=$ resistência à ruptura

Notas:

(1) (2) -materiais provenientes de corridas diferentes

(3) -aço sem qualificação estrutural porém o teor de carbono não foi fornecido pelo distribuidor. 


\section{APÊNDICE B}

\section{CONFIGURAÇÕES GEOMÉTRICAS DAS PEÇAS ENSAIADAS}

\section{- Simbologia utilizada}

d -diâmetro do parafuso

$d_{h}$-diâmetro do furo

el -espaçamento entre centro de furo e borda na direção perpendicular à solicitação

$e_{2}$-espaçamento entre centro de furo e borda na direção perpendicular à solicitação (oposto à e el)

Fu -força última experimental

g -espaçamento entre centro de furos na direção perpendicular à solicitação (no caso de mais de dois furos adotou-se o menor g)

$h_{1}, h_{2}$-altura das abas da cantoneira ou das mesa dos perfis $U$

$h_{3}$-altura da alma dos perfis $U$

n $\quad$-número de parafusos (furos) por seção

s - espaçamento entre o centro do furo da la seção à borda da chapa na direção da solicitação

S) -espaçamento entre o centro do furo da $2^{a}$ seção ao centro do furo da la seção na direção da solicitação

s2 -espaçamento entre o centro do furo da 3a seção ao centro do furo da 2a seção na direção da solicitação

S3 -espaçamento entre o centro do furo da 3a seção ao centro do furo da 4a seção na direção da solicitação

$t=$ espessura da chapa 
TABELA B.1 - Ligações parafusadas em chapa fina de aço sem a utilização de arruelas

\begin{tabular}{|c|c|c|c|c|c|c|c|c|c|c|c|c|c|}
\hline \multicolumn{8}{|c|}{ esmagamento } & & & & & 19,10 & esmagamento \\
\hline $\mathrm{C} 2 \mathrm{~A} 1-1$ & $\frac{0,2}{0,2}$ & 1 & 1,25 & 1,45 & $\frac{3,75}{75}$ & $\frac{1,875}{9,75}$ & $\frac{1,875}{375}$ & $\frac{2,500}{2,500}$ & & & & 23,60 & esmagamento \\
\hline$\frac{C 2 A 2-1}{C 2 A 3-1}$ & $\frac{0,2}{0,2}$ & 2 & $\frac{1,25}{1,25}$ & $\frac{1,45}{1,45}$ & $\frac{7,5}{2,5}$ & $\frac{3,75}{1,25}$ & $\frac{3,13}{1,25}$ & 2,500 & & & & 21,90 & rup. seção liquida \\
\hline C2A4-1 & 0,2 & 2 & 1,25 & 1,45 & 3,75 & 1,875 & 1,875 & 2,500 & & & & 36,30 & esmagamento \\
\hline C2A5-1 & 0,2 & 2 & 1,25 & 1,45 & 3,75 & 3,75 & 3,75 & 2,500 & & & & 42,20 & esmagamento \\
\hline C2A6-1 & 0,2 & 4 & 1,25 & 1,45 & 3,75 & 1,875 & 1,875 & 2,500 & & & & 75,50 & esmagamento \\
\hline $\mathrm{C} 2 \mathrm{~A} 7-1$ & 0,2 & 1 & 1,25 & 1,45 & 4,97 & 2,375 & 2,555 & 2,525 & & & & 19,99 & esmagamento \\
\hline C2A8-1 & 0,2 & 2 & 1,25 & 1,45 & 3,73 & 2,455 & 2,445 & 2,525 & & & & 41,20 & esmagamento \\
\hline C2A9-1 & 0,2 & 2 & 1,25 & 1,45 & 3,73 & 5,705 & 5,525 & 2,505 & & & & 46,93 & esmagamento \\
\hline $\mathrm{C} 2 \mathrm{~A} 10-1$ & 0,2 & 2 & 1,25 & 1,45 & 11,22 & 1,935 & 1,885 & 2,525 & & & & 43,57 & esmagamento \\
\hline & & & & & & & & & & & & & \\
\hline C3A1-1 & 0,26 & 1 & 1,25 & 1,45 & 3,74 & 2,005 & 1,725 & 2,575 & & & & 16,18 & esmagamento \\
\hline C3A4-1 & 0,26 & 2 & 1,25 & 1,45 & 3,67 & 1,825 & 2,005 & 2,480 & & & & 33,95 & esmagamento \\
\hline & & & & & & & & & & & & & \\
\hline C4A1-1 & 0,39 & 1 & 1,6 & 1,8 & 4,79 & 2,125 & 2,315 & 3,055 & & & & 36,47 & esmagamento \\
\hline C4A4-1 & 0,39 & 2 & 1,6 & 1,8 & 4,37 & 2,215 & 2,295 & 2,965 & & & & 75,92 & esmagamento \\
\hline & & & & & & & & & & & & & \\
\hline C5A1-1 & 0,475 & 1 & 1,6 & 1,8 & 4,8 & 2,4 & 2,4 & 3,200 & & & & 62,80 & esmagamento \\
\hline C5A2-1 & 0,475 & 1 & 1,6 & 1,8 & 9,6 & 4,8 & 4,8 & 3,200 & & & & 75,50 & esmagamento \\
\hline C5A3-1 & 0,475 & 2 & 1,6 & 1,8 & 3,2 & 1,6 & 1,6 & 3,200 & & & & 69,10 & rup. seção liquida \\
\hline C5A4-1 & 0,475 & 2 & 1,6 & 1,8 & 4,8 & 2,4 & 2,4 & 3,200 & & & & 130,00 & esmagamento \\
\hline C5A5-1 & 0,475 & 2 & 1,6 & 1,8 & 4,8 & 4,8 & 4,8 & 3,200 & & & & 135,00 & esmagamento \\
\hline C5A6-1 & 0,475 & 4 & 1,6 & 1,8 & 4,8 & 2,4 & 2,4 & 3,200 & & & & 260,00 & esmagamento \\
\hline C5A7-1 & 0,48 & 1 & 1,6 & 1,8 & 6,37 & 2,985 & 3,005 & 3,055 & & & & 69,97 & esmagamento \\
\hline C5A8-1 & 0,48 & 2 & 1,6 & 1,8 & 4,47 & 2,915 & 3,115 & 3,020 & & & & 133,23 & esmagamento \\
\hline C5A9-1 & 0,48 & 2 & 1,6 & 1,8 & 4,51 & 7,125 & 6,885 & 2,980 & & & & 141,62 & esmagamento \\
\hline C5A10-1 & 0,48 & 2 & 1,6 & 1,8 & 14,03 & 2,275 & 2,245 & 2,975 & & & & 144,06 & esmagamento \\
\hline & & & & & & & & & & & & & \\
\hline C6A1-1 & 0,63 & 1 & 1,6 & 1,8 & 4,8 & 2,125 & 2,325 & 2,955 & & & & 68,67 & esmagamento \\
\hline C6A4-1 & 0,63 & 2 & 1,6 & 1,8 & 4,41 & 2,165 & 2,325 & 3,015 & & & & 143,68 & esmagamento \\
\hline
\end{tabular}


TABELA B.1 - (continuação)

\begin{tabular}{|c|c|c|c|c|c|c|c|c|c|c|c|c|c|}
\hline \multirow[t]{2}{*}{ Ligação } & \multirow{2}{*}{$\begin{array}{c}\mathrm{t} \\
(\mathrm{cm}) \\
\end{array}$} & \multirow[t]{2}{*}{$n$} & \multirow{2}{*}{$\begin{array}{c}d \\
(\mathrm{~cm}) \\
\end{array}$} & \multirow{2}{*}{$\begin{array}{c}\mathrm{dh} \\
(\mathrm{cm}) \\
\end{array}$} & \multirow{2}{*}{$\begin{array}{c}g \\
(\mathrm{~cm}) \\
\end{array}$} & \multirow{2}{*}{$\frac{\mathrm{e} 1}{(\mathrm{~cm})}$} & \multirow{2}{*}{$\frac{\mathrm{e} 2}{(\mathrm{~cm})}$} & \multirow{2}{*}{$\begin{array}{c}\mathrm{s} \\
(\mathrm{cm}) \\
\end{array}$} & \multirow{2}{*}{$\begin{array}{c}\mathrm{s} 1 \\
(\mathrm{~cm}) \\
\end{array}$} & \multirow{2}{*}{$\begin{array}{r}\mathrm{s} 2 \\
(\mathrm{~cm}) \\
\end{array}$} & \multirow{2}{*}{$\begin{array}{r}\mathrm{s} 3 \\
(\mathrm{~cm}) \\
\end{array}$} & \multirow{2}{*}{$\begin{array}{r}\mathrm{Fu} \\
(\mathrm{kN}) \\
\end{array}$} & \multirow{2}{*}{$\begin{array}{c}\text { Modo de falha } \\
\text { (obtido em ensaio) }\end{array}$} \\
\hline & & & & & & & & & & & & & \\
\hline \multicolumn{14}{|l|}{ SERIA B } \\
\hline $\mathrm{C} 2 \mathrm{~B} 1-1$ & 0,2 & 1 & 1,25 & 1,45 & 3,75 & 1,875 & 1,875 & 2,500 & 5,000 & & & 22,10 & rup. seção líquida \\
\hline $\mathrm{C} 2 \mathrm{~B} 2-1$ & 0,2 & 1 & 1,25 & 1,45 & 7,5 & 3,75 & 3,75 & 2,500 & 5,000 & & & 42,50 & esmagamento \\
\hline $\mathrm{C} 2 \mathrm{~B} 3-1$ & 0,2 & 2 & 1,25 & 1,45 & 2,5 & 1,25 & 1,25 & 2,500 & $5 ; 000$ & & & 21,40 & rup. seção liquida \\
\hline C2B4-1 & 0,2 & 2 & 1,25 & 1,45 & 3,75 & 1,875 & 1,875 & 2,500 & 5,000 & & & 45,10 & rup. seção líquida \\
\hline C2B5-1 & 0,2 & 2 & 1,25 & 1,45 & 3,75 & 3,75 & 3,75 & 2,500 & 5,000 & & & 74,80 & esmagamento \\
\hline $\mathrm{C} 2 \mathrm{~B} 6-1$ & 0,2 & 4 & 1,25 & 1,45 & 3,75 & 1,875 & 1,875 & 2,500 & 5,000 & & & 94,60 & rup. seção líquida \\
\hline $\mathrm{C} 2 \mathrm{~B} 7-1$ & 0,2 & 1 & 1,25 & 1,45 & 5 & 2,395 & 2,565 & 2,515 & 4,880 & & & 35,02 & rup. seção líquida \\
\hline $\mathrm{C} 2 \mathrm{~B} 8-1$ & 0,2 & 2 & 1,25 & 1,45 & 3,71 & 2,475 & 2,465 & 2,475 & 4,935 & & & 59,14 & rup. seção liquida \\
\hline C2B9-1 & 0,2 & 2 & 1,25 & 1,45 & 3,73 & 5,455 & 5,745 & 2,495 & 4,900 & & & 81,64 & esmag + ruptura \\
\hline $\mathrm{C} 2 \mathrm{~B} 10-1$ & 0,2 & 2 & 1,25 & 1,45 & 11,22 & 1,775 & 1,845 & 2,475 & 4,935 & & & 74,32 & esmag + ruptura \\
\hline C3B1-1 & 0,26 & 1 & 1,25 & 1,45 & 3,74 & 2,015 & 1,715 & 2,505 & 4,960 & & & 19,08 & rup. seção líquida \\
\hline C3B4-1 & 0,26 & 2 & 1,25 & 1,45 & 3,68 & 1,815 & 2,015 & 2,465 & 4,960 & & & 42,73 & rup. seção líquida \\
\hline & & & & & & & & & & & & & \\
\hline C4B1-1 & 0,39 & 1 & 1,6 & 1,8 & 4,78 & 2,135 & 2,285 & 3,055 & 5,960 & & & 42,65 & rup. seção liquida \\
\hline C4B4-1 & 0,39 & 2 & 1,6 & 1,8 & 4,38 & 2,225 & 2,315 & 2,995 & 6,060 & & & 88,89 & rup. seção liquida \\
\hline C5B1-1 & 0,475 & 1 & 1,6 & 1,8 & 4,8 & 2,4 & 2,4 & 3,200 & 6,400 & & & 72,00 & rup. seção líquida \\
\hline C5B2-1 & 0,475 & 1 & 1,6 & 1,8 & 9,6 & 4,8 & 4,8 & 3,200 & 6,400 & & & 146,00 & esmagamento \\
\hline C5B3-1 & 0,475 & 2 & 1,6 & 1,8 & 3,2 & 1,6 & 1,6 & 3,200 & 6,400 & & & 72,00 & rup. seção liquida \\
\hline C5B4-1 & 0,475 & 2 & 1,6 & 1,8 & 4,8 & 2,4 & 2,4 & 3,200 & 6,400 & & & 149,00 & rup. seção líquida \\
\hline C5B5-1 & 0,475 & 2 & 1,6 & 1,8 & 4,8 & 4,8 & 4,8 & 3,200 & 6,400 & & & 235,00 & esmagamento \\
\hline $\mathrm{C} 5 \mathrm{~B} 6-1$ & 0,475 & 4 & 1,6 & 1,8 & 4,8 & 2,4 & 2,4 & 3,200 & 6,400 & & & 298,00 & rup. seção liquida \\
\hline C5B7-1 & 0,48 & 1 & 1,6 & 1,8 & 6,36 & 2,995 & 3,005 & 3,005 & 6,040 & & & 104,92 & esmagamento \\
\hline C5B8-1 & 0,48 & 2 & 1,6 & 1,8 & 4,53 & 2,895 & 3,105 & 2,965 & 6,060 & & & 180,61 & rup. seção líquida \\
\hline C5B9-1 & 0,48 & 2 & 1,6 & 1,8 & 4,45 & 7,115 & 6,935 & 3,010 & 6,000 & & & 257,37 & esmag + ruptura \\
\hline C5B10-1 & 0,48 & 2 & 1,6 & 1,8 & 14,03 & 2,265 & 2,205 & 3,000 & 6,035 & & & 263,25 & esmag + ruptura \\
\hline C6B1-1 & 0,63 & 1 & 1,6 & 1,8 & 4,83 & 2,165 & 2,305 & 2,975 & 6,060 & & & 77,83 & rup. seção líquida \\
\hline C6B4-1 & 0,63 & 2 & 1,6 & 1,8 & 4,41 & 2,185 & 2,325 & 3,080 & 6,040 & & & 181,37 & rup. seção líquida \\
\hline
\end{tabular}


TABELA B.1 - (continuação)

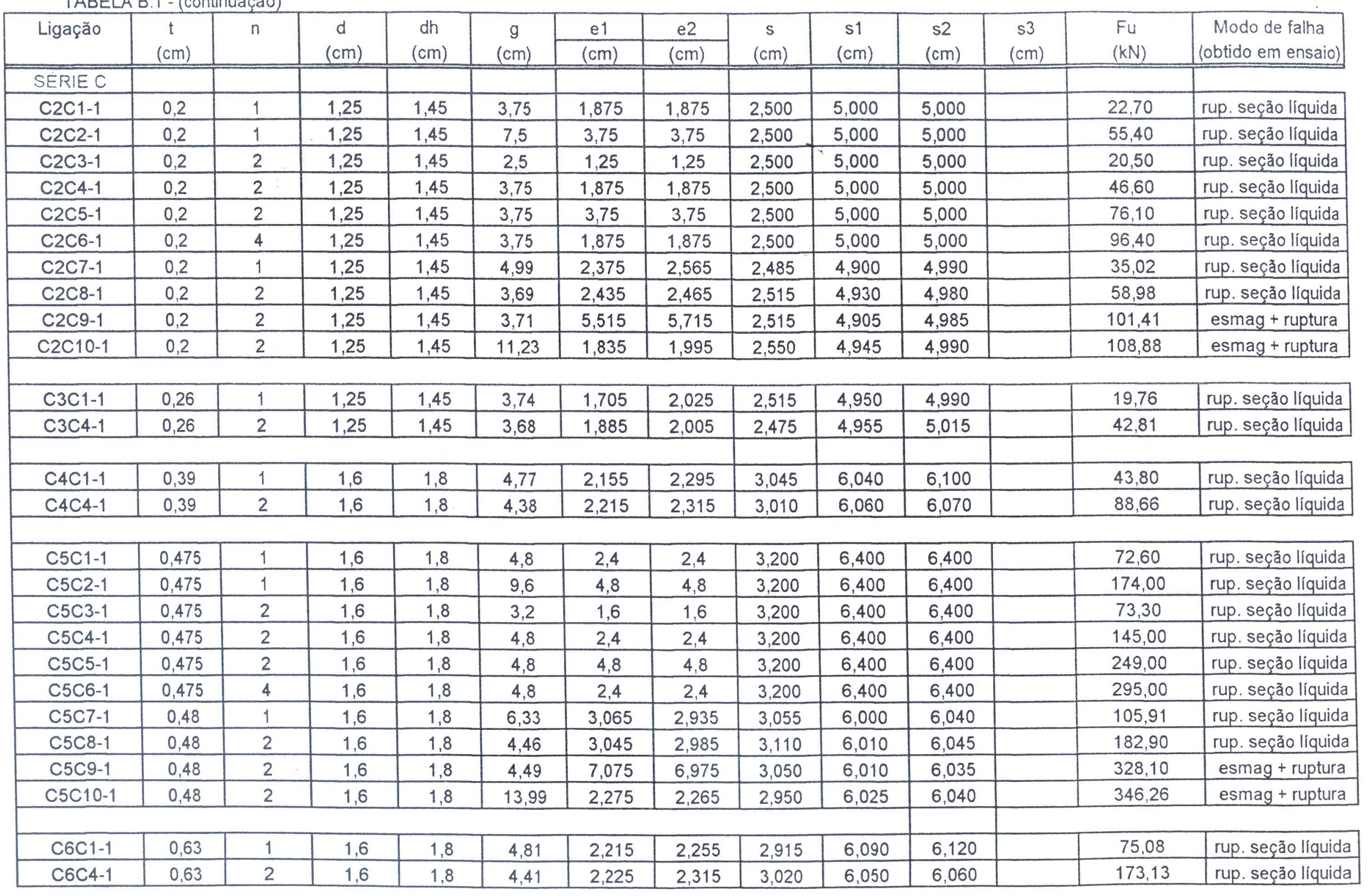


TABELA B.1 - (continuação)

\begin{tabular}{|c|c|c|c|c|c|c|c|c|c|c|c|c|c|}
\hline \multirow[t]{2}{*}{ Ligação } & \multirow{2}{*}{$\begin{array}{c}\mathrm{t} \\
(\mathrm{cm}) \\
\end{array}$} & \multirow[t]{2}{*}{$n$} & \multirow{2}{*}{$\begin{array}{c}d \\
(\mathrm{~cm}) \\
\end{array}$} & \multirow{2}{*}{$\begin{array}{r}\mathrm{dh} \\
(\mathrm{cm}) \\
\end{array}$} & \multirow{2}{*}{$\begin{array}{c}\mathrm{g} \\
(\mathrm{cm}) \\
\end{array}$} & \multirow{2}{*}{$\frac{\mathrm{e} 1}{(\mathrm{~cm})}$} & \multirow{2}{*}{$\frac{\mathrm{e} 2}{(\mathrm{~cm})}$} & \multirow{2}{*}{$\begin{array}{c}\mathrm{s} \\
(\mathrm{cm}) \\
\end{array}$} & \multirow{2}{*}{$\begin{array}{r}\mathrm{s} 1 \\
(\mathrm{~cm}) \\
\end{array}$} & \multirow{2}{*}{$\begin{array}{r}s 2 \\
(\mathrm{~cm}) \\
\end{array}$} & \multirow{2}{*}{$\begin{array}{r}\mathrm{s} 3 \\
(\mathrm{~cm}) \\
\end{array}$} & \multirow{2}{*}{$\begin{array}{r}\mathrm{Fu} \\
(\mathrm{kN}) \\
\end{array}$} & \multirow{2}{*}{$\begin{array}{c}\begin{array}{c}\text { Modo de falha } \\
\text { (obtido em ensaio) }\end{array} \\
\end{array}$} \\
\hline & & & & & & & & & & & & & \\
\hline \multicolumn{14}{|l|}{ SERRIED } \\
\hline C2D1-1 & 0,2 & 1 & $-1,25$ & 1,45 & 3,75 & 1,875 & 1,875 & 2,500 & . 5,000 & 5,000 & 5,000 & 23,00 & rup. seção líquida \\
\hline $\mathrm{C} 2 \mathrm{D} 2-1$ & 0,2 & 1 & 1,25 & 1,45 & 7,5 & 3,75 & 3,75 & 2,500 & 5,000 & 5,000 & 5,000 & 54,90 & rup. seção liquida \\
\hline C2D3-1 & 0,2 & 2 & 1,25 & 1,45 & 2,5 & 1,25 & 1,25 & 2,500 & 5,000 & 5,000 & 5,000 & 23,60 & rup. seção líquida \\
\hline C2D4-1 & 0,2 & 2 & 1,25 & 1,45 & 3,75 & 1,875 & 1,875 & 2,500 & 5,000 & 5,000 & 5,000 & 45,20 & rup. seção liquida \\
\hline C2D5-1 & 0,2 & 2 & 1,25 & 1,45 & 3,75 & 3,75 & 3,75 & 2,500 & 5,000 & 5,000 & 5,000 & 75,20 & rup. seção líquida \\
\hline C2D6-1 & 0,2 & 4 & 1,25 & 1,45 & 3,75 & 1,875 & 1,875 & 2,500 & 5,000 & 5,000 & 5,000 & 93,40 & rup. seção liquida \\
\hline $\mathrm{C} 2 \mathrm{D} 7-1$ & 0,2 & 1 & 1,25 & 1,45 & 4,98 & 2,535 & 2,375 & 2,485 & 4,900 & 4,970 & 4,960 & 35,25 & rup. seção líquida \\
\hline C2D8-1 & 0,2 & 2 & 1,25 & 1,45 & 3,72 & 2,475 & 2,475 & 2,450 & 4,935 & 4,980 & 4,960 & 59,59 & rup. seção líquida \\
\hline C2D9-1 & 0,2 & 2 & 1,25 & 1,45 & 3,7 & 5,545 & 5,695 & 2,470 & 4,910 & 4,985 & 4,965 & 113,39 & esmag + ruptura \\
\hline C2D10-1 & 0,2 & 2 & 1,25 & 1,45 & 11,22 & 1,855 & 1,945 & 2,505 & 4,945 & 4,985 & 5,010 & 117,89 & rup. seção líquida \\
\hline C3D1-1 & 0,26 & 1 & 1,25 & 1,45 & 3,75 & 2,005 & 1,735 & 2,495 & 4,950 & 4,990 & 5,000 & 20,30 & rup. seção líquida \\
\hline C3D4-1 & 0,26 & 2 & 1,25 & 1,45 & 3,68 & 1,855 & 1,985 & 2,475 & 4,955 & 5,015 & 4,995 & 43,04 & rup. seção líquida \\
\hline & & & & & & & & & & & & & \\
\hline C4D1-1 & 0,39 & 1 & 1,6 & 1,8 & 4,86 & 2,185 & 2,325 & 3,005 & 6,050 & 6,070 & 6,040 & $\frac{44,33}{07,52}$ & rup. seção liquida \\
\hline C4D4-1 & 0,39 & 2 & 1,6 & 1,8 & 4,4 & 2,205 & 2,285 & 3,050 & 6,045 & 6,070 & 6,045 & 87,52 & rup. seçad ilquida \\
\hline C5D1-1 & 0,475 & 1 & 1,6 & 1,8 & 4,8 & 2,4 & 2,4 & 3,200 & 6,400 & 6,400 & 6,400 & 71,80 & rup. seção líquida \\
\hline C5D2-1 & 0,475 & 1 & 1,6 & 1,8 & 9,6 & 4,8 & 4,8 & 3,200 & 6,400 & 6,400 & 6,400 & 176,00 & rup. seção líquida \\
\hline C5D3-1 & 0,475 & 2 & 1,6 & 1,8 & 3,2 & 1,6 & 1,6 & 3,200 & 6,400 & 6,400 & 6.400 & 73,60 & rup. seção liquida \\
\hline C5D4-1 & 0,475 & 2 & 1,6 & 1,8 & 4,8 & 2,4 & 2,4 & 3,200 & 6,400 & 6,400 & 6,400 & 146,00 & rup. seção líquida \\
\hline C5D5-1 & 0,475 & 2 & 1,6 & 1,8 & 4,8 & 4,8 & 4,8 & 3,200 & 6,400 & 6,400 & 6,400 & 246,00 & rup. seção liquida \\
\hline C5D6-1 & 0,475 & 4 & 1,6 & 1,8 & 4,8 & 2,4 & 2,4 & 3,200 & 6,400 & 6,400 & 6,400 & 295,00 & rup. seção liquida \\
\hline C5D7-1 & 0,48 & 1 & 1,6 & 1,8 & 6,39 & 3,055 & 2,985 & 3,075 & 6,010 & 6,050 & 6,040 & 103,93 & rup. seção liquida \\
\hline C5D8-1 & 0,48 & 2 & 1,6 & 1,8 & 4,44 & 3,035 & 3,015 & 3,060 & 6,025 & 6,065 & 6,010 & 176,57 & rup. seção líquida \\
\hline C5D9-1 & 0,48 & 2 & 1,6 & 1,8 & 4,49 & 6,885 & 7,155 & 3,015 & 6,045 & 6,060 & 6,060 & 343,14 & esmag + ruptura \\
\hline C5D10-1 & 0,48 & 2 & 1,6 & 1,8 & 14,01 & 2,245 & 2,295 & 2,970 & 6,045 & 6,060 & 6,015 & 360,23 & esmagamento \\
\hline & & & & & & & & & & & & & \\
\hline C6D1-1 & 0,63 & 1 & 1,6 & 1,8 & 4,81 & 2,155 & 2,325 & 3,055 & 6,050 & 6,080 & 6.050 & 74,47 & rup. seção liquida \\
\hline C6D4-1 & 0,63 & 2 & 1,6 & 1,8 & 4,42 & 2,225 & 2,335 & 3,055 & 6,065 & 6,070 & 6.030 & 176,79 & rup. seção líquida \\
\hline
\end{tabular}


TABELA B.2 - Ligações parafusadas em chapa fina de aço com a utilização de arruelas

\begin{tabular}{|c|c|c|c|c|c|c|c|c|c|c|c|c|c|}
\hline \multirow[t]{2}{*}{ Ligação } & \multirow{2}{*}{$\begin{array}{c}\mathrm{t} \\
(\mathrm{cm}) \\
\end{array}$} & \multirow[t]{2}{*}{$n$} & \multirow{2}{*}{$\begin{array}{c}d \\
(\mathrm{~cm}) \\
\end{array}$} & \multirow{2}{*}{$\begin{array}{r}\mathrm{dh} \\
(\mathrm{cm}) \\
\end{array}$} & \multirow{2}{*}{$\begin{array}{r}\mathrm{g} \\
(\mathrm{cm}) \\
\end{array}$} & \multirow{2}{*}{$\frac{\mathrm{e} 1}{(\mathrm{~cm})}$} & \multirow{2}{*}{$\frac{\mathrm{e} 2}{(\mathrm{~cm})}$} & \multirow{2}{*}{$\begin{array}{c}\mathrm{s} \\
(\mathrm{cm}) \\
\end{array}$} & \multirow{2}{*}{$\begin{array}{r}\mathrm{s} 1 \\
(\mathrm{~cm}) \\
\end{array}$} & \multirow{2}{*}{$\begin{array}{r}\mathrm{s} 2 \\
(\mathrm{~cm}) \\
\end{array}$} & \multirow{2}{*}{$\begin{array}{c}\text { s3 } \\
(\mathrm{cm}) \\
\end{array}$} & \multirow{2}{*}{$\begin{array}{l}F u \\
(k N) \\
\end{array}$} & \multirow{2}{*}{$\begin{array}{c}\text { Modo de falha } \\
\text { (obtido em ensaio) } \\
\end{array}$} \\
\hline & & & & & & & & & & & & & \\
\hline \multicolumn{14}{|l|}{ SERIE A } \\
\hline $\mathrm{C} 2 \mathrm{~A} 1-2$ & 0,2 & 1 & 1,25 & 1,45 & 3,75 & 1,875 & 1,875 & 2,500 & & & & & \\
\hline $\mathrm{C} 2 \mathrm{~A} 2-2$ & 0,2 & 1 & 1,25 & 1,45 & 7,5 & 3,75 & 3,75 & 2,500 & $=$ & & & 26,90 & rup seção líquida \\
\hline $\mathrm{C} 2 \mathrm{~A} 3-2$ & 0,2 & 2 & 1,25 & 1,45 & 2,5 & 1,25 & 1,25 & 2,500 & & & & 22,40 & rup seção liquida \\
\hline C2A4-2 & 0,2 & 2 & 1,25 & 1,45 & 3,75 & 1,875 & 1,875 & 2,500 & & & & 46,60 & esmagamento \\
\hline $\mathrm{C} 2 \mathrm{~A} 5-2$ & 0,2 & 2 & 1,25 & 1,45 & 3,75 & 3,75 & 3,75 & 2,500 & & & & 51,30 & esmagamento \\
\hline $\mathrm{C} 2 \mathrm{~A} 6-2$ & 0,2 & 4 & 1,25 & 1,45 & 3,75 & 1,875 & 1,875 & 2,500 & & & & 95,20 & esmagamento \\
\hline $\mathrm{C} 2 \mathrm{~A} 7-2$ & 0,2 & 1 & 1,25 & 1,45 & 4,99 & 2,345 & 2,585 & 2,525 & & & & 25,79 & esmagamento \\
\hline $\mathrm{C} 2 \mathrm{~A} 8 \mathrm{~B}-2$ & 0,2 & 2 & 1,25 & 1,45 & 3,73 & 2,455 & 2,465 & 2,485 & & & & 50,51 & esmagamento \\
\hline $\mathrm{C} 2 \mathrm{~A} 9-2$ & 0,2 & 2 & 1,25 & 1,45 & 3,72 & 5,725 & 5,515 & 2,480 & & & & 50,13 & esmagamento \\
\hline $\mathrm{C} 2 \mathrm{~A} 10-2$ & 0,2 & 2 & 1,25 & 1,45 & 11,22 & 1,915 & 1,915 & 2,545 & & & & 51,81 & esmagamento \\
\hline C3A1-2 & 0,26 & 1 & 1,25 & 1,45 & 3,75 & 2,025 & 1,715 & 2,615 & & & & 17,85 & esmagamento \\
\hline C3A4-2 & 0,26 & 2 & 1,25 & 1,45 & 3,68 & 1,825 & 2,005 & 2,475 & & & & 38,84 & esmagamento \\
\hline & & & & & & & & & & & & & \\
\hline C4A1-2 & 0,39 & 1 & 1,6 & 1,8 & 4,76 & 2,295 & 2,135 & 3,085 & & & & 40,97 & esmagamento \\
\hline C4A4-2 & 0,39 & 2 & 1,6 & 1,8 & 4,38 & 2,225 & 2,305 & 2,840 & & & & 83,48 & esmagamento \\
\hline & & & & & & & & & & & & & \\
\hline C5A1-2 & 0,475 & 1 & 1,6 & 1,8 & 4,8 & 2,4 & 2,4 & 3,200 & & & & 69,00 & rup. seção liquida \\
\hline C5A2-2 & 0,475 & 1 & 1,6 & 1,8 & 9,6 & 4,8 & 4,8 & 3,200 & & & & 87,80 & esmagamento \\
\hline C5A3-2 & 0,475 & 2 & 1,6 & 1,8 & 3,2 & 1,6 & 1,6 & 3,200 & & & & 73,60 & rup. seção liquida \\
\hline C5A4-2 & 0,475 & 2 & 1,6 & 1,8 & 4,8 & 2,4 & 2,4 & 3,200 & & & & 143,00 & rup. seção liquida \\
\hline C5A5-2 & 0,475 & 2 & 1,6 & 1,8 & 4,8 & 4,8 & 4,8 & 3,200 & & & & 158,00 & esmagamento \\
\hline C5A6-2 & 0,475 & 4 & 1,6 & 1,8 & 4,8 & 2,4 & 2,4 & 3,200 & & & & 293,00 & esmagamento \\
\hline C5A7-2 & 0,48 & 1 & 1,6 & 1,8 & 6,41 & 3,025 & 3,055 & 3,055 & & & & 70,58 & esmagamento \\
\hline C5A8-2 & 0,48 & 2 & 1,6 & 1,8 & 4,48 & 2,905 & 3,135 & 2,980 & & & & 139,79 & esmagamento \\
\hline C5A9-2 & 0,48 & 2 & 1,6 & 1,8 & 4,5 & 7,135 & 6,925 & 2,935 & & & & 149,40 & esmagamento \\
\hline C5A10-2 & 0,48 & 2 & 1,6 & 1,8 & 14,03 & 2,255 & 2,215 & 2,970 & & & & 153,29 & esmagamento \\
\hline C6A1-2 & 0,63 & 1 & 1,6 & 1,8 & 4,79 & 2,115 & 2,355 & 2,875 & & & & 80,12 & esmagamento \\
\hline C6A4-2 & 0,63 & 2 & 1,6 & 1,8 & 4,41 & 2,205 & 2,325 & 3,050 & & & & 171,38 & esmagamento \\
\hline
\end{tabular}


TABELA B.2 - (continuação)

\begin{tabular}{|c|c|c|c|c|c|c|c|c|c|c|c|c|c|}
\hline \multirow[t]{2}{*}{ Ligaçāo } & \multirow{2}{*}{$\begin{array}{c}t \\
(\mathrm{~cm}) \\
\end{array}$} & \multirow[t]{2}{*}{$n$} & \multirow{2}{*}{$\begin{array}{c}d \\
(\mathrm{~cm}) \\
\end{array}$} & \multirow{2}{*}{$\begin{array}{c}\mathrm{dh} \\
(\mathrm{cm}) \\
\end{array}$} & \multirow{2}{*}{$\begin{array}{c}9 \\
(\mathrm{~cm}) \\
\end{array}$} & $\mathrm{e} 1$ & $\mathrm{e} 2$ & \multirow{2}{*}{$\begin{array}{c}\mathrm{s} \\
(\mathrm{cm}) \\
\end{array}$} & \multirow{2}{*}{$\begin{array}{r}\mathrm{s} 1 \\
(\mathrm{~cm}) \\
\end{array}$} & \multirow{2}{*}{$\begin{array}{r}\mathrm{s} 2 \\
(\mathrm{~cm}) \\
\end{array}$} & \multirow{2}{*}{$\begin{array}{r}\text { s3 } \\
(\mathrm{cm}) \\
\end{array}$} & \multirow{2}{*}{$\begin{array}{l}\mathrm{Fu} \\
(\mathrm{kN}) \\
\end{array}$} & \multirow{2}{*}{$\begin{array}{c}\text { Modo de falha } \\
\text { (obtido em ensaio) } \\
\end{array}$} \\
\hline & & & & & & $(\mathrm{cm})$ & $(\mathrm{cm})$ & & & & & & \\
\hline C2B1-2 & 0,2 & 1 & 1,25 & 1,45 & 3,75 & 1,875 & 1,875 & 2,500 & 5,000 & & & 23,10 & rup seção líquida \\
\hline $\mathrm{C} 2 \mathrm{~B} 2-2$ & 0,2 & 1 & 1,25 & 1,45 & 7,5 & 3,75 & 3,75 & 2,500 & 5,000 & & & 52,30 & esmagamento \\
\hline C2B3-2 & 0,2 & 2 & 1,25 & 1,45 & 2,5 & 1,25 & 1,25 & 2,500 & 5,000 & & & 24,00 & rup. seção líquida \\
\hline $\mathrm{C} 2 \mathrm{~B} 4-2$ & 0,2 & 2 & 1,25 & 1,45 & 3,75 & 1,875 & 1,875 & 2,500 & 5,000 & & & 47,50 & rup seção líquida \\
\hline $\mathrm{C} 2 \mathrm{~B} 5-2$ & 0,2 & 2 & 1,25 & 1,45 & 3,75 & 3,75 & 3,75 & 2,500 & 5,000 & & & 81,50 & rup seção líquida \\
\hline $\mathrm{C} 2 \mathrm{~B} 6-2$ & 0,2 & 4 & 1,25 & 1,45 & 3,75 & 1,875 & 1,875 & 2,500 & 5,000 & & & 99,40 & rup. seção líquida \\
\hline $\mathrm{C} 2 \mathrm{~B} 7-2$ & 0,2 & 1 & 1,25 & 1,45 & 5 & 2,405 & 2,555 & 2,505 & 4,900 & & & 34,41 & rup. seção liquida \\
\hline $\mathrm{C} 2 \mathrm{~B} 8-2$ & 0,2 & 2 & 1,25 & 1,45 & 3,69 & 2,455 & 2,505 & 2,485 & 4,930 & & & 59,36 & rup. seção líquida \\
\hline $\mathrm{C} 2 \mathrm{~B} 9-2$ & 0,2 & 2 & 1,25 & 1,45 & 3,73 & 5,485 & 5,745 & 2,510 & 4,900 & & & 87,75 & \begin{tabular}{|l} 
esmagamento \\
\end{tabular} \\
\hline $\mathrm{C} 2 \mathrm{~B} 10-2$ & 0,2 & 2 & 1,25 & 1,45 & 11,22 & 1,795 & 1,995 & 2,480 & 4,945 & & & 85,61 & esmag + ruptura \\
\hline & & & & & & & & & & & & & \\
\hline C3B1-2 & 0,26 & 1 & 1,25 & 1,45 & 3,73 & 1,715 & 1,995 & 2,485 & 4,960 & & & 19,46 & rup seção líquida \\
\hline C3B4-2 & 0,26 & 2 & 1,25 & 1,45 & 3,68 & 1,815 & 2,005 & 2,460 & 4,955 & & & 43,04 & rup seção líquida \\
\hline & & & & & & & & & & & & & \\
\hline C4B1-2 & 0,39 & 1 & 1,6 & 1,8 & 4,75 & 2,145 & 2,265 & 3,085 & 6,060 & & & 42,81 & rup. seção liquida \\
\hline C4B4-2 & 0,39 & 2 & 1,6 & 1,8 & 4,39 & 2,195 & 2,355 & 3,035 & 6,065 & & & 89,27 & rup seção líquida \\
\hline & & & & & & & & & & & & & \\
\hline$\frac{\mathrm{C} 5 \mathrm{~B} 1-2}{\mathrm{C} 5 \mathrm{~B} 2-2}$ & 0,475 & 1 & $\frac{1,6}{16}$ & $\frac{1,8}{18}$ & $\frac{4,8}{9,6}$ & 2,4 & 2,4 & 3,200 & 6,400 & & & 71,20 & rup. seçäo liquida \\
\hline $\begin{array}{l}\text { C5B2-2 } \\
\text { C5B3-2 }\end{array}$ & 0,475 & 1 & $\frac{7,0}{16}$ & $\frac{1,8}{1,8}$ & $\frac{9,6}{3,2}$ & 4,8 & 4,8 & 3,200 & 6,400 & & & 153,00 & esmagamento \\
\hline$\frac{\mathrm{C} 5 \mathrm{~B} 3-2}{\mathrm{C} 5 \mathrm{~B} 4-2}$ & 0,475 & $\frac{2}{2}$ & $\frac{1,6}{1,6}$ & 1,8 & $\frac{3,2}{4,8}$ & $\frac{1,6}{24}$ & 1,6 & 3,200 & 6,400 & & & 74,50 & rup seção líquida \\
\hline$\frac{\mathrm{C} 5 \mathrm{~B} 4-2}{\mathrm{C} 5 \mathrm{~B} 5-2}$ & $\frac{0,4 / 5}{0,475}$ & $\frac{2}{2}$ & 1,6 & 1,8 & 4,8 & $\frac{2,4}{4,8}$ & 2,4 & 3,200 & 6,400 & & & 150,00 & \begin{tabular}{|l|} 
rup. seção líquida \\
rup. seção líquida
\end{tabular} \\
\hline $\mathrm{C} 5 \mathrm{~B} 6-2$ & 0,475 & 4 & 1,6 & 1,8 & 4,8 & $\frac{4,8}{2,4}$ & 4,8 & 3,200 & 6,400 & & & 248,00 & $\frac{\text { rup. seção líquida }}{\text { rup. seção líquida }}$ \\
\hline C5B7-2 & 0,48 & 1 & 1,6 & 1,8 & 6,35 & $\frac{2,4}{3,025}$ & 2,4 & 3,200 & 6,400 & & & 303,00 & $\begin{array}{c}\text { rup. seção líquida } \\
\text { esmagamento }\end{array}$ \\
\hline C5B8-2 & 0,48 & 2 & 1,6 & 1,8 & 4,46 & $\begin{array}{l}3,025 \\
2,945 \\
\end{array}$ & 2,985 & 3,115 & 6,040 & & & 105,37 & \begin{tabular}{|c|} 
esmagamento \\
rup. seção líquida
\end{tabular} \\
\hline C5B9-2 & 0,48 & 2 & 1,6 & 1,8 & 4,46 & $\frac{2,945}{7,125}$ & 3,105 & 3,005 & 6,045 & & & 180,61 & \begin{tabular}{|c} 
rup. seção líquida \\
esmagamento
\end{tabular} \\
\hline C5B10-2 & 0,48 & 2 & 1,6 & 1,8 & 14,04 & $\begin{array}{l}7,125 \\
2,215 \\
\end{array}$ & 6,905 & 3,060 & 6,015 & & & 261,95 & $\begin{array}{l}\text { esmagamento } \\
\text { esmagamento }\end{array}$ \\
\hline & & & & & & 2,215 & 2,345 & 2,950 & 6,030 & & & 275,07 & \\
\hline C6B1-2 & 0,63 & 1 & 1,6 & 1,8 & 4,82 & 2,175 & 2,295 & 2,985 & 6,110 & & & & rup seção líquida \\
\hline C6B4-2 & 0,63 & 2 & 1,6 & 1,8 & 4,4 & 2,205 & 2,285 & 3,010 & 6,035 & & & 181,30 & $\frac{\text { rup. seção líquida }}{\text { rup. seção líquida }}$ \\
\hline & & & & & & & & & & & & & \\
\hline
\end{tabular}


TABELA B.2 - (continuação)

\begin{tabular}{|c|c|c|c|c|c|c|c|c|c|c|c|c|c|}
\hline \multirow[t]{2}{*}{ Ligação } & \multirow{2}{*}{$\begin{array}{c}\mathrm{t} \\
(\mathrm{cm}) \\
\end{array}$} & \multirow[t]{2}{*}{$n$} & \multirow{2}{*}{$\begin{array}{c}\mathrm{d} \\
(\mathrm{cm})\end{array}$} & \multirow{2}{*}{$\begin{array}{c}\mathrm{dh} \\
(\mathrm{cm})\end{array}$} & \multirow{2}{*}{$\begin{array}{c}\mathrm{g} \\
(\mathrm{cm}) \\
\end{array}$} & \multirow{2}{*}{$\frac{\mathrm{e} 1}{(\mathrm{~cm})}$} & \multirow{2}{*}{$\frac{\mathrm{e} 2}{(\mathrm{~cm})}$} & \multirow{2}{*}{$\begin{array}{c}\mathrm{s} \\
(\mathrm{cm}) \\
\end{array}$} & \multirow{2}{*}{$\begin{array}{c}\mathrm{s} 1 \\
(\mathrm{~cm}) \\
\end{array}$} & \multirow{2}{*}{$\begin{array}{c}\mathrm{s} 2 \\
(\mathrm{~cm}) \\
\end{array}$} & \multirow{2}{*}{$\begin{array}{l}\mathrm{s} 3 \\
(\mathrm{~cm})\end{array}$} & \multirow{2}{*}{$\begin{array}{c}F_{u} \\
(\mathrm{kN}) \\
\end{array}$} & \multirow{2}{*}{$\begin{array}{c}\text { Modo de falha } \\
\text { (obtido em ensaio) }\end{array}$} \\
\hline & & & & & & & & & & & & & \\
\hline $\mathrm{C} 2 \mathrm{C} 1-2$ & 0,2 & 1 & 1,25 & 1,45 & 3,75 & 1,875 & 1,875 & 2,500 & 5,000 & 5,000 & & 23,60 & rup. seção líquida \\
\hline $\mathrm{C} 2 \mathrm{C} 2-2$ & 0,2 & 1 & 1,25 & 1,45 & 7,5 & 3,75 & 3,75 & 2,500 & 5,000 & 5,000 & & 55,30 & rup. seção liquida \\
\hline $\mathrm{C} 2 \mathrm{C} 3-2$ & 0,2 & 2 & 1,25 & 1,45 & 2,5 & 1,25 & 1,25 & 2,500 & 5,000 & 5,000 & & 24,60 & rup. seção líquida \\
\hline $\mathrm{C} 2 \mathrm{C} 4-2$ & 0,2 & 2 & 1,25 & 1,45 & 3,75 & 1,875 & 1,875 & 2,500 & 5,000 & 5,000 & & 48,80 & rup. seção liquida \\
\hline $\mathrm{C} 2 \mathrm{C} 5-2$ & 0,2 & 2 & 1,25 & 1,45 & 3,75 & 3,75 & 3,75 & 2,500 & 5,000 & 5,000 & & 80,00 & rup. seção liquida \\
\hline C2C6-2 & 0,2 & 4 & 1,25 & 1,45 & 3,75 & 1,875 & 1,875 & 2,500 & 5,000 & 5,000 & & 102,00 & rup. seção liquida \\
\hline $\mathrm{C} 2 \mathrm{C} 7-2$ & 0,2 & 1 & 1,25 & 1,45 & 4,99 & 2,395 & 2,555 & 2,485 & 4,890 & 4,990 & & 35,56 & rup. seção líquida \\
\hline $\mathrm{C} 2 \mathrm{C} 8 \mathrm{-}-2$ & 0,2 & 2 & 1,25 & 1,45 & 3,71 & 2,445 & 2,445 & 2,510 & 4,930 & 4,985 & & 59,36 & rup. seção líquida \\
\hline $\mathrm{C} 2 \mathrm{C} 9-2$ & 0,2 & 2 & 1,25 & 1,45 & 3,75 & 5,495 & 5,735 & 2,505 & 4,910 & 4,990 & & 110,03 & \\
\hline $\mathrm{C} 2 \mathrm{C} 10-2$ & 0,2 & 2 & 1,25 & 1,45 & 11,24 & 1,815 & 1,975 & 2,550 & 4,945 & 4,990 & & 110,56 & esmag + ruptura \\
\hline
\end{tabular}

\begin{tabular}{|c|c|c|c|c|c|c|c|c|c|c|c|c|}
\hline $\mathrm{C} 3 \mathrm{C} 1-2$ & 0,26 & 1 & 1,25 & 1,45 & 3,73 & 1,745 & 1,985 & 2,485 & 4,950 & 4,990 & 20,45 & rup. secão liquida \\
\hline C3C4-2 & 0,26 & 2 & 1,25 & 1,45 & 3,68 & 2,025 & 1,815 & 2,480 & 4,965 & 5,015 & 43,49 & rup. seção líquida \\
\hline $\mathrm{C} 4 \mathrm{C} 1-2$ & 0,39 & 1 & 1,6 & 1,8 & 4,76 & 2,165 & 2,255 & 2,985 & 6,050 & 6,100 & 43,80 & rup. seção líquida \\
\hline C4C4-2 & 0,39 & 2 & 1,6 & 1,8 & 4,39 & 2,195 & 2,335 & 3,070 & 6,040 & 6,045 & 88,82 & rup. seção liquida \\
\hline
\end{tabular}

\begin{tabular}{|c|c|c|c|c|c|c|c|c|c|c|c|c|}
\hline C5C1-2 & 0,475 & 1 & 1,6 & 1,8 & 4,8 & 2,4 & 2,4 & 3,200 & 6,400 & 6,400 & 72,30 & rup. seção líquida \\
\hline C5C2-2 & 0,475 & 1 & 1,6 & 1,8 & 9,6 & 4,8 & 4,8 & 3,200 & 6,400 & 6,400 & 178,00 & rup. seção líquida \\
\hline $\mathrm{C} 5 \mathrm{C} 3-2$ & 0,475 & 2 & 1,6 & 1,8 & 3,2 & 1,6 & 1,6 & 3,200 & 6,400 & 6,400 & 74,50 & rup. seção líquida \\
\hline $\mathrm{C} 5 \mathrm{C} 4-2$ & 0,475 & 2 & 1,6 & 1,8 & 4,8 & 2,4 & 2,4 & 3,200 & 6,400 & 6,400 & 147,00 & rup. seção liquida \\
\hline C5C5-2 & 0,475 & 2 & 1,6 & 1,8 & 4,8 & 4,8 & 4,8 & 3,200 & 6,400 & 6,400 & 250,00 & rup. seção líquida \\
\hline $\mathrm{C} 5 \mathrm{C} 6-2$ & 0,475 & 4 & 1,6 & 1,8 & 4,8 & 2,4 & 2,4 & 3,200 & 6,400 & 6,400 & 299,00 & rup. seção líquida \\
\hline$C 5 C 7-2$ & 0,48 & 1 & 1,6 & 1,8 & 6,36 & 3,045 & 2,955 & 3,035 & 5,990 & 6,040 & 105,68 & rup. seção liquida \\
\hline $\mathrm{C} 5 \mathrm{C} 8 \mathrm{-2}$ & 0,48 & 2 & 1,6 & 1,8 & 4,46 & 3,005 & 3,035 & 3,100 & 6,015 & 6,055 & 179,24 & rup. seção liquida \\
\hline C5C9-2 & 0,48 & 2 & 1,6 & 1,8 & 4,49 & 7,125 & 6,905 & 3,015 & 6,030 & 6,050 & 343,44 & esmagamento \\
\hline $\mathrm{C} 5 \mathrm{C} 10-2$ & 0,48 & 2 & 1,6 & 1,8 & 14 & 2,305 & 2,245 & 2,960 & 6,035 & 6,040 & 351,22 & esmag + ruptura \\
\hline
\end{tabular}

\begin{tabular}{|c|c|c|c|c|c|c|c|c|c|c|c|c|}
\hline c6C1-2 & 0,63 & 1 & 1,6 & 1,8 & 4,83 & 2,145 & 2,325 & 2,915 & 6,070 & 6,120 & 79,20 & rup. seção liquida \\
\hline $\mathrm{C} 6 \mathrm{C} 4-2$ & 0,63 & 2 & 1,6 & 1,8 & 4,4 & 2,175 & 2,315 & 3,030 & 6,050 & 6,065 & 178,93 & rup. seção liquiida \\
\hline
\end{tabular}


TABELA B.2 - (continuação)

\begin{tabular}{|c|c|c|c|c|c|c|c|c|c|c|c|c|c|}
\hline \multirow[t]{2}{*}{ Ligação } & \multirow{2}{*}{$\begin{array}{c}\mathrm{t} \\
(\mathrm{cm}) \\
\end{array}$} & \multirow[t]{2}{*}{$n$} & \multirow{2}{*}{$\begin{array}{c}\mathrm{d} \\
(\mathrm{cm}) \\
\end{array}$} & \multirow{2}{*}{$\begin{array}{c}\mathrm{d} \\
(\mathrm{cm}) \\
\end{array}$} & \multirow{2}{*}{$\begin{array}{r}\mathrm{g} \\
(\mathrm{cm}) \\
\end{array}$} & \multirow{2}{*}{$\frac{\mathrm{e} 1}{(\mathrm{~cm})}$} & \multirow{2}{*}{$\frac{\mathrm{e} 2}{(\mathrm{~cm})}$} & \multirow{2}{*}{$\begin{array}{c}\mathrm{s} \\
(\mathrm{cm}) \\
\end{array}$} & \multirow{2}{*}{$\begin{array}{c}\mathrm{s} 1 \\
(\mathrm{~cm}) \\
\end{array}$} & \multirow{2}{*}{$\begin{array}{c}\mathrm{s} 2 \\
(\mathrm{~cm}) \\
\end{array}$} & \multirow{2}{*}{$\begin{array}{c}\mathrm{s} 3 \\
(\mathrm{~cm}) \\
\end{array}$} & \multirow{2}{*}{$\begin{array}{l}\mathrm{Fu} \\
(\mathrm{kN}) \\
\end{array}$} & \multirow{2}{*}{$\begin{array}{c}\text { Modo de falha } \\
\text { (obtido em ensaio) }\end{array}$} \\
\hline & & & & & & & & & & & & & \\
\hline C2D1-2 & 0,2 & 1 & 1,25 & 1,45 & 3,75 & 1.875 & 1,875 & 2,500 & 5,000 & 5,000 & 5,000 & 24,60 & rup. seção líquida \\
\hline $\mathrm{C} 2 \mathrm{D} 2-2$ & 0,2 & 1 & 1,25 & 1,45 & 7,5 & 3,75 & 3,75 & 2,500 & 5,000 & 5,000 & 5,000 & 55,50 & rup. seção líquida \\
\hline C2D3-2 & 0,2 & 2 & 1,25 & 1,45 & 2,5 & 1,25 & 1,25 & 2,500 & 5,000 & 5,000 & 5,000 & 26,50 & rup. seção liquida \\
\hline $\mathrm{C} 2 \mathrm{D} 4-2$ & 0,2 & 2 & 1,25 & 1,45 & 3,75 & 1,875 & 1,875 & 2,500 & 5,000 & 5,000 & 5,000 & 49,50 & rup. seção liquida \\
\hline $\mathrm{C} 2 \mathrm{D} 5-2$ & 0,2 & 2 & 1,25 & 1,45 & 3,75 & 3,75 & 3,75 & 2,500 & 5,000 & 5,000 & 5,000 & 79,90 & rup. seção líquida \\
\hline C2D6-2 & 0,2 & 4 & 1,25 & 1,45 & 3,75 & 1,875 & 1,875 & 2,500 & 5,000 & 5,000 & 5,000 & 102,00 & rup. seção líquida \\
\hline C2D7-2 & 0,2 & 1 & 1,25 & 1,45 & 4,97 & 2,365 & 2,545 & 2,505 & 4,890 & 4,980 & 4,960 & 35,71 & rup. seção líquida \\
\hline C2D8-2 & 0,2 & 2 & 1,25 & 1,45 & 3,73 & 2,425 & 2,505 & 2,485 & 4,930 & 4,970 & 4,955 & 60,81 & rup. seção liquida \\
\hline C2D9-2 & 0,2 & 2 & 1,25 & 1,45 & 3,72 & 5,535 & 5,725 & 2,480 & 4,905 & 4,995 & 4,970 & 113,84 & esmag + ruptura \\
\hline C2D10-2 & 0,2 & 2 & 1,25 & 1,45 & 11,23 & 1,785 & 1,965 & 2,525 & 4,945 & 4,990 & 5,010 & 113,46 & rup. seção liquida \\
\hline C3D1-2 & 0,26 & 1 & 1,25 & 1,45 & 3,79 & 2,005 & 1,765 & 2,495 & 4,940 & 4,990 & 5,000 & 21,52 & rup. seção liquida \\
\hline C3D4-2 & 0,26 & 2 & 1,25 & 1,45 & 3,68 & 1,995 & 1,825 & 2,465 & 4,955 & 5,005 & 4,985 & 43,87 & rup. seção liquida \\
\hline C4D1-2 & 0,39 & 1 & 1,6 & 1,8 & 4,86 & 2,185 & 2,335 & 3,015 & 6,040 & 6,080 & 6,040 & 44,94 & rup. seção líquida \\
\hline C4D4-2 & 0,39 & 2 & 1,6 & 1,8 & 4,4 & 2,185 & 2,335 & 3,035 & 6,055 & 6,065 & 6,030 & 88,13 & rup. seção liquida \\
\hline C5D1-2 & 0,475 & 1 & 1,6 & 1,8 & 4,8 & 2,4 & 2,4 & 3,200 & 6,400 & 6,400 & 6,400 & 72,00 & rup. seção líquida \\
\hline C5D2-2 & 0,475 & 1 & 1,6 & 1,8 & 9,6 & 4,8 & 4,8 & 3,200 & 6,400 & 6,400 & 6,400 & 178,00 & rup. seção liquida \\
\hline C5D3-2 & 0,475 & 2 & 1,6 & 1,8 & 3,2 & 1,6 & 1,6 & 3,200 & 6,400 & 6,400 & 6,400 & 74,20 & rup. seção líquida \\
\hline C5D4-2 & 0,475 & 2 & 1,6 & 1,8 & 4,8 & 2,4 & 2,4 & 3,200 & 6,400 & 6,400 & 6,400 & 148,00 & rup. seção liquida \\
\hline C5D5-2 & 0,475 & 2 & 1,6 & 1,8 & 4,8 & 4,8 & 4,8 & 3,200 & 6,400 & 6,400 & 6,400 & 245,00 & rup. seção líquida \\
\hline C5D6-2 & 0,475 & 4 & 1,6 & 1,8 & 4,8 & 2,4 & 2,4 & 3,200 & 6,400 & 6,400 & 6,400 & 302,00 & rup. seção liquida \\
\hline C5D7-2 & 0,48 & 1 & 1,6 & 1,8 & 6,35 & 3,035 & 2,965 & 3,115 & 6,020 & 6,050 & 6,040 & 104,84 & rup. seção líquida \\
\hline C5D8-2 & 0,48 & 2 & 1,6 & 1,8 & 4,45 & 3,145 & 2,885 & 3,075 & 6,045 & 6,100 & 6,030 & 180,61 & rup. seção líquida \\
\hline C5D9-2 & 0,48 & 2 & 1,6 & 1,8 & 4,46 & 6,925 & 7,175 & 3,025 & 6,025 & 6,060 & 6,050 & 347,56 & esmag + ruptura \\
\hline C5D10-2 & 0,48 & 2 & 1,6 & 1,8 & 13,99 & 2,305 & 2,335 & 3,030 & 6,045 & 6,060 & 6,020 & 353,06 & esmagamento \\
\hline C6D4-2 & 0,63 & 2 & 1,6 & 1.8 & 4,41 & 2,205 & 2,295 & 3,055 & 6,050 & 6,075 & 6,045 & 181,83 & rup. seção liquida \\
\hline
\end{tabular}


TABELA B.3 - Ligações parafusadas em chapa fina de aço sem a utilização de arruelas submetidas à corte duplo

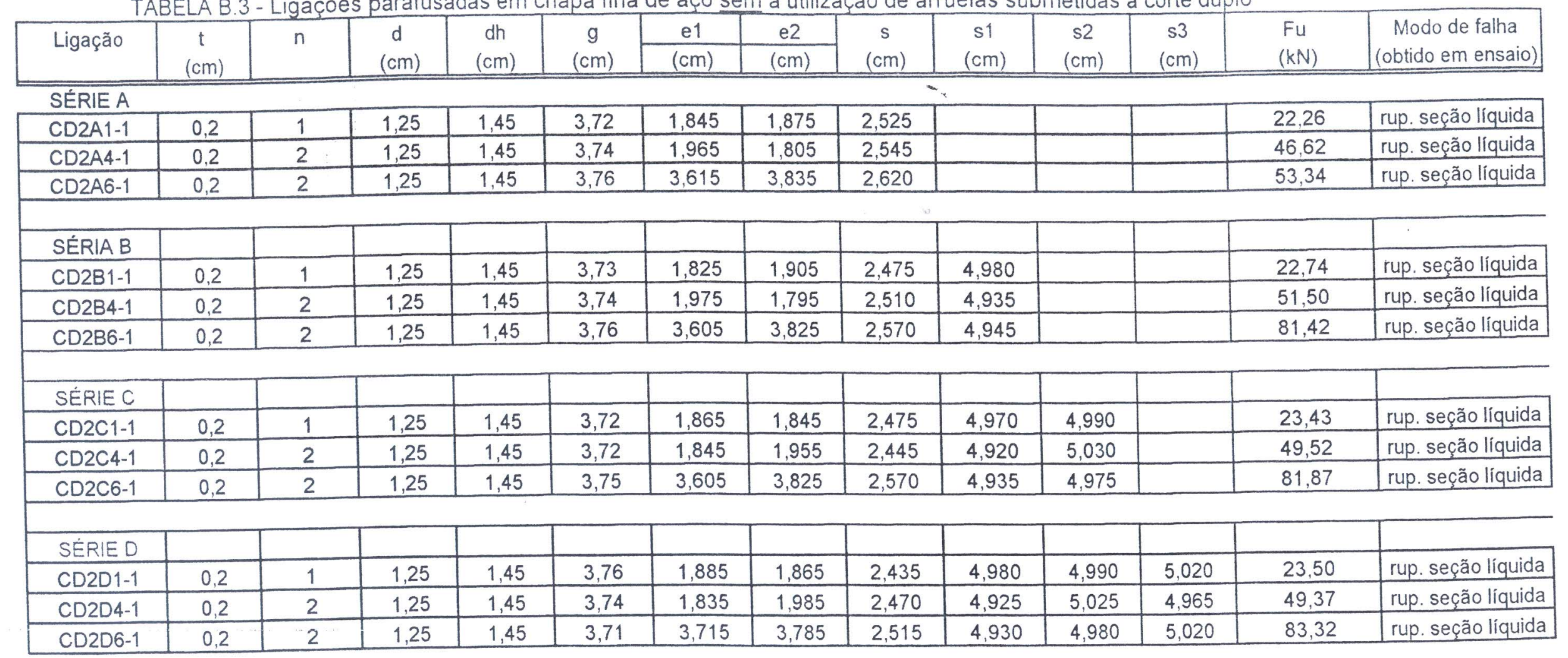


TABELA B.5 - Ligações parafusadas em chapa fina de aço com a utilização de arruelas submetidas à corte duplo

\begin{tabular}{|c|c|c|c|c|c|c|c|c|c|c|c|c|c|c|}
\hline Ligação & $\begin{array}{c}\mathrm{t} \\
(\mathrm{cm})\end{array}$ & $\mathrm{n}$ & $\begin{array}{c}\mathrm{d} \\
(\mathrm{cm})\end{array}$ & $\begin{array}{c}\mathrm{dh} \\
(\mathrm{cm})\end{array}$ & $\begin{array}{c}\mathrm{g} \\
(\mathrm{cm})\end{array}$ & $\mathrm{e} 1$ & $\mathrm{e} 2$ & $\begin{array}{c}\mathrm{s} \\
(\mathrm{cm})\end{array}$ & $\begin{array}{c}\mathrm{s} 1 \\
(\mathrm{~cm})\end{array}$ & $\begin{array}{c}\mathrm{s} 2 \\
(\mathrm{~cm})\end{array}$ & $\begin{array}{c}\mathrm{s} 3 \\
(\mathrm{~cm})\end{array}$ & $\begin{array}{c}\text { Fu } \\
(\mathrm{cm})\end{array}$ & $\begin{array}{c}\text { Modo de falha } \\
(\mathrm{cm})\end{array}$ & $\begin{array}{c}(\mathrm{kN}) \\
(\mathrm{obtido} \mathrm{em} \mathrm{ensaio)}\end{array}$ \\
\hline
\end{tabular}

SÉRIE A
\begin{tabular}{|l|l|l|l|l|l|l|l|l|l|l|l|l|}
\hline CD2A1-2 & 0,2 & 1 & 1,25 & 1,45 & 3,71 & 1,845 & 1,865 & 2,515 & & & & 23,88 \\
\hline CD2A4-2 & 0,2 & 2 & 1,25 & 1,45 & 3,74 & 1,985 & 1,805 & 2,485 & & & rup. seção liquida \\
\hline CD2A6-2 & 0,2 & 2 & 1,25 & 1,45 & 3,75 & 3,585 & 3,865 & 2,630 & & & 48,68 & rup. seção liquida \\
\hline
\end{tabular}

\begin{tabular}{|l|l|l|l|l|l|l|l|l|l|l|l|l|}
\hline SÉRIA B & & & & & & & & & & & & \\
\hline CD2B1-2 & 0,2 & 1 & 1,25 & 1,45 & 3,7 & 1,865 & 1,815 & 2,495 & 4,980 & & & 24,72 \\
\hline CD2B4-2 & 0,2 & 2 & 1,25 & 1,45 & 3,74 & 1,985 & 1,795 & 2,535 & 4,930 & & rup. seção liquida \\
\hline CD2B6-2 & 0,2 & 2 & 1,25 & 1,45 & 3,75 & 3,605 & 3,825 & 2,525 & 4,945 & & 52,42 & rup. seção líquida \\
\hline
\end{tabular}

\begin{tabular}{|c|c|c|c|c|c|c|c|c|c|c|c|c|}
\hline SERIEC & & & & & & & & & & & & \\
\hline$C D 2 C 1-2$ & 0,2 & 1 & 1,25 & 1,45 & 3,7 & 1,865 & 1,835 & 2,475 & 4,980 & 5,000 & 23,04 & rup. seção líquida \\
\hline CD2C4-2 & 0,2 & 2 & 1,25 & 1,45 & 3,74 & 1,855 & 1,925 & 2,480 & 4,910 & 5,030 & 50,74 & rup. seção liquida \\
\hline CD2C6-2 & 0,2 & 2 & 1,25 & 1,45 & 3,77 & 3,585 & 3,855 & 2,540 & 4,920 & 4,975 & 84,09 & rup. seção líquida \\
\hline
\end{tabular}

\begin{tabular}{|c|c|c|c|c|c|c|c|c|c|c|c|c|c|}
\hline SERIED & & & & & & & & & & & & & \\
\hline $\mathrm{CD} 2 \mathrm{D} 1-2$ & 0,2 & 1 & 1,25 & 1,45 & 3,7 & 1,755 & 1,935 & 2.435 & 4,950 & 5,020 & 4,990 & 23,81 & rup. seção liquida \\
\hline $\mathrm{CD} 2 \mathrm{D} 4-2$ & 0,2 & 2 & 1,25 & 1,45 & 3,73 & 1,805 & 1,945 & 2,525 & 4,920 & 5,035 & 4,970 & 52,65 & rup. seção liquida \\
\hline CD2D6-2 & 0,2 & 2 & 1,25 & 1,45 & 3,71 & 3,655 & 3,835 & 2,490 & 4,930 & 4,975 & 5,015 & 83,40 & rup. seção liquida \\
\hline
\end{tabular}


TABELA B.6 - Ligaçōes pararusadas em cantoneıras de adas ıguais

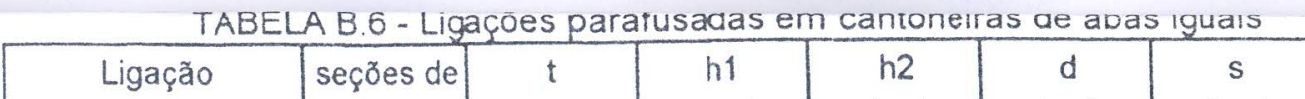

$\left[\begin{array}{c|c}\begin{array}{l}\text { seções de } \\ \text { parafusos }\end{array} & \begin{array}{c}\mathrm{t} \\ (\mathrm{cm})\end{array} \\ \hline\end{array}\right.$

h2
$(\mathrm{cm})$

(cm)

\begin{tabular}{c|c}
$\mathrm{s}$ & $\mathrm{s} 1$ \\
$(\mathrm{~cm})$ & $(\mathrm{cm})$ \\
\hline
\end{tabular}

$\mathrm{s} 2$

s3

$\mathrm{Fu}$

Modo de falha

TIPO 1

\begin{tabular}{|c|c|c|c|c|c|c|c|c|c|c|c|}
\hline \multicolumn{12}{|l|}{ TIPO 1} \\
\hline LIIA1-1 & 1 & 0,15 & 5,01 & 5,04 & 1,45 & 3,91 & & & & 17,50 & esmagamento \\
\hline LI1B B1-1 & 2 & 0,15 & 5,02 & 5,04 & 1,45 & 3,84 & 3,68 & & & 33,50 & rup. c/ esmag não pronun. \\
\hline LIIC1-1 & 3 & 0,15 & 5,03 & 4,98 & 1,45 & 3,81 & 3,66 & 3,74 & & 36,50 & rup. da seção liquída \\
\hline LI1D1-1 & 4 & 0,15 & 5,02 & 5,00 & 1,45 & 3,73 & 3,67 & 3,74 & 3,70 & 43,60 & rup. da seção liquída \\
\hline LIIA1-2 & 1 & 0,15 & 5,00 & 5,01 & 1,45 & 3,86 & & & & 19,10 & esmag. $\mathrm{c} /$ inicio de rup. \\
\hline LIIB1-2 & 2 & 0,15 & 5,03 & 5,02 & 1,45 & 3,91 & 3,67 & & & 32,90 & rup. c/ esmag não pronun. \\
\hline \multicolumn{12}{|l|}{$411 C 1-2$} \\
\hline LIID1-2 & 4 & 0,15 & 5,03 & 5,00 & 1,45 & 3,74 & 3,67 & 3,74 & 3,68 & 42,00 & rup. da seção liquida \\
\hline \multicolumn{12}{|l|}{ TIPO 3} \\
\hline LIIA3-1 & 1 & 0,15 & 5,01 & 4,99 & 1,45 & 3,78 & & & & 41,60 & esmag. $\mathrm{c}$ início de rup. \\
\hline LI11B3-1 & 2 & 0,15 & 5,04 & 5,05 & 1,45 & 3,85 & 3,71 & & & 44,10 & rup. da seção liquída \\
\hline LIIC3-1 & 3 & 0,15 & 5,02 & 5,01 & 1,45 & 3,79 & 3,70 & 3,71 & & 46,90 & rup. da seção liquída \\
\hline LIID3-1 & 4 & 0,15 & 4,89 & 4,99 & 1,45 & 3,78 & 3,76 & 3,67 & 3,72 & 48,30 & rup. da seção liquída \\
\hline LIIA3-2 & 1 & 0,15 & 5,03 & 5,06 & 1,45 & 3,78 & & & & 41,80 & rup. cl esmag pronun. \\
\hline LLI1B3-2 & 2 & 0,15 & 5,02 & 4,99 & 1,45 & 3,74 & 3,71 & & & 47,50 & rup. da extrem. engastada \\
\hline LIIC3-2 & 3 & 0,15 & 5,04 & 5,02 & 1,45 & 3,82 & 3,71 & 3,73 & & 47,70 & \\
\hline LI1D3-2 & 4 & 0,15 & 5,19 & 4,81 & 1,45 & 3,90 & 3,72 & 3,73 & 3,70 & APROX.:48 & rup. da extrem. engastada \\
\hline
\end{tabular}




\begin{tabular}{|c|c|c|c|c|c|c|c|c|c|c|c|}
\hline Ligação & $\begin{array}{l}\text { seções de } \\
\text { parafusos }\end{array}$ & $\begin{array}{c}\mathrm{t} \\
(\mathrm{cm}) \\
\end{array}$ & $\begin{array}{l}\mathrm{h} 1 \\
(\mathrm{~cm}) \\
\end{array}$ & $\begin{array}{l}\mathrm{h} 2 \\
(\mathrm{~cm}) \\
\end{array}$ & $\begin{array}{c}\mathrm{d} \\
(\mathrm{cm}) \\
\end{array}$ & $\begin{array}{c}\mathrm{s} \\
(\mathrm{cm}) \\
\end{array}$ & $\begin{array}{c}\mathrm{s} 1 \\
(\mathrm{~cm}) \\
\end{array}$ & $\begin{array}{c}\mathrm{s} 2 \\
(\mathrm{~cm}) \\
\end{array}$ & $\begin{array}{c}\mathrm{s} 3 \\
(\mathrm{~cm}) \\
\end{array}$ & $\begin{array}{l}\mathrm{Fu} \\
(\mathrm{kN}) \\
\end{array}$ & $\begin{array}{c}\text { Modo de falha } \\
\text { (obtido em ensaio) }\end{array}$ \\
\hline \multicolumn{12}{|r|}{ esmagamento } \\
\hline LIAA1-1 & 1 & 0,39 & 7,88 & 7,30 & 1,79 & 4,72 & & & & 80,90 & esmagamento \\
\hline LIAB1-1 & 2 & 0,39 & 7,51 & 7,60 & 1,79 & 4,78 & 4,80 & & & 116,00 & esmagamento \\
\hline LI 4 C $1-1$ & 3 & 0,39 & 7,59 & 7,55 & 1,79 & 4,81 & 4,80 & $4,80^{-}$ & & 130,00 & rup. cl esmag pronun. \\
\hline LI4D1-1 & 4 & 0,39 & 7,59 & 7,62 & 1,79 & 4,79 & 4,80 & 4,80 & 4,76 & 144,00 & rup. c/ esmag pronun. \\
\hline LI4A1-2 & 1 & 0,39 & 7,52 & 7,54 & 1,79 & 4,84 & & & & & \\
\hline LLI4B1-2 & 2 & 0,39 & 7,58 & 7,51 & 1,79 & 4,84 & 4,80 & & & & esmag. c/ inicio de rup. \\
\hline LIAC1-2 & 3 & 0,39 & 7,60 & 7,47 & 1,79 & 4,67 & 4,79 & 4,80 & & & esmag. c/ inicio de rup. \\
\hline LI4D1-2 & 4 & 0,39 & 7,48 & 7,64 & 1,79 & 4,77 & 4,79 & 4,80 & 4,76 & & esmagamento \\
\hline \multicolumn{12}{|l|}{$\frac{\text { LI4D 1-2 }}{\text { TIPO } 3}$} \\
\hline LI4A3-1 & 1 & 0,39 & 7,56 & 7,52 & 1,79 & 4,79 & & & & 111,00 & esmagamento \\
\hline LLI4B3-1 & 2 & 0,39 & 7,69 & 7,52 & 1,79 & 4,75 & 4,78 & & & 161,00 & esmagamento \\
\hline L14C3-1 & 3 & 0,39 & 7,66 & 7,58 & 1,79 & 4,81 & 4,79 & 4,81 & & 160,00 & esmag. c/ inicio de rup. \\
\hline LL14D3-1 & 4 & 0,39 & 7,54 & 7,68 & 1,79 & 4,87 & 4,79 & 4,80 & 4,79 & 154,00 & rup. da seção liquída \\
\hline LI4A3-2 & 1 & 0,39 & 7,51 & 7,54 & 1,79 & 4,86 & & & & 141,00 & esmagamento \\
\hline LI4B3-2 & 2 & 0,39 & 7,57 & 7,52 & 1,79 & 4,75 & 4,79 & & & 159,00 & esmagamento \\
\hline LL14C3-2 & 3 & 0,39 & 7,53 & 7,58 & 1,79 & 4,84 & 4,88 & 4,81 & & 161,00 & esmag. c/ início de rup. \\
\hline LI4D $3-2$ & 4 & 0,39 & 7,43 & 7,62 & 1,79 & 4,82 & 4,78 & 4,78 & 4,80 & 162,00 & rup. da seção liquída \\
\hline \multicolumn{12}{|l|}{$\frac{\text { LI4D3-2 }}{\text { TIPO } 1}$} \\
\hline LI5A3-1 & 1 & 0,48 & 7,68 & 7,47 & 1,79 & 5,00 & & & & & \\
\hline LI5C3-1 & 3 & 0,48 & 7,40 & 7,65 & 1,79 & 4,81 & 4,77 & 4,79 & & & \\
\hline LI5A3-2 & 1 & 0,48 & 7,61 & 7,38 & 1,79 & 4,84 & & & & 193,58 & esmagamento \\
\hline LI5C3-2 & 3 & 0,48 & 7,72 & 7,31 & 1,79 & 4,77 & 4,79 & 4,78 & & 246,23 & rup. seção liquida \\
\hline
\end{tabular}




\begin{tabular}{|c|c|c|c|c|c|c|c|c|c|c|c|}
\hline Ligação & \begin{tabular}{|l|} 
seçöes de \\
parafusos
\end{tabular} & $\begin{array}{c}\mathrm{t} \\
(\mathrm{cm}) \\
\end{array}$ & $\begin{array}{l}\mathrm{h} 1 \\
(\mathrm{~cm}) \\
\end{array}$ & $\begin{array}{c}\mathrm{h} 2 \\
(\mathrm{~cm}) \\
\end{array}$ & $\begin{array}{c}\mathrm{d} \\
(\mathrm{cm}) \\
\end{array}$ & $\begin{array}{c}\mathrm{s} \\
(\mathrm{cm}) \\
\end{array}$ & $\begin{array}{c}\mathrm{s} 1 \\
(\mathrm{~cm}) \\
\end{array}$ & $\begin{array}{c}\mathrm{s} 2 \\
(\mathrm{~cm}) \\
\end{array}$ & $\begin{array}{c}\mathrm{s} 3 \\
(\mathrm{~cm}) \\
\end{array}$ & $\begin{array}{l}\mathrm{Fu} \\
(\mathrm{kN}) \\
\end{array}$ & $\begin{array}{c}\text { Modo de falha } \\
\text { (obtido em ensaio) }\end{array}$ \\
\hline \multicolumn{12}{|l|}{ TIPO 1} \\
\hline LD1A1-1 & 1 & 0,15 & 6,01 & 4,05 & 1,45 & 3,85 & & & & 17,10 & \\
\hline LD1B1-1 & 2 & 0,15 & 6,01 & 4,01 & 1,45 & 3,82 & 3,74 & & & 34,40 & rup. da seção liquída \\
\hline LD1C1-1 & 3 & 0,15 & 5,98 & 4,10 & 1,45 & 3,84 & 3,74 & $3,74^{-}$ & & 42,00 & rup. da seção liquída \\
\hline LD1D1-1 & 4 & 0,15 & 5,94 & 4,11 & 1,45 & 3,84 & 3,74 & 3,74 & 3,72 & 46,20 & \\
\hline LD1A1-2 & 1 & & & & & & & & & & \\
\hline LD1B1-2 & 2 & 0,15 & 5,99 & 4,05 & 1,45 & 3,85 & 3,74 & & & 34,80 & rup. da seção liquída \\
\hline LD1C1-2 & 3 & 0,15 & 5,96 & 4,07 & 1,45 & 3,85 & 3,74 & 3,75 & & 39,60 & \\
\hline LD1D1-2 & 4 & 0,15 & 5,98 & 4,05 & 1,45 & 3,83 & 3,75 & 3,75 & 3,73 & 44,80 & rup. da seção liquída \\
\hline \multicolumn{12}{|l|}{$\mathrm{TIPO} 2$} \\
\hline LD1A2-1 & 1 & 0,15 & 6,01 & 4,10 & 1,45 & 3,84 & & & & 18,90 & rup. c/ esmag pronun. \\
\hline LD1B2-1 & 2 & 0,15 & 5,96 & 4,08 & 1,45 & 3,86 & 3,76 & & & 28,00 & rup. c/ esmag não pronun. \\
\hline LD1C2-1 & 3 & 0,15 & 6,01 & 4,05 & 1,45 & 3,84 & 3,76 & 3,73 & & 34,50 & rup. da seção liquída \\
\hline LD1D2-1 & 4 & 0,15 & 6,08 & 4,06 & 1,45 & 3,87 & 3,76 & 3,72 & 3,73 & 42,30 & rup. da seção liquída \\
\hline LD1A2-2 & 1 & & & & & & & & & & \\
\hline LD1B2-2 & 2 & 0,15 & 5,91 & 4,06 & 1,45 & 3,82 & 3,76 & & & 29,00 & rup. c/ esmag não pronun \\
\hline LD1C2-2 & 3 & 0,15 & 5,92 & 4,07 & 1,45 & 3,83 & 3,77 & 3,73 & & 33,80 & rup. da seção liquída \\
\hline LD1D2-2 & 4 & 0,15 & 5,99 & 4,11 & 1,45 & 3,82 & 3,76 & 3,73 & 3,74 & 43,00 & rup. da seção liquída \\
\hline \multicolumn{12}{|l|}{ TIPO 3} \\
\hline LD1A3-1 & 1 & 0,15 & 5,98 & 4,08 & 1,45 & 3,84 & & & & 40,70 & rup. c/ esmag pronun. \\
\hline LD1B3-1 & 2 & 0,15 & 5,99 & 4,13 & 1,45 & 3,81 & 3,76 & & & 46,70 & rup. da seção liquída \\
\hline LD1C3-1 & 3 & 0,15 & 6,00 & 4,11 & 1,45 & 3,82 & 3,76 & 3,74 & & 47,50 & rup. da seção liquída \\
\hline LD1D3-1 & 4 & 0,15 & 5,98 & 4,07 & 1,45 & 3,81 & 3,76 & 3,72 & 3,72 & 50,90 & rup. da seção liquída \\
\hline LD1A3-2 & 1 & 0,15 & 5,92 & 4,07 & 1,45 & 3,91 & & & & 39,40 & rup. cl esmag pronun. \\
\hline LD1B3-2 & 2 & 0,15 & 5,98 & 4,05 & 1,45 & 3,80 & 3,76 & & & 43,00 & rup. da seção liquída \\
\hline LD1C3-2 & 3 & 0,15 & 5,95 & 4,06 & 1,45 & 3,86 & 3,76 & 3,74 & & 45,30 & rup. da seção liquída \\
\hline LD1D3-2 & 4 & 0,15 & 5,99 & 4,11 & 1,45 & 3,75 & 3,76 & 3,74 & 3,73 & 46,30 & rup. da extrem. engastada \\
\hline
\end{tabular}


TABELA B.7 - (continuação)

\begin{tabular}{|c|c|c|c|c|c|c|c|c|c|c|c|}
\hline Ligação & $\begin{array}{l}\text { seçə̃es de } \\
\text { parafusos }\end{array}$ & $\begin{array}{c}\mathrm{t} \\
(\mathrm{cm}) \\
\end{array}$ & $\begin{array}{l}\mathrm{h} 1 \\
(\mathrm{~cm}) \\
\end{array}$ & $\begin{array}{l}\mathrm{h} 2 \\
(\mathrm{~cm}) \\
\end{array}$ & $\begin{array}{c}\mathrm{d} \\
(\mathrm{cm}) \\
\end{array}$ & $\begin{array}{c}\mathrm{s} \\
(\mathrm{cm}) \\
\end{array}$ & $\begin{array}{c}\mathrm{s} 1 \\
(\mathrm{~cm}) \\
\end{array}$ & $\begin{array}{c}\mathrm{s} 2 \\
(\mathrm{~cm}) \\
\end{array}$ & $\begin{array}{c}\mathrm{s} 3 \\
(\mathrm{~cm}) \\
\end{array}$ & $\begin{array}{l}\mathrm{Fu} \\
(\mathrm{kN}) \\
\end{array}$ & $\begin{array}{c}\text { Modo de falha } \\
\text { (obtido em ensaio) }\end{array}$ \\
\hline \multicolumn{12}{|l|}{ TIPO 1} \\
\hline LD4A1-1 & 1 & 0,39 & 7,95 & 4,09 & 1,79 & 4,73 & & & & 73,90 & esmagamento \\
\hline LD4B1-1 & 2 & 0,39 & 7,95 & 4,12 & 1,79 & 4,80 & 4,77 & $\cdots$ & & 103,00 & esmagamento \\
\hline LD4C1-1 & 3 & 0,39 & 7,98 & 4,11 & 1,79 & 4,92 & 4,76 & 4,77 & & 116,00 & rup. da extrem. engastada \\
\hline LD4D1-1 & 4 & 0,39 & 7,92 & 4,11 & 1,79 & 4,81 & 4,76 & 4,76 & 4,77 & 122,00 & rup. da extrem. engastada \\
\hline LD4A1-2 & 1 & 0,39 & 7,92 & 4,09 & 1,79 & 4,94 & & & & 70,30 & esmagamento \\
\hline LD4B1-2 & 2 & 0,39 & 7,91 & 4,11 & 1,79 & 4,83 & 4,77 & 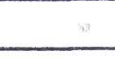 & & & \\
\hline LD4C1-2 & 3 & 0,39 & 7,98 & 4,12 & 1,79 & 4,85 & 4,77 & 4,77 & & 116,00 & \\
\hline LD4D1-2 & 4 & 0,39 & 7,93 & 4,14 & 1,79 & 4,80 & 4,78 & 4,77 & 4,77 & & rup. da extrem. engastada \\
\hline \multicolumn{12}{|l|}{ TIPO 2} \\
\hline LD4A2-1 & 1 & 0,39 & 7,92 & 4,12 & 1,79 & 4,81 & & & & 60,70 & rup. c/ esmag pronun. \\
\hline LD4B2-1 & 2 & 0,39 & 7,90 & 4,08 & 1,79 & 4,71 & 4,80 & & & 86,00 & rup. da seção liquída \\
\hline LD4C2-1 & 3 & 0,39 & 7,64 & 4,40 & 1,79 & 4,68 & 4,81 & 4,76 & & 112,00 & rup. da seção liquída \\
\hline LD4D2-1 & 4 & 0,39 & 7,99 & 4,07 & 1,79 & 4,90 & 4,81 & 4,73 & 4,80 & 119,00 & rup. da seção liquída \\
\hline LD4A2-2 & 1 & 0,39 & 8,02 & 4,03 & 1,79 & 4,87 & & & & 58,70 & rup. c/ esmag pronun. \\
\hline LD4B2-2 & 2 & 0,39 & 7,99 & 4,11 & 1,79 & 4,82 & 4,81 & & & & \\
\hline LD4C2-2 & 3 & 0,39 & 7,91 & 4,12 & 1,79 & 4,88 & 4,80 & 4,74 & & 109,00 & rup. da seção liquída \\
\hline LD4D2-2 & 4 & 0,39 & 7,94 & 4,07 & 1,79 & 4,72 & 4,81 & 4,74 & 4,80 & 117,00 & rup. da seção liquída \\
\hline \multicolumn{12}{|l|}{ TIPO 3} \\
\hline LD4A3-1 & 1 & 0,39 & 7,92 & 4,11 & 1,79 & 4,89 & & & & 103,00 & rup. c/ esmag não pronun \\
\hline LD4B3-1 & 2 & 0,39 & 7,95 & 4,11 & 1,79 & 4,81 & 4,79 & & & 119,00 & rup. da seção liquida \\
\hline LD4C3-1 & 3 & 0,39 & 7,98 & 4,13 & 1,79 & 4,82 & 4,79 & 4,76 & & 119,00 & rup. da seção liquída \\
\hline LD4D3-1 & 4 & 0,39 & 7,99 & 4,10 & 1,79 & 4,83 & 4,81 & 4,72 & 4,80 & 116,00 & rup. da seção liquída \\
\hline LD4A3-2 & 1 & 0,39 & 8,01 & 4,05 & 1,79 & 4,90 & & & & 102,00 & rup. c/ esmag não pronun \\
\hline LD4B3-2 & 2 & 0,39 & 7,88 & 4,23 & 1,79 & 4,81 & 4,79 & & & & \\
\hline LD4C3-2 & 3 & 0,39 & 7,94 & 4,10 & 1,79 & 4,81 & 4,78 & 4,76 & & 113,00 & rup. da seção liquida \\
\hline LD4D3-2 & 4 & 0,39 & 7,97 & 4,10 & 1,79 & 4,90 & 4,79 & 4,76 & 4,78 & 114,00 & rup. da seção liquída \\
\hline
\end{tabular}


TABELA B.7 - (continuação)

\begin{tabular}{|c|c|c|c|c|c|c|c|c|c|c|c|}
\hline Ligação & $\begin{array}{l}\text { seçōes de } \\
\text { parafusos }\end{array}$ & $\begin{array}{r}t \\
(\mathrm{~cm}) \\
\end{array}$ & $\begin{array}{c}\mathrm{h} 1 \\
(\mathrm{~cm}) \\
\end{array}$ & $\begin{array}{l}\mathrm{h} 2 \\
(\mathrm{~cm}) \\
\end{array}$ & $\begin{array}{c}\mathrm{d} \\
(\mathrm{cm}) \\
\end{array}$ & $\begin{array}{c}\mathrm{s} \\
(\mathrm{cm}) \\
\end{array}$ & $\begin{array}{r}\mathrm{s} 1 \\
(\mathrm{~cm}) \\
\end{array}$ & $\begin{array}{r}\mathrm{s} 2 \\
(\mathrm{~cm}) \\
\end{array}$ & $\begin{array}{r}\mathrm{s} 3 \\
(\mathrm{~cm}) \\
\end{array}$ & $\begin{array}{l}\mathrm{Fu} \\
(\mathrm{kN}) \\
\end{array}$ & $\begin{array}{c}\text { Modo de falha } \\
\text { (obtido em ensaio) }\end{array}$ \\
\hline \multicolumn{12}{|l|}{ TIPO 1} \\
\hline LD5A3-1 & 1 & 0,48 & 8,03 & 3,96 & 1,79 & 4,95 & & & & & \\
\hline LD5C3-1 & 3 & 0,48 & 8,05 & 3,86 & 1,79 & 4,89 & 4,79 & $4,79-$. & & 181,37 & rup. da seção liquída \\
\hline LD5A3-2 & 1 & 0,48 & 8,08 & 3,80 & 1,79 & 4,91 & & & & 149,25 & rup. da seção liquída \\
\hline LD5C3-2 & 3 & 0,48 & 8,04 & 3,88 & 1,79 & 4,82 & 4,81 & 4,77 & & 179,31 & rup. da seção liquída \\
\hline
\end{tabular}

TABELA B.8 - Ligações parafusadas em duplas cantoneiras de abas iguais

\begin{tabular}{|c|c|c|c|c|c|c|c|c|c|c|c|}
\hline Ligação & $\begin{array}{l}\text { seções de } \\
\text { parafusos }\end{array}$ & $\begin{array}{c}\mathrm{t} \\
(\mathrm{cm}) \\
\end{array}$ & $\begin{array}{c}\mathrm{h} 1 \\
(\mathrm{~cm}) \\
\end{array}$ & $\begin{array}{c}\mathrm{h} 2 \\
(\mathrm{~cm}) \\
\end{array}$ & $\begin{array}{c}d \\
(\mathrm{~cm}) \\
\end{array}$ & $\begin{array}{c}\mathrm{s} \\
(\mathrm{cm}) \\
\end{array}$ & $\begin{array}{r}\mathrm{s} 1 \\
(\mathrm{~cm}) \\
\end{array}$ & $\begin{array}{r}s 2 \\
(\mathrm{~cm}) \\
\end{array}$ & $\begin{array}{r}\mathrm{s} 3 \\
(\mathrm{~cm}) \\
\end{array}$ & $\begin{array}{c}\mathrm{Fu} \\
(\mathrm{kN}) \\
\end{array}$ & $\begin{array}{c}\text { Modo de falha } \\
\text { (obtido em ensaio) }\end{array}$ \\
\hline \multicolumn{12}{|l|}{ TIPO 1} \\
\hline DLIIA1-1-1 & 1 & 0,15 & 4,98 & 5,13 & 1,45 & 4,11 & & & & 33,80 & esmag. + ruptura \\
\hline DLI1A1-1-2 & 1 & 0,15 & 4,97 & 5,08 & 1,45 & 3,70 & & & & & \\
\hline DLI1C1-1-1 & 3 & 0,15 & 5,06 & 4,99 & 1,45 & 4,17 & 3,71 & 3,70 & & 70,05 & rup. seção líquida \\
\hline DLIIC1-1-2 & 3 & 0,15 & 4,94 & 5,02 & 1,45 & 3,74 & 3,75 & 3,72 & & & \\
\hline DLI1A1-2-1 & 1 & 0,15 & 4,96 & 5,07 & 1,45 & 3,70 & & & & 32,12 & esmagamento \\
\hline DLI1A1-2-2 & .1 & 0,15 & 4,97 & 5,11 & 1,45 & 4,14 & & & & & \\
\hline DLIIC1-2-1 & 3 & 0,15 & 5,06 & 4,99 & 1,45 & 4,19 & 3,73 & 3,72 & & 71,04 & rup. seção liquida \\
\hline DLIIC1-2-2 & 3 & 0,15 & 4,98 & 5,10 & 1,45 & 3,73 & 3,74 & 3,68 & & & \\
\hline \multicolumn{12}{|l|}{ TIPO 1} \\
\hline DLI4A1-1-1 & 1 & 0,39 & 7,68 & 7,68 & 1,79 & 4,36 & & & & 109,95 & \\
\hline DL/4A1-1-2 & 1 & 0,39 & 7,60 & 7,77 & 1,79 & 4,35 & & & & & \\
\hline DLI4C1-1-1 & 3 & 0,39 & 7,66 & 7,56 & 1,79 & 4,39 & 4,83 & 4,79 & & 244,86 & rup. seção liquida \\
\hline DLI4C1-1-2 & 3 & 0,39 & 7,73 & 7,48 & 1,79 & 4,34 & 4,74 & 4,80 & & & \\
\hline DLI4A1-2-1 & 1 & 0,39 & 7,71 & 7,64 & 1,79 & 4,38 & & & & 115,68 & esmagamento \\
\hline DLI4A1-2-2 & 1 & 0,39 & 7,58 & 7,73 & 1,79 & 4,35 & & & & & \\
\hline DLI4C1-2-1 & 3 & 0,39 & 7,67 & 7,55 & 1,79 & 4,39 & 4,79 & 4,78 & & 247,07 & rup. seção liquida \\
\hline DLI4C1-2-2 & 3 & 0,39 & 7,49 & 7,69 & 1,79 & 4,36 & 4,78 & 4,81 & & & \\
\hline
\end{tabular}


TABELA B.9 - Ligaçōes parafusadas em perfis U

\begin{tabular}{|c|c|c|c|c|c|c|c|c|c|c|c|c|}
\hline Ligação & $\begin{array}{l}\text { seções de } \\
\text { parafusos }\end{array}$ & $\begin{array}{c}1 \\
(\mathrm{~cm}) \\
\end{array}$ & $\begin{array}{c}\mathrm{h} 1 \\
(\mathrm{~cm}) \\
\end{array}$ & $\begin{array}{c}\mathrm{h} 2 \\
(\mathrm{~cm}) \\
\end{array}$ & $\begin{array}{r}\mathrm{h} 3 \\
(\mathrm{~cm}) \\
\end{array}$ & $\begin{array}{c}\mathrm{d} \\
(\mathrm{cm}) \\
\end{array}$ & $\begin{array}{c}\mathrm{s} \\
(\mathrm{cm}) \\
\end{array}$ & $\begin{array}{r}\mathrm{s} 1 \\
(\mathrm{~cm}) \\
\end{array}$ & $\begin{array}{c}\mathrm{s} 2 \\
(\mathrm{~cm}) \\
\end{array}$ & $\begin{array}{c}\mathrm{s} 3 \\
(\mathrm{~cm}) \\
\end{array}$ & $\begin{array}{l}\mathrm{Fu} \\
(\mathrm{kN}) \\
\end{array}$ & $\begin{array}{c}\text { Modo de falha } \\
\text { (obtido em ensaio) }\end{array}$ \\
\hline \multicolumn{13}{|l|}{ TIPO 1} \\
\hline U1A1-1 & 1 & 0,15 & 10.00 & 4.02 & 3.99 & 1.45 & 3.70 & & & & 19,80 & esmagamento \\
\hline U1B1-1 & 2 & 0,15 & 10.02 & 4.16 & 3.99 & 1.45 & 3.80 & 3.74 & & & 40,40 & \\
\hline U1C1-1 & 3 & 0,15 & 10.00 & 4,08 & 3.98 & 1.45 & 3.78 & 3.74 & 3.73 & & 55,60 & rup. cl esmag. pronunc. \\
\hline U101-1 & 4 & 0,15 & 10,06 & 4.06 & 3.98 & 1.45 & 3.75 & 3.75 & 3.71 & 3.73 & 68,30 & rup. c/ esmag. pronunc. \\
\hline U1A1-2 & 1 & 0,15 & 10,00 & 4,02 & 3,99 & 1,45 & 3,70 & & & & & esmagamento \\
\hline U1B1-2 & 2 & 0,15 & 10,02 & 4,16 & 3,99 & 1,45 & 3,80 & 3,74 & & & 40,90 & \\
\hline U1C1-2 & 3 & 0,15 & 10,00 & 4,08 & 3,98 & 1,45 & 3,78 & 3,74 & 3,73 & & & rup. c/ esmag. pronunc. \\
\hline U1D1-2 & 4 & 0,15 & 10,06 & 4,06 & 3,98 & 1,45 & 3,75 & 3,75 & 3,71 & 3,73 & 70,00 & rup. c/ esmag. pronunc. \\
\hline \multicolumn{13}{|l|}{ TIPO 1b } \\
\hline U1A1b-1 & 1 & 0,15 & 10,09 & 6,00 & 6,00 & 1,45 & 3,84 & & & & 40,75 & esmagamento \\
\hline U1B1b-1 & 2 & 0,15 & 10,11 & 5,99 & 6,00 & 1,45 & 3,69 & 3,71 & & & 59,29 & rup. da seção líq. \\
\hline U1A1b-2 & 1 & 0,15 & 10,09 & 5,99 & 5,97 & 1,45 & 3,93 & & & & 41,20 & esmagamento \\
\hline U1B1b-2 & 2 & 0,15 & 10,10 & 5,99 & 5,97 & 1,45 & 3,80 & 3,71 & & & 63,71 & rup. da seção líq. \\
\hline \multicolumn{13}{|l|}{ TIPO 1C } \\
\hline U1A1c-1 & 1 & 0,15 & 10,07 & 7,51 & 7,52 & 1,45 & 3,83 & & & & 40,44 & esmagamento \\
\hline U1B1C-1 & 2 & 0,15 & 10,09 & 7,50 & 7,52 & 1,45 & 3,84 & 3,71 & & & 65,01 & rup. da seção líq. \\
\hline U1A1C-2 & 1 & 0,15 & 10,13 & 7,51 & 7,50 & 1,45 & 3,91 & & & & 40,52 & esmagamento \\
\hline U1B1C-2 & 2 & 0,15 & 10,08 & 7,49 & 7,50 & 1,45 & 3,79 & 3,72 & & & 64,17 & rup. da seção líq. \\
\hline \multicolumn{13}{|l|}{ TIPO 2} \\
\hline U1A2-1 & 1 & 0,15 & 10,04 & 4,03 & 4,00 & 1,45 & 3,89 & & & & 46,20 & rup. c/ esmag. pronunc. \\
\hline U1B2-1 & 2 & 0,15 & 10,05 & 4,03 & 4,02 & 1,45 & 3,88 & 3,70 & & & 64,90 & rup. da seção líq. \\
\hline U1C2-1 & 3 & 0,15 & 10,00 & 4,02 & 4,01 & 1,45 & 3,79 & 3,58 & 3,72 & & 82,60 & rup. da seção líq. \\
\hline U1D2-1 & 4 & 0,15 & 10,04 & 4,06 & 4,00 & 1,45 & 3,79 & 3,72 & 3,73 & 3,67 & 91,50 & rup. da seção líq. \\
\hline U1A2-2 & 1 & 0,15 & 10,05 & 4,05 & 4,08 & 1,45 & 3,80 & & & & 41,80 & rup. cl esmag. pronunc. \\
\hline U1B2-2 & 2 & 0,15 & 10,09 & 4,02 & 4,03 & 1,45 & 3,80 & 3,71 & & & 64,00 & rup. da seção líq. \\
\hline U1C2-2 & 3 & 0,15 & 10,07 & 4,01 & 4,04 & 1,45 & 3,84 & 3,70 & 3,71 & & 44,90 & rup. da seção líq. \\
\hline U1D2-2 & 4 & 0,15 & 10,02 & 4,03 & 4,04 & 1,45 & 3,79 & 3,71 & 3,71 & 3,67 & 92,20 & rup. da seção líq. \\
\hline
\end{tabular}




\begin{tabular}{|c|c|c|c|c|c|c|c|c|c|c|c|c|}
\hline Ligação & $\begin{array}{l}\text { seçőes de } \\
\text { paraf́usos }\end{array}$ & $\begin{array}{c}\mathrm{t} \\
(\mathrm{cm}) \\
\end{array}$ & $\begin{array}{r}\mathrm{h} 1 \\
(\mathrm{~cm}) \\
\end{array}$ & $\begin{array}{r}\mathrm{h} 2 \\
(\mathrm{~cm}) \\
\end{array}$ & $\begin{array}{r}\mathrm{h} 3 \\
(\mathrm{~cm}) \\
\end{array}$ & $\begin{array}{c}d \\
(\mathrm{~cm}) \\
\end{array}$ & $\begin{array}{c}\mathrm{s} \\
(\mathrm{cm}) \\
\end{array}$ & $\begin{array}{r}\mathrm{s} 1 \\
(\mathrm{~cm}) \\
\end{array}$ & $\begin{array}{r}s 2 \\
(\mathrm{~cm}) \\
\end{array}$ & $\begin{array}{r}\mathrm{s} 3 \\
(\mathrm{~cm}) \\
\end{array}$ & $\begin{array}{c}F u \\
(k N) \\
\end{array}$ & $\begin{array}{c}\text { Modo de falha } \\
\text { (obtido em ensaio) } \\
\end{array}$ \\
\hline \multicolumn{13}{|r|}{ (obtido em ensaio) } \\
\hline U4A3-1 & 1 & 0,15 & 10,09 & 4,04 & 3,97 & 1,45 & 3,81 & & & & 59,60 & rup. cl esmag. pronunc. \\
\hline U4B3-1 & 2 & 0,15 & 10,04 & 4,04 & 3,98 & 1,45 & 3,76 & 3,71 & & & 84,80 & rup. da seção líq. \\
\hline U4C3-1 & 3 & 0,15 & 10,06 & 4,11 & 4,04 & 1,45 & 3,78 & 3,71 & 3,72 & & 89,70 & rup. da seção líq. \\
\hline U4D3-1 & 4 & 0,15 & 10,05 & 4,09 & 3,99 & 1,45 & 3,82 & 3,71 & 3,72 & 3,69 & 93,80 & \\
\hline U4A3-2 & 1 & 0,15 & 10,01 & 4,01 & 4,03 & 1,45 & 3,79 & & & & 58,60 & rup. c/ esmag. pronunc. \\
\hline U4B3-2 & 2 & 0,15 & 10,04 & 4,02 & 4,08 & 1,45 & 3,79 & 3,71 & & & 84,90 & rup. da seção líq. \\
\hline U4C3-2 & 3 & 0,15 & 10,01 & 4,00 & 4,06 & 1,45 & 3,75 & 3,71 & 3,70 & & 90,10 & rup. da seção líq. \\
\hline U4D3-2 & 4 & 0,15 & 10,00 & 4,01 & 4,07 & 1,45 & 3,73 & 3,71 & 3,71 & 3,68 & 90,70 & rup. da seção líq. \\
\hline \multicolumn{13}{|r|}{ rup. da seção líq. } \\
\hline U3A1-1 & 1 & 0,39 & 15,00 & 4,92 & 5,01 & 1,79 & 4,82 & & & & 79,10 & esmagamento \\
\hline U3B1-1 & 2 & 0,39 & 15,12 & 4,89 & 5,05 & 1,79 & 4,85 & 4,77 & & & 129,00 & esmagamento \\
\hline U3C1-1 & 3 & 0,39 & 15,10 & 4,87 & 4,94 & 1,79 & 4,78 & 4,78 & 4,77 & & 165,00 & esmagamento \\
\hline U3D1-1 & 4 & 0,39 & 15,15 & 4,87 & 4,98 & 1,79 & 4,71 & 4,78 & 4,76 & 4,76 & 202,00 & esmagamento \\
\hline U3A1-2 & 1 & 0,39 & 15,13 & 4,92 & 5,06 & 1,79 & 4,82 & & & & 78,10 & esmagamento \\
\hline U3B1-2 & 2 & 0,39 & 15,17 & 4,89 & 5,02 & 1,79 & 4,74 & 4,78 & & & & NÃO COUBE \\
\hline U3C1-2 & 3 & 0,39 & 15,05 & 4,87 & 5,02 & 1,79 & 4,89 & 4,79 & 4,77 & & 173,00 & esmagamento \\
\hline U3D1-2 & 4 & 0,39 & 15,10 & 4,93 & 5,02 & 1,79 & 4,86 & 4,75 & 4,77 & 4,77 & 210,00 & esmagamento \\
\hline \multicolumn{13}{|l|}{$\frac{\text { TIPO 1a }}{\text { U3A1a-1 }}$} \\
\hline U3A1a-1 & 1 & 0,39 & 15,15 & 4,89 & 4,98 & 1,79 & 4,84 & & & & 140,00 & esmagamento \\
\hline U3B1a-1 & 2 & 0,39 & 15,10 & 4,88 & 4,99 & 1,79 & 4,82 & 4,72 & & & 193,00 & esmagamento \\
\hline U3C1a-1 & 3 & 0,39 & 15,23 & 4,87 & 4,99 & 1,79 & 4,77 & 4,72 & 4,79 & & 230,00 & esmagamento \\
\hline U3D1a-1 & 4 & 0,39 & 15,27 & 4,80 & 5,01 & 1,79 & 4,78 & 4,77 & 4,71 & 4,75 & 255,00 & esmagamento \\
\hline U3A1a-2 & 1 & 0,39 & 15,18 & 4,83 & 4,99 & 1,79 & 4,81 & & & & 143,00 & esmagamento \\
\hline U3B1a-2 & 2 & 0,39 & 15,15 & 4,74 & 5,05 & 1,79 & 4,81 & 4,72 & & & 197,00 & esmagamento \\
\hline U3C1a-2 & 3 & 0,39 & 15,23 & 4,87 & 4,99 & 1,79 & 4,77 & 4,72 & 4,79 & & 228,00 & esmagamento \\
\hline U3D1a-2 & 4 & 0,39 & 15,27 & 4,80 & 5,01 & 1,79 & 4,78 & 4,77 & 4,71 & 4,75 & 247,00 & esmagamento \\
\hline
\end{tabular}




\begin{tabular}{|c|c|c|c|c|c|c|c|c|c|c|c|c|}
\hline U3B2-1 & 2 & 0,39 & 15.20 & 4,94 & 5,04 & 1,79 & 4,87 & 4,77 & & & 188,00 & rup. da seção liquida \\
\hline U $3 C 2-1$ & 3 & 0,39 & 15,10 & 4,90 & 5,02 & 1,79 & 4,85 & 4,77 & 4,78 & & 226,00 & rup. da seção liquida \\
\hline U3D2-1 & 4 & 0,39 & 15,00 & 4,91 & 5,02 & 1,79 & 4,82 & 4,76 & 4,78 & 4,76 & 263.00 & rup. da seção líquida \\
\hline U3A.2-2 & 1 & 0,39 & 15,05 & 4,90 & 5,00 & 1,79 & 4,79 & & & & 132,00 & rup. c/ esmag. pronunc. \\
\hline U3B2-2 & 2 & 0,39 & 15,03 & 4,87 & 4,95 & 1,79 & 4,89 & 4,78 & & & 186,00 & rup. da seção líquida \\
\hline U $3 C 2-2$ & 3 & 0,39 & 15.50 & 4,67 & 4,92 & 1,79 & 4,93 & $4,76-$ & 4,79 & & & NÃO COUBE \\
\hline U3D $2-2$ & 4 & 0,39 & 15,00 & 4,88 & 4,99 & 1,79 & 4,87 & 4,77 & 4,78 & 4,75 & 258,00 & rup. da seção líquida \\
\hline \multicolumn{13}{|l|}{ TIPO 3} \\
\hline U3A3-1 & 1 & 0,39 & 15,15 & 4,97 & 5,01 & 1,79 & 4,88 & & & & 195,00 & rup. c/ esmag. pronunc. \\
\hline U3B 3-1 & 2 & 0,39 & 15,05 & 4,82 & 4,95 & 1,79 & 4,83 & 4,85 & & & 190,00 & rup. da seção líquida \\
\hline U3C3-1 & 3 & 0,39 & 15,15 & 4,83 & 5,03 & 1,79 & 4,83 & 4,81 & 4,82 & & 259,00 & rup. da seção líquida \\
\hline U3D3-1 & 4 & 0,39 & 15,00 & 4,96 & 4,90 & 1,79 & 4,76 & 4,79 & 4,80 & 4,78 & 263,00 & inic. de rup. \\
\hline U3A3-2 & 1 & 0,39 & 15,02 & 4,80 & 5,03 & 1,79 & 4,77 & & & & 250,00 & rup. c/ esmag. pronunc. \\
\hline U3B3-2 & 2 & 0,39 & 15,00 & 4,98 & 5,00 & 1,79 & 4,89 & 4,80 & & & 253,00 & rup. da seção líquida \\
\hline U3C3-2 & 3 & 0,39 & 15,20 & 4,95 & 5,01 & 1,79 & 4,76 & 4,81 & 4,80 & & 257,00 & rup. da seção líquida \\
\hline U3D3-2 & 4 & 0,39 & 15,30 & 4,83 & 4,85 & 1,79 & 4,84 & 4,78 & 4,77 & 4,77 & 259,00 & rup. da seção líquida \\
\hline
\end{tabular}

